Jahrbuch der Deutschen Dostojewskij-Gesellschaft

\title{
Dostojewskij und Europa
}

Herausgegeben von Gudrun Goes 
Jahrbuch der Deutschen Dostojewskij-Gesellschaft • 2010 


\title{
Jahrbuch der Deutschen Dostojewskij-Gesellschaft
}

\author{
Herausgegeben \\ im Auftrag der Deutschen Dostojewskij-Gesellschaft \\ und im Namen des wissenschaftlichen Beirats der Gesellschaft \\ von Gudrun Goes
}

Jahrbuch 17

2010

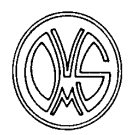

Verlag Otto Sagner

München - Berlin 


\section{Dostojewskij und Europa}

Herausgegeben von Gudrun Goes

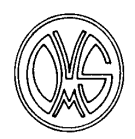

Verlag Otto Sagner · München - Berlin

2010 


\section{Bibliografische Information der Deutschen Bibliothek}

Die Deutsche Bibliothek verzeichnet diese Publikation in der Deutschen Nationalbibliografie; detaillierte bibliografische Informationen sind im Internet über http://dnb.ddb.de abrufbar.

Online steht dieses Jahrbuch in Kürze als Volltextversion über den Katalog der Bayerischen Staatsbibliothek München (www.bsb-muenchen.de) zur Verfügung.

\section{BSBB $\begin{gathered}\text { Bayerische } \\ \text { Staatsibibiothek }\end{gathered}$}

(C) 2010 bei Kubon \& Sagner GmbH

Heßstraße 39/41 Friedrichstraße 200

80798 München 10117 Berlin

Telefon $+49(0) 8954218-106$

Telefax +49(0)8954 218-226

verlag@kubon-sagner.de

«Verlag Otto Sagner» ist ein Imprint der Kubon \& Sagner GmbH

Umschlaggestaltung: Christopher Triplett, Marburg

Satz: robert jones, marburg

Druck und Bindung: Difo-Druck, Bamberg

Printed in Germany

Alle Rechte vorbehalten

ISSN 1437-5265

ISBN 10: 3-86688-128-2

ISBN 13: 978-3-86688-128-0 


\section{Inhaltsverzeichnis}

Gudrun Goes

Vorwort

Christiane Schulz

„Ich habe Schiller auswendig gelernt“.

Das ,geistige Ferment“ Schiller im Erzählwerk Dostoevskijs

Hans Rothe

Ivan Karamazovs Gespräch mit dem Teufel (Buch XI cap. 9)

im Zusammenhang mit Dostojevskijs Gesamtwerk

Dagmar Herrmann

Die neue europäische Ordnung - eine Vision Dostoevskijs

Andreas Guski

Die Konstruktion Westeuropas in Dostoevskijs

„Winteraufzeichnungen über Sommereindrücke“

Karla Hielscher

Die „russische Idee“ - made in Florenz. Dostojewskijs

antiwestlich-russophile Ideologie in seinen Briefen aus Italien.

\section{Hans Günther}

Der Kristallpalast der modernen Zivilisation -

Utopiekritik nach Dostoevskij

Clemens Heithus

Deutsche Dostojewskij-Bibliographie 2009

Rezension

Dirk Uffelmann

Nachruf auf Swetlana Geier 
Gudrun Goes - 978-3-86688-185-3

Downloaded from PubFactory at 01/11/2019 02:25:32AM

via free access 


\title{
Gudrun Goes
}

\section{Vorwort}

\begin{abstract}
Versilov aus Der Jüngling (Podrostok) von Fëdor Dostoevskij: „Damals fand sich in ganz Europa kein einziger Europäer! [...] ich bin als Russe damals in Europa der einzige Europäer gewesen. Ich spreche nicht von mir - ich spreche vom russischen Gedanken insgesamt." 1
\end{abstract}

Die Jahrestagung der Deutschen Dostojewskij-Gesellschaft 2009 an der katholischen Akademie Franz Hitze Haus in Münster war dem Thema Fëdor Dostoevskij und Europa gewidmet gewesen. Diese Themenstellung ist in eine große Tradition eingebettet. ${ }^{2}$ Diese Tagung sollte Fëdor Dostoevskijs unterschiedlichen Beziehungen zur europäischen Geistesgeschichte aufdecken, seine Reisen durch Westeuropa aufleben und seine Briefe und Publizistik über die europäische Gegenwart vorstellen. Europa sollte eine anthropologische, geographische und vor allem eine geistige Perspektivisierung erhalten. Der als großer Erzähler in ganz Europa so nachhaltig rezipierte und geschätzte Fëdor Dostoevskij konnte aus seiner Perspektive die Komplexität der Entwicklungen und Problemstellungen nicht alle erfassen, wobei manche seiner Analysen defizitär blieben. Dostoevskijs politisch-prophetische Denkmuster waren oft die Ursache, daß ihn viele seiner Zeitgenossen nicht verstanden. Die Tagung sollte auch diesen Zusammenhang hinterfragen.

Unsere Aufsatzsammlung beginnt mit Christiane Schulz' Beitrag: Dostoevskij und Schiller. Das ,geistige Ferment' Schiller im Erzählwerk Dostoevskijs. Der Aufsatz entwirft in sechs großen Abschnitten die Komplexität dieser Beziehung über die Darstellung methodischer Prämissen, äußert sich zur Zeitalterkritik

1 Fjodor Dostojewskij: Der Jüngling. Berlin 1994, S. 630f.

2 Vgl. Nikolaj Karamzins Briefe eines russischen Reisenden (Pis'ma russkogo putešestvennika, 1791/92), Petr Čaadaevs Philosophische Briefe ( Filosofskie pis'ma, 1836f.), auch A. Gercens Vom anderen Ufer (1850 zuerst in deutscher Sprache erschienen, S togo berega), Fëdor Tjutčevs Rußand und die Revolution (La Russie et la Révolution, 1848) Ivan Kireevskijs Über den Charakter der Aufklärung Europas und ihr Verhältnis zur Aufklärung in Rußland (O charaktere prosveščenija Evropa i ego otnošenija k prosveščeniju v Rossii,1852), N. Danilevskijs Rußland und Europa (Rossija i Evropa, 1872). 
und ästhetischen Utopie, diskutiert die geschichtsphilosophische Spekulation und das sentimentalisches Bewusstsein, analysiert die Gattungsspezifik und Wirkungsästhetik u.a. Die Autorin diskutiert Schiller als Wegbereiter der Ideenromane Dostoevskijs am Beispiel der Dämonen (Besy) und die Adaption der Dramen Schillers als Inversion, Parodie und Kontrafaktur im Erzählwerk des Dichters Fëdor Dostoevskij. Inhaltlich reiht sich der Beitrag von Hans Rothe zu Ivan Karamazovs Gespräch mit dem Teufel im Zusammenhang mit Dostoevskijs Gesamtwerk an. Hans Rothe entwickelt Dostoevskijs Ideenwelt sowohl auf der Ebene der Geistesgeschichte als auch auf der Ebene der Wortgeschichte (Teufel). Er zeigt, wie die Übernahme des Teufels in die Rolle des lasterhaften und zynischen Amoralisten ein kluger Einfalls Dostoevskijs war, weil er seiner Kulturkritik an der europäischen Aufklärung damit die größte Tiefe gab. Mit freundlicher Genehmigung des Wilhelm Finck-Verlages fügen wir den Beitrag von Dagmar Hermann ein, den sie bereits 2003 publiziert hat. Das Thema dieser umfänglichen Untersuchung lautet: Die neue europäische Ordnung eine Vision Dostoevskijs. Auf der Grundlage des Tagebuchs eines Schriftstellers (Dnevnik pisatelja), publizistischer Beiträge für die Zeitschriften Graždanin (Der Staaasbürger), Vremja (De Zeit) und Ėpocha (Die Epoche) von Dostoevskij skizziert die Autorin ein sehr komplexes Bild über die gesellschaftspolitischen Vorstellungen des russischen Schriftstellers über Europa, so über den Katholizismus, die Balkanpolitik, die damit verbundene Orientkrise, über Bismarck, den Berliner Kongreß, die panslawistische Bewegung, seine Aufteilung der Welt zwischen Deutschland und Russland. Dagmar Herrmann hebt hervor, daß sich Fëdor Dostoevskij hier die Rolle des Zeichensuchers und Zeichendeuters gewählt hatte. Diesem Beitrag folgen nun sehr konkrete Untersuchungen wie die von Andreas Guski: Die Konstruktion Westeuropas in Dostoevskijs Winteraufzeichnungen über Sommereindrücke. Er geht vom Motiv des Reisens und seiner Chronologie aus und zeigt auf, daß der russische Dichter Westeuropa 1862 erstmals in einer für Russland wie für ihn selbst wichtigen Schwellensituation besuchte. Wenn der Dichter dem russischen Leser Paris vorführte, dann machte er das stellvertretend für die gesamte europäische Kultur. Seine Kritik am Forschrittsglauben in Europa verbindet er mit der Entwicklung eigener Positionen. Karla Hielscher analysiert in ihrem Aufsatz Die russische Idee made in Florenz den Briefwechsel von Fëdor Dostoevskij aus Italien vor allem mit A. Majkov und S. Ivanova. Die Themen drehten sich um Atheismus, Katholizismus und Sozialismus und demonstrierten Dostoevskijs antiwestlichrussophile Ideologie. Den Band beschließt der Beitrag von Hans Günther: Der Kristallpalast der modernen Zivilisation - Utopiekritik nach Dostoevskij. 
Indirekt greift der Verfasser hier das in anderen Beiträgen bereits umschriebene Motiv des Kristallplastes auf, um die Geschichte dieses Motiv als antiutopischen Entwurf bis ins 20. Jahrhundert zu verfolgen. Dieses Modell entwickelt er an Texten von Nikolaj Černyševskij, Evgenij Zamjatin und Andrej Platonov. 


\section{Christiane Schulz}

\section{"Ich habe Schiller auswendig gelernt". \\ Das „geistige Ferment“ Schiller im Erzählwerk Dostoevskijs ${ }^{1}$}

Für H. zum 14. August 2009

\section{Rezeptionszeugnisse, Forschungsgeschichte und methodische Prämissen}

„Du schriebst mir, Bruder, ich hätte Schiller nicht gelesen. - Du irrst Bruder! Ich habe Schiller auswendig gelernt, sprach mit seinen Worten, fieberte mit ihm; und ich glaube, daß mir das Schicksal nicht mehr in meinem Leben bescheren konnte als die Bekanntschaft mit diesem gewaltigen Dichter gerade in diesem Lebensabschnitt; zu keiner anderen Zeit hätte ich ihn so verstehen können wie damals.“

Dieses Bekenntnis des neunzehnjährigen Dostoevskij zum Werk Friedrich Schillers steht im Neujahrsbrief 1840 an den älteren Bruder Michail. Fëdor Dostoevskij spielt hier auf seine enge Beziehung zu einem Kameraden der Ingenieurschule an, die im Zeichen der von Schiller inspirierten „Freundesliebe“ und einer enthusiastischen Identifizierung von Literatur und Leben stand.

„Während ich mit ihm Schiller las, maß ich an ihm den edlen, leidenschaftlichen Don Karlos, den Marquis Posa und Mortimer. - Diese Freundschaft hat mir soviel gegeben, sowohl Kummer als auch Wonne! [...] Schillers Name aber ist mir vertraut geworden als ein Zauberklang, der so viele Träume auslöst; sie sind bitter, Bruder; deshalb habe ich Dir nie von Schiller und den durch ihn verursachten Eindrücken gesprochen: es schmerzt mich, auch nur Schillers Namen zu hören." (PSS 28.1, 69) ${ }^{2}$

Diese Haltung wird sich bald ändern, denn in den folgenden Jahren arbeiten die Brüder an einem gemeinsamen Projekt: einer russischen Schiller-Ausgabe. Michail, der fünf Jahre im Baltikum lebte und dadurch die deutsche Sprache beherrschte, übernahm die Übersetzungen, Fëdor, der besser französisch als

1 Vortrag auf der Jahrestagung der Deutschen Dostojewskij-Gesellschaft im August 2009 in Münster.

2 Alle Dostoevskij-Zitate unter Angabe von Band- und Seitenzahl mit der Sigle PSS nach der Ausgabe: Polnoe sobranie sočinenij v tridcati tomach. Leningrad 1972-1990 (Akademieausgabe). 
deutsch sprach, betätigte sich als Kritiker. Man muß wissen, daß Schiller um diese Zeit eine große Popularität in Rußland genoß, und deshalb hatte das Vorhaben neben der Begeisterung für den deutschen Klassiker auch einen kommerziellen Aspekt: Die Brüder wollten mit ihrer Schiller-Ausgabe Geld verdienen!

Die geplante Ausgabe kommt letzthin nicht zustande, aber einige Übertragungen Michails (der „Räuber“, des „Don Karlos“, der „Götter Griechenlands") werden in der ersten russischen Gesamtausgabe der Werke Schillers erscheinen, die den deutschen Dichter bezeichnenderweise in der Übersetzung russischer Schriftsteller bot. Es war übrigens die erste Gesamtausgabe der Werke eines ausländischen Klassikers in Rußland; sie umfaßte neun Bände und erschien zwischen 1857 und $1861 .^{3}$

Wir können also festhalten, daß die Materialbasis für unser Thema sehr sicher ist: Dostoevskij kannte seinen Schiller auswendig; der deutsche Dichter war um die Mitte des 19. Jahrhunderts „in Fleisch und Blut“ der russischen Gesellschaft übergegangen: „Wir wurden an ihm erzogen, er ist uns verwandt und hat in vielerlei Hinsicht unsere Entwicklung beeinflußt." (PSS 19, 17) Im August 1880, wenige Monate vor seinem Tod, wird der inzwischen erfolgreiche Schriftsteller von einem Leser um Lektüreempfehlungen für die heranwachsende Tochter gebeten, und Dostoevskij nennt selbstverständlich die russischen Klassiker, aber eben auch Shakespeare und Walter Scott, Goethe und Schiller. Zugleich generalisiert er in diesem Zusammenhang die eigene Lebenserfahrung:

„Sie sagen, Sie hätten Ihrer Tochter bisher nichts Literarisches zu lesen gegeben, aus Angst, ihre Phantasie anzuregen. Mir scheint das nun nicht ganz richtig zu sein: die Phantasie ist eine Naturkraft im Menschen, um so mehr in jedem Kind, in dem sie sich schon in den frühesten Jahren vor allen anderen Fähigkeiten entfaltet und nach Befriedigung verlangt. Befriedigt man sie jedoch nicht, tötet man sie entweder ab, oder im Gegenteil - sie entwickelt sich aus eigener Kraft übermäßig (was auch schädlich ist). Solche Belastung zehrt die geistigen Kräfte eines Kindes nur vorzeitig aus. Eindrücke des Schönen aber sind gerade in der Kindheit notwendig. Im Alter von zehn Jahren habe ich eine Aufführung von Schillers „Räubern“ mit Močalov gesehen, und ich kann Ihnen versichern, der äußerst starke Eindruck, den ich damals empfing, hat sich für meine geistige Entwicklung als ungemein fruchtbar erwiesen." (PSS 30.1, 211f.)

3 Vgl. R. Ju. Danilevskij: Schiller in der russischen Literatur. 18. Jahrhundert - erste Hälfte 19. Jahrhundert, Dresden 1998, S. 290 ff. 
Die zitierten Briefbelege stehen nicht nur exemplarisch für die jahrzehntelange Auseinandersetzung des russischen Schriftstellers mit dem Werk Friedrich Schillers; sie lassen in Ansätzen auch schon erkennen, was Dostoevskij ein Leben lang fasziniert hat: Es ist der dem lyrischen Subjekt oder den dramatischen Figuren eigene Enthusiasmus, der idealistische Impetus, es ist vor allem die unersetzbare Rolle der Kunst im Entwicklungsgang des Menschen und der Menschheit, wie sie Schiller in seinen großen ästhetischen Abhandlungen entwickelt hatte. Dostoevskij wird zentrale Thesen Schillers von der humanisierenden Macht des Schönen nicht einfach übernehmen, sondern in seinem Erzählwerk in verschiedenen poetischen Versuchsanordnungen immer wieder einer kritischen Prüfung unterziehen. Auf diese Weise entsteht ein äußerst dichtes Geflecht von direkten und indirekten Zitaten, offenen und verdeckten Anspielungen auf Schillers Werk, das in der Literaturkritik seit Jahrzehnten lebhaft und auch kontrovers diskutiert wird.

Unser Thema hat also schon eine lange Forschungsgeschichte, und es ist kein Zufall, daß vor allem deutsche Schriftsteller und Kritiker frühzeitig Parallelen zwischen Schiller und Dostoevskij entdeckten. So hat Thomas Mann in seinem berühmten Essay Goethe und Tolstoi. Fragmente zum Problem der Humanität (1925) aus den vergleichbaren Lebensumständen beider Autoren eine Dichtertypologie entwickelt, die Schiller und Dostoevskij zu „Helden und Heiligen der Idee" erhob. Beide litten an einer schweren Krankheit und starben vergleichsweise jung. Schwindsucht bzw. Epilepsie zeitigten Thomas Mann zufolge einen Adel, der - im Gegensatz zum autobiographischen Aristokratismus der Icherfülltheit bei Goethe oder Tolstoi - „eine ganz anders geartete Vertiefung, Erhöhung und Verstärkung ihrer Menschlichkeit, ja ihrer Menschlichkeit bedeutet, so daß uns angesichts ihrer die Krankheit geradezu als Adelsattribut höheren Menschentums erscheint“. Offenbar gebe es, so Thomas Mann weiter, „Zweierlei Erhöhung und Steigerung des Menschlichen: eine ins Göttliche, von Gnaden der Natur, und eine ins Heilige - von Gnaden einer anderen Macht, die der Natur entgegensteht, die die Emanzipation von ihr, die ewige Revolte gegen sie bedeutet: von Gnaden des Geistes. ${ }^{\text {"4 }}$ Auch das biographische Faktum, daß der Sohn eines schwäbischen Feldschers und der eines Moskauer Hospitalarztes „kleiner Leute Kind waren und in beschränkten, unansehnlichen, man möge sagen: unwürdigen Verhältnissen all ihre Tage verbrachten“, nennt

4 Thomas Mann: Goethe und Tolstoi. Fragmente zum Problem der Humanität. In: Aufsätze, Reden, Essays. Bd.3. Berlin und Weimar 1986, S. 514. 
Thomans Mann „symbolisch, weil sich darin die Christlichkeit des Geistes bewährt, dessen Reich, wie das Schriftwort lautet, 'nicht von dieser Welt' ist" .

Zur gleichen Zeit konstatierte der Kunstkritiker Julius Meier-Graefe in seiner noch immer lesenswerten Monographie Dostojewski der Dichter: „Schiller muß das früheste und stärkste Erlebnis der Jugend gewesen sein und hat einen höchst paradoxen, mit nichts vergleichbaren Einfluß auf ihn ausgeübt. Seine Reflexe reichen bis in die allerletzte Zeit und werden zum Richtscheit des Menschen und Dichters. “6

In der akademischen Forschung hat man die intensive Schiller-Rezeption Dostoevskijs als Ergebnis einer geistigen Affinität zwischen zwei Literaten gewertet, die auch Philosophen und Psychologen waren. Dmitrij Čyževskij, der sich um die Erforschung der geistigen Beziehungen zwischen Ost und West große Verdienste erworben hat, wollte in einer Studie zu Schiller und die Brüder Karamazov aus dem Jahre 1929 zeigen, „wie die innere Verwandtschaft beider in gemeinsamer Weltanschauung, gemeinsamem Weltempfinden zum Ausdruck kommt, die letzten Endes auf geschichtliche Sinnzusammenhänge und nicht etwa auf kausale Zusammenhänge zurückführen."

Seit langem besteht in der Forschung Konsens darüber, daß Dostoevskijs Rezeption repräsentativ für die Wirkungsgeschichte Schillers in Rußland ist und daß mit Schiller zugleich die Philosophie des deutschen Idealismus, namentlich Kants, Eingang in das geistige Leben Rußlands fand. Der Marburger Slavist Hans-Bernd Harder resümierte:

„In einer Kultur, die bis dahin weder eine Philosophie noch nennenswerte Philosophen hervorgebracht hatte, war der Zugang zum Reich der Gedanken über die Brücken und Stege des dichterischen Wortes ein Glücksfall. Dieser Umstand ist es, der Schillers Vorrang in der russischen Literatur begründet, ihn vor Goethe setzt und allem vorordnet, was in deutscher Sprache geschrieben wurde und zu den Russen drang. Schiller war für Rußland ein Denker, der sich der strengen Übung des Kantschen Kritizismus unterzogen hatte und doch der Poesie nicht untreu geworden war, die Naivität des Dichters nicht verloren hatte. Er war ein moralischer Dichter, der dennoch die Geschichte tief verstand, der Dichter der Freiheit und der Darstellung unerbittlicher Notwendigkeit, der Tragiker und der Künder von der höheren Bestimmung des Menschen. ${ }^{\text {" }}$

5 Ebd., S.539.

6 Julius Meier-Graefe: Dostojewski. Der Dichter. Berlin 1926, S. 89.

7 Dmitrij Čyževskij: Schiller und die „Brüder Karamazov“, in: Zeitschrift für slavische Philologie 6 (1929), H. 1/2, S. 5.

8 Hans-Bernd Harder: Schiller und die russische Literatur. In: Wechselbeziehungen zwischen slavischer und deutscher Literatur. Köln, Wien 1978, S. 33 f. 
Umstritten ist hingegen nach wie vor die Frage, ob und wie sich Dostoevskijs Verhältnis zu Schillers Gedanken- und Gestaltenwelt im Laufe der Zeit wandelte. Im allgemeinen wird davon ausgegangen, daß auf die Phase jugendlicher Schiller-Euphorie eine Ernüchterung folgt, die mit der Abkehr von wesentlichen Prämissen Schillerscher Observanz einhergeht. ${ }^{9}$ Der russische Germanist Nikolaj Vil'mont hat für diese komplizierte Materie ein treffendes Bild gefunden, das ich aufgreifen und zum Leitfaden meiner Ausführungen machen möchte. Er sprach in seiner Untersuchung vom "geistigen Ferment Schiller“, das auf Dostoevskijs literarisches Schaffen und Denken zu unterschiedlichen Zeiten in unterschiedlicher Weise wirkte. ${ }^{10}$

Wenn dieser Wirkung im folgenden nachgegangen wird, dann bedarf es einiger methodischer Vorbemerkungen. Die überlieferten Rezeptionszeugnisse legen den Schluß nahe, daß Dostoevskij eine gewisse Vorliebe für bestimmte lyrische und dramatische Texte hatte, die auf eine Favorisierung des „vorklassischen " Schiller hindeuten. ${ }^{11}$ Wiederholt werden Romangestalten als "Schillernaturen“ oder „Idealisten in der Art Schillers“ charakterisiert, womit ihre Begeisterung für alles Große, Schöne und Erhabene, der profanen Wirklichkeit Entrückte gemeint ist oder aber - mit negativem Vorzeichen ihr mangelnder Realitätssinn. Dieses „Schillertum“ darf nicht ohne weiteres mit Dostoevskijs Verhältnis zu Schiller gleichgesetzt werden, denn es handelt sich um Aussagen literarischer Figuren bzw. Wertungen des Erzählers, die innerhalb des jeweiligen Werkes eine bestimmte ästhetische Funktion haben. Durch diese perspektivischen Brechungen entsteht gleichsam ein irisierendes Schillerbild: Schiller schillert sozusagen in den verschiedensten Farben. Es gibt - besonders im Frühwerk - die idealistischen Träumer und Romantiker, jene „schönen Seelen“, die so leicht Opfer der Machtmenschen und Zyniker werden. Es gibt aber auch die Reduktion der komplexen Ideenwelt Schillers auf die Formel vom „Schönen und Erhabenen“ und verschiedene Formen der Trivialisierung eines weltanschaulichen und ästhetischen Idealismus.

Andererseits finden wir in den Romanen Der Idiot, Die Dämonen und Der Jüngling kaum explizite Verweise auf den deutschen Dichter. Aber auch in diesen Fällen muß man sich vor voreiligen Schlüssen hüten. Die immer wieder

9 Vgl. u.a. Čyževskij (1929, S. 15); A. H. Lyngstad: Dostoevskij and Schiller, The Hague. Paris 1975, S. $25 \mathrm{ff}$.

10 Nikolaj Vil'mont: Dostoevskij i Šiller. Moskva 1984, S.61.

11 Dazu zählen vor allem die Gedichte „An die Freude“, „Resignation“, „Die Götter Griechenlands“ und „Sehnsucht“ sowie die Dramen „Die Räuber“, „Kabale und Liebe“ und „Don Karlos“. 
beschworene "geistige Verwandtschaft" beider Autoren erschöpft sich eben nicht in Zitaten, Reminiszenzen, Allusionen oder strukturellen Analogien, sondern zeigt sich auch und vor allem in einer vergleichbaren Reaktion auf den mit der Französischen Revolution von 1789 eingeleiteten Epochenumbruch und die Herausbildung einer modernen bürgerlichen Gesellschaft. An dieser Stelle wird der unmittelbare Bezug auf die Thematik dieser Jahrestagung einsichtig, geht es doch nicht allein um Dostoevskij und Schiller, sondern um Dostoevskij und Europa.

Es ist der rasante gesellschaftliche Wandel, der um 1800 einsetzt und auf dessen krisenhafte Erfahrung Schiller mit einer neuen Funktionsbestimmung der Kunst reagiert. Dostoevskij wird an die von Schiller entworfenen poetischen Strategien auf verschiedene Weise anschließen, sie erproben, für seine Zwecke modifizieren - und auch verwerfen. Diese These soll zunächst am Zusammenhang von geschichtsphilosophischer Spekulation, Zeitaltercharakteristik und Kunstkonzept erläutert werden. ${ }^{12}$

\section{Zeitalterkritik und ästhetische Utopie}

Dostoevskij hat in seinen Werken immer wieder auf eine tradierte Bildlichkeit zurückgegriffen, wenn er Fragen nach dem Sinn der individuellen Existenz und der menschheitsgeschichtlichen Perspektive thematisierte. Da gibt es natürlich die christlichen Vorstellungsformen von „Paradies“, „Neuem Jerusalem“ und „Tausendjährigem Reich“, aber auch das aus der Antike entlehnte Bild vom Goldenen Zeitalter. Es erfährt seine ausführlichste künstlerische Konkretisierung in der Erzählung Der Traum eines lächerlichen Menschen (1877). Darin überspringt der Erzähler „Raum und Zeit und die Gesetze des Seins und der Vernunft" und hält sich „nur an den Punkten auf, von denen das Herz träumt“. Nach seinem Flug durch das Weltall landet er schließlich „auf einer jener Inseln, die auf unserer Erde den griechischen Archipel bilden“ (PSS 25, 110). Auch Stavrogin im Roman Die Dämonen und Versilov im Jüngling sahen im Traum diesen „Winkel der griechischen Inselgruppe; blaue, freundliche Wellen, Inseln und Felsen, blühende Ufer, ein zauberhaftes Panorama in der Ferne, die untergehende lockende Sonne [...]. Hier war, so blieb es in ihrem Gedächtnis, die Wiege der europäischen Menschheit, hier waren die ersten Szenen der Mythologie, ihr irdisches Paradies..." (PSS 11, 21).

12 Vgl. dazu Christiane Schulz: Aspekte der Schillerschen Kunsttheorie im Literaturkonzept Dostoevskijs. München 1992. Im folgenden Abschnitt referiere ich einige Ergebnisse dieser Studie. 
Mit der griechischen Überlieferungslinie seit Hesiods Lehrgedicht Werke und Tage hat Dostoevskijs Bild vom Goldenen Zeitalter dann auch entscheidende Gemeinsamkeiten: den friedlichen Zustand der Erde, die ihre Reichtümer von selbst und im Überfluß schenkt, sowie die unschuldig-kindliche Freude und Schönheit der Menschen, deren Tun keinen Zweck zu verfolgen und für die der Tod keine Bedeutung zu haben scheint. Die Schönheit dieser Wesen fasziniert den „lächerlichen Menschen“, und „schön“ ist auch das von Schiller bevorzugte Attribut zur Charakteristik jenes Zeitalters, in dem die "Götter Griechenlands“ als die „schöne[n] Wesen aus dem Fabelland“ (NA 1, 190 ${ }^{13}$ die Welt regierten. Beide Dichter beschreiben aber nicht nur das Bild einer friedlichen und schönen Welt, in der die Menschen ohne Arbeit, Kampf, Verbrechen und Krankheit lebten, sondern auch Symptome des Abfalls von diesem harmonischen Urzustand. Die einstige Einheit des Weltbezuges zerfällt, und an die Stelle früherer Totalität tritt die einförmige, von Verstandeswissen und Erkenntnisstreben bestimmte Weltaneignung. In Schillers Bildsprache klingt das so:

„fühllos selbst für ihres Künstlers Ehre, gleich dem todten Schlag der Pendeluhr, dient sie knechtisch dem Gesetz der Schwere, die entgötterte Natur!

Morgen wieder neu sich zu entbinden, wühlt sie heute sich ihr eignes Grab, und an ewig gleicher Spindel winden sich von selbst die Monde auf und ab." (NA 1, 194 f.)

Auch Dostoevskijs Fortschrittskritik steht im Zeichen einer Polemik mit den von der klassischen Mechanik dominierten modernen Naturwissenschaften und dem rationalistischen Weltbild. In den Aufzeichnungen aus dem Untergrund opponiert der Protagonist gegen die Herrschaft der "Naturgesetze“ (PSS 5, 105), die den Menschen auf "eine Art Klaviertaste oder einen Stift in einem Leierkasten“ (PSS 5, 112) reduzieren würden. Diese griffige Formel hat Dostoevskij übrigens einem Programmtext der französischen Aufklärung entlehnt, nämlich dem Gespräch zwischen d'Alembert und Diderot (1769), wo es heißt: "Wir sind mit Gefühl und Gedächtnis begabte Instrumente. Unsere Sinne sind ebenso viele Tasten, die von der uns umgebenden Natur angeschlagen werden

13 Alle Schiller-Zitate mit der Sigle NA unter Angabe von Band- und Seitenzahl nach: Schillers Werke. Nationalausgabe. Weimar $1943 \mathrm{ff}$. 
und die sich oft genug sogar selbst anschlagen. "14 Dieser Bezug zu den französischen Enzyklopädisten kann hier nicht weiter verfolgt werden, doch finden wir auch in anderen Erzählwerken Spuren einer Auseinandersetzung Dostoevskijs mit dem von den modernen Naturwissenschaften geprägten Welt- und Menschenbild. ${ }^{15}$ Vor allem aber beschäftigt den russischen Schriftsteller eine Problematik, die auch für Schiller zentral war: der Mensch als moralische Person. ${ }^{16}$

Schiller und Dostoevskij stehen zunächst ganz in den Traditionen der Überlieferungsgeschichte des Topos von der Goldenen Zeit, wenn sie unter Rückgriff auf das antike Griechenland ein ideales Gegenbild zu ihrer als unnatürlich, disharmonisch und inhuman empfundenen Gegenwart entwerfen. Daß dem russischen Autor dieser Zusammenhang mit der antiken Weltalterlehre bewußt war, beweist nicht zuletzt seine Charakteristik des 19. Jahrhunderts als „eiserne Zeit“ (železnoe vremja) ${ }^{17}$. Wie Schiller interessiert sich Dostoevskij für den Kontrast, „der zwischen der heutigen Form der Menschheit, und zwischen der ehemaligen, besonders der griechischen, angetroffen wird“ (NA 20, 321). Das Bild des Menschen „im Spiegel der jetzigen Zeit“ (NA 26, 263) wird bei beiden Autoren also historisch, oder genauer formuliert: geschichtsphilosophisch begründet. Ihr Kunstkonzept basiert, wie gleich noch genauer zu zeigen sein wird, auf dem Unterschied zwischen antiker und moderner Welterfahrung, wobei Zeitaltercharakteristik, Gesellschaftsdiagnose und Kunstproduktion eine Einheit bilden. Dies wird auf besondere Weise sinnfällig in der Auseinandersetzung mit dem Verlauf und den Ergebnissen der französischen Revolution von 1789. „Der Versuch des Französischen Volks“, so der unmittelbare Zeitzeuge Schiller in einem Brief vom 13. Juli 1793 an den Prinzen Friedrich Christian von Augustenburg,

„sich in seine heiligen Menschenrechte einzusetzen, und eine politische Freiheit zu erringen, hat bloß das Unvermögen und die Unwürdigkeit desselben an den Tag gebracht, und nicht nur dieses unglückliche Volk, sondern mit ihm auch einen beträchtlichen Theil Europens, und ein ganzes Jahrhundert, in Barbarey

14 Denis Diderot: Gespräch zwischen d'Alembert und Diderot. In: Erzählungen und Gespräche. Leipzig 1953, S. 427.

15 So beruft sich beispielsweise Raskol'nikov im Roman Schuld und Sühne auf Kepler und Newton, wenn er seine von den „Naturgesetzen“ her entwickelte Theorie des Verbrechens zu begründen sucht.

16 Vgl. dazu Horst-Jürgen Gerigk: Dostojewskij und Schiller. Vorbereitung eines poetologischen Vergleichs. In: Der ganze Schiller, Heidelberg 2006, S. 497-506.

17 Vgl. u.a. PSS 8, 311; PSS 18, 5. 
und Knechtschaft zurückgeschleudert. Der Moment war der günstigste, aber er fand eine verderbte Generation, die ihn nicht werth war, und weder zu würdigen noch zu benutzen wußte." (NA 26, 262)

Es war dies der erste einer Reihe von Briefen über die „Philosophie des Schönen“ - eine Dankesgabe an den dänischen Herzog, der dem kranken Dichter durch eine großzügig bemessene Geldzuwendung über drei Jahre hinweg die materielle Grundlage seines Lebens und Schaffens sicherte. Schiller hat diese Briefe für den Druck überarbeitet und die Ergebnisse seiner „Untersuchungen über das Schöne und die Kunst“ (NA 20, 309) dann unter dem Titel „Über die ästhetische Erziehung des Menschen in einer Reihe von Briefen“ (1795) veröffentlicht. Diese Abhandlung enthält nicht nur eine scharfsinnige Zeitkritik, insbesondere der mit der Französischen Revolution verbundenen Heilserwartungen, sondern entwirft auch ein alternatives Modell individueller und gesellschaftlicher Emanzipation. Schiller unterscheidet hier zwischen „Vernunft“ und „Vernüfteley“ (NA 20,321) und macht deutlich, daß die Aufklärung nicht nur den Kopf, sondern auch das Herz berühren müsse. Angesichts der negativen Erscheinungen und inhumanen Konsequenzen des einseitigen Rationalisierungsprozesses soll die ästhetische Bildung zum Fundament einer wahren Aufklärung des Geistes und des Gefühls werden.

1861 reist der russische Schriftsteller Fëdor Dostoevskij das erste Mal nach Westeuropa, in das „Land meiner so lang gehegten Sehnsüchte und Erwartungen, meines so hartnäckigen Glaubens" (PSS 5, 51). Ausdrücklich, wenngleich mit ironischem Einschlag, betont er in den Winterlichen Aufzeichnungen über sommerliche Eindrücke die historische Rolle Frankreichs im menschheitsgeschichtlichen Fortschritt: Aus eben diesem Land komme „beinahe alles, was es bei uns an Entwicklung, Wissenschaft, Kunst, staatsbürgerlicher Gesinnung, Humanität“ (PSS 5, 50) gibt. Hatte Schiller erwartet, daß in der Französischen Revolution „das große Schicksal der Menschheit“ nicht mehr „durch das blinde Recht des Stärkern“, sondern „vor dem Richterstuhle reiner Vernunft" (NA 20, 311 f.) verhandelt würde, so triumphiert nach Dostoevskijs Beobachtung der französische Bourgeois über alle „Argumente der reinen Vernunft“, denn: „Die Vernunft hat sich doch gegenüber der Wirklichkeit als bankrott erwiesen" (PSS 5, 78).

Damit bestätigt Dostoevskij den schon von Schiller geäußerten Zweifel an einem veredelnden Einfluß der Aufklärung auf die Gesinnung des Menschen. Sie ist „bloß theoretische Kultur“ und verhilft Schiller zufolge lediglich dazu, "die Verderbniß in ein System zu bringen, und unheilbarer zu machen“ (NA 26, 263). Es müsse daher ,jede gründliche Staatsverbesserung mit Veredlung 
des Karakters beginnen, dieser aber an dem Schönen und Erhabenen sich aufrichten" (NA 26, 267). Durch ästhetische Erziehung wollte Schiller die in der Gegenwart vorherrschende „Trennung in dem inneren Menschen“ (NA 20, 329) aufheben. Nicht anders formulierte Dostoevskij sein schöpferisches Credo: „bei vollem Realismus den Menschen im Menschen finden.“ (PSS 27, 65)

Der phantastischen Erzählung Der Traum eines lächerlichen Menschen lag nun ein Denkmodell zugrunde, das in wesentlichen Aspekten mit der geschichtsphilosophischen Grundlage von Schillers ästhetischer Theoriebildung übereinstimmt: Auf den harmonischen Urzustand, die quasi naturgegebene Einheit und Gleichheit der Menschen im „Paradies“ oder „Goldenen Zeitalter" folgt eine jahrtausendelange Periode der Differenzierung, der Vereinzelung und des Kampfes, die wieder in einen Zustand neuer Harmonie und Vollkommenheit münden soll. Konnte in der Erzählung das Endstadium nur gedanklich antizipiert werden, so hat Dostoevskij in einem Aufsatz aus den Jahren 1864/ 65 ein Geschichtsmodell entworfen, in dem dieses Dreistufenschema in aller Ausführlichkeit entwickelt wird. Der Text, der zu Lebzeiten Dostoevskijs nicht veröffentlicht wurde, trägt den bezeichnenden Titel Sozialismus und Christentum $^{18}$, und darin heißt es unter anderem: „Wenn der Mensch als Masse lebt (in den ursprünglichen patriarchalischen Gemeinschaften, von denen Überlieferungen blieben) - dann lebt er unmittelbar." (PSS 20,191) Wie wir am Bild des Goldenen Zeitalters gesehen haben, übt diese Existenzweise auf den modernen Menschen eine unbeschreibliche Faszination aus. Dann aber beginnt eine „Übergangszeit“, in der sich die „Entwicklung individuellen Bewußtseins und die Negation unmittelbarer Ideen und Gesetze“ (PSS 20, 192) vollzieht. Diese Phase der "Zivilisation“, so Dostoevskijs Begriff, ist schädlich, aber unvermeidlich. Den „Zerfall der Massen in Individuen“ wertet er als einen „krankhaften Zustand“, weil „die lebendige Idee von Gott“ verlorengeht und „der Mensch sich in diesem Zustand schlecht fühlt, Sehnsucht verspürt, die Quelle des lebendigen Lebens verliert, keine unmittelbaren Empfindungen mehr kennt und alles bewußtseinsmäßig erfaßt" (PSS 20, 192). An dieser Stelle nun wird der Zusammenhang von geschichtsphilosophischer Spekulation und ästhetischer Konzeptionsbildung einsichtig: Da die Vereinzelung und Deformation des Individuums in der modernen Welt nicht der wahren menschlichen Natur entspricht, muß der Künstler die ursprüngliche Einheit von Mensch, Natur und Universum, wie sie einst im Goldenen Zeitalter existierte, wiederherstellen.

18 In deutscher Übersetzung zugänglich in der Ausgabe des Aufbau-Verlages: Fjodor Dostojewski: Eine verfängliche Frage. Berlin und Weimar 1988, S. 645-648. 
Im Vorwort zur russischen Ausgabe von Victor Hugos Roman Notre-Dame de Paris (1831) hatte Dostoevskij 1862 den „Hauptgedanken aller Kunst im 19. Jahrhundert", den er bei Hugo zum ersten Mal realisiert sah, folgendermaßen formuliert:

„Es ist dies ein christlicher und zutiefst moralischer Gedanke, und auf einen Nenner gebracht lautet er: Wiederherstellung [vosstanovlenie] des untergegangenen Menschen, der zu Unrecht unter der Last der Umstände, der Stagnation der Jahrhunderte und der gesellschaftlichen Vorurteile erdrückt wird." (PSS 20, 28)

\section{Geschichtsphilosophische Spekulation und sentimentalisches Bewußtsein}

In dieser Formel aktualisiert Dostoevskij zugleich die Leitidee der zweiten großen ästhetischen Abhandlung Schillers Über naive und sentimentalische Dichtung (1795/96), die auf der Einsicht in die Verschiedenheit von Antike und Moderne beruht und die mit der Beschreibung des modernen Bewußtseins einen bedeutsamen Beitrag zur Bestimmung neuzeitlicher Kultur liefert. Während die naive Dichtungsart gekennzeichnet ist durch die Bewahrung der Natur, „entzündet sich die sentimentalische Literatur am Bewußtsein des Verlusts solcher Ursprünglichkeit und am daraus folgenden Begehren, die Schönheiten eines goldenen Zeitalters der Zweckfreiheit unter den Bedingungen der Vernunftkultur neu zu gewinnen. ${ }^{19}$ Dieser triadische Stufengang entspricht Schiller zufolge auch der evolutionären Logik von Individual- und Gattungsentwicklung: „Dieser Weg, den die neueren Dichter gehen, ist übrigens derselbe, den der Mensch überhaupt sowohl im Einzelnen als im Ganzen einschlagen muß. Die Natur macht ihn mit sich Eins, die Kunst trennt und entzweyet ihn, durch das Ideal kehrt er zur Einheit zurück.“ (NA 20, 438)

In der Forschung besteht Einmütigkeit darüber, daß das triadische Denkmodell zugleich repräsentativ ist für den geschichtsphilosophisch begründeten deutschen Idealismus um 1800:

„Novalis und Hölderlin, Schelling und Hegel stützen sich gleichermaßen auf die Logik des Dreischritts, demzufolge der geschlossenen Kulturordnung (als Kennzeichen von Antike und Mittelalter) eine Periode der Zersplitterung der Kräfte mit gleichzeitiger Vertiefung der Vernunftvermögen, dieser wiederum die (erwartbare) Neugewinnung der Unschuld unter den veränderten Bedingungen ästhetischer Modernität folge. ${ }^{\text {“20 }}$

19 Peter-André Alt: Schiller. Leben - Werk - Zeit. Bd. 2, München 2009, S. 214.

20 Ebd., S.216. 
Es ist die Fähigkeit zur Selbstreflexion, die den modernen Menschen (und den sentimentalischen Dichter) auszeichnet und ihn in die Lage versetzt, die verlorene Unschuld und Naturnähe gedanklich zu kompensieren. „Weil aber das Ideal ein unendliches ist, das er niemals erreicht, so kann der kultivirte Mensch in seiner Art niemals vollkommen werden, wie doch der natürliche Mensch es in der seinigen zu werden vermag." (NA 20, 348)

Auch der Protagonist der Erzählung Der Traum eines lächerlichen Menschen erfährt die Sehnsucht nach dem Ideal natürlicher Unschuld und seine Unvereinbarkeit mit der Wirklichkeit. Man kann die Erzählung geradezu als exemplarische Demonstration der poetologischen Überlegungen Schillers zur sentimentalischen Poesie lesen, wo es unter anderem heißt: Die poetische Darstellung unschuldiger und glücklicher Menschheit sei von den Dichtern „aus dem Gedränge des bürgerlichen Lebens heraus in den einfachen Hirtenstand verlegt und derselben ihre Stelle vor dem Anfange der Kultur in dem kindlichen Alter der Menschheit angewiesen“, weil „diese Unschuld und dieses Glück mit den künstlichen Verhältnissen der größeren Sozietät und mit einem gewissen Grad von Ausbildung und Verfeinerung unverträglich schienen“. Aber jener Zustand der Harmonie und des Friedens mit sich selbst finde

„nicht bloß vor dem Anfange der Kultur statt, sondern er ist es auch, den die Kultur, wenn sie überall nur eine bestimmte Tendenz haben soll, als ihr letztes Ziel betrachtet. Die Idee dieses Zustandes allein und der Glaube an die mögliche Realität derselben kann den Menschen mit allen den Übeln versöhnen, denen er auf dem Wege der Kultur unterworfen ist [...]. Dem Menschen, der in der Kultur begriffen ist liegt also unendlich viel daran, von der Ausführbarkeit jener Idee in der Sinnenwelt, von der möglichen Realität jenes Zustandes eine sinnliche Bekräftigung zu erhalten, und da die wirkliche Erfahrung, weit entfernt, diesen Glauben zu nähren, ihn vielmehr beständig widerlegt, so kömmt auch hier [...] das Dichtungsvermögen der Vernunft zu Hilfe, um jene Idee zur Anschauung zu bringen und in einem einzelnen Fall zu verwirklichen." (NA 20, 468)

Dem modernen Künstler wird nun die Aufgabe einer Idylle gestellt,

„welche jene Hirtenunschuld auch in Subjekten der Kultur und unter allen Bedingungen des rüstigsten feurigsten Lebens, des ausgebreitetsten Denkens, der raffinirtesten Kunst, der höchsten gesellschaftlichen Verfeinerung ausführt, welche mit einem Wort, den Menschen, der nun einmal nicht mehr nach Arkadien zurückkann, bis nach Elisium führt.“ (NA 20, 472) 
Nicht nur die Erzählung Der Traum eines lächerlichen Menschen, sondern auch die großen Romane Dostoevskijs, in denen das Bild des Goldenen Zeitalters nur episodischen Charakter hat und die Dissonanzen dominieren, lassen eine Orientierung an Schillers poetologischem Programm erkennen. Sie leben von der Spannung zwischen utopischem Entwurf und realistischem Skeptizismus und bestätigen damit aus russischer Perspektive Schillers Bedeutung als Theoretiker der modernen Literatur. ${ }^{21}$

Es sei die Aufgabe der Kunst, so der russische Schriftsteller, „das Ideal zu bewahren“, das "die Historiker nicht kennen“ (PSS 26, 223). Dostoevskij schreibt „Ideenromane“, in denen er ganz im Sinne von Schillers Bestimmung des Sentimentalischen „die Wirklichkeit als Mangel, dem Ideal als der höchsten Realität“ gegenüberstellt (NA 20, 442). Diese künstlerische Verfahrensweise hat er selbst einmal als „phantastischen Realimus“ bezeichnet. In seinen Erzählwerken wolle er den Lesern beweisen, „daß sie längst nicht so gesund sind, wie sie denken, sondern, im Gegenteil, sehr krank, und daß sie sich um Heilung bemühen müssen." (PSS 26, 107).

Diese Situation fanden wir auch in der explizit als "phantastisch“ deklarierten Erzählung Der Traum eines lächerlichen Menschen, aber dort blieb es ebenso bei der Verheißung einer menschlichen Wiedergeburt wie zuvor schon im Epilog von Schuld und Sühne. Dostoevskij sieht sich mit dem Problem konfrontiert, daß die enorme historische Distanz zwischen der unbewußten Existenz des Menschen im paradiesischen Urzustand und dem hochentwickelten individuellen Bewußtein seiner Gestalten - und Leser - im Stadium der "Zivilisation“ erzählerisch nicht zu vermitteln ist, denn die Traumvisionen lassen sich nicht in Handlung umsetzen. Dies gilt übrigens auch für die großen Romane und deren Protagonisten, die kaum eine Entwicklung durchlaufen. Das erzählte Leben endet mit dem Freitod oder im Gefängnis, mit schwerer, unheilbarer Krankheit oder Flucht ins Ausland; die „Wiederherstellung“ des ganzen Menschen bleibt in aller Regel bloße Verheißung.

Im Aufsatzentwurf Sozialismus und Christentum hatte Dostoevskij die dritte und letzte Stufe der Menschheitsentwicklung als „Christentum“ bezeichnet, die dadurch charakterisiert ist, daß der Mensch aus eigenem Antrieb in die Masse und folglich in seinen natürlichen Zustand zurückkehrt: „die volle Macht des Bewußtseins und der Entwicklung erreichen, vollkommen sein Ich erkennen - und das freiwillig für alle hingeben." (PSS 20, 192) Während die

21 Zum Problemkomplex vgl. Walter Hinderer (Hg.): Friedrich Schiller und der Weg in die Moderne, Würzburg 2006. 
Sozialisten allein an den „satten Bauch“ dächten und die Einhaltung gesellschaftlicher Pflichten mit materieller Sicherung honorierten, sei die höchste Menschlichkeit erst in einer Hingabe des Individuums an andere erreicht, die nicht in der Hoffnung auf Belohnung, sondern durch freie und bewußte Selbstentscheidung erfolge. Leidenschaftliche Dostoevskij-Leser werden bemerkt haben, daß dieser Gedankengang unmittelbar mit dem Handlungsverlauf der Brüder Karamazov korrespondiert.

Ich fasse zusammen: Mit der Parallelisierung von Individual- und Gattungsentwicklung, dem triadischen Modell der Menschheitsgeschichte, dem Dreischritt von „Krankheit“, „Kenntnis der Krankheit“ und „Heilung“ und dem teleologischen Geschichtsverständnis aktualisiert Dostoevskij Grundpositionen der ästhetischen Schriften Schillers und des deutschen Idealismus, die an die Philosophie der europäischen Aufklärung anschließen und deren Gedankengut zugleich kritisch reflektieren. Dabei gibt es eine eigentümliche Akzentverlagerung, wenn er das „Christentum“ als „dritte und letzte Stufe des Menschen“ (PSS 20, 194) - nicht der Menschheit! - bezeichnet. Dostoevskij individualisiert also das Endziel der Menschheitsgeschichte, wenn er Christus zur Leitfigur erhebt, denn nur auf diese Weise wird die Differenz zwischen zeitgenössischer Wirklichkeit und intendiertem Ideal künstlerisch darstellbar. Auf diese Weise schafft sich der russische Autor auch die gedanklichen Voraussetzungen dafür, daß er in der zweiten Hälfte des 19. Jahrhunderts überhaupt noch an die von Schiller formulierte Aufgabe anknüpfen kann, der Menschheit ihre höchste Stufe der Vollendung vorzubilden und sie moralisch emporzuheben. Es ist die Christus-Gestalt, die im Erzählwerk und in der Publizistik Dostoevskijs die Einheit von Wahrheit, Schönheit und Sittlichkeit und damit das vom Künstler intendierte ideale Menschentum verkörpert. Diese Ästhetisierung des Religiösen ist aber nicht nur charakteristisch für den russischen Autor, sondern war auch Schiller vertraut. Der „eigenthümliche Charakter des Christenthums“, so im Brief an Goethe vom 17. August 1795, bestehe

„in nichts anderem als in der Aufhebung des Gesetzes oder des Kantischen Imperativs, an deßen Stelle das Christentum die freye Neigung gesetzt haben will. Es ist also in seiner reinen Form Darstellung schöner Sittlichkeit oder der Menschwerdung des heiligen, und in diesem Sinn die einzig aesthetische Religion" (NA $28,28)$.

Obwohl Dostoevskijs Erzählwerk mit seinem dissonanten und fragmentarischen Charakter bereits Momente der avantgardistischen Schreibweisen enthält und insofern einer literarischen Moderne im engeren Sinne den Weg bereitet, 
partizipiert es noch an dem ästhetischen Kompensationsmodell, das Schiller in der Auseinandersetzung mit den Widersprüchen des epochalen Umbruchs entworfen hatte. Dabei gehen, wie im folgenden gezeigt werden soll, die idealistischen Lösungsversuche beider Autoren einher mit einem metaphysischen und anthropologischen Skeptizismus, und gerade diese Verbindung sichert ihren Werken eine die Zeiten überdauernde Wirkung.

\section{Gattungsspezifik und Wirkungsästhetik}

Auf den ersten Blick scheinen in der poetologischen Praxis beider Schriftsteller die Unterschiede zu dominieren. Der Lyriker und Dramatiker Friedrich Schiller hat bekanntlich mythologische und historische Stoffe bevorzugt, während der Erzähler Fëdor Dostoevskij sein Material aus der zeitgenössischen russischen Gesellschaft, oftmals sogar aus Zeitungsmeldungen, gewann. Aber Schiller hat auch Erzählungen geschrieben und ein Romanfragment hinterlassen, obwohl die Prosa in seinem klassischen Kunstkonzept insgesamt eine ungeordnete Rolle spielte und er den Romancier nur als „Halbbruder“ (NA 20, 462) des Dichters gelten lassen wollte. Vom jungen Dostoevskij hingegen ist überliefert, daß er zwei historische Dramen in Anlehnung an Schillers Maria Stuart und Puškins Boris Godunov entwarf - Schiller hat diesen Stoff aus der russischen Geschichte in seinem Demetrius-Fragment verarbeitet!

In der Mitte des 19. Jahrhunderts waren jedoch die ästhetischen Wirkungsmöglichkeiten des Dramas weitgehend erschöpft, und auch das unmittelbare Anknüpfen an klassisch-antike Muster war durch die Ergebnisse der Altertumsforschung suspekt geworden. In den Jugendbriefen erwähnt Dostoevskij zwar noch die verehrten Vorbilder - neben Schiller und Puškin vor allem Shakespeare, Corneille und Racine - aber seine erste Veröffentlichung ist eine Übersetzung von Balzacs Eugénie Grandet. Die Wende in der ästhetischen Orientierung vom Drama zur Erzählprosa und von im weitesten Sinne klassisch-klassizistischen Mustern zu Gegenwartsstoffen wird vermittelt durch die gleichfalls hochgeschätzten Vertreter der europäischen Romantik (George Sand, E.T.A. Hoffmann, Poe, Byron, Scott).

Wiederholt ist in der Forschung darauf hingewiesen worden, daß Schillers „Vorerinnerung“ zu den Philosophischen Briefen von 1786 einen unmittelbaren Anknüpfungspunkt für Dostoevskijs narrative Poetik bildet, wo es unter anderem heißt: „Man scheint sich damit zu begnügen, die Leidenschaften in ihren Extremen, Verirrungen und Folgen zu entwikeln, ohne Rücksicht zu nehmen, wie genau sie mit dem Gedankensysteme des Individuums zusam- 
menhängen." (NA 20,107) Wie Schiller in seinen Dramen, so hat der russische Autor in seinen Erzählwerken die philosophische Begründung bzw. ideologische Motivierung der Affekte und der aus ihnen folgenden Handlungen vor allem an sozial abweichendem Verhalten dargestellt, und das heißt: am Verbrechen und am Typus des Verbrechers.

„In der ganzen Geschichte des Menschen“, so Schiller im ersten Satz seiner Erzählung Der Verbrecher aus verlorener Ehre, sei „kein Kapitel unterrichtender für Herz und Geist als die Annalen seiner Verirrungen." (NA 16, 7) Und es klingt beinahe wie ein Kommentar zu Schuld und Sühne, wenn er wenig später fortfährt, der Leser müsse mit dem Helden bekannt werden, „eh’ er handelt; wir müssen ihn seine Handlung nicht bloß vollbringen, sondern auch wollen sehen. An seinen Gedanken liegt uns unendlich mehr als an seinen Taten, und noch weit mehr an den Quellen seiner Gedanken als an den Folgen jener Taten." (NA 16,9)

In der Lebensgeschichte des Sonnenwirtes Christian Wolf, der zum Dieb und Mörder wird, der zu fühlen beginnt, wie tief er gefallen ist, und der am Ende vor Gericht um göttliche Gnade bittet, finden wir den Weg vieler Dostoevskijscher Romangestalten vorgezeichnet. Vor allem aber folgt der russische Schriftsteller Schillers wirkungsästhetischer Spekulation in der Selbstrezension zu den Räubern, erhabene Verbrecher bedürften „notwendig einer ebenso großen Dosis von Geisteskraft als die erhabene Tugendhafte, und die Empfindung des Abscheus vertrage sich nicht selten mit Anteil und Bewunderung“. (NA 22, 118)

\section{Zwei Prinzen und die Freigeisterei: Schillers Romanfragment „Der Geisterseher“ und Dostoevskijs „Dämonen“}

Eine „ungewöhnliche Fähigkeit zum Verbrechen“ (PSS 10, 201) wird auch Nikolaj Stavrogin aus den Dämonen nachgesagt, aber ein erhabener Verbrecher im Schillerschen Sinne ist er wohl nicht. Er gehört zu den Gestalten Dostoevskijs, die ungeachtet ihrer Amoralität auf den Leser eine eigenartige Faszination ausüben und ihn gleichzeitig irritieren. Auch Stavrogin ist ein innerlich zutiefst gespaltener Charakter, und seine Versuche, sich mit dem „lebendigen Leben“ zu versöhnen, sind zum Scheitern verurteilt. In seiner Beichte mündet der Traum vom Goldenen Zeitalter und einer menschlichen Wiedergeburt in Bilder, die mit seinem schlimmsten Verbrechen assoziiert sind - der Vergewaltigung Matrëšas. Allein im Rausch, in der Erregung, die eine schändliche Tat in ihm hervorruft, hat Stavrogin das Gefühl zu leben, 
kann er Genuß empfinden. Deshalb widerspricht er Šatov auch nicht, als dieser ihm vorwirft, Mar’ja Lebjadkina aus „Nervenkitzel“ [nervnyj nadryv] geheiratet zu haben,

„aus einem leidenschaftlichen Hang zur Quälerei, aus leidenschaftlichem Drang nach Gewissensbissen, aus sittlicher Perversität [...]. Die Herausforderung an den gesunden Menschenverstand war gar zu verlockend! Stavrogin und das reizlose, schwachsinnige, bettelarme hinkende Mädchen! Als Sie den Gouverneur ins Ohr bissen, haben Sie da Wollust gespürt?"(PSS 10, 202).

Die von Stavrogin verübten „Frechheiten“ und seine Tabuverletzungen sind gewöhnlich als zeichenhafte Handlungen interpretiert worden, die auf das ästhetische Programm des Modernismus verweisen. Aber sie tangieren eine Problematik, die schon bei Schiller diskutiert wurde, nämlich im Philosophischen Gespräch (2. Buch, 4. Brief) des Romanfragments Der Geisterseher (1789). Erzählt wird dort die Geschichte eines schwärmerisch veranlagten jungen Mannes, der nach einer rationalistischen Lebensphase die „traurige Einförmigkeit“ seines bisherigen Lebens hinter sich lassen will. Seinen "Sinnentumult“ wertet er als Versuch, „eine innere Stimme zu betäuben, die das Unglück meines Lebens macht“, d. h. „diese grübelnde Vernunft zur Ruhe zu bringen“. (NA 16, 129) Er habe sich „nach dem Leichtsinne“ gesehnt, „der das Dasein der mehresten Menschen so erträglich“ mache: „Alles, was mich mir selbst entführte, war mir willkommen [...]. Ich wünschte zu sinken, um diese Quelle meines Leidens auch mit der Kraft dazu zu zerstören." (NA 16, 168)

Nachdem der Prinz die Unzulänglichkeit des Vernunftprinzips erkannt hat und sich als Individuum in einer Welt ohne transzendente Perspektive verloren sieht, erhofft er sich Befriedigung durch sinnliche Genüsse und das Ausleben augenblicklicher Begierden. Sein Gemütswandel gründet auf der Überzeugung, daß der Mensch als moralisches Wesen allein durch „Schmerz und Vergnügen [...] die Verhältnisse seines gegenwärtigen Zustandes zu dem Zustande seiner höchsten Vollkommenheit" (NA 16, 164) erfahre. Moralität ist für den Prinzen „,eine Beziehung, die nur innerhalb der Seele, außer ihr nie gedacht werden kann.“ (NA 16, 178) Da der Mensch „keinen anderen Wert als seine Wirkungen“ (NA 16, 168) habe, sei allein das Wieviel an innerer Tätigkeit, die Intensität des subjektiven Wollens entscheidend; die Folgen einer Tat erklärt der Prinz für bedeutungslos. So kann er im Gespräch mit dem Baron von $\mathrm{F}^{* * \star}$ auch behaupten, daß eine „sehr künstliche, sehr fein ersonnene, mit Beharrlichkeit verfolgte, mit Mut ausgeführte Bosheit [...] etwas Glänzendes an sich" habe. (NA 16, 176) 
Die Konsequenzen eines derart wertneutralen Moralbegriffs werden im Geisterseher nicht weiter thematisiert. Baron von $\mathrm{F}^{* * *}$ hatte zwar zu bedenken gegeben, daß „die moralische Schönheit verloren“ sei, wenn „zwischen dem Guten und Schlimmen kein Unterschied mehr" bestehe (NA 16, 168). Doch dem Prinzen war vor allem an einer neuen "Quelle des Genusses“ gelegen, denn jeder „will doch gerne ganz sein, was er ist [...] O ich hab' ihn schätzen lernen den Augenblick!“ (NA 16, 159 f.). Indem er alle Spekulationen über die Freiheit des Willens, Gott und die Unsterblichkeit abweist, sucht der Prinz eine Moralität jenseits von Religion und Metaphysik zu begründen.

Es sind Argumente aus dem Denkarsenal des französischen Materialismus, die der Prinz im Geisterseher für seine extrem subjektivistische Moralphilosophie benutzt. Mit Helvétius (De l'esprit, 1758) verteidigt er den auf sinnliche Bedürfnisbefriedigung drängenden Eigennutz des Menschen als Quelle seines sittlichen Handelns, von d'Holbach (Système de la nature, 1770) übernimmt er den Gedanken, daß die Ausrichtung an religiösen Erlösungsvorstellungen dem Individuum die Entfaltung seiner ihm gleichsam organisch innewohnenden Tugend verwehrt. ${ }^{22}$

In diesen ideengeschichtlichen Kontext gehört nun auch Dostoevskijs Roman, in dem Šatov gegenüber Stavrogin insistiert: „Sie sollen erklärt haben, für Sie bestünde kein Unterschied zwischen einem wollüstigen perversen Akt und jeder x-beliebigen Heldentat, und sei es das Opfer des eigenen Lebens zum Wohle der Menschheit - beides sei gleich schön?" Doch Šatov weiß selbst nicht, warum das Böse häßlich und das Gute schön sein soll, aber er glaubt zu wissen, „warum das Gefühl für diesen Unterschied sich bei Herrschaften wie den Stavrogins verwischt und verlorengeht.“ (PSS 10, 201)

An dieser Stelle wird exemplarisch deutlich, daß die moralphilosphischen und metaphysikkritischen Argumente der Schillerschen Protagonisten bei Dostoevskij eine eigentümliche Umfunktionalisierung erfahren, die zugleich eine Ideologisierung darstellt. Šatov konstruiert nämlich einen wechselseitigen Zusammenhang von Atheismus, Aristokratismus und Amoralismus, so daß die heilsgeschichtliche Perspektive allein beim russischen Volk liegen kann: "Sie sind Atheist, weil Sie ein Herrensöhnchen sind, das letzte Herrensöhnchen. Sie haben den Unterschied zwischen Gut und Böse verlernt, weil Sie Ihr Volk nicht mehr kennen [...]. Hören Sie, Sie müssen sich Gott durch Arbeit erringen [...]. Harte Bauernarbeit" (PSS 10, 332).

22 Vgl. Peter-André Alt (wie Anmerkung 19), Bd. 1, S. 583 f. und die Argumentation bei Schiller (NA 16, $165 \mathrm{ff}$.). 
Im Philosophischen Gespräch wollte Schiller die Entwicklung des aufgeklärten Prinzen zum Verbrecher motivieren, aber er kapitulierte vor der damit verbundenen Aufgabe, die extrem subjektivistische Moralphilosophie, die in Amoralismus umschlägt, in Handlung umzusetzen. In späteren Buchausgaben wurde das Philosophische Gespräch gekürzt und 1798 sogar ganz gestrichen. ${ }^{23}$

Man könnte nun zugespitzt formulieren, daß Dostoevskij den fragmentarisch gebliebenen Geisterseher in den Dämonen zuende schreibt. Immerhin war Schillers Romanfragment auch in Rußland ein großer Publikumserfolg, und nach der ersten Übersetzung 1807 gab es dort zahlreiche Nachahmungsund Fortsetzungsversuche. ${ }^{24}$ Zumindest verweisen die zahlreichen thematischen und strukturellen Übereinstimmungen beider Texte auf eine gemeinsame literarische Traditionslinie.

Beide Werke verknüpfen Elemente des Geheimbund- und Verführungsromans mit einer psychologischen Fallstudie, in beiden korrespondiert das multiperspektivische Erzählen, das aus einem Geflecht von Gerüchten und Beglaubigungen besteht, mit den Verwirrungen und der weltanschaulichen Krise der Protagonisten. Für beide Texte gilt, was in der Vorrede bei Schiller angekündigt wird: Erzählt werden soll „eine Begebenheit, die vielen unglaublich scheinen wird" und von der der Herausgeber der Papiere des Grafen O** „größtentheils selbst Augenzeuge war.“ Sie könne

„als ein Beitrag zur Geschichte des Betrugs und der Verirrungen des menschlichen Geistes, vielleicht wichtig sein. Man wird über die Kühnheit des Zwecks erstaunen, den die Bosheit zu entwerfen und zu verfolgen imstande ist; man wird über die Seltsamkeit der Mittel erstaunen, die sie aufzubieten vermag, um sich ihres Zwecks zu versichern." (NA 16, 45)

Der Geisterseher handelt von einer „unerhörte[n] Teufelei“ (NA 16, 102), die sich zur Zeit des Karnevals in Venedig ereignet: vom Komplott eines jesuitischen Geheimbundes, der einen protestantischen Erbfolger durch raffinierte Manipulation zur Konversion veranlaßt. Geheimnis, Betrug und Verschwörung bestimmen auch Dostoevskijs Dämonen, einen Roman der Skandale und Verbrechen, in dem dunkle Mächte obskure politische Absichten verfolgen und in dem die Unbestimmtheit selbst zum Thema wird. ${ }^{25}$ Dabei hat es einen triftigen Grund, wenn der „Chronist“ seine Aufzeichnungen über die „höchst merkwürdigen Ereignisse“ in seiner bis dahin durch nichts aufgefallenen Stadt

23 Vgl. den Kommentar in NA 16, $451 \mathrm{ff}$.

24 Vgl. Danilevskij (wie Anmerkung 3), S. $111 \mathrm{ff}$.

25 Vgl. Maike Schult: Die Dämonen. In: Dostojewskijs Romane, Stuttgart 2005, S. 64 ff. 
„mit einigen biographischen Details über den talentvollen und hochgeschätzten Stepan Trofimovič Verchovenskij" beginnt, die die Exposition für die folgende „eigentliche Geschichte“ (PSS 10, 7) bilden sollen.

Wie Schiller im Geisterseher, so nutzt Dostoevskij in den Dämonen die spannungserzeugenden Elemente des Abenteuerromans und der Kolportage, wenn er die inneren und äußeren Bedingungen thematisiert, unter denen ein junger Mann trotz bester Anlagen ins Bedenkliche, Wahnhafte und zuletzt Verbrecherische hineingetrieben wird. Der dritte Prinz eines protestantischen Hauses und der einzige Sohn der äußerst vermögenden Generalleutnantsgattin Varvara Petrovna Stavrogina sind poetisch verwandt miteinander, wie auch ein Blick auf ihre Biographie beweist: Vom deutschen Prinzen heißt es eingangs, sein Geist sei durch „eine vernachlässigte Erziehung und frühe Kriegsdienste nicht zur Reife“ gekommen. „Alle Kenntnisse, die er nachher schöpfte, vermehrten nur die Verwirrung seiner Begriffe, weil sie auf keinen festen Grund gebauet waren." (NA 16,46) Der Prinz leidet unter einer bigotten und knechtischen Erziehung, die „seinem zarten Gehirne Schreckbilder eingedrückt [hatte], von denen er sich während seines ganzen Lebens nie ganz losmachen konnte." Sein Verhältnis zur Religion ist seit seiner Kindheit gestört, denn seine Erzieher waren „entweder Schwärmer oder Heuchler“ (NA 16, 103).

Wenn wir uns nun die Einleitungskapitel der Dämonen ansehen, in denen die Vorgeschichte der Protagonisten rekapituliert wird, dann fällt gerade wegen der vielen Analogien sogleich die entscheidene Differenz ins Auge: An die Stelle der Religion ist bei Dostoevskij die Ästhetik getreten. Wieder wird mit dem ehemaligen Liberalen Stepan Trofimovič Verchovenskij, der einen „Ruf als Dichter, als Gelehrter, als Demokrat“ (PSS 10, 16) hat, ein Schwärmer (und Heuchler) zum sittlichen Erzieher bestellt. Stepan Trofimovič macht den kleinen Nikolaj sofort zu seinem Freund, schüttet ihm nächtelang sein Herz aus und versteht es, „an die verborgensten Saiten im Herzen seines Freundes zu rühren und ein erstes, noch unbestimmtes Empfinden jener ewigen, heiligen Sehnsucht in ihm auszulösen, die so manche auserwählte Seele [...] nie wieder gegen billige Befriedigung eintauscht.“ Der Erzähler indessen vermutet, daß „der Pädagoge den Nerven seines Zöglings etwas zuviel zugemutet“ habe, denn als „der Sechzehnjährige ins Lyzeum gebracht wurde, war er kränklich und blaß, auffallend still und grüblerisch." (PSS 10, 35)

In diesen wenigen Sätzen scheint sich alles zu verkehren, was eingangs zur Bedeutung Schillers für Dostoevskij gesagt wurde: Freundschaftskult und Herzensergüsse werden ebenso parodiert wie das Programm einer ästhetischen Erziehung. Dostoevskij scheut nicht einmal davor zurück, eine entscheidende 
biographische Zäsur in Schillers Entwicklung zum deutschen Klassiker zu verwerten. Ein dreijähriges Stipendium des Prinzen Friedrich Christian von Schleswig-Holstein-Augustenburg und des Grafen Ernst Heinrich Schimmelmann hatte dem jungen Dichter einst materielle Sicherung geboten. In dieser Zeit arbeitet Schiller die Grundlinien seines klassischen Kunstkonzepts über die ästhetische Erziehung des Menschen aus und teilt seine Überlegungen dem Mäzen in einer Reihe von Briefen mit.

Auch Stepan Trofimovič trägt sich mit dem Plan zu einem bedeutenden Werk, und Varvara Petrovna Stavrogina wird als „eine Frau der Klassik, eine Mäzenatin“ eingeführt, „die sich in ihren Handlungen allein von erhabensten Erwägungen leiten ließ.“ (PSS 10, 12) Nach dem Tode ihres Mannes verbringt sie viele Abende mit dem Erzieher ihres Sohnes in einer Laube, wo sie einander ihre Gedanken und Gefühle anvertrauen. „Es waren Augenblicke voller Poesie [...] Sie schmiegte sich gleichsam an das Herz ihres Seelenfreundes.“ Dieser fragt sich dann auch einigermaßen erschrocken: „Macht sich die untröstliche Witwe in bezug auf mich etwa Hoffnungen und erwartet am Ende des Trauerjahres einen Heiratsantrag?“ (PSS 10, 17)

Wir wissen: die beiden kommen nicht zueinander - und lange Zeit auch nicht voneinander los.

Stepan Trofimovič, der mit dem Geld Varvara Petrovnas ins Ausland gereist ist, um in den Bibliotheken zu arbeiten, schreibt ihr aus Berlin sogar Briefe, aber in denen ist von seinen beiden verstorbenen Frauen die Rede und davon, daß er bis zum Morgengrauen mit jungen Leuten plauderte: „es sind geradezu attische Abende, [...] Träume von Menschheitserneuerung, die Idee ewiger Schönheit, die Sixtinische Madonna“ (PSS 10, 23). Die klassische Mäzenatin Varvara Petrovna hat Stepan Trofimovič nicht nur einen Anzug entworfen, den er dann sein Leben lang trug; sie wird sich auch als Schirmherrin jenes „Klubs“ aufspielen, in dem die „Freigeisterei“ herrscht und in dem die terroristischen Aktionen geplant werden. Stepan Trofimovič aber gesteht dem Erzähler, dem er ebenfalls regelmäßig sein Herz ausschüttet, schon vor Ende des ersten Kapitels unter dem Siegel strengster Verschwiegenheit, er habe „eine fürchterliche Entdeckung gemacht: je suis un ganz gewöhnlicher Gnadenbrotempfänger." (PSS 10, 26)

Dostoevskijs Schiller-Rezeption in den Dämonen geht aber weit über diese parodistischen Inversionen des Programms einer ästhetischen Erziehung und des für die Weimarer Klassik so bedeutenden Mäzenatentums hinaus.

Stavrogin ist, das wird immer wieder betont, ein Mann von großer äußerer Schönheit. Seiner ästhetischen Anziehungskraft erliegen alle Figuren im Roman, 
alle erwarten etwas von ihm, wollen ihm ihr „Banner aufdrängen“ (PSS 10, 201) - aber er ist nicht der, der er scheint. Aus den venezianischen Masken, die in Schillers Geisterseher die wahre Identität der Akteure verhüllten, ist das zur Maske erstarrte Gesicht Stavrogins geworden. Pëtr Verchovenskij wird ihn zur charismatischen Persönlichkeit erheben, denn er hat dem „Herrensöhnchen“ bezeichnenderweise im Ausland - die Rolle des „Ivan-Carevič“ (PSS 10, 325) zugedacht.

Wir erinnern uns, daß sich nach Schiller und Puškin auch der junge Dostoevskij an einem Drama über den falschen Demetrius versuchte. Offenbar war die stoffliche Vorlage besonders geeignet, ein Grundproblem der Moderne in Szene zu setzen: die Frage nach der Legitimation der Macht und der Manipulierbarkeit der Massen. Zugleich ließe sich ein Bezug zum Geisterseher herstellen, in dem die Verschwörung das Ziel verfolgt, den Prinzen zu einem Werkzeug, zu einer bloßen Herrschermarionette zu schmieden.

Aber Stavrogin wird sich nicht wie der dritte Prinz eines protestantischen Hauses, der am Ende seine erste katholische Messe hört, „in eine erniedrigende Abhängigkeit von einem einzigen Menschen“ (NA 16, 101) begeben. Pëtr Verchovenskij agiert auch nicht verdeckt, sondern legt seine Absichten im Gespräch mit Stavrogin offen, allerdings in einem ziemlich schiefen Vergleich: „Sie sind der Führer, die Sonne, und ich bin Ihr Wurm“ (červjak, PSS 10, 324). Deutet man dieses Bild als Schiller-Reminszenz, so kann es als Selbstentlarvung gelesen werden: Er ist von niedrigen Instinkten beherrscht - ein Speichellecker und Intrigant wie der Haussekretär des Präsidenten namens Wurm im Drama Kabale und Liebe.

"Wollust ward der Wurm gegeben“, heißt es im Lied an die Freude, das Dmitrij Karamazov in seiner „Beichte eines heißen Herzens“ zitieren wird, und die Insektenmetaphorik begegnet uns auch in vielen anderen Werken Dostoevskijs. Sie wäre ein eigenes, lohnenswertes Thema, zumal hier der Weg von Schiller über Dostoevskij hin zu Franz Kafka führt.

Wenn Pëtr Verchovenskij Stavrogin zu seinem „Idol“ (PSS 10, 323) erhebt, dann erinnert das an eine vergleichbare Situation in Schillers Wallenstein. Der Feldherr agierte ebenfalls unangefochten und - lange Zeit vom Glück begünstigt - auch sonnengleich. Der von ihm enttäuschte Max Piccolomini bekennt: „Er war mir immer eines Gottes Antlitz,|Kann über mich die Macht nicht gleich verlieren“. Wenn es aber bei Schiller die Schuld des jungen Mannes war, einen Menschen wie einen Gott verehrt zu haben, so verkehrt sich die vergleichbare strukturelle Beziehung bei Dostoevskij ins Gegenteil: Pëtr Verchovenskij weiß um die Wirkung Stavrogins auf andere Menschen und sucht ihn 
für eigene Zwecke zu instrumentalisieren. Er wird sich nicht aus Enttäuschung über den doppelten Betrug des Vaters und seines Idols das Leben nehmen wie Max Piccolomini, und Stavrogin wird nicht ermordet wie Wallenstein, sondern richtet sich selbst. Es gibt eine Fülle weiterer struktureller Verschiebungen und funktionaler Inversionen, die ich hier nicht darstellen kann, doch sei der Hinweis gestattet, daß den Protagonisten von Drama und Roman eines gemeinsam ist - sie agieren als Verblendete.

Wenn Stavrogin schließlich in die Schweiz reist und dort Erlösung im Freitod sucht, dann ist im Erzählerkommentar vom „Bürger des Kantons Uri“ (PSS 10, 516) die Rede. Diese intertextuelle Markierung gibt einen Hinweis auf Wilhelm Tell, und auch hier verkehrt sich die Vorlage: aus dem brüderlichen Bund der Eidgenossen auf dem Rütli wird in den Dämonen der Klub der Unsrigen, der mit seinen terroristischen Aktionen und besonders mit der Ermordung Šatows die Fallhöhe gegenüber Schillers Utopie des ästhetischen Staates im Schlußtableau des Wilhelm Tell demonstriert. Durch die Einführung des Königsmörders Parricida hatte Schiller den Kontrast zwischen dem höheren Recht des Tyrannenmordes und egoistischen Interessen geschärft. In den Reihen der „Unsrigen“ herrschen nur noch niedrige Instinkte, und die Grundfesten des utopischen Gemeinwesens - Freiheit, Gleichheit, Brüderlichkeit - werden pervertiert.

In den Dämonen wird Schiller nicht erwähnt, es gibt keine Zitate oder offensichtliche Reminszenzen, und dennoch lebt der Roman vom geistigen Ferment des deutschen Dichters.

\section{Das geheimnisvolle Räderwerk der Seele und die herzverderbliche} Philosophie: Schillers dramatischer Erstling und Dostoevskijs letzter Roman

Ganz anders sind die Verhältnisse in Dostoevskijs letztem Roman, der durch gehäufte intertextuelle Verweise auf die Schiller-Rezeption aufmerksam macht. Es ist bezeichnenderweise der alte Karamazov, der im 6. Kapitel des 2. Buches auf Schillers Räuber verweist, indem er sich in der Mönchsklause als „Regierender Graf von Moor“ (PSS 14, 66; im Original deutsch!) und seine Söhne Ivan und Dmitrij als Karl und Franz Moor präsentiert (von Alëša ist erst am Ende des 2. Buches wieder die Rede). Damit wird signalisiert, daß Schillers Jugenddrama im Bedeutungsaufbau des Romans eine besondere Rolle spielt.

Offensichtlich sind die Analogien in der Anlage des Figurenensembles, die bereits ein flüchtiger Blick auf das Personenverzeichnis entdeckt. Neben dem 
„alten Moor“ und seinen beiden Söhnen gibt es bei Schiller den Pastor Moser, während in Dostoevskijs Roman Starez Zosima die religiöse Sphäre repräsentiert. Amalia ist die Braut des Älteren und wird von Franz begehrt; in den Brüdern Karamazov wiederholt sich diese Konstellation - allerdings wesentlich subtilerer motiviert - im Verhältnis der beiden Brüder zu Katerina Ivanovna. Der „Bastard von einem Edelmann“ (NA 3, 3) Hermann, der Franz zunächst bei der Verwirklichung seiner teuflischen Pläne zur Seite steht, findet in Smerdjakov sein Pendant. Sagt man von dem einen, er sei „zwischen dem Rindfleisch und Meerrettig gemacht worden" (NA 3, 41), so heißt es vom anderen, er sei „eine Ausgeburt von Badehüttenschweiß“ (PSS 14, 114). Beide sind aber nicht einfach nur „Lakaienseelen“ (PSS 14, 115), sondern durch ihre Abstammung stigmatisierte und in ihrer menschlichen Würde verletzte Gestalten. ${ }^{26}$ Ein zweites Dienerpaar bilden Daniel, „ein alter Diener im Moorischen Hause“ (NA 3, 3), und Grigorij, der sich um die von ihrem Vater vernachlässigten drei Brüder Karamazov und auch um den illegitimen Abkömmling Smerdjakov gekümmert hat.

Denn der alte Karamazov ist das Gegenteil des zärtlichen, sanftmütigen, vortrefflichen Maximilian von Moor, der um seinen „ehrliche[n] Namen“ besorgt ist und mit seinem ältesten Sohn Karl große Hoffnungen und „goldene Träume“ verbindet (NA 3, 13). Wie Stavrogin liebt Fëdor Pavlovič die Selbstinszenierung, sucht er immer neue Reize, zieht er nicht nur aus dem Schönen, sondern auch aus dem Häßlichen und Abscheulichen Genuß. Seine Söhne Dmitrij und Ivan werden in geradezu überdeutlicher Weise den Brüdern Moor nachgebildet und von ihrem „unzärtlichen“ Vater beim ersten Zusammentreffen in der Mönchsklause im Rückbezug auf Schillers Räuber präsentiert. $\mathrm{Daß}$ sich Dostoevskij auch an Schillers Dramaturgie orientiert, belegen weitere vergleichbare Verfahrensweisen.

An keinem Punkt des dramatischen Geschehens stoßen bei Schiller die beiden Widersacher, denen jeweils acht Auftritte zugeordnet sind, aufeinander. Dostoevskij separiert die Brüder ebenfalls und führt zudem mit Alëša eine Mittlergestalt ein. Bereits in früher Kindheit voneinander getrennt, sehen sich die Geschwister erst mit Einsetzen der Romanhandlung wieder, in der ihnen jeweils eigene Kapitel bzw. Bücher gewidmet sind. ${ }^{27}$ In beiden Werken

26 Ausdrücklich wird im Erzählerkommentar darauf hingewiesen, daß Smerdjakov diese Äußerung des alten Grigorij niemals verzeihen konnte.

27 Das 3. Kapitel des 5. Buches trägt zwar die Überschrift: „Die Brüder lernen einander kennen“, doch bezieht sich das nur auf Ivan und Alëša, der zuvor schon den ältesten Bruder Dmitrij durch seine Beichte kennengelernt hatte. Sie enthielt auch den kryptischen Hinweis: „Ivan weiß 
kommt es dann zur Parallelaktion zweier Charaktere, die mehr gemeinsam haben, als es auf den ersten Blick scheinen mag.

Karl und Dmitrij sind die Erstgeborenen, die ein feuriger Geist für alles Große und Schöne empfänglich macht. Weichheit des Gefühls paart sich bei ihnen mit männlichem Mut, Starrsinn und Ehrgeiz mit Offenheit der Seele. Karl Moor, der sich in seiner Räuberexistenz von „Wiedervergeltung“ und „Rache“ (NA 3, 71) leiten läßt, der für die Benachteiligten kämpft, spürt zugleich Sehnsucht nach den „Elisiums Scenen meiner Kindheit“ (NA 3, 80) und beklagt in Liedern seinen moralischen Fall. Er fühlt sich so elend, daß er selbst die Herrschaft über sein Leben verloren glaubt. „Diese Erde ist so herrlich [...] Und ich so häßlich auf dieser schönen Welt - und ich ein Ungeheuer auf dieser herrlichen Erde." (NA 3, 79) Die Erinnerung an die verlorene Unschuld, die im Kontrast zu seiner sozialen Verwilderung und seinen emotionalen Ausbrüchen steht, führt Karl schließlich zur reuevollen und bußfertigen Einsicht und zur Selbstauslieferung an die Justiz. Das Laster nehme, so Schiller in seiner "Vorrede“, „den Ausgang, der seiner würdig ist. Der Verirrte tritt wieder in das Gelaise der Geseze. Die Tugend geht siegend davon.“ (NA 3, 8)

Im analogen Selbsterkenntnisprozeß Dmitrij Karamazovs wird der SchillerBezug noch einmal potenziert. Dmitrij will seine „Beichte eines heißen Herzens" eigentlich mit dem Hymnus An die Freude (im Original deutsch!) beginnen, zitiert dann jedoch erst einmal mehrere Strophen aus Schillers Dichtung Das eleusische Fest (in der Übersetzung Žukovskijs). Im Medium mythologischer Allegorien schildert dieser liedhafte Text den Zivilisationsprozeß nicht als Geschichte des moralischen Verfalls, sondern formuliert mit Bezug auf die Herausbildung des bürgerlichen Gemeinwesens die Hoffnung:

„Doch der Mensch, in ihrer Mitte,

Soll sich an den Menschen reihn,

Und allein durch seine Sitte

Kann er frei und mächtig seyn." (NA 1, 432)

Es sind aber nicht diese Schlußverse über die freiwillige Selbstverpflichtung des Individuums zur Disziplinierung seiner Triebe, die Dmitrij zitiert (und die ihn durchaus unmittelbar betreffen), sondern jene über den Abfall des Menschen von seinem (göttlichen) Urbild und seinen natürlichen Lebensgrundlagen, wie ihn die Göttin Ceres erlebt:

alles. Er hat es lange vor dir erfahren. Aber Ivan ist ein Grab.“ (PSS 14, 101). Eine unmittelbare Konfrontation zwischen Dmitrij und Ivan bleibt ebenso ausgespart wie zwischen Karl und Franz. 


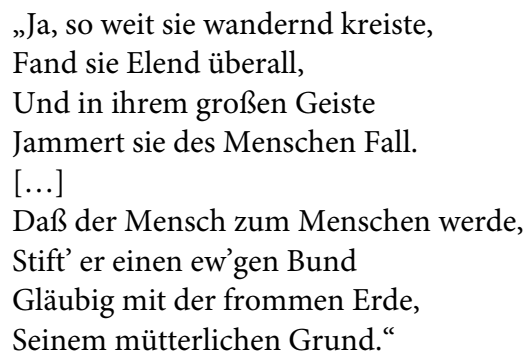

So äußert Dmitrij, der deutschen Sprache nach eigenem Bekenntnis nicht mächtig, in Zitat und Paraphrasierung Schillerscher Verse seine seelischen Nöte. Er denke an „nichts anderes als an des Menschen Fall, an diesen erniedrigten Menschen [...] weil ich selbst so ein Mensch bin.“ Er wisse nicht, wie er sich auf ewig mit der Erde verbinden könne: „soll ich vielleicht Bauer werden oder Hirte? [...] Das ist eben das Unglück, denn alles auf der Welt ist ein Rätsel.“ (PSS 14, 99).

Ein Rätsel ist für Dmitrij vor allem die Schönheit der göttlichen Schöpfung, wie sie Schiller in seiner Ode An die Freude preise. In seinen schlimmsten moralischen Ausschweifungen habe er immer „dieses Gedicht von der Ceres und vom Menschen gelesen“" (PSS 14, 99). Aber es habe ihn nicht gebessert, denn er sei ein Karamazov, und für die gelte Schillers Diagnose im Hymnus an die Freude: „Wollust ward dem Wurm gegeben|Und der Cherub steht vor Gott“. Gegenüber Alëša bekennt er: „Ich, Bruder, bin eben dieser Wurm (nasekomoe), das ist speziell über mich gesagt. Wir alle, wir Karamazovs, sind so, und auch in dir, Engel, lebt dieser Wurm und gebiert schon Stürme in deinem Blut." (PSS 14, 100)

Es ist dies eine in mehrfacher Hinsicht bedeutsame Aussage, die nicht nur die Schiller-Rezeption Dostoevskijs bezeugt, sondern zu einem tieferen Verständnis des ganzen Romans beitragen kann. Der russische Offizier Dmitrij weiß wie Karl Moor um seine sinnliche Natur und die Gefährdungen seines Menschseins, und er wählt für dieses Selbstbekenntnis Schiller-Verse! Bemerkenswert an dieser Textpassage ist aber vor allem, daß die humanisierende Macht des Schönen, die im Zentrum des Programms der ästhetischen Erziehung steht, von Dmitrij zugleich beglaubigt und als unrealisierbar verworfen wird. Nur greift seine Argumentation zu kurz, wenn er den Grund für das Schwanken zwischen Sinnlichkeit und Sittlichkeit auf seine Karamazov-Natur zurückführt. Die poetische Verwandtschaft Dmitrijs mit Karl Moor macht deutlich, daß Dostoevskij am Beispiel einer russischen Familie jene Aporien 
der Aufklärung verhandelt, die auch im Zentrum von Schillers dramatischem Erstling standen. Für beide Gestalten gilt, was der Räuber Moor im Rekurs auf den Satan in Miltons Paradise Lost bekennt: „Ich bin mein Himmel und meine Hölle." (NA 3, 110)

Wie das autonome Individuum seine moralische Verantwortung wahrnimmt, wird in den unterschiedlichsten Konfliktkonstellationen durchgespielt, wobei die Wege der drei Brüder durchaus exemplarischen Charakter haben. Die experimentelle Darstellung menschlicher Grenzsituationen wird in beiden Werken um einen Familienkonflikt zentriert, der zugleich Ausdruck einer dreifachen Krise ist. „In ihr bekunden sich die Rebellion gegen die Autorität des Vaters, das Bewußtsein religiöser Entwurzelung und der Verlust des Vertrauens in die Verheißungen der neuzeitlichen Metaphysik. “28

Als Kontrastgestalten sind die jüngeren Brüder Franz und Ivan konzipiert, die beide als kalt, gewissenlos und zynisch geschildert werden. Sie töten nicht selbst, sondern versuchen, wie es in den Räubern heißt, „den Körper vom Geist aus zu verderben“ (NA 3, 39). Für ihre Verachtung des alten Gebotes der Vater- und Bruderliebe haben sie auch die entsprechende materialistische Philosophie zur Hand: „Wo stikt dann nun das Heilige“, fragt Franz in der Erstfassung der Räuber:

„Etwa im Aktus selber durch den ich entstund? - Als wenn dieser etwas mehr wäre als viehischer Prozeß zur Stillung viehischer Begierden? Oder stickt es vielleicht im Resultat dieses Aktus, der doch nichts ist als eiserne Notwendigkeit, die man so gern wegwünschte, wenns nicht auf Unkosten von Fleisch und Blut geschehen müßte." (NA 3, 357)

Diese drastische Formulierung wurde in späteren Ausgaben weggelassen; geblieben ist die verächtliche Haltung gegenüber dem menschlichen Leben, das als zufälliges Ergebnis wollüstiger Begierden keinen eigenen Wert besitzt: „der Mensch entstehet aus Morast, und watet eine Weile im Morast, und macht Morast, und gährt wieder zusammen in Morast, bis er zulezt an den Schuhsohlen seines Uhrenkels unflätig anklebt.“ (NA 3, 95) ${ }^{29}$ Und Ivan kommentiert die Morddrohungen Dmitrijs gegenüber dem Vater boshaft: „Ein Scheusal [gad] frißt das andere auf, beiden geschieht es recht.“ (PSS 14, 129)

Wie Franz Moor ist Ivan, der studierte Naturwissenschaftler und Journalist, ein „raisonirender Bösewicht“ (NA 23, 21), der sich aus unterschiedlichen

28 Peter-André Alt (wie Anmerkung 19), Bd. 1, S. 297.

29 Vgl. in diesem Zusammenhang das 2. Kapitel des 3. Buches über Lizaveta, die Mutter des Dieners Smerdjakov. 
Quellen eine „herzverderbliche Philosophie“ (NA 22, 122) zusammengebastelt hat und auf intellektuell hohem Niveau seine provozierenden Gedankenexperimente vorträgt. Zugleich intrigiert er auf höchst subtile Weise gegen den älteren Bruder, indem er dem falschen Verdacht gegen Dmitrij Vorschub leistet. Das Objekt seiner heimlichen Begierde ist allerdings nicht das väterliche Erbe und der Erwerb der Macht, sondern eine Frau, die Franz in analoger Situation noch mit roher Gewalt in seinen Besitz zu bringen sucht.

Angesichts dieser offensichtlichen Analogien in der Anlage des Figurenensembles ist es eine bewußt kalkulierte Provokation, ${ }^{30}$ wenn der alte Karamazov seine Söhne spiegelbildlich verkehrt zuordnet und Ivan als seinen „durch und durch ehrerbietigen Karl Moor“ vorstellt, während Dmitrij als „unehrerbietiger Franz Moor“, als „Vatermörder“ denunziert wird. Dies geschieht bereits in der Exposition des Romans, und der Leser erhält auch gleich einen Deutungsrahmen, wenn Fëdor Pavlovič seinem ältesten Sohn Dmitrij droht: „Und was hälst du vom väterlichen Segen? Und wenn ich dich nun verfluche, was dann?" (PSS 14, 116)

Wie der alte Moor greift der alte Karamazov auf das biblische Gleichnis vom verlorenen Sohn zurück, aber im Unterschied zur Exposition in Schillers Drama handelt es sich nicht mehr um ein anerkanntes moralisches Wertgefüge und echte väterliche Trauer, sondern um eine bewußte Inszenierung. Dies gilt auch für Ivans Rückkehr ins Vaterhaus, die von Fëdor Pavlovič im Rahmen der biblischen Parabel gedeutet wird. Aber Ivan ist nicht als reumütiger Sünder zurückgekehrt, sondern verfolgt ganz eigene Interessen. Er wird auch nicht von seinem leiblichen Vater gesegnet, sondern vom Starez Zosima, dem geistigen Vater Alëšas. Während der aufgeklärte Bösewicht Franz Moor nur ein Ziel verfolgt, nämlich als Zweitgeborener HERR zu werden, ${ }^{31}$ agiert Ivan in immer neuen Rollen und bleibt, wie es mehrfach im Text heißt, selbst seinen Brüdern ein Rätsel.

Wir sehen also, daß Dostoevskij die Schillersche Exposition übernimmt und zugleich auf raffinierte Weise modifiziert. ${ }^{32}$ Denn gesündigt hat bei Dostoevskij vor allem der Vater, der sich nach der Geburt der Söhne erneut seinen Ausschweifungen hingab und die Kinder ihrem Schicksal überließ. In Schillers

30 „Beim Kognak“ (3. Buch, 8. Kapitel) wird deutlich, daß der Vater durchaus bemerkt, wie sehr Ivan ihn verachtet, und daß er dessen verborgene Absichten ahnt.

31 Vgl. NA 3, 20.

32 Es gibt eine Fülle weiterer Verschiebungen und Differenzen im Vergleich mit Schillers Drama, die für den Roman bedeutungskonstituierend sind und gesondert betrachtet werden müssen, weil sie den Rahmen dieses Vortrages sprengen. 
Drama war es die Intrige des Zweitgeborenen, die zum Entzug der väterlichen Liebe und für Karl zum Vaterverlust führte. Aus dem Gleichnis des LukasEvangeliums vom verlorenen Sohn wird so in tragischer Verkehrung die Tragödie vom verlorenen Vater. Dostoevskij steigert diese Ausgangssituation noch einmal, indem seine Protagonisten gleichsam vaterlos, bei fremden Menschen aufwachsen. Danach werden alle Möglichkeiten im erzählerischen Experiment durchgespielt: Der älteste Sohn Dmitrij führt als Offizier ein ausschweifendes Leben und sucht doch eine gütliche Einigung mit dem Vater, der ihn um sein Erbteil und die geliebte Frau bringen will. Ivan hingegen entwirft in seinen Gedankenspielen eine radikal vaterlose Existenz; wie Franz Moor wünscht er nicht nur den Tod des leiblichen Vaters, sondern er will jede Herrschaft über sich liquidieren - insbesondere diejenige Gottes: „Ich will alles um mich her ausrotten, was mich einschränkt, daß ich nicht Herr bin“ (NA 3, 20), so verkündet es Franz am Ende der Eingangsszene. Nur Alëša gewinnt mit dem Starez Zosima einen geistigen Führer und eine Art Vaterersatz; er lebt die Überzeugung aus Schillers Lied an die Freude: „Brüder - überm Sternenzelt| Muß ein lieber Vater wohnen."

So zeigt uns gerade der Schiller-Bezug, daß es in Dostoevskijs letztem Roman um mehr geht als eine zufällige russische Familie. Die zerrissenen Familienbande sind poetische Chiffre für die tiefe Krise der traditionellen patriarchalischen Ordnung, und die Vater-Sohn-Beziehung repräsentiert zugleich die Beziehung zwischen Gott und Mensch. Hatte die Aufklärung den Menschen allzu selbstverständlich als vernünftiges Wesen vorausgesetzt, so zeigt sich nun, daß das aufgeklärte Bewußtsein ein unglückliches ist. ${ }^{33} \mathrm{Im}$ Falle Ivans wütet „die Privaterbitterung gegen den unzärtlichen Vater $[\ldots]$ in einen Universalhaß gegen das ganze Menschengeschlecht aus“ (NA 22, 120), während Dmitrij im Vertrauen auf die das Universum durchwaltende Liebeskraft „durch Leiden einen anderen Menschen“ in sich hervorbringen will (PSS 15, 185).

Wie Schiller in seiner „Vorrede“ zu den Räubern erklärte, werde im Stück das Laster „mitsamt seinem ganzen innern Räderwerk entfaltet“ (NA 3, 6). Im Hinblick auf den aufgeklärten Zyniker Franz Moor heißt es, der Dichter „habe versucht, von einem Mißmenschen dieser Art ein treffendes lebendiges Konterfei hinzuwerfen, die vollständige Mechanik seines Lastersystems auseinanderzugliedern - und ihre Kraft an der Wahrheit zu prüfen." (NA 3, 7)

33 Vgl. Dieter Borchmeyer: Die Tragödie vom verlorenen Vater. Der Dramatiker Schiller und die Aufklärung - Das Beispiel der „Räuber“. In: Friedrich Schiller - Angebot und Diskurs, Berlin und Weimar 1987, S. $172 \mathrm{ff}$. 
Auch Dostoevskijs Roman kreist um die Frage, wie das Böse in die Welt kommt. Ob man seinen Vater lieben müsse, nur weil man ihm die Existenz verdanke, diese Frage wird noch in der Gerichtsverhandlung gegen Dmitrij eine Rolle spielen, und der Verteidiger wird ganze Passagen aus den Räubern zitieren, um den moralischen Grundsatz der Blutliebe als Vorurteil zu widerlegen. Die durch die Aufklärung in eine tiefe Krise geratene Vaterordnung hat Schiller nach seinem dramatischen Erstling immer wieder thematisiert: Man denke nur an die verzweifelten Emanzipationsversuche eines Don Karlos oder eines Ferdinand von Walter; auch diese Schiller-Dramen sind in den Text der Brüder Karamazov eingeschrieben.

Es kann hier nicht mehr in allen Einzelheiten dargelegt werden, wie der russische Autor das „Experiment des Universalhasses “"34 in seinem Roman entfaltet und welche Modifizierungen es dabei erfährt. Deshalb sei abschließend nur auf die Antizipation einer neuen Brüderlichkeit verwiesen, die Starez Zosima in seinen Gesprächen und Unterweisungen verkündet und die sein Schüler Alëša zu leben versucht. Um die Welt umzugestalten, so bemerkte es der geheimnisvolle Gast des Starez Zosima einst, „müssen die Menschen selbst seelisch einen anderen Weg beschreiten" (PSS 14, 275). In der Schlußepisode des Romans wird deutlich, wie stark auch diese ästhetische und religiöse Utopie von Schiller inspiriert ist. Alëšas Rede am Stein ist getragen vom Pathos der Ode an die Freude und der Verheißung einer neuen Brüderlichkeit, die in der Familie beginnt:

„So wisset denn, nichts ist höher, stärker, gesünder, nützlicher für das vor uns liegende Leben als eine gute Erinnerung, besonders wenn sie von der Kindheit herrührt, aus dem Elternhaus. Man spricht zu euch viel über eure Erziehung, doch eine solche schöne, heilige Erinnerung, bewahrt seit der Kindheit, ist vielleicht schon die allerbeste Erziehung. Wenn ein Mensch viele solcher Erinnerungen mit sich ins Leben nimmt, ist er schon für sein ganzes Leben gerettet." (PSS 15, 195)

Man mag diesen Schluß für künstlerisch wenig überzeugend halten, obwohl er eine Grunderkenntnis der Entwicklungspsychologie enthält. „[W]er weißt es nicht, daß eben diese Spuren der ersten Erziehung in uns unvertilgbar sind?" (NA 22, 123), so Schillers rhetorische Frage in der Selbstrezension des Dramas, der eine weitere vorausging: „Ein Jüngling, aufgewachsen im Kreis einer fried-

34 Dazu Hans-Jürgen Schings: Schillers „Räuber“: Ein Experiment des Universalhasses. In: W. Wittkowski (Hg): Schiller. Kunst, Humanität und Politik in der späten Aufklärung, Tübingen 1982, S. $1 \mathrm{ff}$ 
lichen, schuldlosen Familie - woher kam ihm eine so herzverderbliche Philosophie?" (NA 22, 122)

Die Geschichte der Familie Karamazov erweist sich als Gegenbild des Schillerschen Entwurfs, aber mit Franz und Ivan sind es jeweils die Bösewichte, die die brisanten Fragen aufwerfen und damit die Wirkungsgeschichte beider Werke wesentlich bestimmen. Auch Dostoevskij war sich wohl nicht sicher, ob die euphorische und ekstatische Schlußszene mit ihrem Lobgesang einer allumfassenden Liebe und Brüderlichkeit, die die Auferstehung verbürgt, das (vorläufig) letzte Wort sein könnte. ${ }^{35}$ Starez Zosima hatte ja wiederholt darauf hingewiesen, daß es nicht auf religiöse Schwärmereien und idealistische Träumereien, sondern vor allem auf die „tätige Liebe“ (dejatel'naja ljubov', PSS 14, 295) ankomme, und die „Tätigkeit“ Alëšas, des eigentlichen „Helden“ (PSS $14,6)$ sollte ja Gegenstand des angekündigten zweiten Romans sein.

Unabhängig von Spekulationen über die geplante Fortsetzung verdeutlicht aber die abschließende Episode der Brüder Karamazov die wirkungsästhetische Problematik des Versuchs, „die Wirklichkeit als Mangel, dem Ideal als der höchsten Realität“ gegenüberzustellen. Schiller hatte dem modernen Dichter „eine Verschiedenheit in der Behandlung“ zugestanden, je nach dem, „ob er mehr bei der Wirklichkeit, ob er mehr bei dem Ideale verweilen - ob er jene als einen Gegenstand der Abneigung, ob er dieses als einen Gegenstand der $\mathrm{Zu}$ neigung ausführen will.“ (NA 20, 442)

Die Kunstentwicklung im 19. und 20. Jahrhundert hat diese Frage eindeutig beantwortet, und auch Dostoevskij war bewußt, auf welche Schwierigkeiten eine ästhetische Konkretisierung des Ideals beim modernen Leser stoßen würde. Der Mensch lache „oft über das Gute und Schöne“ (nad dobrym i chorošim, PSS 15, 196), so Alëša zu den versammelten Knaben, aber nur aus Leichtfertigkeit; in seinem Herzen wisse er es besser. Das ist eine Erklärung aus dem Geiste des Schillerschen Idealismus, und der Dichter der Räuber beschrieb in seiner Selbstrezension auch das psychologische und wirkungsästhetische Phänomen, mit dem sich Dostoevskij konfrontiert sah und das von ungebrochener Aktualität ist:

„Wir sind geneigter den Stempel der Gottheit aus den Grimassen des Lasters herauszulesen, als ebendenselben in einem regelmäßigen Gemälde zu bewundern; eine Rose in der sandigten Wüste entzückt uns mehr als deren ein ganzer Hain in den hesperischen Gärten. Bei Verbrechern, denen das Gesetz als Idealen moralischer Häßlichkeit die Menschheit abgerissen hat, erheben wir auch schon

35 Vgl. Robert L. Jackson: Alëšas Rede am Stein. „Das ganze Bild“, Tübingen 2001, S. 12 f. 
einen geringern Grad von Bosheit zur Tugend, so wie wir im Gegenteil all unserm Witz aufbieten, im Glanz eines Heilgen Flecken zu entdecken. Kraft eines ewigen Hangs, alles in dem Kreis unserer Sympathie zu versammeln, ziehen wir Teufel zu uns empor und Engel herunter." (NA 22, 119) 


\section{Ivan Karamazovs Gespräch mit dem Teufel (Buch XI cap. $9^{1}$ ) im Zusammenhang mit Dostoevskijs Gesamtwerk}

Für Rainer Fuchs zum 95. Geburtstag

Das Kapitel 9 in Buch XI der Brüder Karamazov, die Teufelserscheinung des Ivan Karamazov, ist das letzte von drei Teilstücken, durch die Handlungsaufbau und Thema des Romans geleitet werden. Ihm gehen voraus: Buch II Kapitel $5^{2}$, in dem Ivan seinen Artikel über Kirche und Staat erläutert, sowie Buch V Kapitel 4 und $5^{3}$ mit Ivans Aufruhr gegen die göttliche Ordnung der Schöpfung (,ich nehme sie nicht an“) und danach der Paraphrase seines Poems vom Großinquisitor.

$\mathrm{Zu}$ diesem Teufelskapitel gehören die drei vorhergehenden (Buch XI 6-8) dazu, Ivans drei Gespräche mit dem Mörder Smerdjakov, und diese vier Kapitel sind wieder gerahmt von je einem Gespräch Ivans mit seinem Bruder Alëša (Kapitel XI 5 und 10). In diesen sechs Kapiteln geht es immer um dasselbe, das Thema des Romans: Wer ist schuld am Tod des alten Karamazov? Wer ist Täter?

Sie alle sind in der Personenkonstellation, durch den Redestil der einzelnen Personen und durch eine Vielzahl von Motiven miteinander und mit den eben genannten Kapiteln in Buch II und V verbunden. Wenn man die Motiventwicklung in diesen drei Büchern herausarbeitet, so ergibt sich, daß der Vatermord auf die Gottesidee bezogen wird. Das hebt die Schuldfrage des Themas über ihre bloß soziale oder psychologische Bedeutung hinaus.

1 Zitiert wird nach: F. M. Dostoevskij: Polnoe sobranie sočinenij v tridcati tomach. Leningrad 1972-1990. Römische Ziffer - Band, arabische Ziffer - Seite, nach Punkt - Zeile.

2 Vgl. dazu Hans Rothe: Buch II der „Brüder Karamazov“. In: Jahrbuch der Deutschen Dostojewskij-Gesellschaft. Bd. 12. 2005. S. 51-69.

3 Dazu Hans Rothe: Dostoevskijs Weg zu seinem „Großinquisitor“. In: H.-J. Gerigk (Hg.): „Die Brüder Karamazov“. Dostojevskijs letzter Roman in heutiger Sicht (Artes liberales 1). Dresden (Univ. Press) 1997, S. 159-204. - Außer weiteren Aufsätzen dieses Bandes s. vor allem Viktor Terras: A Karamazov Companion. Commentary on the Genesis, Language, and Style of Dostoevsky's Novel. Univ. Wisconsin Press 1981. - R. L. Jackson (Hg.): A New Word on The Brothers Karamazov. Evanston Illinois (Northwestern Univ. Press) 2004. 
Man kommt also durch die Anordnung des Stoffes nach Personen mit ihrem Redestil und nach Motiven auf die Gestaltung bestimmter Ideen in den Dialogen und im Gang der Handlung insgesamt. Das Eine ist die Erzählart, die literarische Kunst des Erzählens; das Andere sind Stücke aus Philosophie oder Theologie.

Das führt auf ein Dilemma, das dem rechten Verständnis, besonders bei der Erklärung Dostoevskijs, mehr oder weniger hemmend in den Weg tritt. Lange Zeit hat man, von Dostoevskijs Ideenwelt beeindruckt, nur diese Ideen beschrieben, ohne auf die Erzählart, die Form des Berichtes zu achten. ${ }^{4}$ Aber so lernt man Dostoevskij nicht kennen, wenn man ihn liest. Daraus entstand eine andere Route, auf der man dann vorwiegend „Dostoevskij den Dichter“5 kennenlernen wollte und es dabei nicht selten in Kauf nahm, daß Dostoevskijs Hauptideen, um derentwillen er seine Romane doch sicher geschrieben hat, in den Hintergrund traten.

Das Ideal ist die Verbindung beider Richtungen, wie sie Alfred Rammelmeyer in seinen Kieler Vorlesungen versucht hat. ${ }^{6}$ Hier soll versucht werden, ein Stück der Sache im Vorfeld zu klären, nämlich die Personenkonstellation und z. T. die Dialoge; weniger ihren Stil. Dabei soll die Personenkonstellation des Teufelskapitels nach ihrer Entstehung seit den Anfängen Dostoevskijs beschrieben werden.

4 Zunächst von russischen Emigranten, z. B. Nikolaj Berdjajew: Die Weltanschauung Dostojewskijs. München (Beck) 1925. - Wjatscheslaw Iwanow: Dostojewskij. Tragödie - Mythos Mystik. Tübingen (Mohr) 1932. - Fedor Stepun: Dostojewskij. Weltschau und Weltanschauung. Heidelberg (Pepper) 1950. - Dann in Deutschland Nötzel, Dempf, R. Guardini. Später in Rußland etwa M. Gus: Idei i obrazy F. M. Dostoevskogo. Moskva 1971. In Frankreich André Gide: Dostoievsky (Articles et causeries). Paris (Plon) 1923.

5 So der Titel eines seinerzeit viel beachteten Buches von Julius Meier-Graefe: Berlin (Rowohlt) 1926. In Rußland später etwa N. M. Čirkov: O stile Dostoevskogo. Moskva 1963. - In Amerika u. a. R. L. Jackson: Dostojevsky's Quest for Form. A Study of His Philosophy of Art (Yale Russian and East European Studies 1). Yale Univ. Press 1966. - Ders.: The Art of Dostojevsky. Deliriums and Nocturnes. Princton Univ. Press 1981.

6 Vgl. die philologischen Arbeiten von A. S. Dolinin: F. M. Dostoevskij. Bd. I-II. Leningrad 19231924. (Nachdr. Düsseldorf 1970); F. M. Dostoevskij. Materialy i issledovanija (Literaturn. arch.). Leningrad 1935. - Später ders.: V tvorčeskoj laboratorii Dostoevskogo (Istorija sozdanija romana „Podrostok”). b. m. (Leningrad) 1947. - Ders.: Poslednie romany Dostoevskogo. Kak sozdavalis' „Podrostok” i „Brat'ja Karamazovy”. Moskva, Leningrad 1963. Auch L. Grossman: Dostoevskij (Zizn' zamečatel'nych ljudej 24). Moskva 1962. In Deutschland z. B. Maximilian Braun: Dostojewskij. Das Gesamtwerk als Vielfalt und Einheit. Göttingen 1976. Rudolf Neuhäuser: F.M. Dostojevskij. Die großen Romane und Erzählungen. Interpretationen und Analysen. Wien 1993. Auch die in der vorherigen Anmerkung genannten Studien von Jackson. Das Ideal ist bisher nicht erreicht. 
Vorweg kann ein Hinweis nützlich sein: alle Idee ist grundsätzlich; sie ist oder ist nicht, und wenn sie ist, so ist sie für immer, auch wenn sie zeitweise in der Geschichte unsichtbar wird. Eben die Unabhängigkeit von der Geschichte als einer bloß äußeren Erscheinung macht sie zur Idee. Das lehrt die Geschichte der Philosophie von Platon bis Kant. Alle Form aber ist historisch, sie ist immer Teil einer Entwicklung, und deshalb auch immer nur historisch erreichbar.

Die Idee erreicht man nicht ohne die Form ihrer Erscheinung. Die Idee, die Dostoevskij in dem Teufelskapitel etwa gehabt hat, soll erst aus der Art ihrer Erwähnung im Roman erschlossen werden. Das geht aber nur, wenn man das Gesamtwerk nach ihr absucht.

Es sollen also zunächst die Erwähnungen des Teufels in dem Roman zusammengestellt und nach ihrer stilistischen Eigenart geordnet werden. Der Teufel wird in dem Roman an vielen Stellen erwähnt, manchmal nur nebenbei, an einigen Stellen hervorgehoben. Dabei geht es um den stilistischen Unterschied in der Benennung.

Häufig kommt das russische Wort черт vor, ursprünglich eine metaphorische Bezeichnung für der „Verwünschte“, „Hexer“, „Böse“, inzwischen aber ein „nomen proprium“ für den Teufel. Vater Ferapont, ein eifernder Mönch in dem Kloster, bei dem Starec Zosima lebt, sieht leibhafte Teufel (vgl. XIV 75.37). Ihn und seine Vorstellungen darf man nicht unterschätzen. Es ist wohl auch nicht nur eine Redensart, wenn es zu Grušenka heißt: „Какая-то жестокая черточка мелькнула в ее улыбке“ (XV 322.26; Was für ein grausames Teufelchen huschte durch ihr Lächeln). ${ }^{7}$ Grundsätzlicher ist es, wenn der Seminarist Rakitin, ein ungläubiger Theologiestudent, zu Alëša sagt: „Черт вас разберет“ (XIV 75.12; Der Teufel wird euch auseinander nehmen), d.h. alle Karamazovs. Das hängt mit seiner Meinung zusammen, daß etwas Karamazovsches in allen Karamazovs sitzt, auch in Alëša. An allen Stellen sagt Dostoevskij, wie in dem Teufelskapitel, черт.

An einigen anderen Stellen heißt еs дьявол. So in Dmitrijs berühmter Rede über die Schönheit, die „schrecklich“ sei (страшна), man fange immer mit dem reinen Ideal der Madonna an und ende unfehlbar bei dem „sodomitischen

7 Alle Zitate aus dem Roman vom Verfasser übersetzt. 
Ideal“. Er fährt fort: „Тут дьявол с богом борется“ (XIV 100.2-21; Da kämpft der Teufel mit Gott). Ähnlich zweimal in dem Lebensbericht des Starec Zosima: „Господь мой поборол диавола в моем сердце“ (XIV 283.32; Mein Herr hat den Teufel in meinem Herzen bekämpft); und in Anlehnung an Hiob 1,6-8 heißt es: Der Teufel (дьявол) kam zu Gott, der ihn nach seinem Knecht Hiob fragte (XIV 264.29). Solche Stellen sind nicht mehr Redensarten, sondern um einen Grad theologischer. Sie führen auch unmittelbar zu dem Teufelskapitel. Denn die Hiobstelle liegt bekanntlich Goethes Faust zugrunde, und eben darauf wird in diesem Kapitel von dem Teufel-gentleman einmal angespielt (XV 82.7).

Um noch einen weiteren Grad theologischer ist eine Äußerung Ivans zu Alëša nach der Begegnung mit dem Teufel: „Он дразнил меня тем, будто я сержусь, что он просто черт, а не сатана с опаленными крыльями, в громе и блеске“ (XV 86.29; Er ärgerte mich dadurch, daß ich angeblich zornig wurde, weil er bloß ein einfacher Teufel ist und nicht Satan mit Feuerflügeln, in Donner und Blitz). So hatte sich der Teufel auch wirklich geäußert: „[...] что я не явился тебе как-нибудь в красном сиянии «гремя и блистая» с опаленными крыльями“ (XV 81.38; [...] daß ich dir nicht irgendwie in rotem Glanz erschienen bin, „donnernd und blitzend“ mit Feuerflügeln).

Die wichtigsten Stellen stehen aber schließlich in dem Kapitel über den Großinquisitor. Dort ist der Teufel die dritte Person in diesem Gespräch, aber er wird gar nicht beim Namen genannt. Der Großinquisitor sagt zu Christus: „Мы“, d.h. die römische Kirche, „не с тобой, а с ним“ (XV 234.35; wir sind nicht mehr mit dir [...], sondern mit ihm); und: „мы и взяли меч кесаря, a взяв его, конечно, отвергли тебя и пошли за ним“ (XV 235.14; wir haben das Schwert des Cäsar ergriffen; dabei haben wir uns freilich von dir abgewandt und sind ihm gefolgt). Er (im Druck hervorgehoben) - das ist natürlich der Herr der irdischen Welt, der Widersacher Gottes überhaupt.

In all diesen Benennungen des Teufels beobachten wir eine Steigerung der theologischen Bedeutung, sie nimmt in der Reihe Verführer - Teufel - Satan Er (черт - дьявол - сатана - Он) immer mehr zu. Der eigentliche Widersacher Gottes in der Welt ist am Ende außerhalb der Benennungen, die Menschen in ihrer Sprache für ihn finden. Er ist nur „Er“.

Dieser stilistische Unterschied ist eine Grundvoraussetzung in der Einschätzung der Teufelserscheinung durch beide Personen in dem Gespräch, Ivan und den Teufel selbst. Der Teufel sagt: „Ты оскорблен, во-первых, в эстетических чувствах твоих, а во-вторых, в гордости: как, дескать, к такому великому человеку мог войти такой пошлый черт?““ (XV 81.40-42; 
$\mathrm{du}$ bist beleidigt, erstens in deinen ästhetischen Gefühlen, und zweitens in deinem Stolz: wie konnte, heißt das, zu einem so großartigen Mann ein so vulgärer Teufel kommen?). Und seinem Bruder gegenüber will Ivan auf dieser Deutung beharren: „[...] но он не сатана, [...] он просто черт, дрянной, мелкий черт" (XV 86.30; [...] aber er ist nicht Satan [...], er ist bloß ein Teufel, ein lumpiger Teufel).

Hierher gehört die Deutung der Teufelserscheinung als krankhafter Zustand des Ivan. Dieser sagt zum Teufel: „Ты ложь, ты болезнь моя, ты призрак [...], ты моя галлюцинация“ (XV 72.31-33; Du bist Lüge, du bist meine Krankheit, du bist eine Erscheinung [...], du bist meine Halluzination). Tatsächlich ist Ivan in ärztlicher Behandlung, und der Arzt hat ihm bestätigt: „[...] галлюцинации в вашем состоянии очень возможны“ (XV 70.15; [...] Halluzinationen sind in Ihrem Zustand sehr möglich). Ivan weiß das auch selbst: „[...] почти сознавая сам, что в бреду.“ (XV 70.22; [...] fast war er sich darüber klar, daß er im Fieberwahn sei). Später bestätigt ihm das auch Alëša: „[...] говоришь в болезни, в бреду“ (XV 87.37; [...] du redest in Krankheit, im Fieberwahn).

Es gehört auch dazu, daß Ivan die Teufelserscheinung nicht zum ersten Mal hatte. Schon in dem ersten Gespräch mit Alëša, bevor Ivan mit Smerdjakov sprach, hatte er solchen „Besuch“ einmal erwähnt („[...] когда он приходил“; XV 40.26; [...] als er vorbeikam). Ivan sagt das auch dem Teufel: „Я тебя иногда не вижу и голоса твоего даже не слышу, как в прошлый раз.“ (XV 72.8; noch einmal 86.28; Manchmal sehe ich dich nicht und höre sogar deine Stimme nicht, wie letztes Mal). Und schließlich sagte Ivan zu Alëša: „Два раза был, даже почти три.“ (XV 86.28; Zweimal war er da, fast sogar dreimal). „Fast dreimal“ - eben diese Unsicherheit scheint zu belegen, daß alles wirklich nur Ausgeburt seiner kranken Phantasie ist, nicht in der Wirklichkeit existiert. Das Teufelsgespräch ist ganz als Bericht über eine krankhafte Erscheinung angelegt.

Diese Deutung der Teufelserscheinung als periodisch wiederkehrende krankhafte Halluzination ist aber doch nicht eindeutig. Gegenüber Alëša sagt Ivan nicht „Teufel“, er sagt nur: „он“ (er). Alëša ist verwirrt: „Про кого ты говоришь?“ (Von wem sprichst du?) Und Ivan: „Разве ты не знаешь, что он ко мне ходит?“ (Weißt du denn nicht, daß er immer zu mir kommt?) Alëša in zunehmenden Schrecken: „Кто он?“ (XV 40.28-33; Wer ist er?). Und das 
wiederholt sich in dem abschließenden Gespräch der beiden Brüder (XV 88. 35-41). Das stimmt also dazu, wie Ivan den Großinquisitor den unnennbaren großen Widersacher nennen läßt.

Doch Ivan gibt seinem unheimlichen Besucher auch noch andere Namen. $\mathrm{Zu}$ dem Teufel selbst sagt er: „Ты приживальщик.“ (XV 72.22; Du bist ein Schmarotzer), ein Schmarotzer, der auf Anderer Kosten „mitlebt“. - Seinem Bruder erklärt er: „Он самозванец.“ (XV 86.31; Er ist ein Usurpator). Beides sieht aus wie eine witzige Stilvariation, die das Teufelsgespräch ja auch wirklich durchzieht. Dazu findet man im Text des Romans keine Auskunft mehr. Doch kann man Erklärung in früheren Werken Dostoevskijs finden.

Den Typ des Schmarotzers (приживальщик) hat Dostoevskij zuerst in Das Dorf Stepantschikowo und seine Bewohner (Село Степанчиково и его обитатели, 1859) ausgebildet. Personenkonstellation und Handlung dieses ersten Romans nach dem Jahrzehnt seiner Strafe sind ganz durch diesen Typus bestimmt. - Im Doppelgänger (Двойник, 1846) nennt der Held Goljadkin seinen Doppelgänger durchgehend einen самозванец (I 168.1; 191.37; 196.30; 212.17; 217.16), auch unter Anspielung auf den Pseudodemetrius Griška Otrep'jev (I 167.48).

Diese beiden Typen sind nicht einfach da und könnten auch unbeachtet bleiben; sie üben vielmehr eine heimlich-unheimliche Tyrannei über andere Personen aus, mit denen sie in der Erzählung in einem besonderen Verhältnis verbunden sind, und offenkundig ist es eben diese heimliche Tyrannei, die die Personen überhaupt in einer besonderen Konstellation verbindet und auf diese Weise das Thema der Erzählung bildet. Über den Held in dem Roman Das Dorf Stepantschikowo heißt es: „Явился Фома Фомич [...] как приживальщик из хлеба - ни более, ни менее.“ (III 7.43; Foma Fomič [...] als Schmarotzer des (täglichen) Brotes wollte nicht mehr, nicht weniger). Doch kurz darauf: „Фома совершенно неожиданно сделался вдруг важным и чрезвычайным лицом“ (III 8.7-9; Foma wurde völlig unerwartet plötzlich zu einer wichtigen, außergewöhnlichen Person). Und zwar: „[...] особенно хорошо умел толковать сны и мастерски осуждал ближнего.“ (III 8.30; [...] besonders gut konnte er Träume deuten, und meisterhaft bekrittelte er den Nächsten). Erst dadurch, so scheint es, wird Ivans Beschimpfung des Teufels richtig verständlich: „Ты приживальщик, так сплетничай [...].“ (XV 72.22; 
Du bist ein Schmarotzer, so verleumde [...].). - Ähnliches kann man für den Doppelgänger als Usurpator (самозванец) zusammentragen.

Beide Typen haben ein geheimes Wissen über ihren „Nächsten“, mit dem sie als Doppelgänger in einem unlöslichen Verhältnis verbunden sind. Foma Fomič rühmt sich, daß der General, der ihn nur gequält und erniedrigt hatte, kurz vor seinem Tode „[...] ему, Фоме, доверял сокровеннейшие тайны души своей [...]“ (III 8.12; [...] ihm, dem Foma, die allerverborgensten Geheimnisse seiner Seele anvertraute $[\ldots]$ ), und mit diesem geheimen Wissen begründet Foma Fomič nun seine Macht über Andere. Dabei handelt es sich um eine Kenntnis, die der Andere sich selbst eigentlich verbergen will.

Auch dieses Motiv führt bis zu dem Teufelsgespräch. Ivan sagt zu dem Teufel: „Ты моя галлюцинация. Ты воплощение меня самого, только одной, впрочем, моей стороны [...], моих мыслей и чувств, только самых гадких и глупых.“ (XV 72.34; Du bist meine Halluzination. Du bist die Verkörperung meiner selbst, nur, nebenbei gesagt, einer Seite von mir [...] meiner Gedanken und Gefühle, bloß der ekelhaftesten und dümmsten). Doch später sagt er zu Alëša: „Он мне, впрочем, сказал про меня много правды. Я бы никогда этого не сказал себе." (XV 87.10-12; Er hat mir übrigens vieles Wahre über mich gesagt. Ich hätte mir das selbst niemals gesagt). An dieser Stelle ist schon zu spüren, daß für Gedankenführung und Themenentwicklung - übrigens nicht nur des Teufelsgespräches, sondern des Romans im Ganzen eine besondere Personenkonstellation erforderlich ist: wenn jemand sich etwas selber nicht sagen kann, dann muß dafür ein Anderer eintreten.

Das führt nun zurück zu dem zweiten Roman nach der sibirischen Zeit Dostoevskijs, den Erniedrigten und Beleidigten (Униженные и оскорбленные, 1861) und zu den Aufzeichnungen aus dem Untergrund (Записки из подполья, 1864). An zwei fast gleichlautenden Stellen dieser beiden Werke hat Dostoevskij über solch verborgene Geheimnisse der Seele gesprochen. Die erste Stelle aus Erniedrigte und Beleidigte ist zunächst vor allem durch die Personenkonstellation interessant. Fürst Valkovskij ist kein erniedrigter приживальщик, aber dessen Eigenschaft, mit einem geheimen Wissen Andere zu quälen, hat auch er. Er ist ein älterer Aristokrat, dazu ein Zyniker, bewußt und mit Freude amoralisch. Ihm steht ein junger Idealist gegenüber, ein russischer Schillerianer. Valkovskij nennt ihn „мой поэт“. Der Fürst sagt:

„Вот что, мой поэт, хочу я вам открыть одну тайну природы <!>, которая, кажется, вам совсем неизвестна. [...] Если 6 только могло быть (чего, впрочем, по человеческой натуре <!> никогда быть не может), если б могло быть, чтоб каждый из нас описал всю свою подноготную, но так, чтоб не 
побоялся изложить не только то, что он боится сказать и ни за что не скажет людям, не только то, что он боится сказать своим лучшим друзьям, но даже и то, в чем боится подчас признаться самому себе, - то ведь на свете поднялся бы тогда такой смрад, что нам бы всем надо было задохнуться.“

(III 361.37-47; Also, mein Dichter, ich will Ihnen ein Geheimnis der Natur offenbaren, das Ihnen scheinbar ganz unbekannt ist [...] Wenn es nur möglich wäre (was übrigens nach der menschlichen Natur niemals sein kann), wenn es möglich wäre, daß jeder von uns sein tiefstes Innere beschriebe, doch so, daß er sich nicht fürchtet darzulegen, nicht nur, was man auszusprechen fürchtet und um nichts in der Welt den Menschen sagen wird, nicht nur, was er fürchten würde, seinen besten Freunden zu sagen, sondern sogar das, was er bisweilen fürchtet, sich selbst einzugestehen - so würde ja in der Welt sich dann ein solcher Gestank erheben, daß wir alle kaum atmen könnten.).

Es ist wenig beachtet worden, daß diese Rede Teil eines Dialogs ist, sich an jemand Anderen (мой поэт) richtet, der in allem das ganze Gegenteil des zynischen Aristokraten ist. Der Fürst Valkovskij ist ein Aufklärer, der dem jungen Dichter erklärt, daß idealische Dichtung, wie sie in der russischen SchillerRezeption sich gestaltet hatte, etwas mit schönem Schein verbirgt. Er klärt über eine Welt der Ideen auf, die nicht mit dem Bösen zu rechnen schien. Von hier werden die Linien zu Stepan Trofimovič Verchovenskij in Die Dämonen (Бесы) führen. Man darf diese Rede des Fürsten nicht nur als ein Stück Weltanschauung für sich verstehen. Sie ist an den Dichter gerichtet und gehört zur Bestimmung der Dichtung. Es ist eine Umformung des Doppelgänger-Motivs. Doch über das unvermeidliche Zwangsverhältnis der beiden Gesprächspartner ist hier noch nichts zu erfahren.

Das findet man in den Aufzeichnungen. Aus dem Untergrund heraus ließ Dostoevskij den Helden denselben Gedanken wiederholen. Es geht jetzt darum, ob man über sich selbst wahre Aussagen machen kann, wie Rousseau es als „homme de la vérité", als den er sich verstand, behauptet hatte, tun zu können. Der Held dieser Erzählung, die in ihrem ersten Teil ein narratologisch nur wenig verkleideter Essai über diesen Gegenstand ist, sagt: „Гейне утверждает, что верные автобиографии почти невозможны, и человек сам об себе наверно налжет. По его мнению, Руссо, например, непременно налгал на себя в своей исповеди [...]. Я уверен, что Гейне прав.“" (Heine versichert, daß wahrhaftige Autobiographien fast unmöglich seien, und daß der Mensch über sich selbst bestimmt lügen wird [...]. Ich bin überzeugt, dass Heine recht hat). Diesen Exkurs hatte er mit der Wiederholung der Rede des Fürsten Valkovskij eingeleitet: 
„Есть в воспоминаниях всякого человека такие вещи, которые он открывает не всем, а разве только друзьям. Есть и такие, которые он и друзьям не откроет, а разве только себе самому, да и то под секретом. Но есть, наконец, и такие, которые даже и себе человек открывать боится, и таких вещей у всякого порядочного человека довольно-таки накопится. То есть даже так: чем более он порядочный человек, тем более у него их и есть.“

(V 122.21-38; Es gibt in den Erinnerungen eines jeden Menschen solche Dinge, die er nicht allen offenbart, sondern nur Freunden. Und es gibt solche Dinge, die er auch Freunden nicht offenbaren wird, sondern nur sich selbst, und auch das nur im Vertrauen. Es gibt aber schließlich auch solche Dinge, die ein Mensch sogar sich selbst zu offenbaren fürchtet, und solche Dinge häufen sich bei jedem ordentlichen Menschen an. D.h. sogar so: je mehr er ein ordentlicher Mensch ist, um so mehr davon gibt es bei ihm.)

Hier handelt es sich also nicht um ein Problem der Ästhetik, sondern um eine erkenntnistheoretische Frage. Doch obwohl diese Passage nicht in einem Dialog steht, sondern eben Aufzeichnungen eines isolierten Einzelgängers sind, ist die Anlage einer Personenkonstellation gleichwohl erkennbar. Es ist das Verhältnis eines „ordentlichen“ (порядочный) Menschen zu den verborgenen, unbewußten Eigenschaften seiner Seele. Diese können jederzeit, wie in den Erniedrigten und Beleidigten, personifiziert werden. Aus dieser Stelle nun sieht man, daß sie auch personifiziert werden müssen, weil es anders gar nicht geht, denn der Mensch ist anders dazu nicht in der Lage. Die sachliche Einsicht führt notwendig zu einem dramatisch angelegten Dialog.

In beiden Stellen, in ästhetischem und in erkenntnistheoretischem Zusammenhang, steht das Wort подноготная an zentraler Stelle. Es bezeichnet das Allergeheimste, das Allerverborgenste, das man auf keinen Fall sehen lassen will, ja nicht einmal selber kennt. Dieser Ausdruck führt auf den Kern der Sache bei Dostoevskij, sowohl erzähltechnisch narratologisch wie gedanklich philosophisch.

Heute bezeichnet der Ausdruck etwa unsaubere Fingernägel, darüber hinaus aber auch das Unsaubere, was ein Mensch an sich und in sich hat und gerne verbergen will. Doch so verstanden müßte es eigentlich ein Adjektiv Neutrum sein: подноготное. Doch die Form ist feminin: подноготная, und zu ergänzen ist etwa игла - die Nadel, oder правда, истина - die Wahrheit. So im allgemeinen Gebrauch ist es die Bezeichnung für eine alte Folter: unter die 
Fingernägel wurden Nadeln getrieben, um so aus einem verstockten Sünder die Wahrheit herauszuholen: подноготная - das ist die unter Schmerzen offenbarte Wahrheit, und das Doppelgängermotiv, bei dem das Wort vor allem genannt wird, ist eine Form der Wahrheitssuche.

Das Wort führt zugleich an den Anfang von Dostoevskijs literarischer Laufbahn. Über seine erste Erzählung Arme Leute (Бедные люди, 1844) hatte er als Motto den Schlußsatz aus der Erzählung Der lebende Leichnahm (Живой мертвец, 1839) von Vladimir Odoevskij gesetzt, dem bedeutenden, wenn auch wenig bekannten Romantiker. Darin wird berichtet, daß er gestorben ist. Er kann aber, mit den Geisteskräften des Lebenden, überall unbemerkt dabei sein und anhören, was über ihn gesagt wird; nichts Feines. Schließlich aber erwacht er, er hat das alles „nur“ geträumt. Odoevskij läßt ihn am Ende sagen, und das ist Dostoevskijs Epigraph: „Ох, уж эти мне сказочники! Нет чтобы написать что-нибудь полезное, приятное, усладительное, а то всю подноготную в земле вырывают!“ (I 13.3-6; Och, das sind mir so Märchenerzähler! Nein, wenn sie noch was Nützliches, Angenehmes, Erquickliches schreiben möchten, aber nein, bloß das letzte Innere buddeln sie aus der Erde raus!). ${ }^{8}$

Das Motto enthält demnach eine literaturtheoretische oder ästhetische Aussage der Romantik. Zwei Vorstellungen stehen gegeneinander: Literatur müsse angenehm und erquickend sein, wie Horaz es gelehrt und der europäische Klassizismus es übernommen und praktiziert hatte; bzw. sie wühle auf und hole das Unterste, Verborgene hervor. Es ist deutlich, daß sowohl Odoevskij wie Dostoevskij, der ihn zitiert, die letzte Meinung vertreten. Sie verstanden Kunst und Literatur, wie es die Romantik wollte, als Wahrheitssuchende.

Dostoevskij ging also von der späten Romantik in Rußland aus. Es gehörte zu ihren ästhetischen Vorstellungen, daß unter der Oberfläche des Schönen etwas verborgen ist, das die Kunst anschaulich machen könne, vielleicht müsse. Dostoevskij entwickelte daraus mehrere Personenkonstellationen für eine Romanhandlung: den Doppelgänger; den erniedrigten Schmarotzer, der etwas über seine Quälgeister weiß; den zynischen Aristokraten, der den idealischen Dichter mit seiner Kenntnis der menschlichen Natur herausfordert; einen Mensch im Untergrund, der die gesamte „ordentliche“ Gesellschaft herausfordern will. Aus all dem folgt, daß in diesen frühen Werken kein krankhafter Einzelfall beschrieben wird, als der Ivan Karamazov gerne verstanden werden

8 Bei Vladimir Odoevskij: Povesti i rasskazy. Moskva 1959, S. 350, etwas anders: „Ох, уж эти мне сказочники! Нет чтоб написать что-нибудь полезное, приятное, усладительное! а то всю подноготную из земли вырывают!“ 
möchte und als welche ihn manche Interpreten verstanden haben (z.B. Siegmund Freud).

Daß Dostoevskij es anders meinte, läßt er den jungen Dichter, den IchErzähler der Erniedrigten und Beleidigten sagen:

„Я мало-помалу и постепенно [...] стал впадать в то состояние души [...], которое я называю мистическим ужасом. Это - самая тяжелая, мучительная боязнь чего-то, чего я сам определить не могу, чего-то непостигаемого и несуществующего в порядке вещей, но что непременно, может быть сию же минуту, осуществится, как бы в насмешку всем доводам разума придет ко мне и станет передо мною как неотразимый факт, ужасный, безобразный и неумолимый.“

(III 208.1-9; Ich begann, Stück für Stück allmählich in einen Zustand der Seele zu fallen [...], den ich mystisches Entsetzen nenne. Das ist die schwerste, quälendste Furcht vor etwas, das ich selber gar nicht angeben kann, etwas ganz Unfaßbares und gar nicht Existierendes in der Ordnung der Dinge, das aber ganz bestimmt, vielleicht in diesem Augenblick wirklich wird, wie zum Hohn auf alle Beweise der Vernunft wird es zu mir kommen und vor mir als eine unabweisbare Tatsache stehen, furchtbar, scheußlich und gnadenlos.).

Auch das führt unmittelbar zu Ivan. In seinem letzten Gespräch mit Smerdjakov ist er „в безумном ужасе“ (XV 60.26; in irrsinninigem Entsetzen) über das, was er erfährt, was er nicht aussprechen wollte, aber nun einsehen muß.

Das „mystische Entsetzen“ - das ist eine allgemeine Erfahrung, die jeden Menschen ergreifen kann, dem irgendwann die äußere Natur (природа), die er sonst als schön kennt, furchtbar gegenüber tritt oder der die Natur (натура) seines Inneren irgendwann einmal als abstoßend bemerken muß, und der Beides in solchem Augenblick nicht verstehen kann und keine Worte dafür hat.

Den nächsten Schritt bei der Entwicklung dieser Personenkonstellation tat Dostoevskij 1865 in Verbrechen und Strafe (Преступление и наказание). Inzwischen ist dem „lieben Dichter“, dem jungen russischen Schillerianer, wie Valkovskij ihn nannte, der Raskol'nikov gefolgt, der Gespaltene, ein Mörder mit einem idealistischen Tatmotiv. Aber auch ihm tritt noch ein älterer Aristokrat gegenüber, der Zyniker Svidrigajlov, und er erklärt dem jungen Mann das Verhältnis von Krankheit und Traumgesicht (привидение). Es geht nun direkt um den Versuch, solch krankhafte Erscheinung nur als psychiatrischen Sonder- 
fall zu verstehen. Svidrigajlov sagt: „Я согласен, что привидения являются только больным; но ведь это только доказывает, что привидения могут являться не иначе как больным, а не то, что их нет, самих по себе.“ (VI 221.1-3; Ich gebe zu, daß nur Kranke Wahngebilde haben; aber das beweist doch nur, daß Geister eben nur Kranken erscheinen können, und nicht, daß es sie überhaupt nicht gibt).

Und weiter: solche Gesichte seien „[...] клочки и отрывки других миров, их начало. Здоровому человеку, разумеется, их незачем видеть, потому что здоровый человек есть найболее земной человек, а стало быть, должен жить одною здешнею жизнью, для полноты и для порядка. Ну а чуть заболел, чуть нарушился нормальный земной порядок в организме, тотчас и начинает сказываться возможность другого мира.“ ([...] abgerissene Bruchstücke anderer Welten, ihr Anfang. Ein gesunder Mensch hat natürlich keinen Grund, sie zu sehen, weil ein gesunder Mensch der allerirdischste Mensch ist, und deshalb nur ein irdisches Leben leben muß, um der Vollständigkeit und der Ordnung willen. Aber dann, kaum wird er krank, kaum wird die normale irdische Ordnung im Organismus gestört, sofort fängt auch die Möglichkeit einer anderen Welt an, sich zu melden). Und wenn ein Mensch dann stürbe, „[...] то прямо и перейдет в другой мир.“ (VI 221.7-15; [...] so geht er unmittelbar in eine andere Welt hinüber). Gemeint ist offenbar, daß in der anderen Welt die Wahrheit ganz und absolut und unmittelbar erkennbar sei. Dahinter steht 1. Kor. 13,12.

Ohne diese Erklärung des Svidrigajlov würden wir in der Erklärung des Teufelsgespräches von Ivan Karamazov kaum weiter kommen. Traumgesichte, mystisches Entsetzen gehören offenbar zur Natur des Menschen. Es ist dabei unmittelbar evident, daß diese Einsicht nicht im Weg etwa eines theoretischen Artikels deutlich gemacht wird, sondern durch erzählendes Berichten, genauer: durch den Dialog. Das zeigt Dostoevskijs Nähe zu Platon, der der Wahrheit nur im Dialog nahe zu kommen suchte. Ohne Erzählen, nur in philosophischer Abhandlung geht das nicht.

Mit dem Ausdruck подноготная begann dann noch in Verbrechen und Strafe eine Erweiterung der Personenkonstellation, die in den beiden folgenden Romanen Der Idiot (Идиот, 1868) und Die Dämonen (Бесы, 1872) zu ihrer Veränderung führte. Es sind nun Andere, Außenstehende, die über Jemanden die ganze подноготная wissen, sie manchmal auch erzählen. In Verbrechen und 
Strafe weiß Svidrigajlovs verstorbene Frau alles über Raskol'nikovs Schwester (VI 364.26); im Idiot mehrere Personen alles über Andere, eine Gruppe von jungen Lümmeln, die sich nicht scheuen, Andere in niedriger Absicht auszuforschen (VIII 8.23; 254.4; 257.38; Entwürfe IX 157; 248). In den Dämonen ist das dann in Handlungsführung und Themabildung noch weiter entwickelt. Die jungen Leute sind nun in einer regelrechten Bande organisiert, mit Intrige, Fememord und Umsturzversuchen. Mehrmals wird einer von ihnen "Spion“ genannt (X 68.34, 35; 83.25). In Verbrechen und Strafe gab es schon den fragenden Untersuchungsrichter. Jetzt kommt die Figur des Schnüfflers hinzu. Dostoevskij bildet also in seiner Erzähltechnik für die Wahrheitssuche mehr und mehr Figuren nicht aus dem Leben der "gesunden Menschen“, sondern aus dem подполье selbst, Menschen mit niedrigem Charakter und niedrigen Motiven.

Wieder ist ein Blick auf die Zeitverhältnisse zweckmäßig. Wir wissen, daß die beiden Romane Der Idiot und Die Dämonen bereits die revolutionären Zeitereignisse reflektieren: Zellenbildung in der Manier der westeuropäischen sogenannten „roten Zellen“ unserer Tage; gewissenlose Intrige; Fememord und Terrorakte; und alles dies um eines vermeintlich hohen Ideals willen und unter der Maske gesellschaftlicher Ordentlichkeit, nie mit offenem Visier. Das alles war in Rußland damals auch wirklich geschehen: Attentate auf Zar Alexander II. (von Karakozov im April 1866), Fememord (unter Studenten der Landwirtschaftlichen Hochschule in Moskau). Dostoevskijs erweiterte Figurenanordnung, mit der neuen Figur des Schnüfflers, hat auch mit diesen Zeiterscheinungen zu tun.

Der Kern der Figurenkonstellation: spöttischer aristokratischer Zyniker junger verführter Dichter, taucht in Dämonen noch einmal auf. Es ist das Paar Stavrogin - Petr Verchovenskij. Aber die Rollen sind nun vertauscht. Der Aristokrat Stavrogin ist der Gequälte; am Ende erhängt er sich. Der junge Verchovenskij, nicht mehr der Idealist selbst, sondern dessen Sohn, ist der Plebejer und Versucher. Wie dieser, verschwindet auch er am Ende spurlos. Im Jüngling (Подросток) fehlt diese Konstellation, aber im Teufelskapitel der Brüder Karamazov ist sie wieder da: der „пошлый мелкий черт“ (lumpige kleine Teufel), wie Ivan seinen Besucher nennt, ist die Parallele. Er fordert den jungen Ivan heraus, nun aber wieder, ähnlich wie vorher in den Erniedrigten und Beleidigten und in Verbrechen und Strafe, in der Konstellation des älteren Zynikers und des jungen Mannes. 
Wenn diese Entwicklungslinien von Personenkonstellation und Motiven einleuchten, ist es Zeit, nun zu fragen: was sagt der Teufel denn eigentlich? Aus der Vielfalt der Gedanken, Motive und Stilelemente sollen drei zur Sprache kommen: 1) der Teufel und die Aufklärung; 2) der Teufel und die Gottesidee; und 3) der Teufel über sich selbst. Auch hierbei hilft der Rückgang zu Dostoevskijs Anfängen.

Zum ersten Punkt. Die europäische Aufklärung hat Dostoevskij lebenslang beschäftigt. In Brüder Karamazov ist sie ein Nebenthema. Hier ist der Teufel die Karikatur eines Aufklärers. In der wichtigtuerischen Art eines bestimmten Gesellschaftstyps streut er immer mal einen französischen Brocken in seine Rede ein. Philologen haben die Quellen bei französischen Autoren des 18. Jahrhunderts ausfindig gemacht. ${ }^{9}$ Man weiß, in welchem gespannten Doppelverhältnis der Bewunderung und Verachtung Dostoevskij zu Voltaire dachte und schrieb. Einiges ist auch über sein Verhältnis zu Rousseau schon gesagt, obwohl hier das Meiste noch zu tun ist. Ivans Teufel - das ist eigentlich eine polemische Personifizierung Rousseaus, der Oberflächlichkeit einer gewissen weniger bei Rousseau selbst, als bei seinen Nachfolgern im 19. Jahrhundert erschienenen - Auffassung von Natur, Wahrheit und Fortschritt.

Es sind zwei Motive, mit denen der Teufel Rousseau ins Gespräch bringt. Das eine ist Rousseaus Anspruch, als „homme de la nature“ könne man auch ein „homme de la vérité" sein; das war das Programm von Rousseaus autobiographischen Confessions. Dostoevskij hatte das schon im Doppelgänger in Frage gestellt (I 222). In den folgenden Essais wurde das immer deutlicher.

Es geht vor allem um den Naturbegriff. Der Teufel zitiert, ohne einen Autor zu nennen, die Stichworte „угрызения совести“ (XV 78.31; Gewissensbisse) und „смягчения ваших нравов“ (ebd. 78.32; Milderung euer Sitten). Ausweislich der Entwürfe Dostoevskijs sind das aber, wie schon gesagt, Ausdrücke, die mit Rousseau in Verbindung gebracht werden (XV 208; 355). Gewissenbisse, sagt der Teufel auf eine Frage von Ivan, das seien heutzutage die neuen Höllenstrafen, und das käme von dem Sittenmilderungs-Programm, da es doch trotzdem immer noch so viel Unflat unter den Menschen gebe. Also die Natur- und Gesellschaftslehre, anders gesagt: das Fortschrittsdenken der Aufklärung, das zur französischen Revolution geführt habe und seither das

9 Vgl. die Anmerkungen und Kommentare in der Anmerkung 1 genannten Ausgabe und die dort erwähnte Literatur. 
19. (und das 20. und das 21.) Jahrhundert beherrschte, das sei Lüge und führe zu dieser Höllenstrafe: „Древний огонек-то лучше бы [...]“ (XV 78.38; das gute alte Höllenfeuer sei besser [...]), fügt der Teufel hinzu.

Recht klar wird das erst bei dem zweiten Motiv, der Frage nach Gott. Der Teufel kommt erst ganz am Schluß darauf, als er Ivan schon völlig in die Ecke gedrängt hat. Er erinnert ihn an seinen Großinquisitor, und fährt fort, indem er eine längere Passage zitiert. Wieder ist es der Kunstgriff, zu zitieren, ohne einen Autor zu nennen. Aber ganz offensichtlich sollen es Sätze „[...] одного прелестнейшего и милейшего русского барчонка: молодого мыслителя и большого любителя литературы и изящных вещей, автора поэмы [...] под названием «Великий инквизитор»" (XV 83.7-9; [...] eines sehr reizenden, sehr lieben russischen Herrensöhnchens: eines jungen Denkers und großen Liebhabers der Literatur und schöner Dinge, Autor eines Poems unter dem Titel „Der Großinquisitor“) sein, wie der Teufel eben noch den Ivan beschrieben hatte.

Aber was der Teufel dann sagt, steht gar nicht in dem Poem. Dort heißt es nämlich: „О, мы убедим наконец не гордиться [...]; докажем им, что они слабосильны, что они жалкие дети [...]. Они станут робки.“ (XIV 236.6-9; Oh, wir werden (sie) schließlich überzeugen, nicht stolz zu tun [...], wir werden ihnen beweisen, daß sie schwächlich sind, daß sie klägliche Kinder sind). Der Teufel aber zitiert jetzt, was Ivan angeblich geschrieben habe: „[...] надо всего только разрушить в человечестве идею о боге“ ([...] man muß in der Menschheit vor allem nur die Gottesidee vernichten). Dann werde die frühere Tugendlehre verschwinden und alles wird neu sein. „Люди совокупятся, чтобы взять от жизни все, что она может дать, но непременно для счастия и радости в одном только здешнем мире. Человек возвеличится духом божеской, титанической гордости и явится человеко-бог“ (XV 83.22-31; Die Menschen verbinden sich, vom Leben alles zu nehmen, was es geben kann, aber unbedingt für Glück und Fröhlichkeit nur in dieser Welt. Der Mensch erhöht sich durch den Geist eines göttlichen, titanischen Stolzes, und es erscheint der Mensch-Gott). Man sieht den Widerspruch: der Großinquisitor sprach von den Menschen, die willenlose Kinder sind; der Teufel von lauter Großinquisitoren, die als Menschen stolz Gott spielen. Und sie erkennen dann auch, daß er mit diesem Wort Mensch-Gott eine satanische Usurpation Christi entwirft. In dem Großinquisitor selbst steht das so noch 
nicht, nur die Hauptfigur selbst verkörpert es schon. Und Stolz ist sein Kennzeichen.

$\mathrm{Zu}$ der Personenkonstellation, die Dostoevskij in den früheren Werken ausgebildet hatte, gehört, daß Ivan sich nun gepeinigt die Ohren zuhält, als wolle er das alles nicht hören. Doch er hört genau zu, als der Teufel gleichmütig weiterspricht: „Всякий узнает, что он смертен весь, без воскресения, и примет смерть гордо и спокойно, как бог." (XV 83.36; Jeder wird erkennen, daß er ganz sterblich ist, ohne Auferstehung, und er wird den Tod stolz und ruhig annehmen, als Gott). Und dann: wenn vielleicht auch nicht gleich ein Jeder so ein stolzer Mensch-Gott sein werde, „[...] то всякому, сознающему уже и теперь истину, позволительно устроиться совершенно как ему угодно [...]. В этом смысле ему «все позволено»" (XV 84.1-3; [...] so ist es doch jedem, der schon hier die Wahrheit erkennt, erlaubt, sich vollkommen so einzurichten, wie es ihm passt [...]. In diesem Sinne ist ihm , alles erlaubt').

Das „alles ist erlaubt“ war Dostoevskijs Thema seit dem Roskol'nikov. Aber jetzt sagt das der Teufel, der dem Ivan beibringt, daß dies die logische Konsequenz aus seinem Großinquisitor ist, der dem schweigenden Christus erklärt hatte: „wir“ seien nicht mit „dir“, sondern mit „ihm“, d.h. dem Teufel (XIV 235.14). Das alles war für Dostoevskij eine Folge aus der Vorstellung der Aufklärung, daß Menschen allein, ohne Gott, imstande sind, nach der Tugend zu leben. Denn er meinte, auch das ideale Tugendstreben, wie die europäische Klassik es verkörperte, habe ein подполье und eine подноготная. Leben wie Gesellschaft nach solch idealem Tugendstreben ohne Gott einrichten zu wollen, das hielt Dostoevskij für die große Verirrung der Aufklärung und besonders Rousseaus, der so verstanden wurde, als habe er nur gelehrt, daß die Menschen ursprünglich und von Natur aus gut seien. Dostoevskij hatte es bereits im Untergrund und dann in Verbrechen und Strafe sehr deutlich ausgeführt.

\section{1}

Damit sind wir schließlich bei der letzten Frage: Was denkt der Teufel eigentlich von sich selbst? Wofür hält er sich? Was will Dostoevskij, daß wir von ihm denken sollen?

Der Teufel sagt das alles ziemlich offen. Er ist da zunächst ein kleiner Mephisto, der „Geist, der stets verneint“; er nennt sich einmal „необходимый минус“ (XV 82.33; notwendiges Minus). Er wird dann aber viel genauer. Eigentlich, sagte er, sei er ein Träumer („Я люблю мечтать“; XV 73.41; Ich liebe es zu träumen); „[...] очень чувствителен и художественно восприимчив“ 
(XV 82.18; [...] sehr empfindsam und künstlerisch empfänglich). Man ist geneigt, das nur ironisch zu nehmen. Aber es muß auch daran erinnert werden, daß der jugendliche Träumer Dostoevskij selbst war.

Aber ach, fährt der Teufel fort, „самое несчастное свойство моей природы“ („die unglücklichste Eigenschaft meiner Natur“), nämlich „здравый смысл“ („gesunder Menschenverstand“), behindere ihn (XV 82.19). Woran? Eigentlich sagt er, „[...] я, может быть, единственный человек во всей природе, который любит истину и искренно желает добра.“ (XV 82.9-10; [...] ich bin vielleicht der einzige Mensch in der ganzen Natur, der die Wahrheit liebt und aufrichtig das Gute wünscht) - der Teufel sagt Mensch; und er sagt Natur, nicht Schöpfung. Er sei dabei gewesen, als Jesu Geist in den Himmel aufstieg und alle Cherubim und Seraphim „Hоsianna“ sangen. „И вот, клянусь же всем, что есть свято, я хотел примкнуть к хору и крикнуть со всеми: «Осанна!»" (Und bitte, ich schwöre bei allem, was heilig ist, ich wollte mich zu dem Chor gesellen und mit allen „Hosianna“ schreien). Aber eben daran habe ihn der gesunde Menschenverstand gehindert. Denn wenn auch er Hosianna schrie, „тотчас бы все угасло на свете“ (sofort würde alles in der Welt erlöschen). Also „[...] единственно по долгу службы и по социальному моему положению я принужден был задавить в себе хороший момент и остаться при пакостях“ (XV 82.23-25; [...] nur aus Dienstpflicht und nach meiner sozialen Lage bin ich gezwungen, in mir den schönen Augenblick $\mathrm{zu}$ ersticken und bei Gemeinheiten zu bleiben). Das heißt, er müsse um der Weltordnung, um der Ordnung der Schöpfung willen Teufel bleiben und für Gemeinheiten zuständig sein.

Theologisch ist das vielleicht nicht sehr neu, und Theologen müssen sagen, ob es überhaupt etwas bedeutet. Aber nun fragt sich der Teufel weiter, weil er ja sentimental ist: warum gerade ich? „Честь добра кто-то (!) берет всю себе, а мне оставлены в удел только пакости. [...] Почему изо всех существ в мире только я лишь один обречен на проклятия ото всех порядочных людей“ (XV 82.25-29; Die Ehre des Guten wird irgendwer ganz für sich nehmen, und mir bleiben nur Gemeinheiten zugeteilt [...] Warum bin unter allen Geschöpfen der Welt allein ich zu Verfluchungen von allen ordentlichen Menschen bestimmt).

Und dann kommt wohl die entscheidende Stelle: „Я ведь знаю, тут есть секрет." (XV 82.31; Ich weiß ja, das ist ein Geheimnis). Er benutzt das französische Fremdwort. Hier erfahren wir, daß auch diese stilistische Einzelheit, zwischendurch im lässigen Gesellschaftston etwas französisch einzuflechten, von Dostoevskij auf einen tieferen Sinn geführt wird „Я ведь знаю, тут есть 
секрет, но секрет мне ни за что не хотят открыть, потому что я, пожалуй, тогда, догадавшись в чем дело, рявкну «осанну».“ (XV 82.31-33; Ich weiß ja, das ist ein Geheimnis, aber das Geheimnis will man mir um nichts (in der Welt) entdecken, weil ich dann wohl, wenn ich die Sache enträtselt habe, ,Hosanna' brüllen würde.). Der Teufel sieht die Schöpfungsordnung wie ein russischer „разночинец“, ein Parvenü: In dieser Ordnung dürfe er an dem Guten nicht teilhaben, sondern müsse bei seiner sozialen Stellung bleiben. Man fragt sich: Soll das nur witzig sein?

Das russische Wort für Geheimnis ist тайна. Dieses Wort ist aber zugleich die russische Entsprechung für griechisch Mysterium, das „höher ist als alle Vernunft", die geheimnisvolle oder sakramentale Verbindung mit dem Göttlichen im Abendmahl, in der Taufe und jedes Mal, wenn der Mensch des Göttlichen inne wird. Der Großinquisitor, der die Tat Christi usurpiert, sagt тайна; der Teufel, der von dem Göttlichen ausgeschlossen ist, sagt секрет. Beides gehört stilistisch, kompositorisch und in der Entwicklung des Themas zusammen.

Das Verhältnis des Teufels zu diesem Geheimnis ist eine Parodie auf das christliche Mysterium des Göttlichen, das im irdischen Leben erfahrbar ist. Der Teufel leugnet dieses Mysterium nicht. „Нет, пока не открыт секрет, для меня существуют две правды: одна тамошняя, ихняя, мне пока совсем неизвестная, а другая, моя.“ (XV 82.43-45; Nein, solange das Geheimnis nicht entdeckt ist, gibt es für mich zwei Wahrheiten: eine dort, ihre, die mir vorläufig ganz unbekannt ist, und eine andere, meine). Seine Wahrheit, das ist die Parodie des Mysteriums, goethisch gesagt: die Spottgeburt aus Dreck und Feuer, die Welt des „alles ist erlaubt“, wie er kurz darauf aus den Gedanken des Ivan zitiert. Aber daß es die andere, jenseitige, daß es die Wahrheit gibt, das weiß er und leugnet es nicht.

Diese Aussage des Teufels über zwei Wahrheiten ist aus der Personenkonstellation des Zynikers und des idealen Dichters, ursprünglich aus dem подполье und der подноготная entwickelt, aus einer Jahrzehnte anhaltenden Auseinandersetzung mit Rousseau und der Aufklärung, aus der allmählich schmerzlich gewonnenen Einsicht, daß man von alleine nicht ganz „homme de la nature et de la vérité“ sein könne.

Dostoevskij hatte die Schönheit und Ordnung der Außenwelt früh als einen schönen Schein der Oberfläche erkannt, der etwas Anderes verdeckte, das 
unbekannt war und furchtbar sein konnte. Daraus hatte er für die Kunst die Aufgabe abgeleitet, das Verdeckte sichtbar zu machen. Insofern sollte sie der Wahrheitsfindung dienen.

Aber erst nach seinem Höllenjahrzehnt war es die Leistung seines Jahrzehnts des Purgatorio, daß er daraus für eine Romanhandlung eine besondere Personenkonstellation erfand. $\mathrm{Zu}$ ihr gehörten der zynische Amoralist, den er zunächst in die Figur des Aristokraten der guten Gesellschaft kleidete, deren Ordnung das Laster verdeckte. Dann kam der plebejische Schnüffler mit politischen Umsturzmotiven hinzu. Schließlich übernahm der Teufel diese Rolle. Diese Figur steht meist einem idealen Jüngling gegenüber, der von einer schönen Idee geleitet und dann zum Verbrechen verführt wird.

Die Rolle des lasterhaften und zynischen Amoralisten schließlich den Teufel übernehmen zu lassen, war ein Einfall, der Dostoevskijs Kulturkritik wohl die größte Tiefe gab, und zugleich war es ein witziger Einfall, vielleicht das Witzigste, was Dostoevskij erdacht hat; daß er ein großer Komiker war, wird selten beachtet. Tiefe erhielt der Einfall, weil er ihn mit der Kulturkritik an der europäischen Aufklärung verband. Das ist kaum aus dem Roman, aber gut aus Dostoevskijs innerer und literarischer Entwicklung deutlich zu machen.

Existiert aber der Teufel? muß man schließlich fragen. Ivan sagt dem Teufel: „[...] ни одной минуты не принимаю тебя за реальную правду.“ ([...] in keinem Augenblick halte ich dich für die reale Wahrheit). Der Teufel höhnt: „[...] стало быть, одно маленькое мговеньице ведь верил же, верил, что я действительно есть.“ (XV 72.30-42; [...] ein ganz kleines Augenblickchen habe ich wohl wirklich geglaubt, habe geglaubt, daß ich wirklich existiere). Am Ende aber sagt Ivan zu seinem Bruder verzweifelt: „[...] знаешь, Алеша, знаешь [...] я бы очень желал, чтоб он в самом деле был он, а не я!“ (XV 87.12-14; [...] weißt du Aljoscha, weißt du [...], ich würde schon wünschen, daß er wirklich er ist und nicht ich!). Der Teufel ist nach Anlage der Erzählung Ausgeburt der schuldbeladenen Seele des Ivan Karamazov. Als solche Ausgeburt aber zeigt er, daß er in jedem Menschen wirklich existiert. 


\author{
Dagmar Herrmann
}

\title{
Die neue europäische Ordnung - eine Vision Dostoevskijs
}

\section{Ahnungen versus Konzeptionen}

Dostoevskijs Schriften zum Zeitgeschehen sind zum großen Teil in seinem „Tagebuch eines Schriftstellers“ (Dnevnik pisatelja) erschienen, einem publizistischen Projekt, mit dem der Autor seine Anschauungen zu Fragen gesellschaftlicher, politischer, ästhetischer und literarischer Art darlegen wollte. Nachdem das Tagebuch zunächst 1873 und Anfang 1874 als Artikelfolge der Zeitschrift „Graždanin“ (Der Staatsbürger) veröffentlicht worden war, entschloß er sich, es ab 1876 als eigenständiges Periodikum selbst zu verlegen. Das außergewöhnliche Unternehmen weckte in Journalistenkreisen zunächst Skepsis, gewann aber bald eine breite Leserschaft und erwies sich auch finanziell als ein Erfolg. Die Essays reagierten häufig auf aktuelle Meldungen der Tagespresse und erörterten diese in einem größeren historischen, politischen und philosophischen Zusammenhang. In einer ungeschützten Kommunikationssituation überprüfte der Autor vor den Augen der Leser seine religiös-politischen Grundüberzeugungen, indem er weitreichende Interpretationen der laufenden Ereignisse in Rußland und Europa wagte. Der zeitgenössische Leser fragte sich also gespannt nicht nur: Wie wird sich die Lage weiterentwickeln?, sondern auch: Wird Dostoevskij recht behalten? Die Widersprüche, in die er sich verwickelte, die widerstrebende oder vorauseilende Modifikation und Anpassung seines gedanklichen Gerüsts an den Verlauf der Entwicklung, begleitet von Klagen und Zweifeln, von polemischen Ausfällen gegen seine politischen Kontrahenten und von visionären Eingebungen, verleihen den Texten eine einzigartige Dynamik. So singulär auch die Textgattung, war sie dennoch durch Vorbilder inspiriert, die eine ähnliche Verflechtung von autobiographischer Selbstvergewisserung und Geschichtsortung darstellten. Das sind vor allem Gogol's Ausgewählte Stellen aus dem Briefwechsel mit Freunden (Vybrannye mesta iz perepiski s druz'jami, 1847) sowie Alexander Herzens autobiographische Werke ${ }^{1}$, also Schriften

1 Pis'ma iz Francii i Italii (Briefe aus Frankreich und Italien), teilweise veröffentlicht in Rußland 
zweier Denker und Schriftsteller, die politisch entgegengesetzte Positionen vertraten - der eine war ein Orthodox-Konservativer, der andere ein liberaler Sozialist - und die beide von Dostoevskij geschätzt wurden.

Mit beiden hatte Dostoevskij den prophetischen Gestus gemeinsam - und auch jenes eigentümliche Verhältnis zur Gegenwart, mit dem bewegliche Geister in Rußland traditionell auf die Unbeweglichkeit russischer Zustände reagierten und das man als ein Unzeit-Empfinden zwischen Vergangenheit und Zukunft beschreiben kann. Chiliastische Denkmuster finden sich bei den unterschiedlichsten Persönlichkeiten der russischen Geschichte. Im 19. Jahrhundert verbanden sie sich mit der Ahnung, unmittelbar vor gewaltigen historischen Veränderungen zu stehen, die sowohl Westeuropa als auch Rußland eine von Grund auf neue Gestalt verleihen würden. Pëtr Čadaeev, Westler mit katholischen Neigungen, sah das Reich Gottes auf Erden als Bestimmung der Menschheitsgeschichte. ${ }^{2}$ Gogol' meinte ebenfalls, daß Rußland „das Nahen eines anderen Reiches spürt" ${ }^{\text {“3 }}$. Der Atheist Alexander Herzen, den man wegen seines Abgesangs auf die westliche Zivilisation einen "russischen Jeremias“ nannte, sah die folgende Generation als Erbauer von Brücken zu unbekannten Ufern. ${ }^{4}$

Dostoevskij kultivierte den prophetischen Stil in Anlehnung an das jüdische und frühchristliche Schrifttum, insbesondere an die apokalyptischen Texte des Neuen Testaments. Vom Endzeitempfinden geleitet, suchte er im Gegenwartsgeschehen nach den Gesetzen einer apokalyptischen Rhythmik. Er erahnte Wirren und Katastrophen und hoffte auf ein "tausendjähriges“ Reich der Gerechtigkeit, das ihnen folgen würde. Als politischer Kommentator setzte er sich die Aufgabe, im aktuellen Zeitgeschehen Signaturen der sich vollziehenden Geschichte auf ihrem Weg von bekannten Anfängen zu dem erwarteten Endzustand auszumachen, Zeichen, in denen der hellsichtige Beobachter einen erfaßbaren historischen Sinn erkennen könne.

1847, als Buch erschienen in London 1855; S togo berega (Vom anderen Ufer). Hamburg 1850 (dt.); London 1855 (russ.); außerdem seine Memoiren Byloe i dumy (Erlebtes und Gedachtes). London 1852-1868. Vgl. auch Dagmar Herrmann: Alexander Herzens Probleme mit den Deutschen. In: Dagmar Herrmann, Alexander L. Ospovat (Hg.): Deutsche und Deutschland aus russischer Sicht. 19. Jahrhundert: Von der Jahrhundertwende bis zu den Reformen Alexanders II. (=West-östliche Spiegelungen. Hrsg. von Lew Kopelew. Bd. 3 B). München 1998, S. 873-937.

2 Pëtr Čadaeev: Pis'mo vos'moe (Achter Brief [verfaßt um 1831]). In: P. Ja. Čadaeev: Izbrannye sočinenija i pis'ma. Moskau 1991, S. 134-140; hier S. 140.

3 Zitiert nach Igor' Zolotusskij: Gogol'. Zweite, verbesserte und ergänzte Auflage. Moskau 1984, S. $359 f$.

4 Aleksandr I. Gercen: S togo berega (Vom andern Ufer). In: A. I. Gercen: Sobranie sočinenij v 30-ti tomach. Moskau 1954-1966. Hier Bd. VI, S. 9; in seiner Widmung an den Sohn, 1855. 
Dieser prophetische Anspruch war eine der Ursachen dafür, daß Dostoevskij als politischer Denker häufig nicht ernst genommen wurde. ${ }^{5}$ Er hatte sich massiver rationalistischer Kritik zu erwehren, die ihm als Idealisten die Kompetenz für das Reale absprach. ${ }^{6}$ Eine „wissenschaftliche“ Gewißheit, wie sie einen Marx beseelte, kannte Dostoevskij tatsächlich nicht. Weder das Ziel der Geschichte noch die Frist bis zu seiner Erreichung, noch das Wie des historischen Verlaufs schienen ihm für den menschlichen Verstand zugänglich, und er betrachtete es als Verblendung, hierfür Gesetzmäßigkeiten aufzustellen. Vorbild war ihm Aleksandr Puškin, der den Dichter als Medium göttlichen Wirkens und als Verkünder göttlicher Wahrheit verstand. ${ }^{7}$ Dostoevskij wählte sich eine kaum geringere Rolle: die des Zeichensuchers und Zeichendeuters. Woher das Neue in die Welt kommen und wie es aussehen würde, ging ihm in Ahnungen und Visionen auf. Das Erwartete, die Wendung der Geschichte zu einem Stadium brüderlicher Harmonie unter den Menschen, erschien ihm nicht als

5 Noch heute ist diese Meinung verbreitet. Ludolf Müller, der selbst wiederholt die hohe Bedeutung der späten Publizistik Dostoevskijs betont hat, weist darauf hin, daß „Verehrer Dostoevskijs meinen, man tue ihm den größten Dienst, wenn man seine politische Publizistik verschweige“. Ludolf Müller: Dostoevskij und Deutschland. In: Heinz Setzer, Ludolf Müller, RolfDieter Kluge (Hg.): Fjodor Michailowitsch Dostojewskii. Dichter, Denker, Visionär. Tübingen 1998, S. 235-254; hier S: 248. Bestätigung findet sein Hinweis unter vielen anderen bei Hans Kohn: Die Slaven und der Westen. Die Geschichte des Panslawismus. Wien und München 1956, S. 185f., der Dostoevskijs politische Stimme ,aufdringlich und schrill“ nannte. Rudolf Neuhäuser hält Dostoevskijs Werke weitgehend für ungeeignet als Mittel der postkommunistischen Selbstfindung. Auf das gesamte Werk bezogen, schreibt er: „Mit Gewißheit ist Dostoevskij kein ,nationaler Prophet', auch kein ,großer Philosoph'“" Rudolf Neuhäuser: Rußland und der Westen. Zu den ideologischen Grundlagen in Dostoevskijs Werk. In: Jahrbuch der Dostojewskij-Gesellschaft 1 (1992), S. 66-78.

6 Dnevnik pisatelja (Tagebuch eines Schriftstellers), im folgenden zitiert als DP, Juli-August 1876, 2. Kapitel, II: Postydno li byt' idealistom (Ist es beschämend, ein Idealist zu sein?). In: F. M. Dostoevskij: Polnoe sobranie sočinenij v tridacati tomach (Sämtliche Werke in dreißig Bänden). Leningrad 1972-1990; hier Bd. XXIII, S. 70. Diese Ausgabe wird im folgenden abgekürzt mit Band- und Seitenangabe angeführt. Die deutsche Übersetzung der Zitate stammt, wenn nicht anders vermerkt, von mir und ist als möglichst wörtliche Arbeitsübersetzung zu lesen. Gerade bei den Texten, die für das Thema dieses Aufsatzes herangezogen werden mußten, erwies es sich als nicht empfehlenswert, die bei Piper erschienene Übersetzung vom Beginn des Jahrhunderts, die bis in die heutige Zeit immer wieder neu aufgelegt wurde, zugrunde zu legen. Entscheidende Aussagen Dostoevskijs über Deutschland sind dort aus einem deutsch-nationalen Impetus heraus im Ton und teils im Wortlaut verändert. Zum Vorgang des Übersetzens für die Piper-Ausgabe siehe Christoph Garstka: Arthur Moeller van den Bruck und die erste deutsche Gesamtausgabe der Werke Dostojewskijs im Piper-Verlag 1906-1919. Frankfurt a. M. u.a. 1998, S. $70 \mathrm{ff}$.

7 Vgl. etwa Puškins Gedicht Der Prophet, veröffentlicht 1828, aber schon verfaßt 1826, in engem zeitlichem Zusammenhang mit einem politischen Ereignis, dem Dezemberaufstand von 1825, und nach Motiven des Buches Jesaja gestaltet. 
etwas von Menschen Konzipiertes, sondern als etwas göttlich Intendiertes und als solches zugleich historisch-organisch Gewachsenes. ${ }^{8}$

Doch gab es einige gedankliche Konstanten der russischen Geschichtsphilosophie, die ihm - in modifizierter Form - als hermeneutisches Werkzeug zur Interpretation des zeitgenössischen Geschehens dienten. Dies war vor allem der ideelle Grundgegensatz zwischen Rußland und Europa. Europa sah er zersetzt von Kräften, die aus der Fehlentwicklung des westlichen Christentums entstanden seien. Ausgehend von der slavophilen Kritik an der „römischen“ Natur und der „rationalistischen“ Grundlage des Katholizismus, betrachtete er als die größte destruktive Kraft des Westens das Papsttum, das um des Besitzes westlicher Macht willen Christus verraten habe. Als das jüngste Produkt des katholischen Irrwegs erschien ihm die sozialistische Idee, in der er, neben dem immer noch starken Katholizismus selbst, der Menschheit eine zweite große Gefahr erwachsen sah, welche die „katholische Idee“ unter atheistischen Vorzeichen fortführe.

\section{Rußland und Europa - gemeinsame Zukunft?}

Das rettende nationale Prinzip und die russische Sendung

Das Bedrohliche an beiden Ideen, der katholischen wie der sozialistischen, lag für ihn in deren supranationaler und antinationaler Natur. Beide hoben das Prinzip der Völkerpersönlichkeiten auf, das in Dostoevskijs Geschichtskonzeption die treibende Kraft war, zielten auf eine Einebnung aller nationalen Unterschiede, auf eine gesamtmenschheitliche Abstraktion und somit auf eine Entmenschlichung. Ihm aber schien die Neuordnung Europas nach nationalen

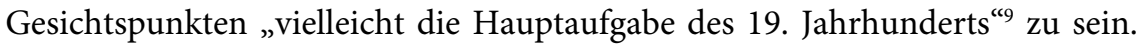
Jeder Volksstamm habe sich um eine „sittliche Idee“ versammelt und auf ihrer Grundlage in seiner Geschichte eine eigene „Wahrheit“ herausgebildet. ${ }^{10}$

„Es fiele mir sehr schwer, die Geschichte des Wandels meiner Überzeugungen zu erzählen“, schreibt Dostoevskij 1873 in seinem Tagebuch eines Schrift-

8 Vgl. Zimnie zametki o letnich vpečatlenijach (Winterliche Notizen über sommerliche Eindrücke [veröffentlicht 1963]), VI. Kapitel (V, 80).

9 IV. Zapisnaja tetrad' 1864-1865 gg. (IV. Notizheft 1864-1865); XX, S. 191.

10 DP August 1880, 3/III: Dve polovinki (Zwei Hälften); XXVI, 165; diese Position hat Dostoevskij wie viele Gedanken dieser Jahre wohl in Auseinandersetzung mit Danilevskij entwickelt, der apodiktisch formulierte: „Was nicht national ist, hat kein Existenzrecht in der politischen Welt.“ Nikolaj Danilevskij: Konstantinopol' (Konstantinopel). In: Russkij mir, 11. und 12. November 1877, Nr. 308 und 309; abgedruckt in: N.D.: Gore pobediteljam. Političeskie stat'i. Moskau 1998, S. 100. 
stellers. ${ }^{11}$ In der Tat, wer es dennoch versucht, gerät in einen Irrgarten gegenläufiger Fährten. Im Spektrum der zeitgenössischen politischen Richtungen, zwischen Liberalen, Demokraten, Sozialisten, Kommunisten, konstitutionellen Monarchisten und Anhängern der Autokratie findet sich kein vordefinierter Platz für seine Position. ${ }^{12}$ Sozialistische Ideen waren ihm teilweise nah, aber als politisches System lehnte er den Sozialismus ab. Als junger Schriftsteller hatte er sich für den frühen, utopischen Sozialismus begeistert, wie er ihn bei seinem Gönner und Förderer, dem Literaturkritiker Belinskij ${ }^{13}$, kennenlernte. Weil er 1849 in einem radikal gesinnten Gesprächszirkel einen Brief Belinskijs an Gogol' verlas, wurde er zum Tode verurteilt und dann zu Zwangsarbeit und Verbannung begnadigt. Später spottete er mit milder Ironie über utopischsozialistische Schwärmerei. Furcht und Haß aber empfand er für den Sozialismus in seiner atheistischen, rationalistischen, materialistischen Variante, wobei er gerade diesen als ein „organisches Produkt des westlichen Lebens“ empfand ${ }^{14}$ - das Element der Brüderlichkeit schien ihm darin zu gewaltsamer materieller Gleichmacherei pervertiert. ${ }^{15}$

Als Gegenidee zum westlichen Sozialismus formulierte er seine eigene Idee der urchristlichen Brüderlichkeit, die er religionsgeschichtlich und zugleich nationalhistorisch herleitet: Dank einer tausendjährigen Tradierung im praktischen Leben sei diese Idee zum Bestandteil des russischen Volkscharakters geworden und werde bei bewußter Anwendung immer vollkommener mit der Wirklichkeit des russischen Lebens verschmelzen. In den sechziger Jahren äußerte er, daß „die Völker von selbst zum Sozialismus kommen werden, wenn es nur die Wahrheit ist, daß er das Universalheilmittel für die ganze Gesellschaft ist ${ }^{\text {"16}}$, und gegen Ende seines Lebens bezeichnete er seine Idee der christlichen Brüderlichkeit explizit als „russischen Sozialismus“"17.

11 XVI. Kapitel: Odna iz sovremennych fal'šej (Eine der zeitgenössischen Fälschungen); XXI, S. 134.

12 Zur Unabhängigkeit der politischen und philosophischen Positionen Dostoevskijs siehe Ludolf Müller: Dostojewskij. Sein Leben, sein Werk, sein Vermächtnis. München 1982, S. 66 und passim.

13 Der einflußreiche westlerische Literaturkritiker und -theoretiker der vierziger Jahre, Vissarion Belinskij (1811-1848), sammelte begabte Autoren um sich und verpflichtete sie auf eine sozialkritische Milieuschilderung des russischen Lebens.

14 III. Zapisnaja knižka 1864-1865 gg. (III. Notizbuch 1864-1865). XX, S. 180.

15 Zimnie zametki o letnich vpečatlenijach (wie Anm. 8). V, S. 79.

16 II. Zapisnaja knižka 1863-1864 gg. (II. Notizbuch 1863-1864). XX, S. 172.

17 Denselben Ausdruck hatte auch Alexander Herzen zur Kennzeichnung seiner Konzeption des russischen Bauernsozialismus gewählt. 
Republikanische Freiheiten, wie sie der Westen entwickelt hatte, lehnte Dostoevskij ab. Seine Idee der persönlichen Freiheit war nicht politisch, sondern ethisch-religiös begründet, das heißt innerhalb eines metaphysischen Sinnzusammenhangs. Die patriarchalische Beziehung zwischen dem russischen Zar und dem Volk schien ihm eine viel umfassendere Freiheit zu gewährleisten als jede westliche Republik. Ihm gefiel der Gedanke, daß ein König resp. Zar, wenn er sich nur im Einverständnis mit seinem Volk befände, den Sozialismus von oben inaugurieren könnte. „Die Idee der Nationalität ist die neue Form der Demokratie“, formulierte er in seinem Notizbuch. ${ }^{18}$

Allerdings bestand zwischen den universalistischen und nationalistischen Elementen der Ideen Dostoevskijs ein unauflösbarer Widerspruch. „Wir ahnen, daß [...] die russische Idee vielleicht die Synthese aller Ideen sein wird, die Europa entwickelt hat“, schrieb er $1860 .{ }^{19}$ Sein Glaube an die „Allmenschlichkeit“ des russischen Wesens scheint jeden engen Nationalismus aufzuheben und ist doch die Grundlage für eine exklusive Auffassung der eigenen Nation, insofern als Rußlands Bestimmung postuliert wird, der Weltchristenheit den Weg zu weisen. Zugleich aber enthalten Dostoevskijs geschichtsphilosophische Ideen in Anlehnung an Nikolaj Danilevskijs zyklische Kulturtypenlehre polyvalente Akzente, die eine Vielfalt von um die Vorherrschaft wetteifernden „Wahrheiten “ verschiedener Volksstämme voraussetzen. ${ }^{20}$

Ebenso widersprüchlich war Dostoevskijs Vorstellung von der Friedfertigkeit des russischen Volkes, die er - im Einklang mit der slavophilen Lehre der Gewaltbereitschaft der westlichen Nationen entgegenstellte. Friedfertigkeit erkannte er in der Rolle, die die unkriegerische Besiedlung von neuem Land in der russischen Geschichte spielte, sowie im Fehlen von Klassengegensätzen, während im Westen Landnahmen blutige Eroberungen bedeuteten und Klassenauseinandersetzungen durch Revolutionen entschieden wurden. Andererseits war Krieg für Dostoevskij kein prinzipiell zu vermeidender Zustand, vielmehr eine periodisch notwendige Bereinigung der Verhältnisse, die eine moralische Erneuerung bewirke. (In diesem Sinn begrüßte er den Deutsch-Französischen

18 II. Zapisnaja knižka 1863-1864 gg. (II. Notizbuch 1863-1864). XX, S. 179.

19 Ob-javlenie o podpiske na žurnal „Vremja“ na 1961 god (Ankündigung des Zeitschriftenabonnements der „Zeit“ für das Jahr 1861). XVIII, S. 35.

20 Nikolaj Danilevskij, philosophierender Naturwissenschaftler, war wie Dostoevskij während der vierziger Jahre Mitglied der Diskussionsrunde um den Freidenker Petraševskij gewesen. Er vollzog eine grundsätzliche Wende in der russischen Geschichtsphilosophie und bereitete die Beendigung der - negativen wie positiven - Fixierung des Denkens auf die europäische Zivilisation vor. Seine Schrift „Rußland und Europa“ (Rossija i Evropa) erschien 1869 in der Zeitschrift „Zarja“ (Morgenröte) und 1871 in Buchform. 
Krieg.) Auch betonte er die kämpferische Seite des Evangeliums und interpretierte sie politisch: In manchen Fällen betrachtete er blutige Gewalt als Christenpflicht - so bei der Niederschlagung des polnischen Aufstands 1863/64 oder im russischen Krieg von 1877/78 gegen das Osmanische Reich.

Manche seiner sehr weitreichenden Ideen entwickelte Dostoevskij nicht in den politischen Schriften, sondern überließ sie den Helden seiner literarischen Werke. Gleichwohl stehen sie in engem Zusammenhang mit seinem politischen Denken und liefern indirekt Hinweise zum Verständnis seiner politischen Analysen oder loten extreme Varianten seiner Ideen aus. Der russische Sendungsgedanke erscheint in den Romanen als Idee des "Gottträgervolks“, aus dessen Mitte das Wiedererscheinen Christi und die Sammlung der Christenheit zu erwarten seien.

Auch im Tagebuch eines Schriftstellers begleiten biblisches „Und siehe“, „Die Zeit ist nahe“, Hinweise auf das Entstehen und Versinken großer Reiche (das Heilige Römische Reich deutscher Nation, die beiden Napoleonischen Imperien, das Deutsche Reich [XXIII, 50]), Blicke in Jahrtausende der Vergangenheit und Zukunft, Ankündigungen des kommenden Gottesreiches die Analyse konkreter zeitgenössischer Ereignisse bis hin etwa zu der Frage, welche Partei der Dritten Französischen Republik sich bei den nächsten Wahlen durchsetzen werde.

Dostoevskij war überzeugt, daß Rußlands religiös-historische Bestimmung sich unmittelbar in der Staatspolitik niederschlug, und versuchte die Ereignisse seiner Gegenwart in diesem Sinn zu interpretieren. Voraussetzung dafür, daß in der Welt das brüderliche christliche Prinzip gegen die katholische Lehre gestärkt würde, war eine starke Stellung des Russischen Reiches unter den europäischen Staaten. Der Sendungsgedanke sollte die Außenpolitik des Russischen Reiches in zweierlei Hinsicht bestimmen: zum einen, indem sie christliche Prinzipien durchsetzte, zum anderen, indem sie Rußlands Macht mehrte und damit die Voraussetzungen für die Erfüllung ihrer Aufgaben verbesserte. Seine politischen Plädoyers folgten der Intention, die Einsicht in diese Zusammenhänge unter seinen Landsleuten zu verbreiten, so daß Staatslenker und Volk gemeinsam der russischen Mission in der Welt zielbewußter zum Durchbruch verhelfen könnten.

Der Philosoph Lev Šestov, der an Dostoevskij die andere, die subversive Seite schätzte, bemerkte unverblümt: „Es versteht sich, daß ein Mensch mit solchen Ansichten und Stimmungen sich besser nicht auf Publizistik eingelassen hätte

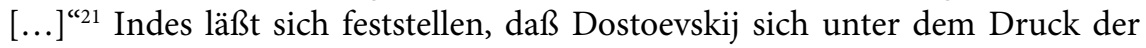

21 Šestovs Worte sind konkret auf die Behauptung Dostoevkijs, das russische Volk liebe das 
erwarteten Zeitenwende nicht vom konkreten Geschehen abwandte, sondern umgekehrt gerade ihres transitorischen Charakters wegen die Gegenwart besonders intensiv beobachtete. Sein nationaler Messianismus und sein eschatologisches Geschichtsverständnis dienten als eine Art Antenne oder Suchsonde zum Auffangen der Botschaften, die, im Zeit- und Tagesgeschehen verschlüsselt, Auskunft über die Geschichte der Menschheit enthalten mochten.

Wie Šestov mit Blick auf Dostoevskij und Nietzsche feststellte, unterliegen Zeichendeuter der Moderne einem grundsätzlichen Dilemma: „Sie suchen selbst das Licht, sie trauen sich selbst nicht, glauben nicht, daß das, was ihnen als Licht erscheint, tatsächlich Licht ist und nicht ein trügerisches Irrlicht

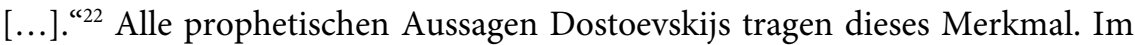
Roman Die Dämonen (Besy) wird Fürst Stavrogin, eine undurchschaubare, frevlerische Gestalt, die Dostoevskij sich aber nach eigenem Bekunden „aus dem Herzen genommen" hat ${ }^{23}$, zur Rede gestellt, weil er an die Idee des Gottträgervolks, die er gepredigt hatte, selbst gar nicht glaubt. Stavrogins Antwort lautet: „Indem ich Sie zu überzeugen versuchte, ging es mir vielleicht noch mehr um mich selbst als um Sie." Die Verirrungen des Wahrheitssuchenden sind es auch, die Cervantes' Don Quijote zu einer der literarischen Lieblingsfiguren Dostoevskijs machten. Im Tagebuch eines Schriftstellers demonstriert er an dessen Beispiel die menschliche Neigung, an einer liebgewordenen Idee festzuhalten und lieber eine zweite, noch phantastischere zu erfinden, als sich die Irrigkeit der ersteren einzugestehen. Der weit abseits der liberalen, patriotisch-modernen Hauptströmung operierende Kommentator Dostoevskij, der sich gegen einen Chor von Kritikern zu behaupten hatte, war sich des riskanten Charakters seiner weitreichenden Hypothesen wohlbewußt.

\section{Zivilisation und drohende Barbarei}

Eines der beeindruckendsten Ergebnisse dieses gewagten Unternehmens, Geschichte in ihrem Verlauf einzufangen, ist die Sicherheit, mit der die Merkmale und Gefahren der entstehenden modernen europäischen Massengesellschaften erfaßt werden. Dostoevskij verfolgt, auf welchen Wegen die Wissenschaftsgläubigkeit seiner Zeit dazu führte, daß angenommene anthropologische und

Leiden, die in engem Zusammenhang mit seinen Vorstellungen vom Christusvolk steht. Lev Šestov: Dostoevskij i Nicše (Dostoevskij und Nitzsche). In: L. Š.: Sočinenija. Moskau 1995; hier Abschnitt XVI, S. 99.

22 Lev Šestov: Dostoevskij i Nicše (ebd.). Vorwort. S. 25.

23 Brief vom 8./20. Oktober 1870 aus Dresden an Michail N. Katkov (XXIX, 1, S. 142). 
wirtschaftliche „positive“ Gesetzmäßigkeiten die Moral als Maßstab menschlicher Vernunft verdrängten (von „Liebe deinen Nächsten“ zum „Kampf ums Dasein“24). Er bemerkte, wie die Gesetze der Wirtschaft verlangen, die Menschen durch das Ansprechen ihrer egoistischen Interessen zu lenken. ${ }^{25}$ Zugleich beobachtet er die beschleunigte Verbreitung von Modeideen, ungeachtet ihres Wahrheitsgehalts, und die sinkende Resistenz des Einzelnen gegen die ständige Wiederholung von Behauptungen („erschreckend, wie sehr der Mensch das liebt, was man ihm fertig vorsetzt ${ }^{\text {“26}}$ ). Aus der Manipulierbarkeit des zeitgenössischen Menschen, die sich geschickte Führer zunutze machen könnten, schließt er auf die Labilität moderner Gesellschaftstrukturen und ihre Anfälligkeit für einen Zivilisationsbruch. Er fürchtet das enthumanisierende Potential von Revolutionen in einer gottlosen Welt. Die Warnung vor einem jederzeit möglichen Rückfall in die Barbarei durchzieht seine Werke.

Dostoevskijs Erkenntnisse bezogen sich auf die westliche Kultur, deren Gefahren er aber meist an ihren Auswirkungen auf den verwestlichten Teil der russischen Gesellschaft, also auf die Gebildeten, analysierte. Doch hielt er die Merkmale der Moderne in Rußland im Grunde für Oberflächenerscheinungen und hoffte auf ihre baldige Überwindung durch die in ihren Traditionen ruhende und erstarkende russische Nationalkultur: Wie Antäus durch Berührung mit der Erde Kraft gewann, würden die verwestlichten Teile der Intelligenz durch Berührung mit dem russischen „Volksboden“ („počva“) ihre Schwächen überwinden - dem Westen fehle eine derartige Kraftquelle.

Solche Gedanken beschäftigten ihn bereits auf seiner ersten Europareise im Jahr 1862. Die hiernach entstandenen feuilletonistischen Skizzen Winterliche Aufzeichnungen über sommerliche Eindrücke (Zimnie zametki o letnich vpečatlenijach ${ }^{27}$ enthalten teils mutwillig subjektive Impressionen, teils schonungs-

24 Vgl. Brief von 7. Juni 1876 an V.E. Alekseev (XXIX, 2, S. 84 ff.); ebenso die Erzählung Krokodil von 1865 (V, S. 180-207); vgl. auch im „Dnevnik pisatelja“, Januar 1877, Kap. 2/II: My v Evrope liš struckie (In Europa sind bloß Landstreicher). (XXV, S. 20-23); Februar 1877, Kap. 1/III: O sdiranii kož voobšče. Raznye aberracii v častnosti. Nenavist'k avoritetu pri lakejstve mysli (Über das Hautabziehen. Verschiedene Aberrationen im einzelnen. Haß auf die Autorität bei Lakaientum im Denken). (XXV, S. 44-47); Februar 1877, Kap. 2/III: Zloba dnja v Evrope (Die Tagesfrage in Europa). (XXV, S. 59 ff.); November 1877, Kap. 3/III: Nado lovit' minutu (Man muß den Moment nutzen). (XXVI, S. 89 ff.).

25 Zimnie zametki o letnich vpečatlenijach (wie Anm. 8), VI. Kapitel; V, S. 81.

26 DP Februar 1877, Kap. 1/III: O sdiranii kož voobšče. Raznye aberracii v častnosti (wie Anm. 24); XXV, S. 47.

27 Zimnie zametki o letnich vpečatlenijach, veröffentlicht in der von den Brüdern Dostoevskij herausgegebenen Zeitschrift „Vremja“ (Die Zeit) 1863 (V, 46-98). Dostoevskij stellte sich bewußt in die Tradition der russischen Reiseschilderungen: von Denis Fonvizin (Reisen 1777/78 
lose Schilderungen der sozialen Mißstände (wie die Kinderprostitution in Londoner Armenvierteln) sowie eine sarkastische Analyse der Mentalität des zeitgenössischen europäischen Bourgeois. Beschrieben sind vor allem die Verhältnisse in Frankreich und England, den Staaten, die während der sechziger Jahre den europäischen Fortschritt repräsentierten. Symbol dieses Fortschritts war das Gebäude der Londoner Weltausstellung von 1851, der sogenannte „Kristallpalast“, dessen innovative Eisen-Glas-Konstruktion ein völlig neues Raumgefühl vermittelte und stilbildend auf die moderne Industriearchitektur wirkte. Es wurde zur Attraktion einer ersten weltweiten Bewegung des Massentourismus. Dostoevskijs Besichtigung des „Kristallpalastes“ mit seiner Produktschau aus aller Welt im Jahr 1862 löste eine große Erschütterung bei ihm aus:

Das Ganze steht, so scheint es, hartnäckig für sich und führt ein Eigenleben, [...] hier spielt sich ein hartnäckiger, dumpfer und uralter Kampf auf Leben und Tod ab, der Kampf des allgemeinwestlichen Persönlichkeitsprinzips mit der Notwendigkeit, sich auf irgendeine Weise vertragen zu müssen, irgendwie eine Gemeinschaft zu bilden und sich zu einem Ameisenhaufen zu organisieren. Und wenn man schon zu einem Ameisenhaufen werden muß, dann immerhin auf eine Weise geregelt, daß man einander nicht auffrißt. Sonst pervertieren wir zu Kannibalen! (Kapitel: „Baal“; V, 69)

Diese Radikalität russischer Kritik an der Verfassung der europäischen Zivilisation des 19. Jahrhunderts mochte einer spontanen Eingebung entsprungen sein, doch die Beschreibung des Westens als Menschenfressergesellschaft war zu diesem Zeitpunkt bereits ein Topos: Gogol' hatte am Vorabend der Revolutionswelle von 1848, wegen seiner konservativen und frommen Spätschriften heftig angegriffen, über die westliche Zivilisation geschrieben:

[...] dort ist jeder bereit, den anderen zu fressen, und man hat so zerstörerische, so vernichtende Grundsätze, daß sogar in Europa bereits jeder denkende Mensch mit unwillkürlichem Schaudern fragt: Wo ist unsere Zivilisation geblieben? ${ }^{28}$

und 1784/85) über Nikolaj Karamzin (Briefe eines russischen Reisenden (Pis'ma russkogo putešestvennika), erste Buchausgabe 1797) bis zu Alexander Herzen (Briefe aus Frankreich und Italien (Pis'ma iz Francii i Italii), 1847-1852). Die letztgenannten dokumentieren wie Dostoevskijs eigene Skizzen ebenfalls die Auslandsreise eines nach langen Jahren aus der Verbannung zurückgekehrten Autors, von der Herzen allerdings nie zurückkehren sollte. (Dostoevskij traf sich mit ihm in London.) Vgl. zu den angegebenen Beispielen der russischen Reiseliteratur: West-östliche Spiegelungen. Bd. 2 B und 3 B.

28 Aus dem nicht abgeschickten Brief an Vissarion Belinskij, geschrieben zwischen Juli und August 1847 aus Ostende als Antwort auf Belinskijs grundsätzliche Kritik. Nikolaj V. Gogol': Sobranie sočinenij v semi tomach (Ausgewählte Werke in sieben Bänden). Moskau 1984 [19841986]. Bd. 7: Pis'ma (Briefe), S. 322. 
Ähnliche Gedanken hatte Aleksandr Herzen 1850 in seiner Schrift Vom andern Ufer (S togo berega) geäußert. Ihm, dem liberalen Sozialisten, gab nicht die Revolution selbst, sondern deren Scheitern Anlaß, den Fortschritt der westlichen Zivilisation in Frage zu stellen. Während Dostoevskij und Gogol' mit der revolutionären Auflösung der alten Ordnung die Menschenfresserei als reale Bedrohung heraufziehen sahen, erblickte Herzen das Menschenfresserische eben in dieser alten Ordnung. Man müsse einsehen,

daß die Aristokratie nichts anderes als eine mehr oder weniger zivilisierte Anthropophagie ist. Ein Kannibal, welcher seinen Gefangenen frißt, ein Grundherr, der von seinem Lande hohe Zinsen nimmt, ein Fabrikant, der sich auf Kosten seines Arbeiters bereichert, stellen nur kleine Variationen und Abstufungen einer und derselben Menschfresserei vor. ${ }^{29}$

Kennzeichnend ist, daß Herzen ebenso wie Dostoevskij seine grundsätzliche Erkenntnis über die westliche Gesellschaft einem Massenereignis verdankte. In Herzens Fall war es die blutige Niederschlagung des Pariser Juniaufstandes von $1848^{30}$, deren Zeuge er wurde. Bei Dostoevskij löste bereits der Eindruck der Herdenhaftigkeit des modernen westlichen Lebens, die im Londoner Großstadttreiben kraß hervortrat, Abscheu aus. Er begriff, daß westlerische Europahörigkeit Rußland genau zu diesem Zeitpunkt hintreiben würde: Dies war Rußlands schlechte Zukunft, die verhindert werden mußte. Ein apokalyptisches Erschrecken aber erfaßte ihn angesichts der blinden Entschlossenheit, mit der die Millionen von Besuchern, die aus aller Welt zur Weltausstellung strömten, augenscheinlich genau diesem Modell zu folgen bereit waren, dessen Unmenschlichkeit sie nicht durchschauten.

Er erkannte eine „kolossale Dekoration“, erzeugt von einem „titanischen Geist“: Babylon ${ }^{31}$. Um der Macht und Verlockung dieses Bildes standzuhalten, das hier Erreichte nicht als das eigene Ideal anzusehen, „den Baal nicht an-

29 S togo berega (wie Anm. 4), Kapitel LVII: God respubliki, edinoj i nerazdel'noj (VI, S. 56). Zitiert nach der Erstausgabe, die auf deutsch erschien: [Alexander Herzen:] Vom anderen Ufer. Hamburg 1850, S. 132.

30 Spontaner Volksaufstand in Paris gegen die Regierung der neugegründeten Republik anläßlich der Schließung der Nationalwerkstätten zur Arbeitsbeschaffung, der durch die Heereseinheiten der Nationalversammlung brutal niedergeschlagen wurde. Dabei wurden Tausende Arbeiter verletzt oder getötet, die genaue Zahl der Opfer ist nicht bekannt.

31 Alexander Herzen kennzeichnete in einem etwas anderen Sinn die unwirkliche Atmosphäre in der europäischen Emigration, wie er sie in Genf erlebte, als „Turmbau zu Babel“. - Byloe i dumy (Memoiren und Reflexionen), 5. Teil, 37. Kapitel. In: A. I. Gercen: Sobranie sočinenij (wie Anm. 4). Bd. X, S. 58 ff.; deutsch Alexander Herzen: Mein Leben. Memoiren und Reflexionen. Aus dem Russischen von Hertha von Schulz. 3 Bde. Berlin (Ost) 1963; hier Bd. 2, S. 69. 
zubeten“, so Dostoevskij, werde es „einer Fülle unaufhörlicher geistiger Gegenwehr und Ablehnung bedürfen“ $(\mathrm{V}, 70)$.

Die „Winterlichen Aufzeichnungen über sommerliche Eindrücke“ waren der Auftakt seiner publizistischen Tätigkeit im Zeichen der „Gegenwehr und Ablehnung". Sie läßt bereits die Kombination von genauer Beobachtung und visionärer Erfassung der Realität erkennen, wie er sie auch weiterhin bewußt als Erkenntnismethode einsetzte. ${ }^{32}$

\section{Deutschland im europäischen Säkularisierungsprozess}

Der Kulturkampf: Entchristlichung oder Abwehr der falschen Lehre?

Während der sechziger Jahre war das Bild Deutschlands von zwei Aspekten bestimmt worden. Einerseits forderten rückständige Kleinstaaterei und provinzielle Exotik gerade die Bewohner eines riesigen Reichs zum Spott heraus. Auch Dostoevskij machte sich im Gefolge von Alexander Herzen („sechsunddreißig Vaterländer") gern darüber lustig. ${ }^{33}$ Noch 1876 warf Dostoevskij russischen Publizisten, die zu einer zurückhaltenden Politik in Europa rieten, vor, sie wollten Petersburg auf die politischen Maßstäbe Baden-Badens reduzieren. Andererseits beunruhigte ihn die Politik Preußens, dessen kriegerisches Auftreten die slavophile Lehre von der aggressiven westlichen Kultur völlig bestätigte.

Doch seit Deutschland nach der Reichsgründung eine ernstzunehmende politische Größe geworden war, begann er, das Nachbarland vornehmlich unter anderen Gesichtspunkten zu beobachten. Das neue Interesse an der deutschen Politik war eng mit seinen zentralen Ideen verbunden, die um einen zu erwartenden europäischen Schicksalskampf kreisten. In seiner Vorstellung stand dem orthodoxen Rußland und seinen Schutzbefohlenen, den slawischen Völkern und orthodoxen Christen außerhalb Rußlands, das von Konflikten zerrissene Europa gegenüber, das, durch die katholische Idee der irdischen Weltherrschaft entartet, von der aufsteigenden Macht des internationalen Sozialismus zerstört zu werden drohte. Die historische Aufgabe Rußlands sah Dostoevskij darin, die Slawen und die orthodoxen Christen zu schützen und mit ihnen die Zukunft zu gestalten. Zugleich schien es ihm wahrscheinlich, daß eines Tages auch Europa selbst bei Rußland letzte Rettung suchen werde.

Ein Thema, das sowohl die außen- als auch innenpolitische Entwicklung Deutschlands betraf, nahm seine Aufmerksamkeit besonders gefangen: Bis-

32 Siehe Aufsatz von Herr Guski in diesem Band.

33 Vgl. III. Zapisnaja tetrad' 1864-1865 gg.; XX, S. 183. 
marcks Kampf gegen den Einfluß der katholischen Kirche in Deutschland. Dieser Vorgang berührte seine Interpretation der westlichen Welt an zentraler Stelle. Seine eigene Auseinandersetzung mit dem Katholizismus im Sinne des westlichen Grundübels ist seit der ersten Hälfte der sechziger Jahre nachweisbar und setzt sich fort bis zur Erzählung Der Großinquisitor, die er in seinen letzten Roman Die Brüder Karamazov (Brat'ja Karamazovy; 1879/80) aufnahm.

Die Ursachen der erhöhten Aufmerksamkeit für die katholische Kirche sind zunächst in deren Geschichte selbst zu sehen. Die dramatischen Ereignisse um den Verlust des Kirchenstaates und den Entzug der weltlichen Machtbasis des Papsttums stellten die Existenz der katholischen Kirche überhaupt in Frage und waren Objekt intensiver Beobachtung in ganz Europa. Papst Pius IX. war durch die italienische Nationalstaatsbewegung in die Enge getrieben und hielt sich im Kirchenstaat nur dank einer Hilfsarmee Napoleons III. Als 1870 die Schutztruppen abgezogen wurden, um sie in den Krieg gegen Deutschland zu schicken, okkupierte die italienische Armee Rom und annektierte den Kirchenstaat. Pius IX. forderte die Herstellung des status quo ante und bekräftigte zugleich den geistigen Führungsanspruch der Kirche, indem er die Hauptströmungen der Moderne verdammte. Einen Tag vor dem Ausbruch des DeutschFranzösischen Krieges wurde auf dem Ersten Vatikanischen Konzil das Dogma der Unfehlbarkeit verkündet. Das intransigente Festhalten des Papstes am universalen Herrschaftsanspruch verschärfte den Konflikt zwischen liberaler Bewegung und katholischer Kirche europaweit.

Dostoevskij ließ sich durch den realen Machtverlust des Vatikans nicht beirren. Da er Geschichte als Geschichte von Ideen begriff, die sich historisch herausbildeten und gegenseitig verdrängten, war er vom Ideenkampf des Papstes in hohem Maße fasziniert und irritiert, und das um so mehr, als Pius IX. seine kämpferische Gegenwehr gerade gegen weltweite Säkularisierungstendenzen richtete, die auch Dostoevskij bekämpfte. Sowohl Dostoevskij als auch Pius IX. waren leidenschaftlicher Gegner der Lehren, die mit dem Aufschwung des Liberalismus während der sechziger Jahre des 19. Jahrhunderts Gemeingut wurden. Beide traten den philosophischen und gesellschaftspolitischen Folgerungen aus den neuesten Erkenntnissen der Naturwissenschaft entgegen, die das Geistige zur Sekundärfunktion der Materie herabstuften und die metaphysische Begründung der Ethik in Zweifel zogen (Karl Marx, Charles Darwin, Ernst Haeckel, Gobineau). ${ }^{34}$ Da Dostoevskij angesichts seiner Grundüberzeu-

34 Die Enzyklika „Quanta cura“ von 1864 war gegen moderne „Irrlehren“ wie Atheismus, Rationalismus, Sozialismus, Kommunismus sowie gegen den Nationalismus gerichtet. 
gungen Pius aber nicht als Verbündeten betrachten konnte, mußte er im Papsttum eine konkurrierende ideelle Instanz sehen. Darum rief der deutsche „Kulturkampf“ bei ihm ein so außerordentliches Interesse hervor. Ging hier doch die Regierung eines mächtigen Staates auf Konfrontationskurs zum Oberhaupt der katholischen Kirche, in dem Dostoevskij einen Prediger des „falschen Christus“, ja den „Hauptfeind der Menschheit“ sah.

Zwischen 1871 und 1876 wurden in Deutschland Gesetzte erlassen, die tief in die Souveränitätsrechte der katholischen Kirche eingriffen. ${ }^{35}$ Sie lösten einen heftigen und langanhaltenden innerdeutschen Ideenstreit aus, in dem sich Konfessionsgegensätze und politisch-ideologische Überzeugungen überlagerten. Hinter den kirchenrechtlichen Maßnahmen der deutschen Reichsregierung und den Abwehrreaktionen der Kirche stand der Grundkonflikt zwischen dem hergebrachten übernationalen Geltungsanspruch der katholischen Kirche und der sich seit der Jahrhundertmitte im politischen Leben durchsetzenden Idee des modernen Nationalstaats. Dieser brauchte für die Realisierung einer angemessenen Wirtschafts- und Gesellschaftsorganisation den direkten Zugriff auf seine Bürger und duldete keine konkurrierenden Instanzen. Ähnliche Konflikte spielten sich - zeitlich verschoben - auch in anderen europäischen Ländern ab. ${ }^{36}$

Der Begriff „Kulturkampf“ war Programm: Geprägt von dem Arzt und liberalen Reichstagsabgeordneten Rudolf Virchow, spiegelt er die Emphase liberaler Fortschrittspolitik als Feldzug für Aufklärung und Bildung gegen mittelalterlichen Aberglauben und Verdummung. Bismarck selbst, der Initiator der Kampagne, führte weder einen Kulturkampf, noch betrieb er eine antireligiöse Politik. Mit der Zurückdrängung der katholischen Einflußmöglichkeiten wollte er die Voraussetzung für die Integration der katholischen Bevölkerung der früheren Kleinstaaten sowie der französischen und polnischen Randgebiete in den Staatskörpern schaffen. Aber statt der erhofften inneren Stabilisierung trat

35 Es waren im einzelnen der „Kanzelparagraph“ gegen staatsschädigende Agitation, das Verbot des Jesuitenordens und fast aller anderen katholischen Vereinigungen, die staatliche Aufsicht über die Ausbildung der Geistlichen und das Einspruchsrecht bei ihrer Ernennung, das Expatriierungsgesetz gegen unbequeme Priester und die obligatorische Zivilehe.

36 Eine konzise und doch differenzierte Analyse des Geschehens liefert Joachim Scholtyseck in seinem Buch: Alliierter oder Vasall? Italien und Deutschland in der Zeit des Kulturkampfes und der „Krieg-in-Sicht“-Krise 1875. Köln, Weimar und Wien 1994, S. 40 f. Der Autor zitiert Dostoevskij als zeitgenössischen Kommentator. Vgl. auch Thomas Nipperdey: Deutsche Geschichte 1866-1918. Zweiter Band: Machtstaat vor der Demokratie. München 1992, S. 364. Zum Kulturkampf wurden außerdem herangezogen Georg Franz: Kulturkampf. München [1955]; Helmut Walser Smith: German Nationalism and Religious Conflict. Culture, Ideology, Politics, 1870-1914. Princeton, NJ, 1994. 
das Gegenteil ein: Im Klerus und im Kirchenvolk erhob sich ein erbitterter Widerstand. Der Protest gegen die staatlichen Repressionen verlief nicht weniger dramatisch als der Klassenkampf, nahm in den siebziger Jahren sogar heftigere Formen an als dieser. ${ }^{37}$

Die Konstellation äußerer Umstände trug zu einer zusätzlichen Radikalisierung des innerdeutschen Konflikts bei. Der Papst setzte außenpolitisch auf die Wiedererrichtung der Monarchie im geschlagenen Frankreich, von der er sich Unterstützung bei seinen restaurativen Zielen erhoffte. Bismarck nahm die Frage äußerst ernst, da er ein bedrohliches Zusammengehen der äußeren und innerdeutschen ultramontanen Kräfte fürchtete. Die Machtübernahme legitimistischer Kräfte in Frankreich hätte eine antideutsche katholische Koalition zwischen Österreich und Frankreich ermöglicht, die zu einem Krieg gegen das Deutsche Reich hätte führen können. Zugleich diente die ultramontane Koalition aber auch als ein taktisch kalkuliertes Schreckbild, mit dem Bismarck die inneren Gegensätze im Reich zu neutralisieren versuchte.

Es entstand in Deutschland und in den Nachbarstaaten eine nervöse Atmosphäre, in der Befürchtungen und gegenseitige Verdächtigungen die realen Interessenunterschiede überlagerten. Die sich gegenseitig aufschaukelnde Erbitterung der innerpolitischen Fronten war nicht mehr zu steuern. Auf internationaler Ebene wuchs der Unmut über Bismarcks notorische diplomatische Vorstöße, ein europäisches Abwehrbündnis gegen den Ultramontanismus zu schaffen und Frankreich zu isolieren. „Der Reichskanzler wurde zunehmend zum Gefangenen seiner eigenen Projektionen. Seine ultramontanen Sorgen rückten verstärkt in sein politisches Weltbild“, lautet das Urteil eines Historikers. ${ }^{38}$

Für Dostoevskij war die Entwicklung des Vatikans nichts weniger als das zentrale europäische Geschehen, das die Geschicke des Westens entscheiden würde. Bereits 1864 beobachtete er den Niedergang der Papstmacht und prophezeite:

Europa wird Wirren erleben, und viel Kraft wird in Europa auf diese Bewegung zugunsten des Papstes und auf die Abwehr dieser Bewegung gehen. Darauf muß man gefaßt sein. Anderseits wird man sich auch die Kirche erneuern, aber auf künstliche Weise, in zwei Phasen, in den Jesuitismus und den Sozialismus. Sie wird sich unmittelbar mit den Revolutionären und Sozialisten verbünden [...]. ${ }^{39}$

37 Vgl. Helmut Walser Smith: German Nationalism, ebd., S. 42.

38 Joachim Scholtyseck: Alliierter oder Vasall? (wie Anm. 36), S. 62.

39 IV. Zapisnaja tetrad' 1864-1865 gg.; XX, S. 189. 
Der erste Bestandteil dieser Prophezeiung war zu jener Zeit in Italien bereits Realität und sollte sich auch in Deutschland erfüllen. Der zweite Bestandteil, die These vom katholisch-sozialistischen Bündnis, war in der Aussage sehr konkret gemeint und entwickelte sich zu einem dauerhaften Grundelement in Dostoevskijs Überzeugungen. Als solches gehörte sie zu den wichtigsten Analyseinstrumenten bei der Einschätzung neueintretender Umstände. Dostoevskij stellte sich das Zustandekommen des katholisch-sozialistischen Bündnisses durchaus in der Form vor, daß der Papst die christliche Lehre den sozialistischen Theorien anpassen und sich in einer absehbaren Zukunft an die Spitze der sozialistischen Bewegung stellen werde. ${ }^{40}$ So phantastisch diese Voraussage anmutet und sosehr sie auch schon zu seinen Lebzeiten verspottet wurde - im Wissenshorizont seiner Zeit mag Dostoevskijs Fehlurteil auf rezente oder auf tieferliegende Tendenzen der historischen Entwicklung hingewiesen haben. Daß sie sich nicht durchsetzen bzw. nicht an die Oberfläche gelangten, bedeutete für einen Kommentator seines Schlages nicht, daß es sie nicht gab.

Im übrigen erscheint Dostoevskijs Vision weniger absurd, wenn man die vorangegangene Entwicklung der katholischen Kirche im 19. Jahrhundert genauer betrachtet. Problematisch für den konservativen europäischen Konsens war bereits in den dreißiger Jahren das Verhalten der katholischen Kirche gegenüber der spanischen Krone gewesen. Gegen spanischen Protest hatte sie die Staatsproklamationen der vom Mutterland abgefallenen lateinamerikanischen Provinzen anerkannt. Aus russischer Sicht ist des weiteren die Tatsache zu berücksichtigen, daß im politischen Aufstand von 1863/64 die katholische Kirche eine aktive Rolle spielte. Hier hatte Dostoevskij, der die Vorgänge vom nationalrussischen Standpunkt aus interpretierte, ein konkretes Beispiel vor Augen, wie der Klerus mit bewaffneten Aufrührern gegen die russische Fremdherrschaft kooperierte. Die Geschichte der katholischen Kriche war in Europa eng mit der 1848er Revolution verknüpft gewesen. Die Kirche hatte deren Freiheitsforderungen (Presse-, Vereins- und Versammlungsfreiheit) aufgegriffen und sich zunutze zu machen gewußt. Sie hatte früh die Bedeutung der sozialen Frage erkannt und noch vor den sozialistischen Kräften organisatorisch im vierten Stand Fuß gefaßt. Während Pius IX. in seiner langen Regierungszeit einen starr rückwärtsgewandten Kurs beibehielt, der auf die Restauration des Kirchenstaates und die Zurückdrängung der säkularistischen Tendenzen abzielte, hatte sich an der Kirchenbasis und auch in einigen Zentren auf Bischofs-

40 Auf einer theoretischen Ebene hat Dostoevskij die Verwandtschaft der katholischen Lehre, wie er sie interpretierte, und der sozialistischen im Großinquisitor vorgeführt. 
ebene die Erkenntnis durchgesetzt, daß die Kirche sich den neuen Aufgaben der Industriegesellschaft zu stellen habe und sich um die wachsende Masse der Armen kümmern müsse. Adolf Kolping, der 1846 den ersten Gesellenverein gründete, und der „Arbeiterbischof“ Wilhelm Freiherr von Ketteler (18111877), der sich energisch für soziale Verbesserungen einsetzte und ein umfassendes soziales Reformprogramm forderte, stehen in Deutschland für diese Strömung.

Während des deutschen Kulturkampfs rückten Sozialdemokraten und Kirche aufgrund ihrer objektiven Situationen einander näher, denn beide Kräfte befanden sich gegenüber der Reichsregierung in einer kämpferischen Opposition, die sich infolge der Repressionen radikalisierte. Die Reichsbehörden stellten während des Kulturkampfs im katholischen Rheinland „eine gefährliche Mischung von sozialdemokratischem und religiösem Fanatismus " ${ }^{\text {"41 }}$ fest. Beide Kräfte konnten große Menschenmassen mobilisieren und waren international organisiert. Im Jahr 1873 etwa hob der Reichskanzler in absichtsvoller Verallgemeinerung vereinzelter Fälle „die Verbindung zwischen den sozialistischen und den ultramontanen Bestrebungen“ hervor: „Man hätte meinen sollen, daß das Verfahren der Pariser Kommune, die Proklamation des Atheismus, die Ermordung des Erzbischofs alle Diener der katholischen Kirche mit Vorsicht auch gegen die milden Formen des Sozialismus und mit Abscheu gegen die extreme Richtung desselben erfüllen müßten. Wie sich aber bald zeigte, war das Verlangen der ultramontanen Partei, den modernen Staat durch eine mittelalterliche Theokratie zu ersetzen, so ungestüm, daß sie mit der Partei, welche auf den Trümmern von Staat und Kirche ihre Ideale verwirklichen will, zur gemeinsamen Tätigkeit Fühlung suchte. ${ }^{\text {"42 }}$ Vor allem nach dem Attentat auf Bismarck im Jahr 1874 wurde die katholische Kirche in Deutschland verstärkt verdächtigt, mit revolutionären Kräften im Bündnis zu stehen. ${ }^{43}$

41 Karl Bringmann: Die konfessionell-politische Tagespresse des Niederrheins im 19. Jahrhundert. Ein Beitrag zur Geschichte des Presse und des Kulturkampfes im Rheinland mit Aktenstücken. Bochum 1992 (Reprint der Ausgabe von 1938), S. 110.

42 Erlaß an den damaligen deutschen Botschafter in Wien, Hans Lothar von Schweinitz. In: [Otto von] Bismarck. Die gesammelten Werke. Berlin 1924-1935; hier Bd. 6c: Politische Schriften 1871-1890 (1935), N. 39. Siehe Georg Franz: Kulturkampf (wie Anm. 36), S. 213.

Siehe Christian von Krockow: Bismarck. Stuttgart 1997, S. 291. 


\section{Verlauf und Interpretation des Kulturkamps}

Falsche Prophezeiungen können manchmal, wenn man ihre Aussage weniger wörtlich nimmt und die damit verbundenen zeitlichen Fristen großzügig auslegt, auf etwas Richtiges hinweisen (was freilich immer erst nachträglich erkannt wird). Auch Dostoevskijs seit Ende der sechziger Jahre vorgebrachte Weissagung, der Papst werde die Führung der sozialistischen Bewegung übernehmen, enthält solche Elemente: Ab 1874 begann der Vatikan, aktiver in die untersten Schichten hineinzuwirken. ${ }^{44}$ Nach dem Tod Pius' IX. (1878) wandte sich dessen Nachfolger Leo XIII. der sozialen Frage zu und erließ 1891 die erste Sozialenzyklika. Es handelte sich indes im Gegensatz zu Dostoevskijs Eindruck, der Papst wolle sich an die Spitze der sozialistischen Bewegung setzen, nicht um eine Annäherung an die Sozialisten, sondern umgekehrt um christlich-katholische Gegenentwürfe, ebenso wie Dostoevskijs eigene Lehre der Brüderlichkeit ein christlicher Gegenentwurf zur sozialistischen Idee war.

Die russische Regierung, die die Aktivität der katholischen Kirche in den polnischen Gebieten als eine beständige Gefahr für die innere Sicherheit betrachtete, brachte dem deutschen Kampf gegen den Ultramontanismus prinzipielles Wohlwollen entgegen, allerdings ohne ihn aktiv zu unterstützen. In der russischen Presse stand das Thema im allgemeinen hinter den Ereignissen in Frankreich zurück, wo sich nach der Kapitulation der Prozeß der politischen Neukonstituierung hinzog und ständig neue Nachrichten hervorbrachte. Doch in der konservativen Zeitschrift „Graždanin“ (Der Staatsbürger), deren Redakteur Dostoevskij für kurze Zeit war, fand der deutsche Kulturkampf bald erhöhte Aufmerksamkeit, und Dostoevskij selbst wies 1873, im zweiten Jahr seiner nach acht Jahren wiederaufgenommenen publizistischen Tätigkeit ${ }^{45}$, auf die grundsätzliche Bedeutung dieses Phänomens hin.

Er schilderte Bismarcks Politik gegen ultramontane Strömungen, die ihm als Gegner des Papsttums eigentlich hätte zusagen müssen, mit kritischer Distanz. Dies hat mit den Vorbehalten zu tun, die er in den sechziger Jahren gegenüber Preußen herausgebildet hatte. Der deutsche Staatsmann war zunächst als eine typisch europäische Erscheinung in sein Blickfeld geraten: als exemplarische Politikergestalt der westlichen Staaten, für deren nationales und internationales Leben nach slavophiler Lehre Habgier, Konkurrenz und Aggressivität bestimmend waren. Diese Auffassung von Europa hatte seit dem Krimkrieg

44 Joachim Scholtyseck: Alliierter oder Vasall? (wie Anm. 36), S. 35.

45 In den sechziger Jahren hatte er mit seinem Bruder Michail Dostoevskij die Zeitschriften „Vremja“ (Die Zeit; 1860-1863) und „Ėpocha“ (Die Epoche; 1864) herausgegeben. 
1854/55 in der russischen Öffentlichkeit an Überzeugungskraft erheblich hinzugewonnen und war durch den Krieg um Schleswig-Holstein sowie den „Bruderkrieg“ zwischen Preußen und Österreich 1866 bestätigt worden. In den letzten beiden Konflikten hatte sich Preußen als aggressiver Repräsentant Europas erwiesen: „Preußen trumpft auf, es kennt kein Maß. Es fiebert nach Kriegstaten. Sie marschieren in Formation “46, vermerkte Dostoevskij 1864/65 in seinem Notizbuch. Die Formel „Blut und Eisen“, auch in der russischen Presse stehende Wendung für Bismarcks Politik, evozierte und bestätigte zugleich stets von neuem die slavophile Interpretation Europas als eines aggressiven Kulturraumes.

Hinter den Fronten des politischen Konflikts um die ultramontanen Bestrebung sah Dostoevskij den historischen Kampf zwischen Glauben und Atheismus, zwischen dem „christlichen Prinzip und dem sich ankündigenden Grundgesetz der neuen, künftigen Gesellschaft, die davon träumt, ihren Thron an die Stelle von Gottes Thron zu setzen “47. Bismarcks Rolle in diesem Zusammenhang hatte für ihn noch wenig Kontur gewonnen:

Fürst Bismarck reicht, natürlich ohne sich dessen völlig bewußt zu sein, gleichsam durch sein verächtliches und despotisches Verhältnis zur Kirche [...], seine Hand den neuen Menschen, den Atheisten und Sozialisten. ${ }^{48}$

Das Handeln des Reichskanzlers wird hier auf zwei Ebenen kritisiert: Zum einen erscheint er persönlich als ein roher, wenig weitsichtiger Politiker, der die Folgen seines Handelns nicht absehen kann; zum anderen wird seine Politik prinzipiell abgelehnt, weil sie mit der katholischen Kirche den christlichen Glauben selbst schwäche. Dostoevskijs Kritik war nicht weiter argumentativ untermauert und aus der Sicht eines Gegners des Katholizismus auch nicht schlüssig. Sie paßte eher in die Argumentation katholischer Kräfte, die Bismarck in ähnlicher Weise vorwarfen, er sei schuld an den Erfolgen des Sozialismus in Deutschland, weil er sich mit den Liberalen verbündet und geglaubt habe, sich der Revolution bedienen zu können, bis die Revolution sich seiner bediente. ${ }^{49}$

46 IV. Zapisnaja tetrad' 1864-1865 gg.; XX, S. 190.

47 Artikel aus der Rubrik „Inostrannye sobytija“ (Auslandsereignisse) der Zeitschrift „Graždanin“, 1. Oktober 1873; XXI, S. 192.

48 Ebd. hervorgehoben im Original.

49 So 1878 in der jesuitischen Zeitschrift „Civilta cattolica“. Siehe Otto Weiss: Der deutsche Kulturkampf (1871-1890) in der öffentlichen Meinung Italiens. In: Rudolf Lill, Francesco Traniello (Hg.): Der Kulturkampf in Italien und in den deutschsprachigen Ländern. Berlin 1993, S. 221250; hier S. 243. 
Inzwischen war der Briefwechsel zwischen dem Papst und dem deutschen Kaiser vom August/September 1873 bekannt geworden, in dem der Kaiser den Anspruch des Papstes zurückwies, seiner Autorität unterstünden alle Christen, gleich welcher Konfession. Hier zeigt sich, daß Dostoevskijs Urteil über die Vorgänge im gerade gegründeten Deutschen Reich noch nicht festgelegt war: Ihm imponierte das Schreiben Wilhelms I., aus dem er in seinem Artikel den Hinweis des Verfassers zitiert, daß der evangelische Glaube keinen anderen Vermittler zwischen Mensch und Gott kenne als „unseren Herrn Jesus Christus“. „Der Protestant auf dem Kaiserthron antwortete scharf und bestimmt und mit äußerster Würde ${ }^{\text {"50 }}$, kommentierte Dostoevskij. Nicht ohne Einfluß auf sein Urteil dürfte auch der Mitte Oktober 1873 erfolgende Beitritt des Deutschen Reichs zum Abkommen zwischen Rußland und Österreich-Ungarn gewesen sein. ${ }^{51}$ Jedenfalls wich die distanzierte Analyse bald einer eher fragenden Haltung. Im Januar 1874 äußerste Dostoevskij die Vermutung, daß Bismarck wahrscheinlich einen zweiten Feldzug gegen Frankreich vorbereite. „Ob er damit geschickt handelt oder nicht, ist noch die Frage, aber er hat einen scharfen Blick. " 52 War Bismarck hier immerhin vom nicht ganz bewußt handelnden zum klarsichtigen Staatsmann avanciert, konnte Dostoevskij zwei Jahre später bereits sogar dem von vielen Zeitgenossen erwarteten Angriff des Deutschen Reichs gegen Frankreich positive Seiten abgewinnen. 1876 hatte er sich eine festgefügte, immer konkreter werdende Konzeption der prinzipiellen europäischen Konstellation und ihrer weiteren Entwicklung erarbeitet, von der ausgehend er seine Analysen entwarf. Danach agierte das zeitgenössische Frankreich als katholische Hauptmacht im Einvernehmen mit dem Vatikan und wurde von diesem gedrängt, das protestantische Deutschland zu vernichten, das sich den päpstlichen Plänen in den Weg stellte. Diese Analyse entwarf einen Extremfall, befand sich aber tendenziell durchaus im Einklang mit Teilen der europäischen Öffentlichkeit, die die ultramontanen Verbindungen Frankreichs als eine Bedrohung des Friedens betrachteten. Die Möglichkeit, daß Frankreich einen Krieg gegen Deutschland zur Verteidigung des Vatikan führen würde, gehörte zu den Szenarien, die in diplomatischen Kreisen ernsthaft erörtert wurden..$^{53}$

50 Artikel aus der Rubrik „Inostrannye sobytija“, 15. Oktober 1873; XXI, S. 207.

51 Alexander II. und Franz Joseph I. hatten im selben Jahr in der Schönbrunner Konvention die friedliche Beilegung von Konflikten und eine gemeinsame Haltung bei kriegerischen Auseinandersetzungen vereinbart.

52 „Inostrannye sobytija“, 7. Januar 1874; XXI, S. 246.

53 Siehe Joachim Scholtyseck: Alliierter oder Vasall? (wie Anm. 36), S. 58. 
Da Dostoevskij das Deutsche Reich angesichts solcher Voraussetzungen als Bollwerk gegen die Weltherrschaftspläne der katholischen Kirche und der sozialistischen und kommunistischen Kräfte erschien, ergab sich daraus folgerichtig die Befürwortung eines weiteren Krieges, in dem das katholische Frankreich, das „Schwert des Papstes“, so Dostoevskijs Formel, endgültig zerschlagen werde. Doch noch hatte er gewisse Vorbehalte: Bismarcks politische Klugheit sah er durch einen persönlichen Fehler eingeschränkt, den er zugleich für eine Volkseigenschaft hielt: Der Reichskanzler vertraue „in allzu deutscher Weise“ auf Blut und Eisen - Dostoevskij befürchtete, Bismarck könnte im falschen Moment losschlagen. ${ }^{54}$

Im Kreis der seriösen russischen Publizistik seiner Zeit stand Dostoevskij mit seiner exponierten Einschätzung der katholischen Bedrohung der Welt völlig allein, auch die Slavophilen folgten ihm hier nicht. Man verspottete seine Theorie als phantastische Überschätzung des bedeutungslos gewordenen Papstes. Wenn er auch ein wehrhafter Polemiker war, so hoffte er doch inständig, in Rußland irgendwann Zustimmung von anderen Meinungsführern für seine religiöse Interpretation der aktuellen politischen Ereignisse zu erhalten. ${ }^{55}$ Der einzige Zeitgenosse, der die katholische Kirche ebenfalls als ernstzunehmenden Gegner der Menschheit begriff, schien aber der deutsche Reichskanzler Bismarck zu sein. Es war also ein wenn auch nicht naheliegender, so doch verständlicher Vorgang, daß der dem russischen „Volksbogen“ verpflichtete Dostoevskij, um seine politischen Gegner unter den russischen Publizisten in die Schranken zu weisen, begann, sich auf den deutschen Staatsmann zu berufen: „Fürst Bismarck ist ein zu stolzer $\mathrm{Mann}^{56}$, um so viel Kraft auf einen lächerlichen und machtlosen Feind zu verwenden“, argumentierte er im März 1876.

In die Jahre der publizistischen Tätigkeit Dostoevskijs fiel ein politisches Ereignis, das große internationale Aufregung und diplomatische Betriebsamkeit hervorrief: die Krieg-in-Sicht-Krise - 1875 ausgelöst durch einen Artikel

54 DP März 1876, Kap. 1/IV: Mečty o Evrope (Träume von Europa); XXII, S. 87.

55 So las er begierig Nikolaj Danilevskijs bereits erwähnte Schrift „Rußland und Europa“, die 1869 in der Zeitschrift „Zarja“ (Morgenröte) in Fortsetzungen (Nr. 1-6. 8-10) erschien, sah aber bald enttäuscht ein, daß die religiöse Seite in dessen Überlegungen eine untergeordnete Rolle spielte.

56 DP März 1876, Kap. 1/V: Sila mërtvaja i sily grjadiščie (Tote Kraft und kommende Kräfte); XX, S. 90. Immer wieder wird nach der Übersetzung von E. K. Rahsin diese Stelle mit den Worten zitiert: „Fürst Bismarck ist ein zu großer Mensch, um seine Kräfte an einen lächerlichen und machtlosen Feind zu verschwenden." Hier liegt eine positive Umdeutung des Originals vor: Stolz im Sinn einer hohen Meinung von sich selbst, von „Einbildung“ ist bei Dostoevskij ein Signalwort im Zusammenhang mit deutschen Themen. Er betrachtet diesen als eine unwandelbare Eigenheit des deutschen Nationalcharakters, die als politischer Faktor zu berücksichtigen sei, die er aber keineswegs positiv beurteilte. 
über die französischen Aufrüstungsbemühungen, den Bismarck in die Presse lancierte. Bei der Publikation dieses Artikels hatte Bismarck mehrere Ziele im Auge. Er wollte sowohl die deutschen Sorgen wegen eines möglichen Revanchekriegs zerstreuen als auch das Ausland vor möglichen Schritten Frankreichs warnen und zum dritten Präventivkriegsüberlegungen des deutschen Generalstabs abwehren. Seine Absicht war es, einer befürchteten Eskalation der Lage vorzubauen. Doch der Artikel erzielte eine unerwartete Wirkung: Frankreich faßte ihn als deutsche Kriegsdrohung auf, und England, das sich diese Auffassung zu eigen machte, bemühte sich um eine europaweite Initiative zur Friedensvermittlung, deren Ziel es war, deutsche Hegemonialansprüche zurückzuweisen. Die russische Regierung schloß sich der Initiative an und zog einen erheblichen Prestigegewinn aus ihrer Vermittlungsaktion, während Bismarck eine diplomatische Niederlage erlitt. Die Krise ließ zum ersten Mal die nach der Reichsgründung in Europa entstandene neue Interessenlage schlaglichtartig hervortreten: Deutschen Hegemonialbestrebungen konnte durch die Stärkung der französischen Position entgegengewirkt werden. Damit waren die Grenzen der deutschen Außenpolitik abgesteckt. Bismarck erkannte die Zeichen der Zeit und leitete eine Kurskorrektur ein, wie die weitere Politik des Deutschen Reiches unter seiner Ägide zeigte.

Dostoevskij, bei der Informationsschöpfung auf Pressemeldungen angewiesen, sah keinen Grund, den international entstandenen Eindruck, Bismarck habe Frankreich überfallen wollen, anzuzweifeln. ${ }^{57} \mathrm{Zu}$ perfekt paßte er zu dem Bild des kriegerischen Kanzlers, der mit „Blut und Eisen“ das Reich geeint hatte, und zum slavophilen Bild der raubgierigen europäischen Staaten. Gern glaubte er auch der Selbstdarstellung der russischen Regierung als überlegener Friedensstifterin, einer politischen Legende, die sich in der russischen Öffentlichkeit großer Zustimmung erfreute. Nicht ohne Stolz auf den russischen Erfolg und sichtlicher Schadenfreude stichelte er:

Nun, und die Deutschen, was ist mit ihnen los, wovor hat sich ihre Presse denn so erschreckt? [Gemeint ist deren Schweigen nach der diplomatischen Intervention Rußlands.] Daß Rußland hinter ihrem Rücken steht und ihnen die Hände bindet. Daß sie seinetwegen den geeigneten Moment verpaßten, Frankreich endgültig vom Antlitz der Erde zu tilgen, um sich nicht ewig mit ihm herum-

57 Ein Beispiel für die Haltbarkeit historischer Vorurteile ist die Tatsache, daß der Sachverhalt der Krieg-in-Sicht-Krise auch noch 1981 im Kommentar der russischen Gesamtausgabe der Werke Dostoevskijs einseitig in diesem Sinne dargestellt wird; siehe XXIII, 382, zu S. 62 f. Die Kommentatoren stützen sich auf die Darstellung von A. Z. Manfred: Obrazovanie russko-francuzskogo sojuza (Die Entstehung des russisch-französischen Bündnisses). Moskau 1975, S. 97-100. 
schlagen zu müssen. ,Rußland stört, Rußland muß man die Grenzen zeigen, aber wie macht man das bloß, wenn auf der anderen Seite das noch gänzlich unversehrte Frankreich steht? ${ }^{\text {58 }}$

Die Krieg-in-Sicht-Krise erschien Dostoevskij als eine - nicht ganz durchsichtige, aber auch nicht weiter bedeutsame - Episode. Sie bestärkte ihn in der Auffassung vom kriegerischen Charakter und Expansionswillen der deutschen Politik. Nach seiner Lesart war die russische Regierung dem deutschen Draufgänger in den Arm gefallen. Auch Jahre nach dem Ergebnis blieb ihm verborgen, daß hier eine entscheidende Umorientierung in der deutschen Außenpolitik stattgefunden hatte. ${ }^{59}$ Begünstigt wurde sein Irrtum wohl dadurch, daß die Erkenntnisse, die Bismarck aus seiner Niederlage zog, sich nicht in einer Kehrtwende, sondern in einer vorsichtigen, allmählich vorgenommenen, vorerst kaum merklichen politischen Korrektur niederschlugen. Zudem ergaben sich aus russischer Sicht keine bleibenden Belastungen für das deutsch-russische Verhältnis, da die Angelegenheit relativ schnell zur Zufriedenheit der russischen Regierung geregelt war.

Auch in der Frage, die für Dostoevskijs Verhältnis zu Deutschland die zentrale war und in der sich mit Bismarck prinzipiell einig wähnte, leitete die Krieg-in-Sicht-Krise eine politische Wende ein, nämlich in der Frage des Kulturkampfs. In den Jahren nach 1872/73 hatten sich in Deutschland die ultramontanen Befürchtungen zu einer "fast pathologischen Angst“ gesteigert. ${ }^{60}$ Auch für Bismarck gilt, daß seine Angst vor einer katholischen Einkreisung die Gefahr hatte bedrohlicher erscheinen lassen, als sie in Wirklichkeit war. Das ultramontane Bündnis war nicht zustande gekommen, um so mehr aber hatten sein unerbittliches Durchgreifen gegen den Klerus sowie seine nervösen außenpolitischen Versuche, eine vermeintliche katholische Verschwörung zu konterkarieren, das Befremden der europäischen Mächte erregt.

Mit der Entschärfung der Krieg-in-Sicht-Krise und der Abschwächung des Kulturkampfes gelang es Bismarck allmählich, die Akzeptanz des Deutschen Reiches in Europa zu erhöhen und Vertrauen in die Verläßlichkeit seines Friedenswillens zu wecken. Der innerpolitische Rückzug von den Kulturkampf-

58 DP Juli und August 1876, Kap. 1/IV: Samoe poslednee slovo civilizacii (Das allerletzte Wort der Zivilisation); XXIII, S. $62 \mathrm{f}$.

59 DP Januar 1877, Kap. 1/I: Tri idei (Drei Ideen); XXV, S. 8 f.

60 So das Urteil von John C. G. Röhl: Glanz und Ohnmacht des deutschendiplomatischen Dienstes 1871-1945. In: Klaus Schwabe (Hg.): Das Diplomatische Korps 1971-1945. Boppard am Rhein 1985, S. 201-217; die Einschätzung wird bestätigt von Joachim Scholtyseck: Alliierter oder Vasall? (wie Anm. 36), S. 39. 
positionen verlief allerdings langsamer als die außenpolitische Konsolidierung. Viele Bestimmungen hatten Gesetzeskraft erlangt und waren nicht kurzfristig zurückzunehmen. Die Konfliktfronten zwischen den Gegnern im Deutschen Reich hatten sich verselbständigt und wurden von den Konfessionsgegensätzen überlagert und zementiert.

Dostoevskij hatte keine rechte Vorstellung von der politischen Belastung, die der Kirchenkampf für den neuen Staat bedeutete. Daß die harsche Behandlung des Klerus auf der katholischen Seite tiefe Vorbehalte gegen die neue Regierung säte, daß die notorische Verdächtigung, die katholischen Kräfte würden dem Erbfeind Frankreich in die Hände spielen, auf der anderen, der protestantischen und liberalen Seite, eine fanatische Erbitterung hervorrief, führte bei Dostoevskij nicht zur Einsicht, daß diese Politik tendenziell den Bestand des Reiches gefährden könnte, obwohl aus seinen Schriften zu ersehen ist, daß er solche Überlegungen in der russischen Presse sehr wohl zur Kenntnis genommen hat.

Innere Konflikte dieser Art waren für ihn Phänomene zufälliger, vorübergehender Natur, die durch den Sog der ideellen Geschichtskräfte von allein verschwinden würden. Der äußere Aspekt des Kulturkampfes blieb für ihn der entscheidende, wie er überhaupt dazu neigte, innere Widersprüche gegenüber jener machtpolitischen Manifestation zu vernachlässigen, die ihm als Ausdruck der „Idee“ einer Nation galt. Die innerdeutsche Unruhe hielt er für eine Folge päpstlicher Intrigen, denen Bismarck mit aller Härte entgegentreten müsse. Bismarcks Kulturkampfpolitik betrachtete er als genial und glaubte, daß sie die innere Einheit des Reichs gewährleiste, hielt also an einer Position fest, die Bismarck selbst eingenommen, spätestens 1875 aber als falsch erkannt hatte.

Während Bismarck seine Lehren aus der Entwicklung zog und den geordneten Rückzug einleitete, blieb demnach Dostoevskij bei seiner Sicht der Dinge und ignorierte die Anzeichen der Abschwächung des deutschen Kampfes gegen den Ultramontanismus. Bismarck interessierte ihn weiter ausschließlich als derjenige, der der „katholischen Verschwörung“ Einhalt gebieten konnte, und in dieser Rolle gleichsam als Arm der Vorsehung, als Motor der ideellen historischen Kräfte. Dieser Irrtum führte nachfolgend zu schwerwiegenden Fehleinschätzungen bei der Interpretation des Geschichtsverlaufs.

\section{Gesteigerte Nervosität in der Orientkrise}

„Wir" und die anderen

Kaum war die Krieg-in-Sicht-Krise von 1875 beigelegt, als im Sommer desselben Jahres in der Herzegowina ein Aufstand gegen die Türkenherrschaft 
eine Kette von Unruhen auf dem Balkan auslöste, die nun als „Orientkrise“ den europäischen Frieden in Frage stellte. Involviert waren die Interessen Rußlands, das die Vorherrschaft über die slawischen Länder zu gewinnen suchte, und Österreich-Ungarns, das, unterstützt von Deutschland, Herzegowina und Bosnien beanspruchte, sowie Englands, das wegen seines Anspruchs auf die Kontrolle der Meerengen das Vordringen des russischen Einflusses auf dem Balkan fest im Auge behielt. Trotz der Spannungen kam es zunächst zu einer gemeinsam mit Rußland abgestimmten Initiative Österreichs, die der Türkei eine Beruhigung der Lage durch Reformschritte in den aufständischen Gebieten nahelegte. ${ }^{61}$ Doch im Sommer 1876 spitzte sich die Situation zu, als Serbien zusammen mit Montenegro einen Krieg die Türkei begann. Zwar war die russische Regierung gegen einen solchen Schritt, aber in der russischen Öffentlichkeit löste die Aktion eine Begeisterungswelle aus. Freiwillige strömten aus Rußland nach Serbien, um ihren orthodoxen Brüdern beizustehen.

Ein möglicher Krieg mit der Türkei, gerechtfertigt durch die Hilfe für die unterdrückten Balkanchristen, enthielt die Perspektive, an der Spitze der Slawenbewegung den russischen Machtbereich schlagartig entscheidend zu vergrößern. Die Fragen im Spannungsfeld zwischen slawischer und religiöser Idee einerseits und der Aussicht auf Machtentfaltung anderseits wurden nun zu den aktuellsten Themen der russischen Politik. Aufgewühlt von den neuen Perspektiven, gab sich die russische Presse einer lebhaften Diskussion über die künftige Verwendung von Konstantinopel hin, wenn man es denn erobert hätte. Aufschlußreich ist diese Debatte über die einstige Hauptstadt des byzantischen Reiches, an der sich nicht nur Slavophile, sondern auch Liberale und Westler beteiligten, vor allem für die damalige mentale Verfassung der russischen Gesellschaft, jene „bis zur Siedehitze erregte öffentliche Meinung “" ${ }^{\text {, }}$, die berücksichtigt werden muß, will man Dostoevskijs politische Entwürfe im historischen Zusammenhang beurteilen.

Mit der Aussicht auf einen kolossalen Machtzuwachs verbanden sich Hoffnungen verschiedener Art, je nach politisch-weltanschaulicher Richtung natio-

61 Ausführlich behandelt wird die internationale Lage während der Orientkrise und des RussischTürkischen Kriegs bei Heinz Wolter: Bismarcks Außenpolitik 1871-1881. Außenpolitische Grundlinien von der Reichsgründung bis zum Dreikaiserbündnis. Berlin (Ost) 1983, S. 197 f.; eine überblicksartige Darstellung findet sich bei Ernst Engelberg: Bismarck. Das Reich in der Mitte Europas. Berlin 1990; siehe außerdem Gottfried Schramm (Hg.): Handbuch der Geschichte Rußlands. Bd. 3 (1856-1845: Von den autokratischen Reformen zum Sowjetstaat). 1. Halbband. Stuttgart 1983; Günther Stökl: Russische Geschichte. Von den Anfängen bis zur Gegenwart. 3., erw. Aufl. Stuttgart 1990.

62 Günther Stökl: Russische Geschichte (wie Anm. 61), S. 519. 
nalistischer, panslavistischer oder orthodox-religiöser Färbung. Dostoevskij, von der panslawischen Hochstimmung ergriffen, hielt die Ereignisse für Vorzeichen einer unmittelbar bevorstehenden historischen Wende zu einer neuen Ära. Seit dem Beginn der Balkankrise 1875 stellten sich für ihn wichtige Fragen der europäischen und russischen Politik anders und schärfer als zuvor. Ein Vorschlag Nikolaj Danilevskijs, Konstantinopel zur freien Hauptstadt eines slawisch-orthodoxen Bundes zu machen ${ }^{63}$, war ihm zu föderalistisch und $\mathrm{zu}$ wenig an der religiösen Bestimmung des alten Byzanz orientiert: Er bevorzugte ein internationales Zentrum der rechtgläubigen Christenheit, dessen Sicherheit uneingeschränkt von der führenden orthodoxen Macht, dem Russischen Reich, zu garantieren sei; Rußlands Stärke müsse in dieser Frage ausgespielt werden, um nicht die Einheit der orthodoxen Christenheit im Gezänk der kleinen Staaten untergehen zu lassen. Macht und Sendungsauftrag waren für Dostoevskij untrennbar verbunden.

In der russischen Balkanpolitik glaubte Dostoevskij die Ideen, die hierbei wirksam waren, bereits realisiert zu sehen: die christliche Brüderlichkeit oder in diesem Fall Mütterlichkeit („Alma mater" nannte er Rußland im Verhältnis zu den anderen Slawen in seinem Notizheft), der selbstlose Dienst an der Menschheit. Gegenüber Anzeichen, die seiner Theorie widersprachen, blieb er unbeirrbar. Die massive Angst der Slawen vor Rußlands „mütterlicher“ Politik interpretierte er als „Kaprizen“. Die europäischen Staaten, so Dostoevskij, seien ohnehin verblendet, weil sie, von ihren eigenen gewaltsamen politischen Maximen und Methoden ausgehend, diese auch dem östlichen Nachbarn unterstellten. Er war sich aber sicher, daß das Beispiel der christlichen russischen Politik dereinst auch die Westeuropäer überzeugen werde, allerdings erst, wenn eine blutige Katastrophe sie belehrt hätte, daß sie Rußland immer falsch verstanden hatten. Das Dilemma, daß der Sendungsauftrag russischer Politik von den Beglückten als Machtanmaßung aufgefaßt werden würde, müsse sich mit der Zeit von selbst lösen, da es auf einem Irrtum der Missionierten beruhe.

Militärische Stärke und politische Macht erschienen Dostoevskij unverzichtbar, verliehen sie doch der christlichen Mission die nötige Durchsetzungskraft und Autorität. Rußland konnte gar nicht mächtig genug sein, und da es in der Geschichte sein friedliches Wesen und seinen Wunsch, der Menschheit zu die-

63 Nikolaj Danilevskij: Vojna za Bolgariju (Artikelreihe in „Russkij mir“, 1877). Darin: Konstantinopol' (Konstantinopel; „Russkij mir“, 1877, 11. und 12. November, Nr. 308 und 309). Abgedruckt in: N. Danilevskij: Gore pobediteljam. Političeskie statí (Weh den Siegern [Der Titel bezieht sich auf den Berliner Kongreß]. Politische Aufsätze). Moskau 1998, S. 111 ff. Siehe auch Hans Kohn: Die Slawen und der Westen (wie Anm. 5), S. 184 f. 
nen, bewiesen hatte, war jede Angst vor seiner Macht unbegründet. Die langsame, aber stetige, weitgehend unblutige Errichtung eines riesigen Reiches und die Begründung einer scheinbar beispiellosen politischen Stabilität war eine historische Leistung, die den Errungenschaften der westeuropäischen Völker mindestens gleichwertig gegenüberstand:

Also jedem das Seine, und wer hier wen beneiden muß, ist noch nicht heraus. Wir werden die Wissenschaft in jedem Fall erwerben, was aber aus der politischen Entwicklung Europas wird, ist noch nicht heraus. Vielleicht wären die Deutschen noch vor fünfzehn Jahren einverstanden gewesen, die Hälfte ihres wissenschaftlichen Ruhms gegen eine so kraftvolle politische Einheit einzutauschen, wie wir sie schon seit langem haben. Heute haben die Deutschen auch eine starke politische Einheit erzielt, wenigstens nach ihren Begriffen, aber damals hatten sie das Deutsche Reich noch nicht, und natürlich haben sie uns heimlich beneidet, trotz all ihrer Verachtung für uns. ${ }^{64}$

Im Juli/August-Heft 1876 des Tagebuchs eines Schriftstellers wandte sich Dostoevskij der Frage zu, wie die Aufstände der Balkanvölker gegen die türkische Fremdherrschaft im Westen aufgenommen wurden. Daß man in Westeuropa der wachsenden russischen Einflußnahme auf dem Balkan mit Mißtrauen und Furcht begegnete, führte in einer Gegenreaktion der russischen Öffentlichkeit zu einer vertieften Entfremdung. Echte und propagandistische Entrüstung verschafften sich Gehör: Europa zeigte den christlichen Glaubensbrüdern auf dem Balkan, die unter der islamischen Gewaltherrschaft litten, die kalte Schulter und unterstütze um des eigenen Vorteils willen die „wilde und abstoßende muselmanische Horde, den unversöhnlichen Feind der Zivilisation“ (XXIII, 62) - für Dostoevskij ein erneuter Beweis der grundsätzlichen Fehlentwicklung des Westens, die mit dem Verrat der katholischen Kirche am Christentum eingetreten sei:

18 Jahrhunderte Christentum, Humanisierung, Wissenschaft, Bildung erweisen sich plötzlich als Humbug [...]. [...] Wo ist die erarbeitete, unter Qualen erworbene Wahrheit, wo die Menschenliebe? Ist das etwa schon die Wahrheit? ${ }^{65}$

Es gab auch in Europa namhafte Staatsmänner, die die russische Befreiung der meist orthodoxen Balkanchristen vom türkischen Joch aus grundsätzlichen Erwägungen begrüßten. Dazu gehörten Liberale wie Gladstone und Christlich-

64 DP April 1876, Kap. 1/III: Sbivčivost' i netočnost' spornych punktov (Ungereimtheit und Ungenauigkeit strittiger Fragen); XXII, S. 111.

65 DP Juli und August 1876, Kap. 1/IV: Samoe poslednee slovo civilizacii (wie Anm. 58); XXIII, S. 61. 
Konservative wie Carlyle ${ }^{66}$, Feldmarschall Edwin von Manteuffel oder Kaiser Wilhelm I. Der deutsche Botschafter in Moskau, General von Schweinitz ${ }^{67}$, der das Vertrauen Wilhelms I. genoß, glaubte, daß Rußland im Sinne des europäischen und christlichen Selbstverständnisses handle und die Unterstützung Europas verdiene, wenn es auf dem Balkan Ordnung schaffe. ${ }^{68}$ Westliche Hilfsinitiativen gab es auf privater oder gesellschaftlicher Ebene, Protestbroschüren gegen die türkischen Repressionen wurden herausgegeben.

Aber Dostoevskij, orientiert an großen Zeiträumen und politischen Machtfragen, wollte den Hinweis auf diese Einzelheiten nicht als Gegenargument gelten lassen. Auf die Politik eines Landes kam es an, die als Ausdruck der nationalen "Idee“ anzusehen sei. Sie dürfe nicht egoistischen Staatsinteressen dienen, sondern müsse eine christliche Richtung verfolgen. Dies kam in der gegebenen Konstellation des Balkankonflikts der Erwartung an die europäischen Länder nahe, Rußland als stärkstes christliches Land beim Ausbau seiner Macht zu unterstützen.

\section{Sondierung von Freund und Feind}

Dostoevskijs Position stand im Einklang mit einer Tendenz der russischen Politik des 19. Jahrhunderts, die Bismarck aus seiner Sicht als „Prinzipienpolitik" kritisierte. Der russische Kanzler Gorčakov ${ }^{69}$ begründete den Anspruch der russischen Balkanpolitik auf europäische Unterstützung damit, daß Rußland sich in einer Frage engagierte, die ganz Europa betreffe, womit er, wie gesehen, in Teilen der europäischen Öffentlichkeit durchaus auf Beifall rechnen konnte. Bismarck wies solche überstaatlichen Ziele in der Politik als Phantasterei oder als Heuchelei zurück: „Ich habe das Wort Europa immer im Munde derjenigen Politiker gefunden, die von andern Mächten etwas verlangten, was sie im eigenen Namen nicht zu fordern wagten“, kommentierte er Gorčakovs Ansinnen. ${ }^{70}$ Wie einst Nikolaus I. im Krimkrieg vergeblich Österreichs Dankbarkeit für die Niederschlagung des ungarischen Aufstands ein-

66 William Ewart Gladstone (1809-1898), liberaler britischer Politiker, unterstützte die Balkanvölker in ihren nationalen Bestrebungen unter völkerrechtlichem Aspekt; Thomas Carlyle (1795-1881), englischer Historiker und Publizist, Vermittler deutscher Literatur in England.

67 Hans Lothar von Schweinitz (1822-1901), preußischer General und Diplomat, deutscher Botschafter in Wien 1871-1876 und in St. Petersburg 1876-1892.

68 Erich Eyck: Bismarck. Leben und Werk. 3 Bde. Zürich 1941-1944; hier Bd. 3 (1944), S. 242 f.

69 Aleksandr Michajlovič Gorčakov (1798-1883 in Baden-Baden), ab 1856 Außenminister, ab 1866 Kanzler des Russischen Reichs, 1878 Erster Bevollmächtigter auf dem Berliner Kongreß.

70 Zitiert nach Erich Eyck: Bismarck (wie Anm. 68), Bd. 3, S. 244. 
gefordert hatte, um den Partner der Heiligen Allianz dann als verräterisch und wortbrüchig zu bezeichnen, so verstärkte die russische Regierung im Zuge der Krisenentwicklung auf dem Balkan den Druck auf Deutschland, die Dankesschuld aus dem Deutsch-Französischen Krieg zu begleichen und sich eindeutig auf ihre Seite zu stellen. Das war vor allem die Meinung des Zaren persönlich. 1870 hatte Alexander II. in Wien, wo man nach dem „Bruderkrieg“ von 1866 zu Preußen gespannte Beziehungen unterhielt, erklären lassen, daß er seinem Onkel Wilhelm mit einer Armee von 300000 Mann beistehen werde, falls Österreich vorhabe, gegen Preußen zu mobilisieren. Wilhelm I. hatte nach dem Sieg ein Telegramm an den Zaren geschickt, in dem es hieß: „Niemals wird Preußen vergessen, daß es Ihnen zu verdanken ist, wenn der Krieg nicht außerordentliche Dimensionen angenommen und die anderen Länder ergriffen hat. "71 Bismarck hatte im Gegenzug die Erklärung der russischen Regierung von 1870 unterstützt, daß sie sich an die Pontus-Klausel des Vertrags, der 1856 auf dem Pariser Kongreß geschlossen wurde, nicht mehr gebunden fühle, eine Klausel, die Rußland die Unterhaltung einer Kriegsflotte im Schwarzen Meer untersagte.

Doch diese Gefälligkeit genügte der russischen Regierung nicht. Sie brauchte in der Orientkrise Sicherheit über die deutsche Haltung im Dreikaiserbündnis, das durch die Rivalität zwischen Österreich-Ungarn und Rußland auf dem Balkan belastet war. Österreich-Ungarn befürchtete einen russischen Angriff und hoffte, Deutschland von der Unterstützung eines solchen Angriffs abhalten zu können. Rußland wiederum fürchtete ein deutsch-österreichisches $\mathrm{Zu}$ sammengehen. Diese konfliktträchtige Konstellation wurde von Bismarck in gewissem Maße als vorteilhaft angesehen, da sie ihn vor einer ausschließlichen Bindung Deutschlands an das mächtige Russische Reich bewahrte, ohne den wichtigen außenpolitischen Partner ganz brüskieren zu müssen. Er ermutigte Österreich, sich Bosnien und Herzegowina als Einflußgebiete zu sichern, denn er bevorzugte ein Szenario, in dem die Verbündeten mit begrenzten Konflikten beschäftigt waren, so daß die deutsche Politik den Spielraum erhielt, den sie brauchte. ${ }^{72}$

Es ist also nicht verwunderlich, daß gerade im Jahr 1876, in dem die Balkankrise einen Krieg immer wahrscheinlicher werden ließ und Deutschland in die Bündnispflicht genommen werden sollte, Dostoevskij begann, sich in seinem „Tagebuch eines Schriftstellers“ intensiver als zuvor der deutschen Nation

71 Siehe Ebd., Bd. 2, S. 494.

72 Ernst Engelberg: Bismarck (wie Anm. 61), S. 225. 
und ihrem Staat zuzuwenden. Was Rußland betrifft, hatte er vom Sollzustand, das heißt von den erstrebten nationalen Idealen der Russen, ein ebenso deutlich umrissenes Bild wie vom Istzustand. Auch deutsche Lebensverhältnisse waren ihm nicht unbekannt. Er hatte sie während seiner zahlreichen Reisen und langen Aufenthalte studiert und festgestellt, daß das Alltagsverhalten der Deutschen sich durch eine gewisse umständliche Beflissenheit auszeichnete, die in seinen Augen ans Absurde grenzte. ${ }^{73}$ Ihr Auftreten erschien ihm häufig arrogant. Stolz bezeichnete er als die hervorstehende deutsche Nationaleigenschaft, die auch Bismarcks Handeln charakterisierte und in der Außenpolitik des Deutschen Reichs als eine feste Größe zu betrachten sei. Aber mit Hinblick auf seine Maxime „Der Maßstab für ein Volk ist nicht, wie es ist, sondern [...] wonach es strebt ${ }^{\text {"74 }}$ genügten ihm diese Erkenntnisse nicht.

Für seine „Prophezeiungen“ (so nannte er seine visionären Prognosen manchmal selbst) bediente sich Dostoevskij der Kategorie der „nationalen Idee“, die ihm die Richtung zeigte, in der er den Sinn der politischen Schritte eines Staates zu suchen hatte. Wie die Russen ihre Idee der Brüderlichkeit in Jahrhunderten der Einübung und Tradierung erarbeitet und konserviert hatten, so mußten auch die Deutschen als Nation etwas in ihrer Geschichte entwickelt und bewahrt haben. Aber welches war ihre höhere Idee, der das so plötzlich entstandene neue Deutsche Reich gehorchen mußte? Es schien, als hätten die Deutschen noch nicht wirklich gezeigt, wer sie eigentlich sind, als stünde diese Offenbarung noch bevor. 1876 notierte er bei seinen Vorarbeiten für das Tagebuch eines Schriftstellers ungehalten:

Im Deutschen Reich gibt es ebensowenig eine Idee wie in Frankreich. In Frankreich gibt es wenigstens die kommunistischen, in Deutschland nur: Es lebe der deutsche Stolz. ${ }^{75}$

Im spannungsgeladenen Jahr 1876 sondierten alle Seiten die Optionen für einen Krieg auf dem Balkan, wobei zunächst unklar blieb, wer gegen wen kämpfen würde. In russischen Zeitungen wurde im Zusammenhang mit der Balkankrise die Möglichkeit eines Krieges gegen Deutschland erörtert, wenn es die österreichischen Interessen unterstützte. Bismarck sorgte sich eine Zeitlang, Rußland

73 Siehe z. B. DP Juli und August 1876, Kap. 2/III: Nemcy i trud. Nepostižimye fokusy. Ob ostroumii (Die Deutschen und die Arbeit. Unbegreifliche Zaubertricks. Über die Geistesschärfe); XXIII, S. $76 \mathrm{f}$.

74 Zapisi k „Dnevniku pisatelja“ 1876 g. Iz rabočich tetradej 1875-1877 gg. (Notizen zum „Tagebuch eines Schriftstellers“) 1876. Aus den Arbeitsheften 1875-1877); XXIV, S. 147.

75 Ebd., S. 76. 
könnte sich gegen den gemeinsamen Verbündeten Österreich wenden, was die deutsche Politik in eine prekäre Lage gebracht hätte. In den deutschen Presseorganen, die die Regierungspolitik üblicherweise unterstützten, erschienen antirussische Artikel, in denen gewarnt wurde, daß ein Vormarsch Rußlands auf dem Balkan nicht auf slawischem Gebiet anhalten, sondern sich nach Europa fortsetzen werde. ${ }^{76}$

Solche Signale wertete Dostoevskij als taktische Manöver, die von einer ihm undurchsichtig bleibenden Ambivalenz der deutschen Politik zeugten. Sie entmutigten ihn aber nicht, nach deutlichen Hinweisen Ausschau zu halten, wie sich das Land in Zukunft bündnispolitisch orientieren werde. Wie die russische Regierung erwartete er von Deutschland eine gradlinige Politik der Dankbarkeit für 1870/71. ${ }^{77}$ Zunächst konnte er aber nur festhalten:

[...] daß dieser ganze wütende Chor [der deutschen Presse] um so erstaunlicher ist, als er sich, wie absichtlich, eben jetzt nach den freundschaftlichen Konferenzen und Treffen der drei Kaiser ${ }^{78}$ erhoben hat, und daß dies zumindest seltsam ist.

Als es 1876 kurzfristig zu einer Steigerung der Spannungen zwischen beiden Ländern kam, war er ratlos, wie diese Tatsache zu interpretieren sei. Solange sich die „nationale Idee“ Deutschlands für ihn noch nicht offenbart hatte, die für seine Methode der politischen Prognose unabdingbar war, konnte er nicht mehr als andere Kommentatoren leisten, die versuchten, die Lage aus den aktuellen Interessen der einzelnen Länder heraus zu deuten. Er umkreiste die Frage vorsichtig abwägend unter Heranziehung von Pressemeinungen, ohne zu einem abschließenden Urteil zu kommen. In seinem Notizheft vermerkte er:

Die Moskovskie vedomosti [Moskauer Nachrichten] [...] sagen, solange Rußland und Preußen befreundet und mit ihrer Angelegenheit beschäftigt seien, werde es keinen Zusammenstoß geben. Aber schon allein die Fragestellung weist doch nur auf das ,solange' hin und leugnet folglich nicht eine Verschlechterung mit der Zeit. Die Frage ist nur: Wann wird diese Zeit kommen

76 Vgl. hierzu den Kommentar XXIII, S. 382.

77 DP Juli und August 1876, Kap. 1/II. O voinstvennosti nemcev (Über den kriegerischen Geist der Deutschen); XXIII, S. 60 f.

78 Gemeint ist der Besuch Alexanders II. in Berlin im Mai 1875 und das Treffen des Zaren mit Franz-Joseph in Reichstadt Anfang Juli 1876, auf dem eine vorläufige Aussprache über die territoriale Aufteilung der europäischen Türkei getroffen wurde. 
Ergänzend fügte er hinzu:

Diese Angst Deutschlands vor der Rache Frankreichs ist vorläufig die Garantie für unseren Frieden (das heißt, mit Deutschland) ${ }^{79}$

Die Position der deutschen Regierung gegenüber Rußland war tatsächlich nicht so eindeutig, daß hier keine Fragen offen blieben. Bismarck, geleitet von seinem „cauchemar des coalitions "80, akzentuierte bei Ausbruch der Balkankrise im Konflikt zwischen Rußland und Österreich-Ungarn die Unterstützung der schwächeren österreichischen Position. ${ }^{81}$ Nicht nur Dostoevskij kam diese Politik zweifelhaft vor. Die russische Regierung nannte die deutsche Sympathie für Rußland „allzu platonisch" ${ }^{\text {“2 }}$ und verlor die Geduld. Noch in seinen Erinnerungen empörte sich Bismarck über das formlose Verfahren, mit dem Kaiser Alexander II., bewogen von Staatskanzler Gorčakov, ihn 1876 ultimativ zu einer Erklärung nötigte, ob Deutschland im Falle eines russisch-österreichischen Krieges neutral bleiben werde. Den Preis, den das Deutsche Reich für seine Bündnistreue verlangte, die Anerkennung der Annexion Elsaß-Lothringens, wollte die russische Regierung allerdings nicht zahlen. So ließ sich Bismarck auch jetzt nicht festlegen. Wertvoller als ein Gebietsgewinn, der bei der Zerschlagung Österreichs für das Deutsche Reich entstanden wäre, war für Bismarck die Erhaltung des Bündnispartners Österreich als Gegenkraft gegen russische Anmaßung oder russisch-französische Zangenbewegungen.

Dostoevskij seinerseits begriff die deutsche Politik des Gleichgewichts der Kräfte nicht. In den für ihn undurchschaubaren Balanceakten Bismarcks vermißte er weiterhin die klar erkennbare nationale Leitidee der Deutschen, ohne deren Erkenntnis ihm sein wichtigstes Analyseinstrument fehlte. So glaubte er, die Neigung des Deutschen Reiches während des Balkonkonflikts, Österreich zu unterstützen, sei von Habgier und Raubgelüsten motiviert und ÖsterreichUngarns Interessenschwerpunkt solle von den Kernländern weg nach Osten verlagert werden, damit Deutschland dessen deutsche Gebiete eines Tages

79 Hervorhebung des Autors. Zapiski k „Dnevniku pisatelja“ 1876 g. (wie Anm. 74); XXIV, S. 163.

80 Die von Bismarck selbst zustimmend gebrauchten Formel wurde von dem russischen Diplomaten und Politiker Graf Pëtr Andreevič Šuvalov (1827-1889) geprägt; Šuvalov befürwortete ein enges Bündnis mit Deutschland und bewog 1878 den russischen Kaiser, der Abhaltung eines Friedenskongresses in Berlin zuzustimmen, auf dem er Rußland als zweiter Bevollmächtigter vertrat. Šuvalov war ab 1866 Chef der 3. Abteilung, 1874-1879 Botschafter in London.

81 Heinz Wolter: Bismarcks Außenpolitik (wie Anm. 60), S. 236.

82 Siehe Otto von Bismarck: Gedanken und Erinnerungen. Essen [o. J.]; hier Bd. 2 (25. Kapitel: Der Berliner Kongreß), S. 250 f. 
leichter an sich reißen könne. ${ }^{83}$ Er griff also bei der Deutung der deutschen Politik auf allgemeine Kategorien zurück, mit denen in der slavophilen Theorie der europäische Kulturtypus beschrieben wird.

\section{Nachsicht mit den Deutschen}

Bei der Suche nach Anhaltspunkten für das Verständnis der „deutschen Idee“ stützte sich Dostoevskij, getreu seiner Methode, im Kleinen und Kleinsten nach den Spuren der großen Bewegung der Weltgeschichte zu suchen, auf die eigene Anschauung. Waren die Deutschen in seinen Briefen oder publizistischen Texten bis Mitte der siebziger Jahre als langweilige, unverständliche und unangenehme Zeitgenossen skizziert worden ${ }^{84}$ und hatten sie seine Aufmerksamkeit im Vergleich zu Engländern und Franzosen wenig beansprucht, widmete er ihnen nun im Juli/August-Heft des Tagebuchs eines Schriftstellers 1876 ein ganzes Kapitel unter der Überschrift: „Die Deutschen und die Arbeit. Unbegreifliche Zaubertricks. Über die Geistesschärfe“, in dem er seine bisherige Meinung einer Prüfung unterzog.

Anschauungsmaterial boten ihm seine Kuraufenthalte in Bad Ems. Die dort beobachtete Arbeitshaltung der Bevölkerung im Alltag - das Zusammenwirken der Faktoren Disziplin, Kooperation, erlernte Fertigkeit, Aufmerksamkeit für bestimmte Arbeitsgänge und Hingabe an die Tätigkeit - wird mit Bewunderung anhand verschiedener Beispiele geschildert. Einschränkung findet das positive Urteil allerdings durch das Bewußtsein der sozialen Problematik, sah er doch die Dienstmädchen in Bad Ems von morgens bis nachts auf den Beinen und wußte, wie wenig Lohn sie erhielten. Befremdend schien vor allem die Genügsamkeit, mit der sich die Deutschen freiwillig in ihrem Arbeitsund Lebensausschnitt einrichteten:

Nein, so arbeitet man nicht bei uns; bei uns ließe sich nicht eines der Dienstmädchen auf eine solche Zwangsarbeit ein, nicht für noch so viel Geld, ja und außerdem würde sie es nicht so machen, sondern hundertmal vergessen, verschütten, nicht bringen, zerschlagen, sich irren, böse und grob werden - hier dagegen gab es einen ganzen Monat lang glatt nichts zu beanstanden. Meiner

83 Dostoevskij hatte es bereits 1864/65 für möglich gehalten, daß Preußen eines Tages Österreich zu seinem Protektorat macht, um es sich dann ganz einzuverleiben wie Schleswig-Holstein. Siehe IV. Zapisnaja tetrad'1864-1865 gg. (IV. Notizheft 1864-1865); XX, S. 190.

84 Vgl. etwa die flüchtigen Bemerkungen in Zimnie zametki o letnich vpečatlenijach (wie Anm. 8), V, S. 47; oder den Brief vom 30. Dezember 1870/11. Januar 1871 aus Dresden an Apollon Majkov (XXIX, 1, S. 160). 
Ansicht nach ist das erstaunlich - und ich als Russe weiß nicht recht: soll ich es nun loben oder tadeln? Übrigens, ich riskiere mal etwas und will es loben, obwohl es doch zu denken gibt. Hier akzeptiert jeder seine Lage so, wie sie ist, und fügt sich darein, ohne Neid und Argwohn, jedenfalls in der übergroßen Mehrheit. $^{85}$

Trotz aller Einschränkungen bedeutete diese Passage eine Aufhellung des früheren Bildes. Kennzeichnend für die Urteilsfindung Dostoevskijs ist, daß der geschilderte Eindruck bereits über ein Jahrzehnt früher als Kurznotiz ohne eindeutige Wertung festgehalten wurde. ${ }^{86}$ Viele der im „Tagebuch eines Schriftstellers“ geäußerten Ideen wurden erst nach einer langen Latenzzeit publiziert. Im Kontext der jeweiligen politischen Situation nahmen sie ihre aktuelle Bedeutung an oder wurden einer Umwertung unterzogen. Die vorsichtige neue Sympathie Dostoevskijs für die Deutschen ging über den konkreten Bereich der Arbeitskultur hinaus:

Bei uns, bei den Russen, gibt es eine Menge Witze über die deutsche Begriffsstutzigkeit und Stumpfsinnigkeit, trotz aller aufrichtigen Bewunderung für ihre Gelehrsamkeit. Aber die Deutschen haben, scheint mir, einfach nur eine allzu stark ausgeprägte Eigenart, einen bis zur Überheblichkeit dickköpfigen Nationalcharakter, der einen verblüffen oder auch verärgern kann, wodurch man möglicherweise zu falschen Urteilen über sie kommt. (XXIII, 76)

Hier ist nichts weniger als ein Wendepunkt im Verhältnis zu den Deutschen festzustellen, erkennbar an dem indirekten Bekenntnis, womöglich einem Irrtum erlegen zu sein. Noch deutlicher läßt sich der Prozeß des Umdenkens in einer Erinnerung an die Zeit des Deutsch-Französischen Krieges nachweisen, die Dostoevskij nun, fünf bis sechs Jahre danach, im „Tagebuch eines Schriftstellers“ niederschreibt. In seinem Artikel „Über den kriegerischen Geist der Deutschen“ entsinnt er sich der Truppenformationen, die er während der Mobilmachung auf Dresdner Straßen vorbeimarschieren sah:

[...] welche Frische in den Gesichtern, welcher helle, frohe und zugleich ernste Ausdruck in den Augen! Das waren alles junge Leute, und wenn man eine solche Kompanie vorbeimarschieren sah, konnte man nicht umhin, ihre erstaunliche militärische Haltung, ihren festen Schritt, das genaue, strenge Gleichmaß zu bewundern, zugleich aber auch eine ungewöhnliche Freiheit, wie ich sie an Soldaten noch nie gesehen hatte, eine bewußte Entschlossenheit, die sich in jeder Geste, in jedem Schritt dieser prächtigen Kerle ausdrückte. Man sah, daß sie nicht

85 DP Juli und August 1876, Kap. 1/III: Nemcy i trud (wie Anm. 73); XXIII, S. 70-77; hier S. 74 f.

86 II. Zapisnaja knižka 1863-1864 gg. (II. Notizbuch 1863-1864); XX, S. 171. 
getrieben wurden, sondern von selbst gingen. Nichts Hölzernes, nichts vom Stockkorporal, und das bei den Deutschen, bei eben jenen Deutschen, von denen wir, als wir unter Peter ein Heer anschafften, den Korporal und den Stock übernahmen. Nein, diese Deutschen gingen ohne Stock, wie ein Mann, mit völliger Entschlossenheit und unbedingtem Glauben an den Sieg. Es war eine Volkskrieg: In jedem Soldat leuchtete der Bürger $\left[\ldots . .{ }^{87}\right.$

Ein Vergleich mit seinen Äußerungen aus den Jahren 1870/1871 fördert nichts zutage, was diese Erinnerung aus dem Abstand von sechs bzw. fünf Jahren bestätigen würde. Aus den Dresdner Briefen während des Deutsch-Französischen Krieges spricht im Gegenteil heftige Kritik am abstoßenden deutschen Militarismus und die Hoffnung auf einen französischen Sieg. Die Deutschen plünderten und folterten, heißt es dort, „wie Attilas Horde, wenn nicht schlimmer“; „Mehr List und Tücke kann man sich nicht vorstellen. [...] Wer zum Schwert greift, wird durch das Schwert umkommen. ${ }^{\text {"88 }}$ Mit solchen Beobachtungen und Einschätzungen bediente er seine an Lageberichten interessierten Briefpartner, die selbst Gegner der deutschen Kriegspolitik waren und die allgemeine russische Sympathie für die französische Republik oder Frankreich überhaupt teilten. Noch Ende des Jahres 1870 hoffte er auf die levée en masse in Frankreich, eine Gegenoffensive der von Gambetta ausgerufenen Dritten Republik, in der sich „der Geist der Nation gegen die rohe Gewalt erhebt“ und „die Deutschen vertrieben werden “89. Seine eingehenden Recherchen unter der Dresdner Bevölkerung führten zu der Erkenntnis, daß die deutschen Soldaten an Hunger und Krankheiten litten, daß unter einfachen Leuten der Krieg, nachdem die anfängliche Jubelstimmung verflogen war, nicht sehr populär war und die eigentlichen nationalistischen Fanatiker unter den „Professoren“ $\mathrm{zu}$ finden waren (von denen er einige täglich in der Dresdener „Lese-Bibliothek" traf). „Paris muß bombardiert sein! ${ }^{“ 90}$ zitiert er einen von ihnen und konstatiert: „Das ist nun das Ergebnis ihrer ganzen Wissenschaft.“

Auch im Jahr 1876, mehr als fünf Jahre danach, bei nunmehr offenkundiger Breitschaft zur Sympathie, konnte Dostoevskij nicht ganz leugnen, daß sich die mentale Verfassung der Deutschen nach dem Sieg zum Negativen verändert

87 DP Juli und August 1876, Kap. 1/II: O voinstvennosti nemcev (wie Anm. 77); XXIII, S. 58-61; hier S. 60.

88 Briefe vom 30. Dezember 1870/11. Januar 1871 und vom 26. Januar/7. Februar 1871 an Apollon N. Majkov (XXIX, 1, S. 161 und 176).

89 Brief vom 30. Dezember 1870/11 Januar 1871 aus Dresden an Apollon N. Maijkov (XXIX, 1, S. 161).

90 Im Original deutsch; ebd. S. 160. 
hatte. Er war in einem Zeitraum von fast fünfzehn Jahren immer wieder dort gewesen ${ }^{91}$ und hatte die Entwicklung der Stimmungen im Land gut verfolgen können:

Man kann sich danach vorstellen, wie dieselben Soldaten dann in Dresden eingezogen sind, ein Jahr später, nach den Siegen, die sie endlich über den Franzosen errungen hatten, von dem sie ein ganzes Jahrhundert jegliche Erniedrigungen hatten erleiden müssen. Fügen Sie dem noch die übliche deutsche, ja landesweite Volkseigenschaft der unmäßigen Prahlsucht [...] hinzu, die im Falle eines Erfolges kleinlich bis ins Kindische wird und die beim Deutschen immer in Unverschämtheit umschlägt - ein ziemlicher unschöner nationaler Zug und fast erstaunlich an diesem Volk: Dieses Volk kann sich gar zu vieler Dinge rühmen, mit welcher Nation es sich auch vergleicht, um sich so kleinlich zu gebärden. Es zeigte sich, daß diese Ehre so neu für sie war, daß sie für sie selbst unerwartet kam. $^{92}$

Die Nachsicht, mit der diese Kritik vorgetragen wird, ist bemerkenswert. Thomas Mann nannte Dostoevskijs abwägendes Urteil dieser Jahre über die Deutschen einen Akt der „Selbstbeherrschung“: „[...] denn wir wissen, daß er recht weit entfernt war, Deutschland zu lieben [... “".93 Die Ursachen für den Wandel sind offensichtlich nicht nur durch persönliche Eindrücke oder Erlebnisse zu erklären, sondern verbergen sich in den Prozessen des Umdenkens, zu denen der Szenenwechsel auf der großen politischen Bühne Europas Dostoevskij bewog. Er war dabei, die deutsche Rolle in Europa neu zu konzipieren.

\section{Kriegsstimmung und Heilserwartung}

Trotz ihrer Selbstverpflichtung im Dreikaiserabkommen, eine konservative Friedenspolitik im gegenseitigen Einvernehmen zu verfolgen, erklärte die russische Regierung am 24. April 1877 dem Osmanischen Reich den Krieg und gab damit dem Druck der panslawischen Strömung im Land nach. Viele ideologische Motive aus der Zeit des Krimkriegs wurden wachgerufen: die russische Fürsorge für die Christen unter der türkischen Herrschaft, das Stereotyp vom „verräterischen Österreich“, die moralische Überlegenheit der russischen

91 Dostoevskij reiste seit 1862 in den Westen; von August 1869 bis Juli 1871 lebte er in Dresden. Die Erlebnisse und Erkenntnisse seiner Deutschlandaufenthalte sind dokumentiert und kommentiert bei Karla Hielscher: Dostojewski in Deutschland. Frankfurt a. M. und Leipzig 1999.

92 DP Juli und August 1876, Kap. 1/II: O voinstvennosti nemcev (wie Anm. 76); XXIII, S. 60.

93 Thomas Mann. Betrachtung eines Unpolitischen. In: Th. Mann: Gesammelte Werke in 12 Bänden. Frankfurt a. M. 1960; hier Bd. 12, S. 49. 
Regierungspolitik über die der egoistischen europäischen Mächte. Der orthodoxe Sendungsgedanke, der 1853/54 Nikolaus I. glauben ließ, einen Kreuzzug zu führen, verband sich in den Vorstellungen Alexanders II. mit der panslawischen Idee.

Die Aussicht auf die plötzliche riesige Ausweitung des russischen Einflußbereichs durch die Verdrängung der Türkei vom Balkan führte zu einer momentanen Überschätzung der eigenen Möglichkeiten. ${ }^{94}$ Als die russische Armee vor Konstantinopel stand, befand sich die russische Politik in einer Zwickmühle: Einerseits erwarteten der Zar und die Öffentlichkeit von der Heeresleistung die Einnahme der einstigen Hauptstadt der Christenstadt, anderseits positionierte England zur Demonstration britischer Interessen eine Flotte im Marmarameer. Die russischen Bedingungen des Vorfriedens von San Stefano, die den Panslavisten bereits als „Gipfel weiser Mäßigung ${ }^{“ 95}$ galten, waren weder für Großbritannien noch für Österreich-Ungarn akzeptabel und führten auch nicht zu dankbarer Zustimmung unter den Balkanslawen, die je nach Wohlverhalten von Rußland willkürlich mit Landzuteilungen bedacht wurden.

Dostoevskij gehörte zur Mehrheit seiner Landsleute, die die Kriegserklärung der russischen Regierung ohne Vorbehalt begrüßt hatte. Von einem siegreichen Einzug in die alte Hauptstadt des Ostchristentums erwartete er eine Hebung des moralischen Sinnes (wie sie nach seiner Auffassung jeder Krieg mit sich brachte), eine Vertiefung des brüderlichen Geistes und eine bewußtere Ausübung der welthistorischen Mission des rechtgläubigen Rußland. Zugleich sah er eine Ballung von Konflikten heraufziehen, die auf einen Entscheidungskampf der europäischen Geschichte hinwies und sogar „den Beginn des Endes der gesamten bisherigen Geschichte der europäischen Menschheit“ (XXV, 9) bedeuten könnte.

In Europa ist es unruhig, daran ist nicht zu zweifeln. Aber ist dies eine vorübergehende, augenblickliche Unruhe? Ganz und gar nicht: Für etwas Ewiges, Tausendjähriges, etwas, das sich in der Welt seit Beginn ihrer Zivilisation vorbereitet hat, ist nun die Zeit gekommen. ${ }^{96}$

Die apokalyptischen Anklänge sind nicht ausschließlich metaphorisch zu verstehen: Das „Tausendjährige“, das sich seit Beginn der europäischen Zivilisation

94 Alexander II. befahl wiederholt, Konstantinopel einzunehmen; vgl. Günther Stökl: Russische Geschichte (wie Anm. 61), S. 519 f.

95 Ebd., S. 520. Zum Russisch-Türkischen Krieg und den internationalen Folgen siehe Thomas Nipperdey: Deutsche Geschichte 1866-1918 (wie Anm. 35), Bd. 2, S. 434 f.

96 DP Januar 1877, Kap. 1/I: Tri idei (wie Anm. 59); XXV, S. 6. 
ankündigte, steht für die Vorahnung eines theokratischen Reiches, wie es in der Offenbarung des Johannes geweissagt wird: für eine kommende Weltregierung der Gerechten unter der Herrschaft Christi. Tausendjahresräume schufen in Dostoevskijs historischem Horizont eine reale Periodisierung der Menschheitsgeschichte. Die fast tausendjährige Geschichte des Russischen Reiches und die über tausendjährige Geschichte der Römischen Kirche (gezählt seit Karl dem Großen) sowie die zweitausendjährige Geschichte des Christentums waren darin feste Orientierungsgrößen. Dabei mischten sich die apokalyptischen Bezüge mit säkularen Aspekten einer bereits vom Darwinismus beeinflußten zyklischen Kulturtheorie: Auch der Naturwissenschaftler Nikolaj Danilevskij, der in der Entwicklung von Völkern biologische Zyklen des Entstehens, Wachsens und Vorgehens am Werk sah, dachte in Jahrtausendräumen.

Für die Bestätigung seiner weitreichenden Voraussagen suchte Dostoevskij 1877 mit größter Aufmerksamkeit konkrete Anzeichen in den politischen Abläufen. Zwei Ereignisse oder Ereignisfolgen machte er aus, die in ihrem Zusammenwirken zu Katalysatoren für eine historische Wende von noch unabsehbaren Dimensionen werden könnten. Entsprechend seiner Konzeption der europäischen Welt, in der das katholische Frankreich Vorreiter aller neuen Entwicklungen war, richtete er seine Erwartung auf das dortige Geschehen. Die französische Republik wurde 1877 vom sogenannten „Maiumsturz“ erschüttert, als der konservative Staatspräsident Marschall Mac-Mahon, von klerikalen Kräften bewogen, die Minister unter dem gemäßigt republikanischen Ministerpräsidenten Jules Simon entließ und kurz darauf im Juni die Deputiertenkammer auflöste, um sich nicht der republikanischen Mehrheit beugen zu müssen. Die Neuwahlen wurden für den 14. Oktober desselben Jahres angesetzt.

Dostoevskij glaubte den Pressekommentatoren nicht, die versicherten, daß es sich nur um einen Schachzug handle, der den monarchistischen Kräften größere politische Einflußmöglichkeiten verschaffen sollte, und daß kein legitimistisch-klerikaler Umsturz geplant sei. Er vermutete eine vom Vatikan gelenkte „katholische Verschwörung“, die er sich als eine europaweit in straffer militärischer Formation operierende Untergrundorganisation nach kommunistischer Manier vorstellte: Die eigentliche Motivation dieser Initiatoren sei es, Frankreich so schnell wie möglich in einen neuen Krieg gegen Deutschland, den Hauptfeind des Vatikan, zu treiben. Vom Ergebnis der für Oktober 1877 angesetzten Neuwahlen in Frankreich schien Dostoevskij die Frage von Krieg und Frieden in Europa abzuhängen, denn wenn die Legitimisten siegten, würde Frankreich, „das Schwert des Vatikans“, zum Angriff auf das Deutsche Reich übergehen. 
Das zweite Datum, noch unsicher, aber seit Jahren allseits erwartet, war der nahe Tod des unbeugsamen und kompromißlosen Papstes Pius IX. Dostoevskij glaubte, Bismarck würde seine Macht ausspielen, um bei der Wahl des neuen Kirchenoberhauptes einen schwachen Kandidaten durchzusetzen, dessen Einflußmöglichkeiten man auf die Position eines „Patriarchen von Rom“ zurechtstutzen könnte, und um eine Spaltung der katholischen Kirche herbeizuführen $^{97}$; da die Spitze der katholischen Kirche dies erkannt habe, werde sie auf einen möglichst baldigen Krieg Frankreichs gegen das Deutsche Reich drängen, noch vor dem Tod des jetzigen Papstes. Je nach der Entwicklung der Lage sah Dostoevskij weitreichende Folgen voraus: Im Falle eines deutschen Sieges könnte es geschehen, daß die Macht der katholischen Kirche ganz gebrochen würde. Damit wäre die Hauptvoraussetzung für die Wiedervereinigung der Christenheit gegeben, die allerdings noch einmal durch den Angriff der sozialistischen Bewegung bedroht wäre.

\section{Ein deutscher Heros}

Dostoevskijs Analyse des Jahres 1877 baute bereits auf irrigen Annahmen auf. Zwar hatte Bismarck im Mai 1872 tatsächlich in einer „Papstwahldepesche“ eine Initiative gegenüber den europäischen Mächten gestartet, in der er vorschlug, sich über Bedingungen zu verständigen, unter denen man die Wahl eines neuen Papstes annehmen könne. ${ }^{98}$ Der Vorstoß war aber auf geringe Resonanz getroffen und im Sande verlaufen wie alle Versuche Bismarcks in jenen Jahren, eine internationale Abwehrfront gegen den Ultramontanismus zu schaffen. Das Scheitern war Ausdruck der Tatsache, daß er sowohl die ultramontane Gefahr überschätzt als auch die internationale Stimmung unrealistisch beurteilt hatte. Fünf Jahre später aber, als ihm Dostoevskij die Absicht unterstellte, die Papstwahl zu beeinflussen, war Bismarck von solchen Intentionen bereits weit entfernt. Er wartete die Wahl gelassen ab und setzte auf die Erfahrung, daß auf einen militanten Papst meist ein versöhnlicher folgen würde. ${ }^{99}$

97 DP September 1877, Kap. 1/III: To da ne to. Ssylka na to, o čem pisal eščë tri mesjaca nazad (Dasselbe und dich nicht dasselbe. Verweis darauf, worüber ich bereits vor drei Monaten geschrieben habe); XXVI, S. 11-17; hier S. 14. Zur Papstwahldepesche siehe Georg Franz: Kulturkampf (wie Anm. 36), S. 227.

98 Die „Papstwahldepesche“ wurde 1874 der Öffentlichkeit bekannt; Joachim Scholtyseck: Alliierter oder Vasall? (wie Anm. 35), S. 52 f. und 66.

99 Siehe Erich van Eyck: Bismarck und das Deutsche Reich. 8. Aufl. München 1990, S. 221. 
Der Höhepunkt der Dostoevskijschen Bismarck-Bewunderung war im Jahr 1877 erreicht, als Deutschland Verständnis für die Kriegsziele der russischen Regierung signalisierte. ${ }^{100}$ Einer langfristigen Strategie gemäß hielt es Bismarck für nützlich, „wenn die Russen auf dem einen oder andern Wege, physisch oder diplomatisch, sich in Konstantinopel festgesetzt und dasselbe zu verteidigen hätten "101. Darüber hinaus gab es im selben Jahr eine weitere wirkliche, nicht nur von Dostoevskij angenommene Konvergenz seiner eigenen politischen Analyse mit der Bismarcks. Auch dieser beurteilte 1877 aufgrund des klerikal inspirierten „Maiumsturzes“ und der darauf folgenden Politik des französischen Staatspräsidenten Mac-Mahon die Gefahr eines Revanchekrieges als akut gegeben, denn die Machtübernahme der klerusfreundlichen legitimistischen Kräfte rückte ein österreichisch-französisches oder russisch-französisches Bündnis und damit eine Einkreisung Deutschlands in den Bereich des Möglichen. ${ }^{102}$

Dostoevskij erschien die Nachricht von der deutschen Unterstützung der weitgehenden russischen Eroberungswünsche als sensationell und begeisternd. Während ihn in Rußland alle „real“ denkenden politischen Köpfe wegen seiner Konstantinopel-Träume auslachten und als Phantasten verspotteten, gab ihm der Kanzler des Deutschen Reiches in der ruhigsten Weise recht. „Fürst Bismarck“ erschien im „Tagebuch eines Schriftstellers“ nun als ein in jeder Hinsicht genialer Politiker: Er allein habe nur mit einer kleinen Schar einsichtiger Deutscher im chauvinistischen Chor deutscher Selbstüberschätzung die Gefahren erkannt, die der deutschen Einheit und Europa insgesamt drohten:

Es ist bemerkenswert, daß Fürst Bismarck den Sozialismus nicht weniger haßt als das Papsttum und daß die deutsche Regierung besonders in der letzten Zeit irgendwie die sozialistische Propaganda allzusehr zu fürchten begann. Zweifellos deshalb, weil der Sozialismus das nationale Prinzip entpersönlicht und die Nationalität an der Wurzel zersetzt, die Nationalität aber die Hauptidee der ganzen deutschen Vereinigung ist, alles dessen, was in Deutschland sich in den letzten Jahren vollzogen hat. Es kann aber durchaus sein, daß Fürst Bismarck noch tiefer blickt, nämlich, daß der Sozialismus die kommende Kraft für ganz Westeuropa

100 Vgl. Bismarcks Kissinger Diktat vom 15. Juni 1877. In: Die große Politik der europäischen Kabinette 1871-1914. Sammlung der diplomatischen Akten des Auswärtigen Amtes. Hrsg. von Johannes Lepsius [u.a.]. Berlin 1922 ff.; hier Bd. 2: Der Berliner Kongreß und seine Vorgeschichte. 1922, S. 153, Nr. 294.

101 Otto von Bismarck: Gedanken und Erinnerungen (wie Anm. 81), 2. Bd. (27. Kapitel: Die zukünftige Politik Rußlands), S. 281.

102 Erich Eyck: Bismarck (wie Anm. 68), Bd. 3, S. 250. 
sein wird und daß, wenn das Papsttum einmal von den Regierungen dieser Welt verlassen und verworfen sein wird, es sehr wohl geschehen kann, daß es sich dem Sozialismus in die Arme werfen und mit ihm eins werden wird. ${ }^{103}$

Vergleicht man diese Einschätzung mit der Bemerkung Dostoevskijs über Bismarcks Kampf gegen den Ultramontanismus von 1873, die diesem noch eine unbewußte Unterstützung der Sozialisten unterstellte, wird deutlich, welche Entwicklung Dostoevskijs Verhältnis zu dem deutschen Staatsmann durchlaufen hat.

Mit der wachsenden Bewunderung für Bismarck, die ihn Übereinstimmung suchen ließ, wo sie nicht gegeben war, entfernte sich andererseits Dostoevskijs Verständnis der deutschen Politik weiter von der Realität als zuvor. Bismarcks Billigung des russischen Feldzugs entsprang staatspolitischen und strategischen Erwägungen. Die Balkanvölker waren für ihn weniger christliche Brüder als „nationale Fragmente“, so wie für ihn Europa eine „notion géographique“104 und keinesfalls das „Land der heiligen Wunder“ war, um dessen Ergehen sich Dostoevskij unentwegt sorgte. Bismarck erkannte zwar in der Tat die Sprengkraft der „sozialen Frage“, blickte indes nicht „so tief“, daß er eine Vereinigung der Sozialdemokraten mit der Kirche erwartet hätte. 1877 sah Bismarck das Deutsche Reich aufgrund des Umschwungs in Frankreich noch einmal von einer äußeren Umklammerung katholischer Kräfte bedroht, die sich mit den katholischen Kräften im Innern verbünden konnten. Zwar waren sowohl Ultramontanisten als auch Sozialdemokraten für ihn „Reichsfeinde“, aber eher kann man von einem Substitutionsprozeß sprechen, insofern nach dem Abklingen des Kulturkampfs das katholische Feindbild durch das sozialdemokratische ersetzt wurde.

Dostoevskij hat also Bismarck in Form einer Vermutung die eigene, in ihren letzten Konsequenzen von niemandem geteilte Theorie untergeschoben. Hinter vielen Entscheidungen, in denen Bismarck der Staatsräson folgte, vermutete Dostoevskij ideelle Motive wie den Widerstand gegen Rom oder den Prinzipienkampf gegen den Sozialismus. Daß Bismarck keineswegs darauf brannte, dem Papst das „Schwert“ Frankreich aus der Hand zu schlagen, sondern einen Revanchekrieg gerade zu vermeiden suchte ${ }^{105}$, fand keinen Eingang in Dostoevskijs Vorstellungen. Hatte er aber einst die tatsächliche deutsche

103 DP Mai-Juni 1877, Kap. 3/III: I serdity i sil'ny (Sowohl verärgert als auch stark); XXV, S. 160.

104 Otto von Bismarck: Gedanken und Erinnerungen (wie Anm. 81), Bd. 2 (26. Kapitel: Der Dreibund), S. 259; Erich Eyck: Bismarck (wie Anm. 68), Bd. 3, S. 244.

105 Siehe Die große Politik (wie Anm. 100), Bd. 1, Nr. 136, 194, 160; vgl. Erich Eyck: Bismarck (wie Anm. 67), Bd. 3, S. 154. 
Kriegsbereitschaft als Aggressivität und Raubgier gedeutet, heroisierte er nun die vermutete Kriegsbereitschaft als Politik überlegener Stärke.

Seine Bewunderung nahm die Form einer exklusiven Identifikation mit dem deutschen Reichskanzler an. Bismarck war für ihn der einzige Politiker Europas, dessen Blick in die Tiefe der Erscheinungen drang. Von Mac-Mahons klerikal inspiriertem Coup im Mai 1877 fühlte sich Dostoevskij zum einen triumphal bestätigt, hatte er doch die „katholische Verschwörung“ gegen die französische Republik immer vorausgesagt. Zum anderen fühlte er sich mehr denn je einig mit Bismarck. Nun sprach er schon nicht mehr von seinen eigenen Analysen, sondern überließ dem Kanzler ganz das Feld, um selbst nur dessen Weitsicht (im Grunde aber die eigene) zu preisen:

Nun erweist es sich, daß sein [Bismarcks] Genie dieses ganze ,Abenteuer' [den Coup Mac-Mahons] vorausgesehen hat. Oder ist es nicht sein Genius, sagt, ist es nicht sein geniales Auge, das den Hauptfeind bereits vor so langer Zeit erspähte? ${ }^{106}$

Die Gegner der Bismarckschen Politik in ganz Europa (und damit natürlich auch die russischen Zweifler an Dostoevskijs Position) seien aufgrund ihrer liberalen Ansichten einem Irrtum aufgesessen und hätten den Kampf des Staatsmannes gegen das Papsttum fälschlich als einen „Kampf des Elefanten mit der Mücke" eingeschätzt oder die Angelegenheit zu einer Marotte des alten Herrn erklärt. Dabei sei dieser „vielleicht der einzige Politiker der Welt“, der die Stärke der römischen Idee richtig einschätze. ${ }^{107}$

Eine weitere Steigerung der Identifikation mit Bismarck war kaum denkbar. Dennoch ging Dostoevskij ab September 1877 noch einen Schritt weiter: Er glaubte zu wissen, was der Reichskanzler, der nun in seiner Vorstellung heroische Züge annahm, vorhatte und wie er seine historische Aufgabe lösen würde.

[...] Fürst Bismarck hat Frankreichs Schicksal wahrscheinlich schon besiegelt. Das Schicksal Polens erwartet auch Frankreich, und politisch wird es tot sein, oder Deutschland müßte aufhören zu sein. Wenn Bismarck das erreicht haben wird, dann wird er auch den militanten römischen Katholizismus [...] zwingen, in eine neue Phase des Daseins und des Kampfes um das Dasein einzutreten, - in die Phase des unterirdischen, reptilhaften Verschwörerkriegs. Bismarck aber erwartet ihn schon in dieser neuen Phase. Und je früher dies geschehen wird, desto besser für ihn, denn hier erwartet er bereits die Vereinigung beider Feinde

106 DP Mai-Juni 1877, Kap. 3/II: Odin genial'no-mnitel'nyj čelovek (Ein genial-mißtrauischer Mann); XXV, S. 157.

107 XXV, 156 f., sowie andere Stellen, z. B. XXVI, S. 88. 
Deutschlands und der Menschheit, die Vereinigung des Katholizismus mit dem Sozialismus, und hofft, sie gerade so leichter vernichten zu können, beide auf einmal ... ${ }^{108}$

Wie diese Stelle zeigt, bezieht sich die Identifikation nicht nur auf die Person des Kanzlers und das gemeinsame Durchschauen der Zeitläufte, sondern es werden auch die Länder sowie ihre jeweiligen Probleme parallel gesetzt: Was Polen für Rußland, das ist für Deutschland Frankreich - ein benachbarter katholischer Unruheherd, den es niederzuhalten und einzuverleiben gilt.

Im Tagebuch eines Schriftstellers häuften sich die Vermutungen über Bismarcks Absichten ebenso die obstinaten Beteuerungen seines Weitblicks. Der deutsche Staatsmann verwandelte sich aus einem Identifikationsobjekt in einen Vollstrecker der von Dostoevskij seit über einem Jahrzehnt vorausgesagten Wendung der Weltpolitik: Er sollte die Prophezeiung erfüllen, sollte Frankreich vernichten, den militanten römischen Katholizismus in einen „unterirdischen, reptilhaften Verschwörerkrieg“ zwingen und den Sozialismus besiegen. Wie Hegel in Napoleon scheint Dostoevskij - wenn auch für eine kurze Zeitspanne - in Bismarck den personifizierten „Weltgeist“ gesehen zu haben.

\section{Deutschland als dritte Kraft}

Die Umgewichtung der Kräfteverhältnisse auf dem Kontinent seit der Reichsgründung, die baldige Erwartung eines neuen deutsch-französischen Krieges und die Balkankrise, durch die ein neuer bündnispolitischer Orientierungsbedarf für Rußland entstand, lösten bei Dostoevskij in den Jahren 1876/1877 einen Umdenkprozeß aus, der seine Gesamtsicht Europas betraf. Er sprach nun von drei "Ideen“ der Weltgeschichte (im Sinne geschichtlich wirksamer Kräfte), die ihre letzte Entwicklungsphase erreicht hätten und nach einer historischen Entscheidung über ihre Existenz verlangten. Zwei der „Ideen“ hatte er immer wieder formuliert und beschrieben: Dies war erstens das katholische Prinzip der Weltmonarchie; es war dem romanischen Teil Europas zugeordnet, den er nun die „äußerste westliche Welt“ nannte; zweitens das russische Prinzip der Brüderlichkeit und Allgemeinmenschlichkeit, das er nun unter dem Begriff „Allmenschlichkeit“ faßte.

Die russische „Idee“ schien durch die Balkankrise und den Russisch-Türkischen Krieg an der Schwelle zum endgültigen historischen Durchbruch zu

108 DP November 1877, Kap. 3/II: Opjat' v poslednij raz „proricanija“ (Wieder ein letztes Mal „Vorsehungen“); XXVI, S. 89. 
stehen: Das Prinzip christlicher Brüderlichkeit werde den slawischen Brüdern nahegebracht werden., durch Gewährung von Schutz und geduldige Belehrung; Rußland werde seine gewaltige Macht nutzen, um der Menschheit zu dienen, wie es das bisher bereits durch seine Politik getan habe. Wenn die russische "Idee“ in Europa an Boden gewinne, dann werde das alte Europa sich völlig verändern, es werde die alten Prinzipien der Konkurrenz, des Egoismus und des materiellen Vorteils abstreifen, und etwas Neues, „Tausendjähriges“ werde entstehen.

Diese beiden „Ideen“, für sich genommen, gaben die Dostoevskijsche Interpretation der Einteilung der Welt in West und Ost wieder, wie sie für das russische Geschichtsdenken grundlegend war. Sieben Jahre nach der Gründung des Deutschen Reichs entsprach diese Zweiteilung in Dostoevskijs Augen den nun geltenden Kräfteverhältnissen nicht mehr. Das neue Kraftzentrum in der Mitte Europas erschien ihm so bedeutsam, daß er dem jungen Staat eine dritte große „Idee“ zuordnete. Der ursprünglich als eine Einheit begriffene Staatenund Kulturenkomplex Europa, die „romanisch-germanische Welt“, polarisierte sich in eine romanische und eine germanische Welt.

In der germanischen Welt sah er als dritte große „Idee“ den deutschen Protestantismus nach Weltgeltung drängen, verstanden als Prinzip des Protestes gegen die römische Weltherrschaft in ihren wechselnden historischen Formen. Über die Deutschen äußerte er in diesem Zusammenhang:

Der charakteristischste, wesentlichste Zug dieses großen, stolzen und besonderen Volkes bestand schon seit dem ersten Augenblick seines Auftretens in der geschichtlichen Welt darin, daß es sich niemals, weder in seiner Bestimmung noch in seinen Grundsätzen, mit der äußersten westlichen Welt hat vereinigen wollen, d.h. mit all den Erben der altrömischen Idee. ${ }^{109}$

Hatte er 1873 betont, daß der Protestantismus ein Teil der römischen Welt sei, der mit ihr untergehen werde, hob er nun den eigenständigen Charakter des "deutschen Geistes“ hervor, dessen Leistung es war, die Freiheit des Denkens entdeckt zu haben. Deutschland werde auch in Zukunft der Hauptgegner des römischen Prinzips sein - und das bedeutete im Sinne der Theorie Dostoevskijs: auch das Bollwerk Europas gegen den erstarkenden Sozialismus. Beide Gegner, der „deutsche Geist“ und der Sozialismus, seien in den Vorbereitungen zum Entscheidungskampf begriffen, hätten sich organisiert und zur gleichen Zeit eine feste Form für sich geschaffen: der „deutsche Geist“ in dem neuen Staat

109 DP Mai-Juni 1877, Kap. 3/I: Germanskij mirovoj vopros. Germanija - strana protestujuščaja

(Die deutsche Weltfrage. Deutschland - das protestierende Land); XXV, S. 151-154, hier S. 153. 
und der Sozialismus in der Internationale. ${ }^{110}$ In der Beschreibung der „deutschen Idee" folgt Dostoevskij weitgehend deutschen Eigenmythen, die bereits in der ersten Hälfte des 19. Jahrhunderts zur Konstituierung und Bekräftigung einer nationalen Identität dienten und während der Jahre des Kulturkampfs in der Geschichtsschreibung verstärkt aufgegriffen wurden. Diese deutschnationale Schule der Historiographie untermauerte den behaupteten Gegensatz zwischen germanischer und romanischer Welt durch den Rückgriff auf deutsche Vorgeschichte und Geschichte, die einseitig unter dem Aspekt der Gegnerschaft zu Rom beschrieben wurde. Begonnen mit Arminius und der Schlacht im Teutoburger Wald über den Kampf der mittelalterlichen Kaiser gegen das Papsttum, die Reformation, den Krieg gegen Roms Hauptstütze Frankreich reihten sich die antirömischen und antiromanisch/antifranzösischen Kernmythen nahtlos bis zum Kulturkampf. Diese konstruierte historische Linie der sich steigernden deutschen Gegnerschaft zum katholischen, „romanischen“ Europa konnte und sollte für Dostoevskij logisch zu einem nicht fernen Zeitpunkt in der Entmachtung des Papstes gipfeln. Der positive Gehalt des protestierenden deutschen Wesens wurde indes von ihm noch immer zögernd und vage formuliert:

[...] und wenn es [das deutsche Volk] auch sein eigenes Wort [...] noch nie ausgesprochen hat, sein scharf formuliertes eigenes Ideal [...], so war es doch, wie es scheint, in seinem Inneren immer überzeugt, daß es noch einmal imstande sein werde, dieses neue Wort zu sagen und Anführer der Menschheit zu werden. ${ }^{111}$

In merkwürdigem Gegensatz dazu steht die Bestimmtheit, mit der er die „deutsche Frage“ als eine universale Frage definierte, die „mehr als jede andere eine europäische Frage“ sei, „denn sie ist mit dem Schicksal ganz Europas und dem aller übrigen Weltfragen engstens organisch verschmolzen“. ${ }^{112}$ Vom kriegeri-

110 Ebd., S. $153 \mathrm{f}$.

111 DP Mai-Juni 1877, Kap. 3/I: Germanskij mirovoj vopros. Germanija - strana protestujuščaja (Die deutsche Weltfrage. Deutschland - das protestierende Land); XXV, S. 151-154, hier S. 153; in der deutschen Ausgabe Fjodor M. Dostojewski: Politische Schriften. München 1920, S. 70, ist die Fortsetzung dieser Passage offenbar aus politisch-weltanschaulichen Motiven manipuliert worden: Der Satz: „Es [das deutsche Volk] verkündete die Freiheit der Forschung und erhob das Banner Luthers“ ist ersetzt durch die bedeutungsschwere Aussage: „Die Stimme Gottes tönte aus ihm und verkündete die Freiheit des Geistes“, eine Veränderung, die, im Gesamtzusammenhang gesehen, eine fundamentale Entstellung der politischen Äußerungen Dostoevskijs über Deutschland bedeutet. Sie wurde in allen Neuauflagen bis heute beibehalten.

112 DP Mai-Juni 1877, Kap. 2/III: Nikogda Rossija ne byla stol'moguščestvennoju, kak teper'rešenie ne diplomatičeskoe (Niemals war Rußland so mächtig wie heute - eine nicht diplomatische Lösung); XXV, S. 150. 
schen Charakter der deutschen Vereinigung, von Aggressivität, preußischem Militarismus, „Blut und Eisen“ ist keine Rede mehr:

Überhaupt haben wir Russen alles, was in Deutschland in den letzten zehn, fünfzehn Jahren geschehen ist, für etwas Endgültiges, im höchsten Grad nicht Zufälliges, sondern durchaus Natürliches angesehen, etwas, das sich nun nicht mehr verändern kann. Die vollbrachten Taten flößten uns außerordentliche Achtung ein. ${ }^{113}$

Für ebenso natürlich und respektabel wie den Willen zur Einheit hielt Dostoevskij den Glauben der Deutschen an die Sendung ihres Volkes. Auch wenn ihm der Grad des Nationalstolzes weiterhin unangemessen erschien und er die deutsche Überzeugung tadelte, „nach der es in der Welt nichts Erhabeneres gibt als den deutschen Geist und das deutsche Wort [...]“ (XXV, 8), blieb seine Kritik an den Übertreibungen im Ton verhalten. Man kann sogar durchaus behaupten, daß er, ausgehend von der Vorstellung, die „Ideen“ der Völker müßten sich im Wettstreit gegeneinander durchsetzen, den fremden Nationalismus billigte. Ein großes Volk müsse glauben,

daß in ihm, und nur in ihm allein, die Rettung der Welt liegt, daß es dazu da ist, an die Spitze aller Völker zu treten, sie alle um sich zu scharen und in vereintem Chor zum endgültigen, ihnen allen vorbestimmten Ziel zu führen. ${ }^{114}$

Ein solcher Glaube sei die Voraussetzung dafür, daß dieses Volk der Menschheit Nutzen bringen werde.

Hier offenbart sich zweifellos die innere Bruchstelle von Dostoevskijs Deutschlandvorstellungen: Einerseits ist er bestrebt zu erkennen, worin nun eigentlich der Charakter der "deutschen Idee“ besteht, und glaubt, ohne diese Erkenntnis keine weitergehenden Analysen liefern zu können. Andererseits erliegt er, hierin ein Mensch seines Jahrhunderts, der Faszination des deutschen Machtanspruchs, unabhängig vom Inhalt der sich dahinter verbergenden Werte. Die lauten Bekundungen des deutschen Nationalismus scheinen anzuzeigen, daß dieses Land zu großen Taten bereit ist. Er nimmt die Deutschen bei ihren tönenden Worten.

113 DP Mai-Juni 1877, Kap. 3/II: Odin genial'no-mnitel'nyj čelovek (Ein genial-mißtrauischer Mann); XXV, S. 154-157, hier S. 154.

114 DP Mai-Juni 1877, Kap. 2/I: Primiritel'naja mečta vne nauki (Der Traum von Versöhnung außerhalb der Wissenschaft); XXV, S. 17. 


\section{Vision einer Zweiteilung der Welt}

Festzuhalten ist, daß in den Jahren 1876/77 Dostoevskijs Verhältnis zu Deutschland einen grundlegenden Wandel durchmacht, der sich zunächst im Ton der Berichte oder in veränderten Wertungen alter Erkenntnisse äußert, dessen eigentliche Ursachen aber nicht in den Berichten selbst zu finden sind. Ausschlaggebend dafür, daß in diesen Jahren alle Erfahrungen mit Deutschen und Deutschland in neuem Licht erscheinen, sind die strategischen politischen Überlegungen, die Dostoevskij zur Rolle des Deutschen Reichs im weiteren Schicksal Europas anstellte, und die Erwartung, daß es zu einem schicksalhaften deutsch-russischen Bündnis kommen werde.

Die Umorientierung begann sich 1876 abzuzeichnen, seit Deutschland Verständnis für Rußlands „orientalische“ Ambitionen signalisierte und Bismarck deutlich machte, daß er gegen die russische Einnahme Konstantinopels nicht einzuwenden hatte. Die stabile und gleichbleibende Distanz, von der Dostoevskijs persönliches Verhältnis zu Deutschland gekennzeichnet war, schmolz dahin. Immerhin bejahte die deutsche Politik die populärste russisch-patriotische Forderung. Gerade Dostoevkij war für solche Zeichen aus dem Westen empfänglich, denn sein Patriotismus zeichnete sich nicht durch ein prinzipiell ablehnendes Verhältnis zu Europa aus, sondern war von einem Gefühl der Zurücksetzung bestimmt. Es war für ihn beständiger Anlaß zur Klage, daß aus Europa, dem teuren „Land der heiligen Wunder“, dem Russischen Reich so viel Unverständnis, Angst und Haß entgegenschlug. Er ersehnte die Anerkennung Rußlands im Kreis der europäischen Staaten, unter denen es jedoch eine herausragende Position verdiente. Die unerwarteten Zeichen deutschen Wohlwollens für das Herzstück allslawischer und orthodoxer Großprojekte gaben dem russischen Dichter offenbar das Gefühl: Hier ist ein Volk in Europa, das uns zu verstehen beginnt.

Doch ging es nicht nur um Emotionen. Das gestörte Verhältnis des Westens zu Rußland führte nach Dostoevskijs Einschätzung dazu, daß die westlichen Länder Rußland daran hinderten, seine uneigennützige christliche Politik auf Europa auszudehnen und damit seine Sendung zu erfüllen - womit sie letztlich sich selbst schadeten und ihre eigene Zukunft gefährdeten. Den Ausweg aus diesem Dilemma fand Dostoevskij in einer neuen Kräftekonstellation: Rußland brauchte ein mächtiges Land als Bündnispartner, das die widerspenstigen Länder unterwerfen würde.

Vorsichtig umkreiste er die Frage, ob Deutschland nicht eine größere Rolle in Europa spielen sollte als bisher. Ab September 1876 trug er sich mit dem 
Plan, einen Artikel „Europa und zwei Kräfte“ zu schreiben (der nicht zur Ausführung kam). In einer Notiz aus den Vorarbeiten heißt es:

Idee; Es geht heute nicht um das Gleichgewicht in Europa: Rußland kann sich nicht an es wenden und ihm nicht dienen, man muß das Gleichgewicht kühn zerstören und eine neue Kombination zweier oder dreier Kräfte schaffen. Deutschland und Rußland.

Das Planspiel führt er in einer anderen Notiz weiter aus:

Besser ist, wenn sich Europa in zwei Kräfte teilt, in Deutschland und die allslawische (England einmal beiseite). Dann wäre ein Ende und beide Kräfte könnten miteinander auskommen, entschieden ohne einander zu stören. (Die Änderung der Karte Europas ist endgültig und radikal.) Die Entfernung des romanischen Stammes. Sie könnte höchstens der Papst einigen. Die übrigen europäischen Völkchen könnten in kleinen Segmenten gedeihen. Aber politisch gäbe es nur zwei Kräfte. ${ }^{115}$

Es war die Ahnung einer möglichen historischen Entwicklung, geboren aus dem Wunsch nach dem Ende der politischen Isolation Rußlands in Europa und einer Rettung Europas vor dem Zerfall. Deutschland sollte aus dem Abwehrkampf in die Offensive gehen und Frankreich endgültig politisch vernichten, indem es dieses in eine Art deutsches Protektorat verwandelte. Die neugefundene Zukunftsperspektive warf ihr Licht zurück auf die Gegenwart der Jahre 1876/77, die sich, auf diese Weise beleuchtet, in Dostoevskijs Augen stark verändert ausnahm: Seine Schilderungen des Status quo lasen sich nun so, als wäre die Unterwerfung Frankreichs bereits eine vollendete Tatsache. Im November 1877 behauptete er, daß jede größere Entscheidung der französischen Regierung bei der deutschen Regierung zur Bestätigung vorgelegt werden müsse. Die französischen Republikaner beschrieb er als „Deutschlands Sklaven, die ganz Frankreich an Deutschland nicht bloß zu politischer, sondern auch zu innerer, geistiger Sklaverei ausliefern" ${ }^{116}$.

In dieser Phase seiner Überlegungen begannen kurzfristige Prognosen mit großen visionären Prophezeiungen zu verschmelzen. 1877 fürchtete er ganz konkret, daß der Krieg gegen die Türkei in einen Weltkrieg umschlagen würde. Die Möglichkeit einer Verkettung des Orientkrieges mit dem deutsch-

115 Zapisi k Dnevniku pisatelja 1876 g. Iz rabočich tetradej 1875-1877 gg. (Notizen zum Tagebuch des Schriftstellers 1876. Aus den Arbeitsheften 1875-1877); XXIV, S. 251 und 270; vgl. den Kommentar XXIV, S. 487.

116 DP November 1877, Kap. 3/II: Opjat' v poslednij raz „proricanija“ (Wieder ein letztes Mal „Vorsehungen“); XX, S. 89. 
französischen Konflikt, der jederzeit wieder auszubrechen drohte, wurde damals von vielen gesehen. Dostoevskijs Voraussicht aber ging weiter, er erkannte, daß ein solcher globaler Krieg neue Dimensionen anzunehmen drohte, weil der ungelöste soziale Konflikt durch ihn zum Ausbruch kommen würde (hinter dem er die Tätigkeit der katholischen Kirche vermutete).

Entsprechend seiner apokalyptischen Weltempfindung neigte er zu der Ansicht, daß man den Lauf der Dinge nicht aufhalten sollte. ${ }^{117}$

[...] und dermaßen wird sich Europas Antlitz verändern, so viel Neues und Progressives wird in den Beziehungen der Menschen beginnen, daß es vielleicht überflüssig ist, im Geiste zu leiden und die letzten Zuckungen des alten Europa am Vorabend seiner sicheren und großen Erneuerung allzusehr zu fürchten ... ${ }^{18}$

In bezug auf die Erneuerung Europas stimmte ihn die neugewonnene Überzeugung zuversichtlich, daß Deutschland mit seinen von ihm so hochgeschätzten Führern an Rußlands Seite stehen würde.

Im September 1877 faßte Dostoevskij seine Einschätzung der Lage und die sich daraus ergebenden Perspektiven thesenartig zusammen: ${ }^{119}$

1. Der Vatikan erkennt im Orientkrieg eine günstige Gelegenheit, unbehelligt von russischer Einmischung Frankreich in einen Krieg gegen Deutschland zu treiben. „Fürst Bismarck“ hat aber die große Bedeutung jenes letzten Kampfes ums Dasein, den der päpstliche Katholizismus vor seinem Untergange mit der Welt aufnehmen wird, erkannt.

2. Dieser Schicksalskampf ist unvermeidlich und wird in allernächster $\mathrm{Zu}$ kunft stattfinden.

3. Der Kampf wird sich sofort in einen alleuropäischen verwandeln. Die Orientfrage und der Orientkampf werden „durch die Macht des Schicksals“ mit dem alleuropäischen Kampf verschmelzen. Die „tausendjährige römischkatholische Frage“ wird durch ihn gelöst werden, und das östliche Christentum wird „durch den Willen der Vorsehung“ den ihm gebührenden Platz einnehmen.

4. Dies wird Europa vor größerem Blutvergießen bewahren. Zudem wird mit einemmal vieles endgültig entschieden werden - die römisch-katholische

117 DP September 1877, Kap. 1/III: To da ne to. Ssylka na to, o čëm pisal eščë tri mesjaca nazad (Dasselbe und dich nicht dasselbe. Verweis darauf, worüber ich bereits vor drei Monaten geschrieben habe); XXVI, S. 11-17; hier S. 14.

118 DP September 1877, Kap. 1/V: Kto stučitsja v dver'? Kto vojdët? Neizbežnaja sud'ba (Wer klopft an die Tür? Wer kommt rein? Das unausweichliche Schicksal); XXVI, S. 23.

119 Ebd., XXVI, S. 22 f. 
Frage samt dem Schicksal Frankreichs, die deutsche, die orientalische und mohammedanische Frage.

Dostoevskij schätze die Stärke des Deutschen Reiches offensichtlich sehr hoch ein. Daß der legitimistisch-konservative, hochbetagte Wilhelm I. Europa unterwerfen würde, war ein phantastischer Gedanke. Bismarck seinerseits sah die Grenzen deutscher Macht sehr viel enger als Dostoevskij und auch als viele seiner eigenen Landsleute. Er erklärte in seinem sogenannten Kissinger Diktat vom Juni 1877, Deutschland dürfe sich nicht in Bündniszwänge begeben und müsse eine Politik der Stärke vermeiden, eine Strategie, die Dostoevskij gar nicht wahrnahm, weil sie in den Kategorien seines politischen Denkens von Idee, Sendung und Macht keinen Platz hatte. Bismarcks strategischen Äußerungen hätte Dostoevskij entnehmen müssen, daß die deutsche Zustimmung $\mathrm{zu}$ den orientalischen Projekten Rußlands an das deutsche Eigeninteresse gekoppelt war und Rußland mit dem Deutschen Reich als Bündnispartner nur eingeschränkt rechnen konnte.

Aber in der nervösen Kriegsstimmung des Jahres 1877 konnten einfache Gesten und symbolhafte Handlungen die Gemüter mehr bewegen als komplizierte strategische Überlegungen. Nachdem die russische Regierung am 24. April den Krieg erklärt hatte, gab die deutsche Regierung im Juli eine Stellungnahme ab, in der die türkischen Verbrechen auf dem Balkan verurteilt wurden. Diese Solidaritätsbekundung machte großen Eindruck. In Moskau bildete sich eine enthusiastische Initiative von Bürgern, die Geschenke für den deutschen Kaiser und seinen Kanzler vorbereiteten und eine Dankadresse an Wilhelm I. richteten, in der „die aufrichtige und ehrliche Art des Verhaltens seiner Majestät in der Orientfrage" gelobt wurde. ${ }^{120}$ Es ist durchaus möglich, daß Dostoevskij in solchen eher atmosphärischen Vorkommnissen „Zeichen“ zu erkennen glaubte, die ihm Hinweise für seine Interpretationen der politischen Großlage gaben.

Das wohlwollende deutsche Verhalten führte jedenfalls dazu, daß die Idee der künftigen deutsch-russischen Teilung der Welt nun aus den Notizen den Weg in das Tagebuch eines Schriftstellers fand und mit einer neuen emotionalen Wärme und Entschiedenheit vorgetragen wurde:

Die Idee des wiedervereinten Deutschland ist groß und erhaben und blickt in die Tiefe der Jahrhunderte hinab. Was kann Deutschland mit uns teilen? Sein Objekt

120 Vgl. Kommentar XXVI, 433, Anm. zu S. 180, wo auf eine Meldung in „Novoe vremja“ (Neue Zeit), 1877, 18./30. Juli, Nr. 497, hingewiesen wird. 
ist die ganze westliche Menschheit, es hat die ganze westliche Welt Europas für sich bestimmt und ist entschlossen, statt der römischen und romanischen Ideen in ihr seine eigenen Prinzipien durchzusetzen und künftig ihre Anführerin zu sein, Rußland aber überläßt es den Osten. Zwei großen Völkern ist es auf solche Weise bestimmt, das Antlitz dieser Welt zu ändern. Dies sind keine Gedankenspiele oder Eingebungen der Ruhmsucht. Es hat sich nun einmal in der Welt so ergeben. ${ }^{121}$

Dostoevskij glaubte, daß sowohl Deutschland als auch Rußland, die beide jeweils einen Feind der europäischen Menschheit bekämpften, ihre anstehenden Aufgaben, die Neuordnung ihres Einflußbereichs, nur gemeinsam erfüllen können. Die Bündnisperspektive löste sich aber von der konkreten Interessenlage und schien eine dauerhafte Verbindung zu versprechen:

[...] Deutschland rechnet in jedem Fall auf uns nicht als zeitweiligen Bündnispartner, sondern als ewigen. ${ }^{122}$

Als günstig für die Haltbarkeit des Bündnisses schätzte Dostoevskij die Tätigkeit des Gespanns an der Spitze des Deutschen Reichs ein, die Zusammenarbeit der „heutigen großen deutschen Führer", (XXVI, 91) Bismarck und Wilhelm I. Dabei ging er von deren völligem Einvernehmen aus, ohne den Widerspruch zwischen den dynastisch-konservativen Überzeugungen des alten Kaisers und der beweglichen, auf realpolitischem Kalkül beruhenden Politik seines Kanzlers zu berücksichtigen, der gerade in den Beziehungen zu Rußland, das von Wilhelms Neffen regiert wurde, deutlich hervortrat. Das Alter beider Politiker warf zudem die Frage auf, welche Wendung das gegenseitige Verhältnis nehmen werde, wenn an der Spitze der deutschen Regierung ein Generationswechsel anstehe.

Trotz dieser Unsicherheit hielt Dostoevskij die Stabilität des deutsch-russischen Bündnisses für so gefestigt, daß Rußland in der aktuellen Lage kühn handeln könne, denn Deutschland werde auf lange Sicht an seiner Seite stehen:

Man muß es so einschätzen, daß die Freundschaft zwischen Rußland und Deutschland ohne Falsch und stabil ist und je länger, desto fester werden wird. Sie wird sich allmählich im Volksbewußtsein beider Nationen verbreiten und festigen, und darum gäbe es vielleicht sogar für Rußland keinen günstigeren Moment zur endgültigen Lösung der Orientfrage als jetzt. (XXVI, 91)

121 DP November 1877, Kap. 3/III: Nado lovit' minutu (Man muß den Moment nutzen); XXVI, S. 91. 
Deutschland sollte im gegebenen Moment nicht bloß Rußland den Rücken frei halten für die Regelung seiner Angelegenheiten im Orient und in Asien - ihm war eine viel größere Aufgabe zugedacht. Als eine Macht von angemessener Stärke und Dynamik, durch preußische Traditionen mit Rußland verbunden, durch seine protestantische Regierung ein Gegengewicht gegen den katholischen Machtanspruch, sollte das Deutsche Reich mit seinem Abwehrkampf gegen die romanische Welt - so muß man es interpretieren - den Boden bereiten für eine spätere Rückwendung Rußlands hin zu Europa, die Dostoevskij für eine kommende historische Etappe vorhersah. Dem Deutschen Reich war damit eine Art Geburtshelferfunktion für die künftige Weltordnung zugedacht.

\section{Ernüchterung, Neuorientierung und Verdrängung}

Die Enttäuschung des Berliner Kongresses

Dostoevskijs Entwurf einer Aufteilung der Welt zwischen Rußland und Deutschland entstand in einer Phase des deutsch-russischen Verhältnisses, dem ein Jahrhundert russisch-preußischer Bündnispolitik vorausgegangen war. Das "Nachwirken“ (Bismarck) der traditionellen dynastischen Beziehungen zwischen Rußland und deutschen Fürstenhäusern war in den Überlegungen des russischen Schriftstellers noch spürbar.

Doch die öffentliche Meinung tendierte in beiden Ländern bereits zu einem auf Expansion und Machtzuwachs orientierten Nationalismus und blieb nicht ohne Einfluß auf Alexander II. Der Idealist Dostoevskij - so bezeichnete er sich selbst - befand sich im Einverständnis mit der expansionistischen Außenpolitik der zarischen Regierung, die er als eine christliche und moralische Politik interpretierte. Seine aufrichtige Verehrung für Wilhelm I. basierte auf der Verwandtschaft der Hohenzollern mit dem russischen Herrscherhaus, galt aber darüber hinaus der Persönlichkeit des alten Kaisers. Der traditionsbewußte und glaubensfeste Wilhelm I. hielt durch sein Verhalten die Erinnerung an den Geist der im Krimkrieg untergegangenen Heiligen Allianz wach. Dostoevskij übertrug teilweise dessen Eigenschaften auf Bismarck, dem die „Sentimentalitäten" seines preußisch-konservativen Souveräns indes oft recht hinderlich waren.

Dostoevskijs russisch-deutsche Vision beruhte auf einer Reihe von Fehlinterpretationen und Mißverständnissen, wie sie während der ersten Jahre der Existenz des neuen, noch nicht festgelegten Staates nicht ausbleiben konnten. In der konfliktgeladenen politischen Situation Europas, in der die imperiale Konkurrenz und die ungelöste soziale Frage eine gefährliche Instabilität her- 
beigeführt hatten, prophezeite und befürwortete er eine moderne „Heilige Allianz" der konservativen Monarchien gegen Katholizismus und Sozialismus. Charakteristisch für diese Konzeption war das Verschmelzen von apokalyptischen und säkular-kulturzyklischen Elementen. Das nationale Prinzip wird in einer Weise interpretiert, die den Widerschein des imperialistischen Zeitalters erkennbar werden läßt: Es gilt ihm als movens der Geschichte, da es einen Ausscheidungskampf der großen Völker herbeiführt, die darum wetteifern, an der Spitze zu stehen und ihre Sendung zu Erfüllen.

Trotz der konservativen Züge seiner politischen Anschauungen war Dostoevskij keineswegs rückwärtsgewandt. Er wollte nicht Altes bewahren, sondern das Neue absichern, der Menschheit die gefährdete Zukunft erhalten, das heißt diejenigen Werte verteidigen und durchsetzen, ohne die von einer Zukunft keine Rede mehr sein konnte, ohne die „von neuem eine Epoche der Anthropophagie beginnen würde und die Menschen gezwungen wären, wieder ganz von vorn anzufangen, wie vor zehntausend Jahren" ${ }^{\prime 23}$.

Über einen Zeitraum von etwa zehn Jahren hatten sich Dostoevskijs Überlegungen zur deutschen Politik weit von der Realität entfernt. Seine persönliche Bewunderung galt einer mythischen Figur, die mit dem lebendigen Vorbild des deutschen Reichskanzlers immer weniger gemeinsam hatte. Die drei Kriege, die mit Bismarcks Namen verbunden waren, und die historische Leistung der Reichsgründung hatten in Dostoevskijs Vorstellung den Eindruck von Handlungsstärke und Machtfülle in den Vordergrund gerückt, hinter dem die charakteristischen Züge der realen Bismarckschen Politik vor allem seit Mitte der siebziger Jahre nicht wahrgenommen oder falsch interpretiert wurden. Der Kanzler nahm bei ihm Züge eines Nationalhelden an, wie ihn die moderne Archaik des 19. Jahrhunderts hervorbrachte: Mehrmals wird er im Tagebuch eines Schriftstellers als ein "echter Germane“ apostrophiert. ${ }^{124}$ Ganz dem Dienste ewiger Ideen geweiht, wuchs die Gestalt des deutschen Staatsmanns in Dostoevskijs Zukunftsprojektionen zum radikalen Neuordner des westeuropäischen Raums, zum Arm der Vorsehung und Bereiter des Bodens für eine kommende Zeit. Die Ernüchterung war unausweichlich. Es war nur eine Frage der Zeit, wann Dostoevskij seinen Irrtum erkennen würde.

1878 stellte Dostoevskij das Erscheinen des Tagebuchs eines Schriftstellers

123 Ebd., S. 90.

124 Etwa an folgender Stelle: „Indem er Frankreich des politischen Lebens beraubt, gedenkt Bismarck, auch dem Sozialismus einen Schlag zu versetzen. Niemand haßt den Sozialismus als Erbe des Katholizismus und Frankreichs mehr als der echte Germane.“ DP November 1877, 3/III: Nado lovit' minutu (Man muß den Moment nutzen). Ebd., S. 89. 
für mehr als zwei Jahre ein, um sich auf die Arbeit an dem Roman Die Brüder Karamazov (Brat'ja Karamazovy) zu konzentrieren. Die Unterbrechung fiel in die Jahre, in denen die deutsche Regierung eine politische Umorientierung zur Stabilisierung der äußeren und inneren Lage des Reichs vornahm. Hellhörige Kommentatoren verschiedener Länder hatten spätestens 1875 erkannt, daß der Kulturkampf die deutsche Innen- und Außenpolitik in eine Sackgasse führte und eine Korrektur im deutschen Eigeninteresse lag. ${ }^{125}$ Dostoevskij, der in manchen großen Fragen weit vorausschauen konnte, war in dieser Frage zu sehr in seinen politischen Erwartungen verfangen, um die Zeichen richtig lesen zu können. 1877 wurde die in Fragen des Ultramontanismus zurückhaltender gewordene deutsche Politik tatsächlich noch einmal aufgeschreckt von der Sorge einer möglichen österreichisch-französischen Allianz unter dem Einfluß des Papstes, als in Frankreich die Legitimisten die Regierung zu übernehmen drohten. Hier konvergierten Dostoevskijs Analysen graduell ein letztes Mal mit denen Bismarcks.

Aber in den wesentlichen Einschätzungen der deutschen Politik irrte Dostoevskij. Seine Befürchtungen zerstreuten sich: Im Oktober 1877 siegten bei den französischen Wahlen die Republikaner, und 1878 starb der „intransigente" Papst Pius IX. Wie von Bismarck erwartet, trat mit Leo XIII. ein versöhnlicher Papst an dessen Stelle. Damit entspannte sich die Lage, was Bismarck für den Rückzug aus dem Kulturkampf nutzte. Dostoevskij hatte eine solche Wendung der Papstfrage nicht ins Auge gefaßt. Das Ereignis aber, das ihm endgültig die Augen öffnete und ihn die Größe seines Irrtums erkennen ließ, war der Berliner Kongreß von 1878, auf dem die Großmächte die Ergebnisse des Russisch-Türkischen Krieges verhandelten. Die russische Regierung hatte die weitgehenden Forderungen, die sie der Türkei im Vorfrieden von San Stefano diktiert hatte, international nicht durchsetzen können. Dem Kongreß hatte sie nur unter der Bedingung zugestimmt, daß er in Berlin, in der Hauptstadt des verbündeten Deutschland, stattfände. ${ }^{126}$ Man setzte darauf, daß die deutsche Regierung, die ja bereits ihr Verständnis für eine russische Einnahme Konstantinopels bekundet hatte, ihrer Dankespflicht für 1870/71 nachkommen und sich auf dem Kongreß hinter Rußlands Forderungen stellen werde. Bismarck aber war verstimmt über den russischen Ton, „der mehr für säumige

125 Joachim Scholtyseck: Allierter oder Vasall? (wie Anm. 36), S. 160 f., 180, 345 f., führt englische, italienische und französische Stimmen an; ebenso den russischen Staatskanzler Gorčakov, der die zunehmende internationale Isolation des Deutschen Reichs erkannte und zu nutzen wußte. 126 Siehe Die große Politik der europäischen Kabinette 1871-1914. Reihe 2, Bd. 1 (wie Anm. 100), S. $31 \mathrm{f}$. 


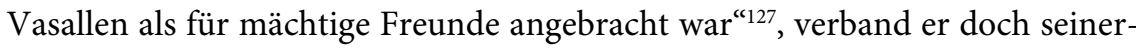
seits mit der Vermittlerrolle beim Interessenausgleich auf dem Balkan die Absicht, gerade die Unabhängigkeit der deutschen Außenpolitik zu unterstreichen und so internationales Ansehen zu gewinnen. Der Zar und der alte russische Staatskanzler Gorčakov waren erbost über die deutsche Haltung. Rußland fühlte sich um die Früchte des Sieges betrogen. In der Folge kam es zu einer empfindlichen Abkühlung des deutsch-russischen Verhältnisses, sowohl auf Regierungsebene als auch in der öffentlichen Stimmung.

Während der konservative alte Kaiser Wilhelm zu retten versuchte, was zu retten war, indem er seinen Neffen Alexander beschwichtigte, suchte Bismarck nach neuen Bündnisoptionen. ${ }^{128}$ Er sondierte in London die Stimmung und schloß mit Österreich einen Zweibund, dem sich Rußland notgedrungen anschloß, um zu verhindern, daß das Bündnis zu seinem Schaden ausschlagen würde. Eine Verbesserung des deutsch-russischen Verhältnisses konnte damit aber nicht mehr bewirkt werden. Da das Deutsche Reich nicht als fester Bündnispartner zu gewinnen war, orientierte sich die russische Politik nun um auf ein Bündnis mit Frankreich, um Deutschland in Schach halten zu können.

Über die Ereignisse der Jahre 1878/79 liegen von Dostoevskij keine Kommentare vor. Doch unübersehbar ist, daß er sich nach Wiederaufnahme des „Tagebuchs“ im Jahr 1880 im Sinne einer Sonderrolle Deutschlands nicht mehr geäußert hat. Das Land in der Mitte Europas sank in seiner Vorstellung wieder hinter die Grenzen der westlichen Welt zurück. Die alte Zeiteilung in „Rußland und den Westen“ trat wieder in Geltung.

\section{Schweigen über Deutschland}

Dennoch war dies keine Rückkehr zur slavophilen Konzeption. Dostoevskij wandte in den letzten Nummern seines "Tagebuchs eines Schriftstellers“ den Blick nach Osten. Seine Überlegungen zur Position Rußlands lösten sich von der Fixierung auf Europa und richteten sich auf die Lage Rußlands zwischen zwei Kontinenten. Auch diese Wende war eng verbunden mit aktuellen politischen Ereignissen. Die Siege des Generals Michail D. Skobelev ${ }^{129}$ in Turkestan

127 Bismarck an Kaiser Wilhelm I. am 7. September 1879. In: Die große Politik (wie Anm. 100), Bd. 3, 4. Aufl. Berlin 1927, S. 53.

128 Im sogenannten „Ohrfeigenbrief“ Alexanders an seinen Onkel vom 15. August 1879, ein Jahr nach Ende des Berliner Kongresses, drohte der Verfasser, mit Deutschland zu brechen, wenn es weiter reserviert bleibe.

$129 \mathrm{Zu}$ den deutschfeindlichen Positionen des Generals Michail Skobelev vgl. Lew Kopelew: Am 
vom Januar 1881 versprachen eine Zurückdrängung des britischen Einflusses, durch die dem „weißen Zar“ die Vorherrschaft über „alle Khane, Emire und Kalifen Asiens" anheimfallen könnte. Dostoevkij sprach nun von zwei Wurzeln Rußlands, deren eine, asiatische, zugunsten der anderen, europäischen, vernachlässigt worden sei und nun wiederentdeckt und gepflegt werden müsse. Rußland sollte seine Politik auf dieser Doppelbasis definieren. Kennzeichnend ist, daß selbst in der Abwendung von Europa sich die Identifikation mit eben diesem Europa fortsetzte. Dostoevskijs geistige Bindung an den Westen war so unwiderruflich, daß sich seine ganze Hoffnung darauf richtete, in Asien könne Rußland endlich wie Europa werden. In einem imaginären Dialog erklärte er dem Zweifler:

„Sehen Sie, durch die Wendung nach Asien und durch unsere neue Auffassung dieses Landes kann mit uns vielleicht dasselbe geschehen, was zum Beispiel mit Europa geschah, als Amerika entdeckt wurde. [...] Mit der Hinwendung nach Asien wird sich unser Geist wieder erheben und werden unsere Kräfte wieder erstarken. ${ }^{\text {"130 }}$

Dieser Wunsch hatte wie alle politischen Überlegungen Dostoevskijs neben einer geistig-ideellen Seite wiederum den Aspekt von Macht und Prestige:

In Europa waren wir [...] Gnadenbrotesser und Sklaven; nach Asien aber kommen wir als Herren. In Europa waren wir Tataren, in Asien aber sind auch wir Europäer. Unsere Mission, die zivilisatorische Mission in Asien, wird unseren Geist beflügeln und uns dorthin locken, sobald die Sache in Bewegung kommt. ${ }^{131}$

Hervorzuheben ist, daß Dostoevskij die Abwendung von Europa nicht mit der Altersschwäche oder Überlebtheit der europäischen Kultur begründete - ein slavophiles Stereotyp, das aber auch unter den Westlern geläufig war und im russischen Revolutionsdenken weiterverfolgt wurde -, sondern daß sie mit dem Scheitern des jahrhundertelangen russischen Werbens um die Gunst Europas erklärt wurde. In Anlehnung an Nikolaj Danilevskij ${ }^{132}$ erinnerte er an die

Vorabend des großen Krieges. In: Mechthild Keller (Hg.): Russen und Rußland aus deutscher Sicht. 19./20. Jahrhundert: Von der Bismarckzeit bis zum Ersten Weltkrieg (= West-östliche Spiegelungen, Bd. 4 A). München 2000, S. 55 ff.

130 DP Januar 1881, Kap. 2/IV: Voprosy i otvety (Fragen und Antworten); XXVII, S. 36.

131 Ebd., S. 36 f.

132 N. Danilevskij: Rossija i Evropa (Rußland und Europa). Moskau 1991, Kap. 2: „Warum ist Europa Rußland feindlich gesonnen?", S. 23-53. Dieses 2. Kapitel ist - wie andere auch - in der deutschen Ausgabe nicht enthalten. Karl Nötzel schreibt in der Vorbemerkung: „Unübersetzt bleiben bloß diejenigen Abschnitte, die entweder durch den Lauf der Geschichte schon all- 
historischen Momente, in denen angeblich Rußland im erfolglosen Bemühen um die Anerkennung Europas diesem seine Dienste angeboten habe. Bereits früher hatte er die gesamte russische Geschichte des 19. Jahrhunderts als eine Politik der Sorge um Europa interpretiert, wobei er die christliche Uneigennützigkeit der russischen Politik hervorgehoben hatte. Nun aber kam es ihm nicht auf das Wesen der Politik Alexanders I. und Nikolaus I. an, sondern auf die Prüfung ihrer Ergebnisse. Dabei gelangte er zu der Schlußfolgerung, daß der Dienst an Europa dem Zarenreich nichts als Isolation und Unverständnis eingebracht habe, während die Möglichkeiten des Machtgewinns ungenutzt blieben.

Als den schwerwiegendsten Initialfehler russischer Europapolitik betrachtete er die Tatsache, daß Rußland „unsere Heere aussandte, um ihre Könige zu retten" (XXXVII, 33; gemeint sind die Feldzüge gegen Frankreich). Die Kriege Alexanders I. gegen Napoleon hätten Europa gerettet, ohne Rußland irgendeinen Gewinn zu bringen, selbst die Anerkennung dafür sei ihm versagt worden. Ähnlich fruchtlos habe der Einsatz des russischen Heeres im Jahr 1849 zur Niederschlagung des ungarischen Aufstands geendet. Österreich, das dabei vor dem Untergang bewahrt wurde, habe keine Dankbarkeit gezeigt, Rußland aber habe sich den Haß der europäischen Völker zugezogen. Als weitere nachteilige politische Entscheidungen nannte er die Unterstützung der „deutschen Mächte“, die unter russischem Schutz hätten stark werden können (XXVII, 34), Rußlands Bereitschaft, Konflikte zwischen den europäischen Staaten zu schlichten (hier kann man an die Olmützer Punktation 1850 und an die Kriegin-Sicht-Krise denken) und seine freiwillige Unterwerfung unter europäische Kongreßbeschlüsse ${ }^{133}$, die seinen Interessen nicht entsprachen, obwohl es, machtpolitisch gesehen, auf eigene Faust erfolgreicher hätte handeln können.

Ein aufschlußreiches Bild ergibt die Überprüfung dieser meist in Andeutungen und Anspielungen gehaltenen Aufzählung Dostoevskijs von 1881 auf die Frage hin, welche Länder im einzelnen unverdient von der russischen Politik profitierten und so seinen Unmut hervorriefen: Die Vorwürfe und Klagen, auch

zusehr überholt sind oder gar zu ausführlich in die Einzelheiten der geschichtlichen Theorie des Autors einführen." Vgl. N. J. Danilewsky: Rußland und Europa. Eine Untersuchung über die kulturellen und politischen Beziehungen der slawischen zur germanisch-romanischen Welt. Übers. und eingeleitet von Karl Nötzel. Osnabrück 1965 (= Neudruck der Ausgabe 1920), S. 9.

133 DP Januar 1881, Kap. 2/III: Geok-Tepe. Čto takoe dlja nas Azija? (Geok-Tepe. Was bedeutet uns Asien?); XXVII, S. 34. Angespielt wird etwa auf den Wiener Kongreß 1814/15, auf dem die Forderung Alexanders I., das Herzogtum Warschau Rußland zuzuschlagen und Preußen mit Sachsen zu entschädigen, England, Frankreich und Österreich provozierte und fast einen Krieg heraufbeschworen hätte, aber auch auf den Berliner Kongreß 1878. 
wenn sie allgemein formuliert sind, beziehen sich nämlich fast ausschließlich auf Österreich und Deutschland. Ganz offensichtlich vermied es Dostoevskij aber, diese Länder zu nennen, und zog es vor, allgemein von „Europa“ zu sprechen.

Intensiv setzte er sich im Rückblick besonders mit der politischen Lage von 1813/14 auseinander. In der Nachfolge Nikolaj Danilevskijs, der sich seinerseits auf Michail Kutuzov berief, den russischen Oberbefehlshaber des Befreiungskrieges, formulierte Dostoevskij die These, daß es falsch gewesen sei, nach der Vernichtung des französischen Heeres die russische Armee nach Westen weitermarschieren zu lassen, „um Europa zu beglücken“. Rußland hätte damals besser daran getan, sich mit Napoleon zu versöhnen.

Das gab natürlich ein schönes Bild ab: Auf der einen Seite stand der Despot und Räuber, auf der anderen - der Friedensstifter und Erwecker. Doch unsere politische Fortune bestand damals durchaus nicht in jenem Bild, sondern darin, daß sich dieser Räuber gerade zu jeder Zeit, zum ersten Mal während seiner ganzen Laufbahn, in einer Lage befand, in der er mit uns einen festen und aufrichtigen Frieden geschlossen hätte, und das für lange Zeit, vielleicht für immer. Unter der Bedingung, daß wir ihm in Europa nicht ins Gehege kommen, hätte er uns den Osten überlassen, und unsere heutige Orientfrage [...] wäre jetzt schon längst gelöst. [...] Wir aber gaben alles hin um eines schönen Bildes willen! ${ }^{134}$

Gerade für Preußen und Deutschland war die damalige russische Entscheidung gegen ein Bündnis mit Napoleon eine schicksalhafte Wende und der Beginn eines nationalen Aufstiegs gewesen. Dostoevskij aber trauerte nun aus einem antideutschen Impuls heraus der verlorenen politischen Chance eines frühen russisch-französischen Bündnisses nach und schloß sich mit einer Verspätung von zwölf Jahren der Geschichtsinterpretation an, die Danilevskij bereits ein Ende der sechziger Jahre vorgetragen hatte. Kennzeichnend ist die gleichbleibende übersichtliche Grundkonzeption: Rußland teilt die Herrschaft mit einem mächtigen westlichen Nachbarn, der sich in Europa durchsetzt und alle anderen europäischen Staaten in Schach hält. Hatte er doch vier Jahre zuvor über Deutschland geschrieben:

$[\ldots]$ es hat die ganze westliche Welt Europas für sich bestimmt [...], Rußland aber überläßt es den Osten. ${ }^{135}$

134 Ebd.

135 DP November 1877, Kap. 3/III: Nado lovit' minutu (Man muß den Moment nutzen); XXVI, S. 91. 
$\mathrm{Da}$ der antideutsche Impuls aus einer großen persönlichen Enttäuschung entstand, hat Dostoevskij nirgends direkt geäußert. Man kann nur feststellen, daß Bismarcks Name in seinen Texten fortan kaum noch Erwähnung fand, es sei denn beiläufig oder abfällig. Um so signifikanter ist eine Warnung, die Dostoevskij 1879 an den in Berlin ansässigen Herausgeber einer russischen Zeitung richtete, dem er des öfteren gute Ratschläge erteilte. Er schrieb dem jüngeren Journalistenkollegen ins Stammbuch:

Wenn Sie noch einmal eine Nr. mit einer solchen Unterwürfigkeit gegen Bismarck herausgeben, wird ganz Rußland von Ihnen Abstand nehmen. [...] Man wird sogar denken, daß Sie sich im Reptilgang an ihn heranmachen wollen. ${ }^{136}$

Ähnlich erniedrigend mochte ihm im nachhinein seine eigene Idealisierung des Deutschen Reichs und sein Bismarcklob vorgekommen sein. Auch manche Nebentöne seiner großen Klage über die europäische Ablehnung Rußlands in Tagebuch eines Schriftstellers bestätigen diese verborgenen emotionalen Vorgänge und lassen Spuren der persönlichen Enttäuschung erkennen:

[...] zuweilen sind wir ihnen [den Europäern] so zuwider, so völlig zuwider, besonders wenn wir uns ihnen mit brüderlichen Küssen an den Hals werfen. ${ }^{137}$

Wer waren die Europäer, denen man sich „an den Hals geworfen“ hatte? Frankreich, das er am liebsten politisch vernichtet gesehen hätte, konnte nicht gemeint sein, und England hatte für ihn immer abseits der europäischen Bühne gestanden. Gemeint waren in erster Linie die Deutschen. Schmerz und Scham über sein kolossales persönliches Fehlurteil bezüglich der deutsch-russischen Zukunft waren es, die ihn das Objekt seiner Anklage hinter dem weiten Begriff „Europa“ verbergen ließen.

\section{Habent sua fata libelli}

Bücher haben ihre Schicksale. Das Tagebuch eines Schriftstellers war in seiner Wirkung eng an die persönliche Autorität des Autors gebunden. Gaben aber bereits zu Lebzeiten Dostoevskijs manche seiner Analysen sich als zeitverhaftet zu erkennen, mußten die aus der Kriegsstimmung von 1876/77 entstandenen Weissagungen über Deutschland während der nächsten Jahrzehnte, die po-

136 Brief vom 23. August/4. September 1879 aus Bad Ems an V. F. Pucykovič, den Herausgeber der Zeitschrift „Russkij graždanin“, die in Berlin erschien (XXX, 1, S. 118).

137 DP Januar 1881, Kap. 2/III: Geok-Tepe. Čto takoe dlja nas Azija? (Geok-Tepe. Was bedeutet uns Asien?); XXVII, S. 35. 
litisch von der russisch-französischen Verständigung geprägt waren, völlig widerlegt und überholt wirken.

Doch der zunehmende literarische Ruhm Dostoevskijs beim europäischen Lesepublikum bewog den frischgegründeten Piper Verlag, 1906 mit der Herausgabe seiner gesammelten Werke auf deutsch zu beginnen. Dabei nahm man sich auch des „Tagebuchs eines Schriftstellers“ an. Die Texte wurden gekürzt, neu arrangiert, Politisches und Literarisches getrennt und thematisch gruppiert. Die Artikel zur deutschen Frage fanden Aufnahme in einem Band mit dem Titel „Politische Schriften“, der 1907 zum ersten Mal erschien.

Als Herausgeber wirkte der jungkonservative Publizist Arthur Moeller van den Bruck mit, der später, 1923, die Schrift „Das Dritte Reich2 veröffentlichen sollte. Ihn interessierte die zentrale Stellung der nationalen Idee in Dostoevskijs Denken. ${ }^{138}$ Teils glaubte er sich mit dem russischen Schriftsteller in wesentlichen Fragen einig, vor allem in der Ablehnung der westeuropäischen Zivilisation, teils ahmte er dessen russisch-nationales Pathos nach, um seine eigenen deutsch-nationalistischen, rassistisch beeinflußten Phantasien vorzutragen, die mit Dostoevskijs religiös begründetem Sendungsgedanken allerdings bereits nichts mehr zu tin hatten. Inhaltlich weniger zentral scheinen für Moeller van den Bruck Dostoevskij Äußerungen über Deutschland gewesen zu sein, da sie mit seinem Ziel einer exklusiven deutschen Vormachtstellung nicht vereinbar waren.

Das Großprojekt des Piper Verlags fand zunächst insgesamt eine verhaltene Aufmerksamkeit. Dies änderte sich erst, als die Erfahrung des Ersten Weltkriegs der Dostoevskij-Rezeption eine neue Grundlage gab. Auch die vierzig Jahre zurückliegenden Aussagen des „Tagebuchs eines Schriftstellers“ erhielten ein völlig neues Gewicht. Die Prophezeiung vom Zusammenwachsen der Orientfrage und des Deutsch-Französischen Kriegs zu einem Weltkrieg bewahrheitete sich, vor allem aber erwies sich unvermutet, wie hellsichtig, allen Irrtümern zum Trotz, die Analysen und Weissagungen zur Brüchigkeit der europäischen Gesellschaftsordnung gewesen waren. Eine neue Welle der Auseinandersetzung mit Dostoevskij begann. (Doch der Prophet galt nichts im eigenen Land: man überließ seine Schriften den Emigranten und den Ausländern.)

Auch die veralteten Weissagungen des „Tagebuchs eines Schriftstellers“ wurden wieder gelesen. Die aufgewühlte Stimmung des Ersten Weltkriegs förderte

138 Vgl. Christoph Garstka: Arthur Moeller van den Bruck und die erste deutsche Gesamtausgabe der Werke Dostojewskijs im Piper-Verlag 1906-1919. Frankfurt a. M. u.a. 1998, S. 52 f. 
eine Beschäftigung mit Fragen der nationalen Sendung, und so fanden nicht zufällig gerade jetzt Dostoevskijs Gedanken aus den Jahren 1876/77 über Deutschlands historische Rolle Eingang in die aktuelle deutsche Selbstreflexion.

Einer der aufmerksamsten, verständnisvollsten und dankbarsten Leser, die das Tagebuch eines Schriftstellers während des Ersten Weltkriegs hatte, war Thomas Mann. Bereits der Titel des Buches, an dem er damals schrieb, Betrachtungen eines Unpolitischen, klingt wie ein Echo auf den Titel Tagebuch eines Schriftstellers. ${ }^{139}$ Der russische Schriftsteller war ihm als konservativer Publizist ein Vorbild, ein Bundesgenosse gegen französische „Zivilisation“, als Angehöriger eines allseits verkannten und verhaßten Volks ein Leidensgenosse und ein großer Anreger durch seine kluge Aufmerksamkeit für das Schicksal Deutschlands.

Dostoevskijs Wort vom „protestierenden Land“ durchzieht als Leitmotiv das ganze Buch. Bereits das erste Kapitel trägt die fanalartige Überschrift „Protest" und macht Dostoevskijs Gedanken zum Ausgangspunkt aller folgenden Überlegungen. Man kann in der Tat Thomas Manns Schrift wie einen großen Dialog mit dem Autor des „Tagebuchs eines Schriftstellers“ lesen. Dieser Dialog basierte auf einem breiten gemeinsamen Themenfundus. Die eigentliche Herausforderung jedoch bestand für Thomas Mann in der offen gebliebenen Frage Dostoevskijs: Was macht die deutsche „Idee“ aus? Was steckt hinter dem deutschen „Protestantentum“?

Dostoevskij hatte erwartet, daß die Deutschen ihr nicht ausgesprochenes „Wort“ einmal sagen würden und wie alle großen Völker, indem sie es aussprechen, die Welt anführen wollten. Thomas Mann griff diesen Gedanken in seinen „Betrachtungen“ auf: Auch er konnte keine fest umrissene nationale Idee bei den Deutschen finden. Doch vermeinte er gerade im Fehlen des „Worts“, in der „Unartikuliertheit“ etwas charakteristisch Deutsches zu erkennen, das in einem ursächlichen Zusammenhang mit den Neigungen der deutschen Kultur zu den universalen, nicht sagbaren Dingen stehe. Mit künstlerischer Intuition Dostoevskijs Faden weiterspinnend, setzte Thomas Mann die „Wortlosigkeit“ in Beziehung zur Musikalität der deutschen Kultur (die er persönlich am intensivsten in Richard Wagners Werk erfahren hatte). Das Musikalische aber, an das Elementare, „Barbarische“ rührend, sah er in einer „lockeren“ Beziehung zur Humanität als die romanische Kultur des Wortes.

139 Über Thomas Manns Verhältnis zu Rußland siehe ausführlich Gerd Koenen: Betrachtungen eines Unpolitischen. Thomas Mann über Rußland und den Bolschewismus. In: Gerd Koenen, Lew Kopelew (Hg.): Deutschland und die russische Revolution 1917-1924 (= West-östliche Spiegelungen, Bd. 5 A). München 1998, S. 313-379. 
Hier deuten sich Motive an, die Thomas Mann später im Doktor Faustus ausarbeitete und mit deren Hilfe er in der deutschen Geistesgeschichte die Linie $\mathrm{zu}$ finden suchte, die die Katastrophe des Nationalsozialismus vorbereitet hatten.

So entwickelten sich Grundzüge deutscher Selbstreflexion des 20. Jahrhunderts in der Berührung mit Dostojevskijs Deutschlandvisionen. Auch prognostisches Potential wurde aktiviert: Thomas Mann formulierte die Ahnung, daß ein Volk, das „wortlos“ ist, keine führende Rolle in der Welt übernehmen kann. Und er äußerte, ermutigt durch das russische Vorbild, wenn auch mit deutscher Zurückhaltung vorgetragen, selbst eine Voraussage, die die deutsche Geschichte des 20. Jahrhunderts zusammenfaßte: „Europäische Kriege, sofern sie nur auch im Geistigen geführt werden, und das müssen sie immer, werden zugleich auch deutsche Bruderkriege sein, das bleibt das Schicksal dieses europäischen Herzvolks, und das ist, bei aller Wucht seines Leibes, seine innere, sittliche, seine politische Schwäche - es wird vielleicht sein Verhängnis sein.“

Zuerst erschienen in: Dagmar Herrmann, Mechthild Keller (Hg.): Zauber und Abwehr. Zur Kulturgeschichte der deutsch-russischen Beziehungen. München 2003, S. 202-263. 


\section{Andreas Guski}

\section{Die Konstruktion Westeuropas in Dostoevskijs „Winteraufzeichnungen über Sommereindrücke“}

Im Dezember 1859, fast auf den Tag genau zehn Jahre nachdem er in Ketten den langen Weg nach Sibirien angetreten hatte, kehrt Dostoevskij nach Sankt Petersburg und damit ins literarische Leben Rußlands zurück. Hier versucht er, an seine Erfolge der 1840er Jahre anzuknüpfen, vor allem an den seines Debütwerks Arme Leute (Bednye Ljudi, 1846). Die Romane Das Dorf Stepantschikowo und seine Bewohner (Selo Stepančikovo i ego obitateli 1859) und Die Erniedrigten und Beleidigten (Unižennye i oskorblennye, 1861) nimmt die Kritik allerdings eher ungnädig auf. Umso größer wird dafür der Erfolg der Aufzeichnungen aus einem Totenhaus (1861). Vielversprechend läßt sich in dieser Zeit auch die gemeinsame Tätigkeit Dostoevskijs und seines Bruders Michail als Verleger und Herausgeber des Journals „Die Zeit“ (Vremja) an. Ideologisch vertritt „Die Zeit“ die Position der sogenannten „Bodenständigkeit“ (počvenničestvo), eine gemäßigte Form des Slavophilentums, die neben den Brüdern Dostoevskij vor allem die Kritiker Apollon Grigor'ev und Nikolaj Strachov (1828-96) repräsentierten. Daß die Zeitschrift der Dostoevskij-Brüder überhaupt erscheinen konnte, verdankte sie der Reformpolitik des neuen Zaren Alexander II., der nicht nur die Aufhebung der Leibeigenschaft und eine grundlegende Justizreform, sondern auch eine ausgesprochen liberale Pressepolitik durchsetzte.

Die Lockerung der Zensur führt in den 1860er Jahren zu einem deutlichen Aufschwung des Verlags- und Pressewesens, damit aber auch zur wachsenden Polarisierung der veröffentlichten wie der öffentlichen Meinung. Der politischen Linken geht das Manifest über die Aufhebung der Leibeigenschaft nicht weit genug. In verschiedenen Provinzen des Reiches kommt es zu Bauernaufständen, in Petersburg zwei Wochen lang zu Brandschatzungen durch eine Gruppe, die sich als „Junges Russland“ bezeichnet und deren geistigen Vater Dostoevskij in Nikolaj Černyševskij sieht, dem Herausgeber des linken Journals „Der Zeitgenosse“ (Sovremennik). Von den Positionen des utopischen Sozialismus, die er in den 1840er Jahren bezogen hatte, hat sich Dostoevskij 
inzwischen weit entfernt. Diesen Abstand zu markieren, sollte die wesentliche Aufgabe eines Textes sein, der - obwohl in deutschen Dostoevskij-Ausgaben eher vernachlässigt - zu den programmatischen Schlüsselwerken des Autors zählt und der den Titel trägt Winteraufzeichnungen über Sommereindrücke (Zimnie zapiski o letnich vpečatlenijach). Entstanden im Winter 1862/63 und erstmals 1863 in Dostoevskijs "Zeit“ veröffentlicht, stellt dieser Text den literarisch-publizistischen Ertrag seiner ersten Europareise dar, die er vom 7. (19.) 6. bis 22.8. (3.9.) 1862 unternahm.

„Erst mit vierzig Jahren sollte es mir endlich möglich sein, ins Ausland zu reisen - da wollte ich selbstverständlich nicht nur so viel wie möglich, sondern unbedingt alles, unbedingt alles sehen, ungeachtet der kurzen Zeit, die mir zur Verfügung stand. “1

Ein Dreivierteljahrhundert zuvor war ein anderer russischer Autor von Petersburg nach Westeuropa aufgebrochen: der Schriftsteller, Publizist und Historiker Nikolaj Karamzin, dessen 1791/92 erschienene „Briefe eines russischen Reisenden" dem heimischen Publikum über ein Europa berichteten, das der Verfasser sich zuvor durch die Lektüre großer Geister des 18. Jahrhunderts angeeignet hatte. Als Bildungsreisender war Karamzin auf den Spuren dieser Geistesgrößen gewandelt oder in direkten persönlichen Kontakt mit ihnen getreten (Kant in Königsberg, Herder in Weimar, Lavater in Zürich), und zwar stets als „russischer Europäer und europäisierter Russe“.2 Karamzins Tour durch Deutschland, die Schweiz, Frankreich und England galt in Rußland jahrzehntelang als Norm der Europareise. Spätere russische Europatouristen pflegten ihre Erfahrungen und Eindrücke mit denen Karamzins zu vergleichen. ${ }^{3}$ Noch 1866 schreibt Fedor Buslaev, einer der Gründungsväter der slavischen Philologie, Karamzins „Reisebriefen“ eine für Rußland „außergewöhnlich zivilisierende

1 Fedor M. Dostoevskij: Polnoe sobranie sočinenij v tridcati tomach. Tom 5. Leningrad 1973, S. 46. Im weiteren beziehen sich alle in Klammern gesetzten Seitenzahlen der (von mir übersetzten) Dostoevskij-Zitate auf diese Ausgabe. - Der des Russischen nicht kundige Leser sei zur Lektüre der „Winteraufzeichnungen“ verwiesen auf die insgesamt zwar durchaus brauchbare, nach fast einem Jahrhundert in vielen Punkten jedoch revisionsbedürftige Übersetzung von E.K. Rahsin in: F.M. Dostojewski: Autobiographische Schriften, München 1923, neuerdings wieder zugänglich durch die Ausgabe: F. Dostojewski: Aufzeichnungen aus einem Totenhaus und drei Erzählungen, München 2004.

2 Klaus Städtke: Russische Literaturgeschichte. Stuttgart und Weimar 2002, S. 119.

3 Jurij M. Lotman, Boris A. Uspenskij: „Pis'ma russkogo putešestvennika Karamzina“ i ich mesto v razvitii russkoj kul'tury. In: Nikolaj M. Karamzin: Pis'ma russkogo putešestvennika. Lenin$\operatorname{grad} 1987$, S. 531. 
Kraft“ zu. ${ }^{4}$ Obwohl erst drei Jahre nach den „Winteraufzeichnungen“ erschienen, ist diese Aussage für die Lektüre unseres Textes als Kontrastfolie insofern aufschlußreich, als die polemische Dimension von Dostoevskijs „Winteraufzeichnungen“ sich nicht zuletzt aus ihrer kritischen Einstellung zu Karamzins Reisebriefen, insbesondere zur Attitüde des „europäisierten Russen“ erklärt.

Natürlich hat Dostoevskijs Abstandnahme von Karamzin ihren Grund auch darin, daß sich der Reisetypus der Grand Tour, dem sich Karamzins Text verdankt, spätestens seit Mitte des 19. Jahrhunderts erledigt hat. Der mit dem Ausbau des europäischen Eisenbahnnetzes einsetzende Massentourismus macht das Erfahrungsmuster der klassischen Bildungsreise, zu der das behagliche Tempo der Postkutsche gehört hatte, obsolet. Ironisch skizziert Aleksandr Gercen (Alexander Herzen) 1858 in seinen Briefen aus Frankreich und Italien die durch die Eisenbahn bewirkte Beschleunigung des Reisens und der Wahrnehmung:

„Wie oft habe ich davon geträumt, wie großartig und nützlich das Reisen sein würde, wenn endlich die Königsberger Eisenbahn fertig ist! Ich schleppte mich nach Königsberg, nahm Platz in einem Waggon - und dann ging es los. Die Maschine stieß einen Pfiff aus und setzte sich stampfend in Bewegung: Berlin - 4 Minuten für das Auffüllen der Wassertanks; Köln - 3 Minuten für das Schmieren der Waggonräder; Brüssel - 5 Minuten für die Eroberung eines Schinkenbrötchens; Valenciennes - 4 Minuten, um der französischen Regierung zu beweisen, daß sie nicht imstande ist, geschmuggelte Zigarren zu entdecken; Paris 15 Minuten für die Omnibusfahrt von einem Bahnhof zum anderen; Le Havre drei Minuten für die Einschiffung ... und dann kommt schon New York, und Du bist, mit einem Wort, hast Du nicht gesehen, wieder [...] in Sibirien, d.h. schon wieder zu Hause. ${ }^{\text {"5 }}$

Dostoevskijs „Winteraufzeichnungen“ folgen dem Textmuster von Gercens „Briefen“ in stilistischer wie teilweise auch in konzeptioneller Hinsicht. An die Stelle des bildungsbeflissenen Enthusiasten und Schwärmers, zu dem Karamzin sich in seinen Reisebriefen stilisiert hatte ${ }^{6}$, tritt der moderne Intellektuelle, dessen Blick auf die Welt ein grundsätzlich kritischer, skeptischer und fast immer ironisch gefilterter ist. Waren Karamzins Reisebriefe „eine Art belletrisierter Baedeker" ${ }^{\text {"7 }}$, so gilt für Dostoevskijs „Winteraufzeichnungen“ das genaue

4 Vgl. ebd. S. 530.

5 Aleksandr I. Gercen: Sočinenija i perepiska s N. A. Zachar'ina v semi tomach. Tom 5. SanktPeterburg 1905, S. 7.

6 Zur Figur des Schwärmers vgl. N. Miller: Der empfindsame Erzähler. Untersuchungen zu Romananfängen des 18. Jahrhunderts. München 1968.

7 Lotman, Uspenskij (1987), S. 531. 
Gegenteil. Nichts liege ihm ferner, so läßt der Autor seine Leser schon einleitend wissen, als ein Bericht über europäische Sehenswürdigkeiten, denn:

„Was könnte ich Ihnen schon Neues, Unbekanntes, nicht längst schon Erzähltes berichten? Wem von uns Russen (zumindest denjenigen, die Zeitschriften lesen) ist Europa nicht doppelt so bekannt wie Rußland?“ (46)

Damit entfällt ein wesentliches Motiv nahezu allen Reisens: die Neugier des Reisenden und im Zusammenhang damit das Motiv des Staunens, des SichWunderns, das zu den elementaren Effekten des Reisens ebenso wie des Reiseberichts gehört. Verwunderung ist eine elementare Reaktion auf Fremdes; und das Wunderbare war denn auch das „zentrale Merkmal des gesamten Repräsentationssystems, mittels dessen die Europäer des Spät-Mittelalters und der Renaissance“ die neue Welt „in Besitz nahmen oder verwarfen“. 8 Als Erwartungshorizont des Reisenden wird das Wunderbare auch von Dostoevskij erwähnt, so wenn er - in Anspielung auf Aleksej Chomjakovs slavophiles Programmgedicht „Traum“ (Mečta, 1835) - Europa als „heiliges Land der Wunder“ (47) bezeichnet. Vergegenwärtigt man sich allerdings den Kontext dieses Zitats, so zeigt sich, daß das Wunderbare als Wesensmerkmal Westeuropas und damit auch jede Bewunderungspflicht der Russen gegenüber dem Westen hier gerade in Frage gestellt werden. Chomjakovs Gedicht beginnt mit den Worten: „Weh ist mir, weh ums Herz! Aufs Land der heil'gen Wunder, / Den fernen Westen, senkt sich tiefe Nacht [dichte Finsternis] “. ${ }^{9}$ Es folgt eine Vision Europas als weltweit bewundertes und gepriesenes Reich der Wissenschaften, in dem die Sonne der Vernunft nie unterzugehen schien, ein Land der höchsten Kultur, wie die Welt es zuvor nie gesehen habe. Dieses goldene Zeitalter Europas aber ist für Chomjakov Vergangenheit. Wo einst die Fackel der Aufklärung geleuchtet habe, werde nun bald tiefste Finsternis herrschen. ${ }^{10}$ Das Gedicht endet mit einem Appell an „den Osten“: „Vernimm des Schicksals Wort, erstrahl' in neuem Glanze, / Erwache, Ost, aus deinem Schlaf!“"11 Unüberhörbar

8 Stephen Greenblatt: Wunderbare Besitztümer. Die Erfindung des Fremden: Reisende und Entdecker. Berlin 1994, S. 35. Zum Motiv der Neugier bei Karamzin vgl. auch Joachim Klein: Russische Literatur im 18. Jahrhundert. Köln, Weimar, Wien 2008, S. 310 f.

9 „O grustno, grustno mne! Ložitsja t'ma gustaja / Na dal'nem Zapade, strane svjatych čudes.“ Aleksandr S. Chomjakov: Stichotvorenija i dramy. Leningrad 1969, S. 103.

10 Die Reflexionen Stavrogins in den „Dämonen“ und Versilovs im „Jüngling“ über Claude Lorrains berühmtes Gemälde „Küstenlandschaft mit Acis und Galatea“ werden Chomjakovs Motiv der untergehenden Sonne der Aufklärung später wieder aufgreifen.

11 „Uslyš, že glas sud'by, vosprjan' v sijan'i novom, / Prosnisja, dremljuščij Vostok!“ Chomjakov (1969), S. 103. 
klingt hier ein Leitmotiv des russischen Slavophilentums an, die Vorstellung nämlich, daß nach der Dominanz verschiedener westeuropäischer Kulturen nunmehr Rußland bzw. die Slaven an der Reihe seien, die kulturelle Führung Europas zu übernehmen.

Dostoevskij passiert am Morgen des 7. Juni im ostpreußischen Eydtkuhnen (heute Černyševskoe) die Grenze zu Deutschland. Entschlossen, in diesem Land keinerlei Sehenswürdigkeiten zu bewundern, ja es zur Sehensunwürdigkeit schlechthin zu degradieren, bereist er im Eiltempo die deutschen Fürstentümer, wo er von den insgesamt zehn Wochen seiner ersten Europa-Reise immerhin zweieinhalb verbringt, allerdings fast jede Nacht in einer anderen Stadt. Am 9.6. ist er in Berlin, am 10.6. in Dresden, am 11.6. in Frankfurt am Main, am 12.6. in Wiesbaden, am 13.6. in Heidelberg, am 14.6. in Mainz, am 15.6. in Köln. Über Berlin, das damals bereits mehr als eine halbe Million Einwohner zählte und in den 1860er Jahren zunehmend zum Schauplatz der großen europäischen Politik wurde, heißt es: „Berlin hat auf mich einen ausgesprochen säuerlichen Eindruck gemacht, und ich habe dort auch nur 24 Stunden verbracht.“ (47) Gegen das Wunderbare und dessen ästhetische Entsprechungen - das Erhabene und das Schöne - tritt hier „das Säuerliche“ an, also eine Kategorie des Gewöhnlichen und Trivialen. Berlin wirkt deshalb trivial, weil es „unwahrscheinlich ähnlich aussieht wie Petersburg. Die gleichen schnurgeraden Straßen, die gleichen Gerüche [...] Mein Gott, dachte ich, hat es sich gelohnt, sich zweimal vierundzwanzig Stunden lang im Zug rädern zu lassen, um dann genau das Gleiche zu Gesicht zu bekommen wie das, was man hinter sich gelassen hat?" (47) Kaum besser als Berlin kommt Dresden weg. Hier nämlich hat der Reisende, „kaum auf die Straße getreten, den Eindruck, daß es nichts Widerwärtigeres gibt als den Typus der Dresdner Frauen." Und auch der Kölner Dom läßt den Reisenden unbeeindruckt: „Er kam mir vor wie geklöppelte Spitze, Spitze und noch mal Spitze, wie ein zierlicher Schreibtischbriefbeschwerer von einhundertfünfzig Metern Höhe.“ (48) Spätestens hier wird deutlich, daß neben Aleksandr Gercen auch Heines poetische „Reisen“ bei der Entstehung der „Winteraufzeichnungen“ Pate gestanden haben, in diesem Fall Deutschland. Ein Wintermärchen (1844), wo der Kölner Dom wie folgt in den Blick kommt:

„Doch siehe! dort im Mondenschein, / Den kolossalen Gesellen!/ Er ragt verteufelt schwarz empor, / Das ist der Dom von Köllen. [...] Er sollte des Geistes Bastille sein / Und die listigen Römer dachten: / In diesem Riesenkerker wird / Die deutsche Vernunft verschmachten. ${ }^{\text {"12 }}$

12 Paul Stapf (Hg.): Heinrich Heine. Werke. Berlin, Darmstadt, Wien 1963, S. 616 f. 
Die unübersehbare Parallele von „Wintermärchen“ und „Winternotizen“ legt die Vermutung nahe, daß sich für Dostoevskij, der mit Heines Werk wohl vertraut war, alternativ auch ein Titel wie „Europa. Ein Wintermärchen“ angeboten hatte.

Dostoevskijs Ressentiment gegen Berlin, Dresden, Köln, den Rhein usw. war der Beginn einer lebenslangen Skepsis des Autors gegenüber den Deutschen. Deutschland ist in den "Winteraufzeichnungen“ nicht mehr als ein Transitraum, für den der Reisende kein Auge zu haben scheint und den er, wenn überhaupt, so nur eines ebenso flüchtigen wie geringschätzigen Blickes würdigt. Noch schlechter freilich kommen die Schweiz und Italien weg. Für die Schweiz waren im Reiseplan des Autors immerhin anderthalb Wochen vorgesehen; doch die von anderen russischen Reisenden besungenen Reize der Schweizer Landschaft ${ }^{13}$ scheinen spurlos an ihm vorübergegangen zu sein; und ein Gleiches gilt für Italien. Dies liegt zum einen daran, daß Dostoevskij als Person wie als Autor - im Gegensatz zu Turgenev oder Tolstoj ${ }^{14}$ - vergleichsweise unempfänglich war für die Reize der Natur; auch in seinen Romanen und Erzählungen kommen natürliche Landschaften als das Andere der Stadt, der Straße, des Hauses, der Dachkammer, des Kellerlochs so gut wie nicht und wenn überhaupt, so in künstlerisch eher dürftiger Ausführung vor.

Der eigentliche Grund für Dostoevskijs Gleichgültigkeit gegenüber pittoresken europäischen Landschaften indes ist ein anderer: Nicht Deutschland, die Schweiz oder Italien sind das primäre Ziel seiner Reise, sondern Frankreich, genauer Paris: Paris, dessen Sprache er (anders als Deutsch, Italienisch oder Englisch) fließend beherrschte; Paris, dessen Literatur er schon in den dreißiger und vierziger Jahren verschlungen hatte; Paris, dessen Topographie ihm dank der Werke eines Eugène Sue, Frédéric Soulié und Honoré de Balzac fast ebenso vertraut war wie die von Sankt Petersburg; Paris nicht zuletzt als intellektuelles Laboratorium und Hauptstadt sozialer Ideen wie derjenigen von Saint-Simon, Fourier, Louis Blanc, Blanqui, Proudhon, deren Schriften ins Rußland der 1840er Jahre vorgedrungen waren und die seinerzeit auch Dostoevskij und den Petraševskij-Kreis inspiriert hatten.

Im Sommer des Jahres 1862 aber gibt es dieses Paris ebenso wenig mehr wie den Revolutionär Fedor Dostoevskij der Jahre 1848/49. Das Paris des Jahres 1862 ist das Paris Louis Napoleons, der, nach der gescheiterten Revolution von

13 Vgl. Peter Brang u.a. (Hg.): Bild und Begegnung. Kulturelle Wechselseitigkeit zwischen der Schweiz und Osteuropa im Wandel der Zeit. Basel 1996.

14 Man denke nur an die opulente Beschreibung des Vierwaldstättersees in Tolstojs Erzählung „Luzern“(1857). 
1848 zum Präsidenten gewählt, drei Jahre später die Republik abgeschafft hatte, um sich als Napoleon III. zum Kaiser aller Franzosen krönen zu lassen. Aus dem revolutionären Paris der 1840er Jahre ist unter Napoleon III. eine Stadt der „Autorität und Ordnung“ geworden. ${ }^{15}$ Es ist dies das Paris des GeorgesEugène Haussmann, der die Stadt seit 1853 im Auftrag Napoleons III. zu einer europäischen Metropole des Industriezeitalters umbaut; das Paris der Passagen als einer neuen Erscheinungsform des Marktes; das Paris der großen Bahnhöfe, der Weltausstellungen, der Boulevards, der Vergnügungsetablissements und der Offenbachschen Operette, der ironischen Utopie einer dauerhaften Herrschaft des Kapitals ${ }^{16}$, der politisch wie ökonomisch siegreichen Bourgeoisie, der Börsen und der Banken:

„Es wurde viel Geld verdient, die Staatsanleihen wurden jetzt nicht mehr bei den Rothschilds oder anderen Privatbanken, sondern bei dem Publikum untergebracht. Die ,Société Générale' und der ,Crédit Lyonnais' machten die Bevölkerung mit den neuen Formen der Geldanlage vertraut. So bereitete die Finanzierung des sich rapide ausbreitenden Eisenbahnnetzes keine Schwierigkeiten [...] Die großen Schifffahrtsgesellschaften entstanden, die koloniale Ausbeutung begann. ${ }^{\text {"17 }}$

Es ist dieses neue Paris, die „Hauptstadt des 19. Jahrhunderts“"18, das Dostoevskij dem russischen Publikum stellvertretend für die gesamte zeitgenössische europäische Kultur vor Augen führt, und zwar aus einer Sicht, die alles andere als objektiv sein will. Von Anfang an läßt er keinen Zweifel daran, daß er parteiisch und voreingenommen ist. Mit seinem Bekenntnis zum eigenen „VorUrteil“ markiert er eine dezidiert antiaufklärerische Position (vgl. 60 f.). Es waren die Vorurteile seiner Moskauer Zeitgenossen gewesen, gegen die in den 1820er Jahren Aleksandr Čackij, der Held von Aleksandr Griboedovs Sittenkomödie Verstand schafft Leiden (Gore ot uma, 1824), gekämpft hatte und an denen er zuletzt gescheitert war. Čackij jedoch, der Prototyp des sogenannten „überflüssigen Menschen“ (lišnij čelovek), ist für den Autor der „Winteraufzeichnungen“" schon längst kein Vorbild mehr:

„Čackij ist ein ganz besonderer Typ unseres russischen Europa, er ist der Typ eines lieben, enthusiastischen Menschen, der wirklich leidet, den es eigentlich schon hinzieht zu Rußland und zum Heimatboden (počva), der dann aber doch wieder nach Europa reist, um dort ,einen Winkel für seine gekränkte Seele zu

15 Friedrich Sieburg: Französische Geschichte. Frankfurt am Main 1964, S. 143.

16 Walter Benjamin: Paris, die Hauptstadt des XIX. Jahrhunderts. Frankfurt am Main 1961, S. 192.

17 Sieburg (1964), S. $145 \mathrm{f}$.

18 Benjamin (1961), S. 185-200. 
suchen' [...]. Er ist ein Phraseur, ein Schwätzer, aber einer mit Herz, der aufrichtigen Gewissens seine Nutzlosigkeit bedauert." (61 f.)

Čackij verkörpert das Ausgangsproblem der „Winteraufzeichnungen“, das der Autor Dostoevskij in die Frage gekleidet hatte:

„Mein Gott, was sind wir schon für Russen [...] Sind wir überhaupt echte Russen? Warum nur hat Europa auf uns, wer auch immer wir sein mögen, einen so starken, zauberischen, verlockenden Einfluß? Natürlich rede ich nicht von jenen Russen, die dort [in Europa, A.G.] geblieben sind, und nicht von jenen einfachen Russen, die fünfzig Millionen zählen und die wir, einhunderttausend an der Zahl, entschieden für nichts erachten und über die sich unsere tiefschürfenden satirischen Zeitschriften bis heute lustig machen, weil sie sich nicht die Bärte rasieren. Nein, ich spreche jetzt von unserem Häuflein der privilegierten und patentierten Menschen. Ist doch fürwahr alles, entschieden so gut wie alles, was es bei uns an Entwicklung, Wissenschaft, Kunst, Bürgersinn, Humanität gibt, ist doch alles von dort her gekommen, alles aus diesem Land der heiligen Wunder! Hat sich doch unser ganzes Leben schon von frühester Kindheit an nach europäischer Art gefügt." (51)

So weit gehe die europäische Prägung der kulturellen Eliten Rußlands, daß das einfache Volk diese bereits für Ausländer hält. Dennoch, so fährt der Autor fort, ganz und gar europäisiert sei Rußland noch nicht. Das zeige das Beispiel Aleksandr Puškins, der ungeachtet seines Europäertums die Verbindung zum Russentum nie verloren habe. Im Gegensatz zu Puškin gleiche das heutige russische Europäertum allerdings dem der verzärtelten Heldin Sof ja in Aleksandr Griboedovs schon erwähnter Komödie Verstand schafft Leiden: Sofjas Europäertum beschränke sich darauf, mit ihrem Geliebten Molčalin Hausmusik zu machen, kitschige Romane zu lesen und blind zu sein für die Realitäten der russischen Gesellschaft. Entfremdet ist Rußlands Elite also nicht nur dem einfachen Volk, sondern auch dem Leben. Dostoevskij führt als Beispiel für diese Verdrängungsstrategie eine Episode aus Denis Fonvizins Komödie Der Brigadier (1768) an. ${ }^{19}$ Die Frau des Brigadegenerals berichtet der Heldin (sie heißt ebenfalls Sof ja) von einem Hauptmann, der seine Frau ständig und besonders im Alkoholrausch verprügelt. Die empfindsam-moralische, ganz im europäischen Geist erzogene Sof ja reagiert darauf mit dem manierierten Satz: „Bitte, meine Dame, hören Sie auf, von etwas zu sprechen, was die Menschheit

19 Ivanuška, der komisch-tumbe Held dieser Komödie, erklärt: „Geboren bin ich in Rußland, mein Herz jedoch gehört der französischen Krone“. Damit repräsentiert er jene Gallomanie, die ein bevorzugtes Objekt der russischen Satire schon des 18. Jahrhunderts gewesen war und an die Dostoevskij hier anknüpft. 
empört.“ (58). Die Brigadiersfrau antwortet darauf: „Du, meine Beste, magst offenbar nicht einmal hören, was die Hauptmannsfrau erleiden mußte." (58). Die Entfremdung des europäisierten russischen Adels vom russischen Volk erscheint hier als Resultat eines Verdrängungs- bzw. Tabuisierungsvorgangs, der mit Norbert Elias als Vorrücken der „Peinlichkeitsschwelle und Schamgrenze“ $\mathrm{zu}$ verstehen ist. ${ }^{20}$ Der wachsende Abstand zwischen Oberschicht und Volk nämlich manifestiert sich nicht nur in der Verachtung des einfachen Volkes, sondern auch in einem wachsenden, „nie dagewesenen Ekel“ (59) der russischen Eliten vor einer Leibhaftigkeit des russischen Volkes, wie sie Dostoevskij in seinen „Aufzeichnungen aus einem Totenhaus“ in bisher nicht für möglich gehaltener Drastik dargestellt hatte. ${ }^{21}$ Für diesen Typus zivilisationsbedingter Verdrängung (er)findet der Autor den Begriff „Treibhaushaftigkeit“ (oranžerejnost'), der das Künstliche und Unnatürliche des russischen Europäertums zum Ausdruck bringen soll:

„Jetzt hält uns das Volk bereits ganz und gar für Ausländer, kein Wort versteht es von uns, kein einziges unserer Bücher, keinen einzigen Gedanken. Aber eben das, sagen Sie, was Sie wollen, ist doch gerade Fortschritt - hält man dem entgegen. Jetzt verachten wir das Volk und die völkischen Prinzipien schon so tief, daß wir uns bereits mit einem ganz neuen Ekel zu ihm verhalten, einem nie da gewesenen Ekel [...] Uns fehlt der Boden, fehlt das Volk; Nationalität - das ist nur noch ein bestimmtes Steuersystem, die Seele eine tabula rasa, ein Ding aus Wachs [...]“

Im Fluchtpunkt eines solchen „treibhausartigen“ Fortschritts steht für Dostoevskij ein „universaler Allgemeinmensch“ (obščečelovek vsemirnyj, 59), den man, da seine Seele eine tabula rasa sei, nach bestimmten anthropologischen Rezepten wie einen Homunculus herstellen könne.

Nachdem er das westliche Menschenbild bis zu diesem Punkt entwickelt und, wie er glaubt, ad absurdum geführt hat, bestimmt Dostoevskij erstmals seine eigene Position mit der Formel: „Zuerst Natur, dann Wissenschaft, dann selbständiges Leben, bodenständiges und unbehindertes, und der Glaube an die eigenen nationalen Kräfte“ (61). Dies ist - auch wenn der Stellenwert der Wissenschaft hier noch etwas unklar erscheint - im Kern das Programm der von Dostoevskij und seinem Journal „Die Zeit“ propagierten Idee der „Boden-

20 Norbert Elias: Über den Prozeß der Zivilisation. Soziogenetische Untersuchungen. Bd.1. Frankfurt am Main 1989, S. 89 und passim.

21 Vgl. dazu Andrea Zink: Wie aus Bauern Russen wurden. Die Konstruktion des Volkes in der Literatur des russischen Realismus 1860-1880. Zürich 2009 (= Basler Studien zur Kulturgeschichte Osteuropas, Bd.18), S. 260. 
ständigkeit“, des počvenničestvo, als einer Sonderform des europäischen Nationalismus. Dieser Formel schließt sich der bereits erwähnte Exkurs über Čackij und seine Flucht nach Europa an, eine Flucht, die dem Irrglauben aller „überflüssigen Menschen“ zuzuschreiben sei, daß es für sie in Rußland kein Betätigungsfeld gebe:

„Ja, Čackij hat doch gut daran getan, daß er damals wieder ins Ausland entschlüpft ist: es lag ihm wohl nicht, hier ein wenig länger zu verweilen und sich dann dem Osten statt dem Westen zuzuwenden. Man liebt bei uns den Westen nun mal, liebt ihn eben, und im Ernstfall, wenn es zum Schwur kommt, fahren alle dorthin. Nun ja, auch ich fahre jetzt hin. „Mais moi c'est autre chose“ [...]. Paris, Paris war es doch, wovon ich reden wollte und das ich ganz vergessen habe. Ich habe mich denn wohl doch etwas zu sehr über unser russisches Europa ausgelassen; aber das mag verzeihlich sein, wenn man gerade auf Besuch ins europäische Europa fährt.“ (63 f.)

Nachdem der Autor auf diese Weise gewissermaßen im Rückspiegel noch einmal sein eigenes Land in den Blick genommen hat, wendet er sich - nach einem kurzen Zwischenspiel, das seine Reise von der französischen Grenze nach Paris beschreibt - der französischen Hauptstadt zu. Auch hier läßt er von Anfang an keine Zweifel daran, daß ihn Sehenswürdigkeiten nicht interessieren. Zum einen deshalb nicht, weil Russen, sobald sie die eigene Grenze überschritten haben, sich benähmen wie herrenlose Hündchen, die ängstlich, orientierungslos und vor allem würdelos hin- und herhetzen (63). Aber auch, weil der Autor es haßt, alles nach den Vorgaben eines Reiseführers, gleichsam auf Befehl bzw. aus Pflichtgefühl zu besichtigen, nicht aber eigener Neigung und eigenen Interessen folgend:

„[...] sie begaffen das Rindfleisch eines Rubens und glauben, dies seien drei Grazien, weil der Reiseführer dies zu glauben vorschreibt; sie stürzen zur Sixtinischen Madonna und stehen vor ihr in der dumpfen Erwartung, daß jetzt gleich irgendwer unter dem Fußboden hervorkriechen und ihre unbestimmte Sehnsucht und ihre Müdigkeit vertreiben werde. Und sie gehen fort und wundern sich, daß überhaupt nichts passiert ist." (63)

Der Vergleich der russischen Touristen mit herrenlosen Hündchen ist eine Variante des von Dostoevskij immer verwendeten Motivs der Selbsterniedrigung, hier mit deutlich nationalistischem Pedal gespielt. „Schämt euch!“, so ist dieser Vergleich zu lesen, „So wenig Selbstbewußtsein habt ihr, daß ihr ständig auf der Suche seid nach fremder Hilfe und fremden Orientierungsangeboten!“ Das Motiv des „Reiseführers“ nimmt dabei ein Schlüsselmotiv slavophiler OstWest-Typologie vorweg: nämlich die These von der Abhängigkeit des West- 
europäers von externen (heteronomen) Vorgaben, also von Regeln, Vorschriften, Gesetzen (dafür steht symbolisch der „Reiseführer“, also der Baedeker), während die Russen ihr Handeln auf der Grundlage freier und autonomer (sittlicher) Entscheidungen treffen. ${ }^{22}$

Der Autor hat damit ein drittes Motiv, Sehenswürdigkeiten zu ignorieren, nämlich seine inzwischen mehr als deutlich gewordene Absicht, durch die Darstellung von national Fremdem, Anderem, Andersartigem in erster Hinsicht ein Bild des national Eigenen zu gewinnen. Die moderne Anthropologie bezeichnet eine solche Haltung gegenüber dem Fremden, in der es nicht um dessen geistige Aneignung, sondern um die Konstruktion von Andersartigkeit zum Zweck der Aufwertung von „Eigenart[igkeit]“ geht, als „Othering“ bzw. deutsch als „Veranderung “. ${ }^{23}$ In Bezug auf Frankreich bzw. Paris, das für ihn die Hauptstadt der europäischen Bourgeoisie ist und insofern die zentralen Werte des modernen Europa verkörpert, besteht Dostoevskijs othering im Wesentlichen aus drei Argumentationslinien:

Ein zentraler Wert der Bourgeoisie ist die Ordnung. Im Gegensatz zu Fonvizin, der in seinen Reisebriefen aus Frankreich Paris als Ort des Lasters beschrieben hatte, stellt Dostoevskij Paris dar als

„moralischste und tugendhafteste Stadt auf dem ganzen Erdenrund. Was für eine Ordnung! Was für eine Vernünftigkeit! [...] Wie ist alles sichergestellt und vorliniiert, wie sind alle zufrieden und vollkommen glücklich [...] “ (68)

Dies bezieht sich auf ein Maß an Vorsorge, Geregeltheit und Komfort des täglichen Lebens, wie man es sich selbst im urbanen Petersburg damals nicht träumen lassen konnte. Dostoevskij ist davon fasziniert, doch er ist auch entsetzt. Denn wenn sich die Bourgeoisie so behaglich und sicher in der von ihr eingerichteten Ordnung fühlt, scheint kein Weg mehr über diesen einmal erreichten Stand der Dinge hinauszuweisen und hinauszuführen. In dieser modellhaften Zuspitzung wird Paris zu einem Ort - genauer: zu einem Nichtort (Utopos) stilisiert, an dem die Geschichte an ihr Ende gekommen ist.

Kontrastiv zu Paris werden an dieser Stelle, sozusagen in einer Art literarischer Parallelmontage, Bilder von London eingeblendet, das Dostoevskij Anfang Juli 1862 für eine Woche besuchte. War ihm Paris als Hauptstadt der Bourgeoisie erschienen, so stellt sich London als Hauptstadt einer Klasse dar: des Proletariats, dessen Lage Dostoevskij in ähnlich düsteren Farben malt wie

22 Vgl. dazu Wilhelm Goerdt: Russische Philosophie. Zugänge und Durchblicke. Freiburg, München 1984, S. $307 \mathrm{ff}$.

23 Vgl. Julia Reuter: Ordnungen des Anderen. Bielefeld 2002. 
Friedrich Engels in seiner berühmten Abhandlung „Die Lage der arbeitenden Klasse in England“ (1845). Der Ordnung der Pariser Bourgeoisie stellt Dostoevskij die dynamische Wucht der proletarischen und subproletarischen Lebenswelten Londons gegenüber. Sie besteht zum einen in der Kraft der großen Industrie, die hier aus aller Welt zusammengeströmten Massen zu einer einheitlichen Herde zusammenzuschmieden, zum anderen in deren anarchischer Kehrseite: dem moralischen Untergrund, der Welt der Laster, des Alkohols, des Verbrechens und der Prostitution. Die disparatesten Dinge scheinen in dieser Welt problemlos nebeneinander zu existieren: Hier der Dreck, der Lärm und die Ausdünstungen der Slums von Whitechapel; dort „die City mit ihren Millionen und dem Welthandel, der Kristallpalast, die Weltausstellung... Ja, die Ausstellung hat etwas Frappierendes“ (69).

Mit einem untrüglichen Blick für die historische Symptomatik gesellschaftlicher Prozesse erfaßt Dostoevskij, wie sehr gerade die Weltausstellungen des 19. Jahrhunderts ${ }^{24}$ eine neue Epoche repräsentieren. Hier nämlich „fanden ungebrochener Fortschrittsglaube, die Aufbruchsstimmung der Gründerzeit, die Hoffnungen auf die Segnungen der liberalen Wirtschaftsordnung - Freihandel und uneingeschränkter Wettbewerb und grenzenloses Vertrauen in die Möglichkeiten von Technik und Industrie zueinander; hier trat nationaler Ehrgeiz neben den Versuch einer Synthese aller menschlichen Errungenschaften “. 25

Prinz Albert von Sachsen-Coburg und Gotha, seines Zeichens Prinzgemahl Königin Viktorias und zentraler Kopf bei der Planung und Vorbereitung der Londoner Weltausstellung, hatte bei deren Eröffnung im Jahre 1851 davon gesprochen, daß nunmehr ,jenes große, von der Geschichte überall angedeutete Ziel“ in greifbare Nähe gerückt sei, nämlich „die Vereinigung des Menschengeschlechts “. ${ }^{26}$ Dieses Ziel, wenn auch vom Prinzgemahl anders gemeint, steht schon sehr nahe bei Dostoevskijs Schreckensvision vom universalen Allgemeinmenschen. Ein weniger prominenter Zeitgenosse, der deutsche Journalist Georg Schirges, drückt unter dem Eindruck der Londoner Weltausstellung die Erwartung aus, daß es nun nicht mehr lange dauern könne, „bis die Menschheit von ihrem Fluch erlöst und endlich nicht mehr gezwungen ist, im Schweiße ihres Angesichts ihr Brod [sic] zu essen“. ${ }^{27}$ Damit wäre die Menschheit ins

241851 hatte die erste Weltausstellung in London stattgefunden, und bis 1867 sollten sich die englische und die französische Hauptstadt als Ausstellungsorte abwechseln.

25 Helmut Gold: Wege zur Weltausstellung. In: Hermann Bausinger u.a. (Hg.): Reisekultur. Von der Pilgerfahrt zum modernen Tourismus. München 1991, S. 320.

26 Zit. nach Gold (1991), ebd.

27 Zit. nach Gold (1991), ebd. 
Paradies zurückgekehrt: wenn auch nicht in den Garten Eden, sondern in ein von ihr selbst bereitetes irdisches Paradies.

Der biblische Ton dieser Äußerung kommt nicht von ungefähr. Joseph Paxtons berühmter (1936 abgebrannter) Kristallpalast im Hyde Park, wo 1851 die erste Weltausstellung stattfand - eine der ersten Stahl-Glas-Konstruktionen der Welt $^{28}$ - hatte, wie seine Besucher bestätigten, sowohl mit seiner Größe als auch mit seiner Atmosphäre etwas Kathedralenhaftes. ${ }^{29}$ Und diese Überschneidung von Zweck- und Sakralbau, diese Vermischung von Profanem und Heiligem muss sich auch Dostoevskij mitgeteilt haben, der im 5. Kapitel der „Winteraufzeichnungen schreibt:

„Ja, die Ausstellung hat etwas Frappierendes, man spürt die furchtbare Kraft, die hier alle diese unzähligen Menschen aus der ganzen Welt zur einen Herde zusammengetrieben hat; man erkennt einen Riesengedanken; man fühlt, daß hier bereits etwas erreicht ist: ein Sieg, ein Triumph. Und eine unbestimmte Angst beginnt sich in einem zu regen [...] Sollte am Ende dies das erreichte Ideal sein? denkt man bei sich. Ist hier nicht das Ende? Ist das nicht schon die Wirklichkeit gewordene ,eine Herde' [...] Sie sehen diese Hunderttausende, diese Millionen von Menschen, die gehorsam aus aller Welt hier zusammenströmen, Menschen, die alle mit einem einzigen Gedanken gekommen sind, die still, unablässig und stumm sich in diesem kolossalen Palast umherdrängen, und Sie fühlen, daß sich hier etwas vollendet, vollendet und vollbracht hat. Das ist irgendein biblisches Bild, irgendetwas von Babylon, eine Prophezeiung der Apokalypse, die sich leibhaftig verwirklicht hat. Sie fühlen, daß es viel an dauerhafter Gegenwehr und Verneinung bedarf, um standzuhalten und der Faszination des Eindrucks nicht zu erliegen, nicht vor dem Fakt in die Knie zu gehen und Baal nicht für Gott, das heißt, das Existierende nicht für sein Ideal zu halten." (69 f.)

Joseph Paxton, der Erbauer des Londoner Kristallpalastes, war kein ausgebildeter Architekt, sondern Gärtner. Seit den 1830er Jahren hatte er sich auf den Bau von Gewächshäusern aus den Industriematerialien Stahl und Glas nach besonderen Konstruktionsprinzipien spezialisiert, die sowohl den Lichteinfall als auch die Verdampfung von Kondenswasser und die Drainage von Regenwasser optimierten. Eine der für die Zeitgenossen spektakulärsten Leistungen dieser Bauweise war es, daß damit eine Gruppe hochgewachsener Ulmen des Hyde-Parks überbaut werden konnte, so daß sich der Kristallpalast als eine

28 Vgl. Andreas Guski: Babylonische Türme. Zu einem Motiv der neueren russischen Kulturgeschichte. In: Wolfgang Girke u.a. (Hg.): Vertograd mnogocvetnyj. Festschrift für Helmut Jachnow. München 1999 (Specimina philologiae slavicae), Supplementband 64, S. 59-70.

29 Vgl. Gold (1991), S. 323. 
Synthese aus Natur und Technik präsentierte. Für Dostoevskij aber ist dies eine Kunstnatur, der die nämliche „Treibhaushaftigkeit“ zueigen ist wie Fonvizins Heldin Sof ja. Der Rousseausche Naturmensch, „l'homme de la nature et de la vérité" (89 und 94), wird als Phantasieprodukt entlarvt, an dem speziell die französische Bourgeoisie mit ihrem unstillbaren Bedürfnis festhält, (de) „voir la mer" und „se rouler dans l'herbe“ (94 f.).

So unterschiedlich sich London und Paris dem Auge des Reisenden darstellen, sind sie für ihn doch Hervorbringungen ein und derselben bürgerlichkapitalistischen Ordnung. Der Kristallpalast mit seinen Tausenden von Besuchern versinnbildlicht für Dostoevskij klarer und brutaler als das bürgerlichere Paris die Gleichschaltung von Individuen zur stumpfen Masse, zum Vieh, zur „einen Herde“, die nur noch eines Übervaters oder Führers bedarf, der ihnen mit der Sorge ums tägliche Brot auch die Last der Freiheit abnimmt - lauter Schreckensbilder des „,irdischen Paradieses“, die in Ivan Karamazovs „Großinquisitor" wieder auftauchen werden.

Für die Mentalität der irdischen Paradiesbewohner findet Dostoevskij in den abschließenden, nun wieder auf Paris bezogenen Kapiteln eine Formel, deren er sich bis hin zum Roman „Die Brüder Karamazov“ immer wieder bedienen wird, und zwar bewußt auf Französisch: „Après moi le déluge“, „Nach mir die Sintflut!“ (85) - eine Formel des rücksichtslosen Egoismus, die sich als psychologisches Äquivalent der Vorstellung vom Ende der Geschichte deuten läßt. Der Bourgeois kennt und anerkennt nur einen einzigen Wert, wie es im 6. Kapitel heißt, nämlich den des Geldes. Der Katechismus des Parisers bestehe in der Akkumulation von Kapital zum Zweck der Akkumulation von Sachen (76). Der ganze Komfort, die Investition in die Verschönerung von Boulevards und Plätzen, von Bahnhöfen und Regierungspalästen, von Restaurants, Opernhäusern und Salons ist aus dieser Sicht eine Fehlinvestition, da es sich um Scheinwerte handelt, die keine moralischen Äquivalente haben. Wo „Geld die höchste Tugend“ ist (76), ist kein Platz für andere Tugenden. Die Kehrseite dieser Lebensordnung ist eine typisch bourgeoise Bigotterie. Der zur Schau gestellten Wohlanständigkeit des bürgerlichen Lebens, das sich nicht zuletzt in der Vorliebe der Pariser für das Theater, speziell für Melodramen und die dort inszenierten edlen Gefühle manifestiert, steht nicht nur der faktische Libertinismus des bürgerlichen Ehelebens, sondern auch und vor allem der Egoismus des Europäers gegenüber, der echtes moralisches Verhalten nicht zuläßt. Insofern erweisen sich denn aber auch die vom nachrevolutionären Frankreich in Erz gegossenen Ideale der Französischen Revolution - liberté, égalité, fraternité - als utopisch. Freiheit nämlich gibt es nur für denjenigen, der wenigstens 
eine Million auf dem Konto hat. Gleichheit herrscht nur unter Menschen mit gleich großem Geldbeutel, das heißt im Rahmen einer "égalité des poches“ (91). Und zu wahrer Brüderlichkeit, das heißt zu echtem Sozialismus, ist der Westeuropäer mit seinem angeborenen Individualismus schon von Natur aus nicht imstande.

An dieser Stelle geht der Autor von der bis dahin vorherrschenden satirischen zu einer ernsten, ja prophetischen Tonart über. Dem europäischen Individuum stellt er die Kategorie der Persönlichkeit gegenüber. Darunter versteht er einen Menschentypus, dem es ein natürliches Bedürfnis ist, sich für die Gemeinschaft seiner Brüder hinzugeben, sich aufzuopfern. Und gegen das Modell des gleichgeschalteten Ameisenstaates setzt er das Bild einer Gemeinschaft von Brüdern, die bereit ist, sich für den Einzelnen zu opfern, so wie umgekehrt auch der Einzelne sich für jene. ${ }^{30}$

Mit der Vision einer solchermaßen brüderlichen Gesellschaft öffnet Dostoevskij ein utopisches Fenster, durch das der Blick auf eine freie Form von Gemeinschaft jenseits von Ameisenbau und babylonischem Turm fällt - ein Blick, der Ideen von Ferdinand Tönnies' soziologischem Grundbuch „Gemeinschaft und Gesellschaft“ (1887) vorwegnimmt. Darüber hinaus deutet er aber auch eine Alternative zur bürgerlichen Ökonomie an, die mit gängigen Marktkategorien wie Äquivalent, Tausch, Symmetrie, Gegenseitigkeit usw. bricht und auf eine Ökonomie des „Maß-Losen“, also des nicht Be- und Verrechenbaren hinausläuft, ${ }^{31}$ deren großes welt- und heilsgeschichtliches Vorbild für Dostoevskij der Opfertod Jesu Christi ist.

Ich fasse zusammen: Dostoevskij besucht Westeuropa erstmals in einer für Rußland wie für ihn selbst wichtigen Schwellensituation, in der ähnlich dramatische, für das Land existentielle Entscheidungen anstehen wie häufig zu Beginn seiner großen Romane. Die „Winteraufzeichnungen“ stellen den Versuch einer Standortbestimmung Rußlands gegenüber dem Westens dar, in Bezug auf den „sich Rußland während seiner ganzen Geschichte“ immer wieder definiert hat. ${ }^{32}$ Die Konstruktion Westeuropas läuft dabei zuallererst über die Destruktion des Europabildes, das Nikolaj Karamzin den Russen vermittelt hatte. Gegen Karamzins Weltbürgertum stellt Dostoevskij das nationale,

30 Damit wäre eine Gegenposition zu Max Stirner umrissen, der in seiner Schrift „Der Einzige und sein Eigentum“ (1845) die Geschichte solcher Aufopferungen des Einzelnen für die Gemeinschaft gerade beenden wollte.

31 Vgl. Martin M. Lintner: Eine Ethik des Schenkens. Von einer anthropologischen zu einer theologischen Deutung der Gabe. Berlin (Studien der Moraltheologie, Bd. 35), 2006.

32 Vgl. Boris Groys: Die Erfindung Rußlands. München 1995, S. 8. 
selbstbewußte Staatsbürgertum des Russen. Dabei wird Paris als Kapitale der Bourgeoisie zum typischen Ort bürgerlicher Lebensart und Kultur. Diese Welt zeichnet sich aus durch die Fetischisierung von Besitz und die Vergottung materieller Sicherheit, durch die selbstgefällige Überzeugung, mit dieser vermeintlich besten aller Welten am Ende der Geschichte angelangt zu sein, durch Bigotterie und Doppelmoral, durch die Entfremdung des Menschen von der Natur bzw. durch eine Strategie der Verdrängung von Natur, welche die eigene innere Natur miteinbezieht.

Im Schatten dieser Wohlstandswelt registriert Dostoevskij am Beispiel Londons Phänomene der modernen Welt wie die Vermassung, die Verelendung und die Verrohung derjenigen, auf deren Knochen diese Welt des Wohlstands und der Wohlanständigkeit letztlich errichtet wurde. Die großen Weltausstellungen, egal ob in London oder Paris ${ }^{33}$, verdrängen das Elend des Proletariats, indem sie es überblenden durch den Schau- und Tauschwert der von ihm produzierten Waren. In den Weltausstellungen kommt überdies eine Erscheinung zum Ausdruck, der Dostoevskij als ein gerade die nationale Eigenheit Rußlands betonender Autor mit besonderer Skepsis begegnen mußte, nämlich die Globalisierung der Geld- und Warenzirkulation als letzter noch verbleibender Kommunikationsform der Menschheit - mythologisch formuliert „der Tanz um das Goldene Kalb“ und damit auch die Aufhebung aller Formen von nationaler und kultureller Differenz.

Die „Winteraufzeichnungen“ sind jedoch nicht nur politische Programmschrift, sondern auch ein Medium der Selbstverortung des Autors. Zum einen gewinnt Dostoevskij im Kontakt mit Europa einen Fundus an Einsichten, Themen und Motiven, auf den er bis zum Ende seines Schaffens immer wieder zurückkommen wird. Darüber hinaus bietet ihm die Auseinandersetzung mit dem bürgerlichen Frankreich Napoleons III. Gelegenheit zur demonstrativen Abstandnahme von seinen alten, im wesentlichen von der französischen Revolution geprägten Idealen der 1840er Jahre. Mit dieser Auseinandersetzung wird zugleich aber auch ein Stück personaler Kontinuität beschworen, wird also nicht nur Differenz, sondern auch Identität markiert, denn diskreditiert wird hier nicht die Losung „Freiheit, Gleichheit, Brüderlichkeit“ als solche, sondern deren Beschlagnahme durch die Bourgeoisie. Was die Selbstverortung des Autors betrifft, so ist schließlich ein letzter Aspekt geltend zu machen. Die Verachtung und der Ekel vor dem gemeinen Volk, den Dostoevskij den euro-

33 Im Jahre 1862, also während Dostoevskijs London-Aufenthalt, fand dort, nach Paris 1855, bereits die dritte Weltausstellung statt, allerdings nicht mehr im Hyde Park, sondern auf dem Gelände der Royal Horticultural Society in South Kensington. 
päischen Russen vorwirft, war auch Teil seiner eigenen Haltung und Selbsterfahrung in der Katorga. Wenn er diesen Ekel nun auf das Konto des hier von ihm konstruierten Feindbildes der „Europarussen“ überträgt, dann handelt es sich psychologisch gesehen um eine Projektion, also einen Vorgang, der bekanntlich darin besteht, daß eigene negative Wesensmerkmale einer anderen Person oder Personengruppe zugeschrieben werden.

Dem ließen sich weitere „europäische“ Wesensmerkmale des Autors hinzufügen, angefangen von Banalitäten wie Dostoevskijs mehrfach bezeugter pedantischer Vorliebe für saubere Manschetten und Hemdkragen über einen bemerkenswert hoch entwickelten Erwerbstrieb bis hin zur Poetik der „Winteraufzeichnungen", deren Besonderheiten hier aus Platzgründen vernachlässigt werden mußten. Nur angedeutet sei, daß der Stil der „Winteraufzeichnungen“ ein in hohem Maße „westlicher" ist, daß dies eine Prosa ist, die Karamzin weit hinter sich läßt. Gattungsmäßig ist sie dem Feuilleton zuzuordnen, und ihr stilistisches Vorbild hat sie in einem Autor, dessen Prosa zum Brilliantesten gehört, was die russische Literatursprache im 19. Jahrhundert hervorgebracht hat: nämlich Aleksandr Gercen mit seinen bereits erwähnten Briefen aus Frankreich und Italien. Der Witz, der Assoziationsreichtum und die Stilisierung des Diskurses zur mündlichen Improvisation, sie stellen allerdings nur die eine Seite der Poetik der Winteraufzeichnungen dar. Die andere ist die (einem Gercen völlig fremde) Erzählermaske des Neurotikers, des „kranken Menschen“, mit der es das russische Lesepublikum wenig später in den Aufzeichnungen aus einem Kellerloch (Zapiski iz podpol'ja, 1864) neuerlich zu tun haben sollte. Es handelt sich dabei um einen Erzähler, dessen überwaches Bewußtsein mit den Mitteln einer fiebrigen, galligen Sprache gegen die Mauern einschlägiger Dogmen des 19. Jahrhunderts anrennt und das nachdrücklich auf der Autonomie des Subjekts besteht. Wie modern bzw. wie europäisch dieses hochkomplexe Bewußtsein ist, hat die Karriere des Kellerloch-Menschen in der europäischen Literatur und Philosophie des 20. Jahrhunderts hinlänglich bewiesen. Die Abgrenzung vom modernen Europa vollzieht sich bei Dostoevskij demnach in einer Form, die sich selbst dem „Land der heiligen Wunder" verdankt, nämlich Westeuropa. 


\section{Karla Hielscher}

\section{Die „russische Idee“ - made in Florenz. Dostoevskijs antiwestlich-russophile Ideologie in seinen Briefen aus Italien.}

Dostoevskij, aufgewachsen mit westlicher Literatur und Philosophie und als junger Mann von den französischen utopischen Sozialisten und deren revolutionären Ideen fasziniert, kam aus der sibirischen Katorga als ein anderer zurück: Tief orthodox religiös und voller Glauben an das russische Volk, mit dem er als Häftling im Omsker Ostrog zum ersten Mal in engste Beziehung gekommen und vier Jahre lang qualvoll gelitten hatte. Trotzdem war sein Fazit:

„Welch wunderbares Volk.... Zwar habe ich nicht Rußland kennen gelernt, wohl aber das russische Volk und zwar so gut, wie es nur wenige kennen." ${ }^{1}$

Nach seiner Rückkehr nach Petersburg begann er - bewegt und begeistert von der durch den Reformzar Alexander II. dekretierten Abschaffung der Leibeigenschaft - für einen eigenständigen Weg Rußlands zu kämpfen, dafür, daß sein Land sich nun endlich vom Einfluß Westeuropas befreit und den eigenen Wurzeln und Traditionen zuwendet.

In der gemeinsam mit seinem Bruder Michail herausgegebenen Zeitschrift „Die Zeit“ (Vremja), später in der Zeitschrift „Epoche“ (Épocha) entwickelte er Anfang der 60er Jahre in einer ganzen Reihe von Artikeln seine Ideologie der „Bodenständigkeit“ (počvenničestvo von russ. počva = Boden, Scholle).

Die Grundthesen dieses Denkgebäudes seien hier kurz zusammengefaßt:

Überzeugt von der Eigenart und Eigenständigkeit (samobytnost') des russischen Volkes, lehnt Dostoevskij die Zivilisation „,in ihrer ausschließlich europäischen Form“ ab und fordert die Rückkehr der russischen Gesellschaft zu den "Quellen des Volkes, zum heimatlichen Boden“" (narodnaja počva"). Es geht dabei um die Überwindung der seit den Reformen Peters des Großen be-

Die Quellenangabe aller Briefzitate nach der 30bändigen Akademie-Ausgabe (Polnoe sobranie sočinenij, Leningrad 1972 - 1990, Abk. PSS).

1 Brief an den Bruder Michail M. Dostoevskij aus Omsk vom 30. Jan. - 22. Febr. 1854, PSS 28/I, S. $172 f$. 
stehenden Kluft zwischen der europäisierten, gebildeten Oberschicht und dem russischen Volk, um die Versöhnung zwischen allen gesellschaftlichen Ständen. Grundlage dafür ist der Glaube, daß „die russische Nation eine ungewöhnliche Erscheinung in der Geschichte der ganzen Menschheit“ sei. Im russischen Charakter erkennt er die Fähigkeit zur "Allaussöhnung und Allmenschlichkeit“, einen „Instinkt für das Allmenschliche“.

In seinem großen Essay Winterliche Aufzeichnungen über sommerliche Eindrücke über die erste Auslandsreise 1862, die ihn in wenigen Wochen durch Deutschland, Frankreich, England, die Schweiz und Italien führte, hat er die Ideologie des "počvenničestvo“ literarisch entfaltet. Dieser Reisebericht ist eine radikale Abrechnung mit der bourgeoisen westlichen Zivilisation, verbunden mit sarkastischer Kritik an den russischen „Westlern“. Mit den Begriffen „Kristallpalast“ - für die Warenwelt der Londoner Weltausstellung - und „Ameisenhaufen“ - für die sich entwickelnde Industriegesellschaft - fand der Schriftsteller eindrückliche Bilder, mit denen er den Kapitalismus wie auch die Utopie des Sozialismus, die er beide nur als unterschiedliche Ausprägungen der einen gottlosen, säkularisierten, materialistischen westlichen Zivilisation ansieht, warnend charakterisierte.

In den Grundzügen war Dostoevskijs „russische Idee“ also schon entwickelt, bevor er Westeuropa persönlich kennenlernte, wobei die ersten kurzen Reisen in den Westen seine vorgefaßten Urteile bzw. Vorurteile nur bestätigten. Und in seinen Romanen Verbrechen und Strafe (Prestuplenie i nakazanie) und Der Spieler (Igrok) sind diese Gedanken auch in künstlerischer Form verarbeitet.

Jedoch enthält die russische Idee zu dieser Zeit - trotz der scharfen wertenden Gegenüberstellung von Rußland und Westeuropa und trotz einer gewissen Idealisierung des russischen Volkes - noch keinen messianischen Anspruch. Es fehlt das religiöse Element!

Erst während seines erzwungenen Europa-Aufenthalts von 1867 - 1871 erlangt die Ideologie der Bodenständigkeit (počvenničestvo) ihre radikale Zuspitzung, bekommt eine neue Qualität. Erst in diesen Jahren im Ausland kommt es zur endgültigen Ausprägung seiner antiwestlichen, nationalistischen, zarentreuen „russischen Idee“, die nun immer mehr mit messianischem Eifer vertreten wird.

Die Analyse seiner vielen ausführlichen Briefe aus dem Westen bestätigt, daß diese Radikalisierung während seines Aufenthalts in der Schweiz und in Italien von Ende 1867 bis Mitte 1869 erfolgt, also während der Arbeit am Roman Der Idiot (Idiot). 
Zunächst ein kurzer Blick auf seine biographische Situation:

Dostoevskij war mit seiner jungen Frau Anna Grigorevna gleich nach der Hochzeit im Februar 1867 nach Westeuropa abgereist, und dies war nicht nur eine Flucht des Hochverschuldeten vor seinen Gläubigern, sondern auch vor den Querelen und Versorgungsansprüchen der Familie seines verstorbenen Bruders und seines Stiefsohns. Schon in den ersten glücklichen Wochen in Dresden arbeitete er an einem leider nicht erhaltenen Essay über den „Mistkäfer" und Westler Vissarion Belinskij, beschäftigte sich also mit der Auseinandersetzung zwischen Westlern und Slavophilen. Die folgenden Jahre - geprägt von qualvollen Erfahrungen durch seine krankhafte Spielleidenschaft waren Jahre der Unbehaustheit, ständiger Geldsorgen und oftmals bitterer Armut. In der Spielerhochburg Baden-Baden kam es zu dem berühmten Zerwürfnis mit dem „Westler“ und „Atheisten“ Ivan Turgenev über Rußland und den Westen. In der Schweiz geriet das Ehepaar in tiefe Verzweiflung über den Tod seines ersten Kindes Sonja, das im Alter von drei Monaten in Genf gestorben war.

„Und dazu kommt noch der Gedanke, dass Sonja ganz sicher leben würde, wenn wir in Rußland gewesen wären!“2

Unter diesen Bedingungen nimmt Dostoevskijs Haß und seine Verachtung gegenüber allem Deutschen und Schweizerischen, den er in vielen Briefen wortreich ausdrückt, manchmal überspannte Züge an.

Im September 1867 hatte Dostoevskij in Genf, dem Hauptsitz der linken sozialistischen russischen Emigration, eine Sitzung der „Liga für Frieden und Freiheit" besucht. Er berichtet voller Empörung darüber und fühlt sich in seiner harschen Ablehnung aller sozialistischen Ideen bestätigt:

„Was diese Herren Sozialisten und Revolutionäre, die ich zum ersten Mal nicht in Büchern, sondern in Wirklichkeit erlebt habe, da von der Tribüne vor 5000 Zuhörern herunterlügen, ist nicht auszudrücken. [...] Sie begannen damit, dass es zur Erlangung des Friedens auf Erden notwendig ist, den christlichen Glauben auszurotten. Große Staaten müssen vernichtet und kleine daraus gemacht werden; weg mit allem Kapital, damit alles per Order Gemeineigentum wird usw. [...] Und das Wichtigste, Feuer und Schwert [...]."3

Im Herbst 1868 siedelt er mit seiner Frau aus Vevey nach Italien über, zunächst nach Mailand, dann nach Florenz. Neben der Hoffnung auf einen milden

2 Brief an A. Majkov aus Mailand vom 26. Okt./7. Nov. 1868, PSS 28/II, S. 324. Alle Briefe wurden von der Verfasserin übersetzt.

3 Brief an S. A. Ivanova vom 29.Sept./11. Okt. 1867 aus Genf. PSS 28/II, S. 224. 
Winter dort war das wichtigste Argument, hier habe er Zugang zu russischen Zeitungen und Zeitschriften.

All die Jahre im Ausland litt er unter schrecklichem Heimweh. Das Leben im Westen erschien ihm „schlimmer als Verbannung nach Sibirien. Ich meine es durchaus ernst ohne zu übertreiben [...]. Ich kann die Russen im Ausland nicht begreifen “. ${ }^{4}$ Immer wieder drückt er seine Empörung über die Ahnungslosigkeit der Westeuropäer gegenüber Rußland aus, und die ganze Zeit ist er besessen von dem Gedanken an die Rückkehr nach Rußland, die er auch für sein Schreiben als lebensnotwendig und unverzichtbar ansieht. In fast allen Briefen stellt er umständliche Berechnungen an, auf welche Weise er das Geld für die Rückkehr beschaffen könnte.

Nun ist ja die ganze Zeit in der Schweiz und Italien ausgefüllt mit der Arbeit an dem Roman Der Idiot. Und obwohl die „russische Idee“ in diesem Buch auf den ersten Blick wahrlich nicht im Mittelpunkt steht, läßt sich zeigen, daß sein Denken zunehmend um dieses Thema kreist. Schon in den vielen, seitenlangen Briefen aus Genf nimmt die „russische Idee“ immer mehr Raum ein, besonders ausgeprägt und weitschweifig in Briefen an den Schriftsteller Apollon Majkov, der ihm ideologisch besonders nahesteht. Da heißt es z.B. nach einer boshaften Haßtirade gegen Schweizer und Deutsche:

"Wir aber haben in dieser Zeit eine große Nation aufgebaut, Asien für immer Einhalt geboten, unendliches Leid ertragen, das wir ertragen konnten, haben niemals die russische Idee aufgegeben, die Welt zu erneuern, sondern diese noch gefestigt. Und schließlich haben wir auch die Deutschen ertragen, und trotz allem steht unser Volk unermeßlich höher, ist edler, ehrlicher, naiver, fähiger und von einer anderen höherstehenden christlichen Idee erfüllt, die Europa mit seinem im Sterben liegenden Katholizismus und seinem sich auf einfältige Weise selbst widersprechenden Lutheranertum nie begreifen wird. ${ }^{\text {"5 }}$

Und in einem Brief aus Genf schreibt er:

„Unsere Konstitution ist die gegenseitige Liebe des Volkes zum Monarchen und des Monarchen zum Volk. Ja, die mit Liebe verbundene und nicht die kriegerische Grundlage unseres Staates (was offenbar als erste die Slawophilen erkannt haben) ist der ganz große Gedanke, auf dem man aufbauen kann. [...] Hier im Ausland bin ich für Rußland endgültig zum überzeugten Monarchisten geworden. ${ }^{\text {“6 }}$

4 Brief an S. A. Ivanova vom 25. Jan./6. Febr. 1869 aus Florenz. PSS 29/I. S. 10.

5 Brief an A. Majkov vom 31. Dez. 67/12. Jan. 68 aus Genf, PSS 28/II, S. 243.

6 Brief an A. Majkov aus Genf vom 21.-22. März/2.-3. April 1868, PSS 28/II, S. $280 f$. 
Das wesentlich Neue ist aber vor allem, daß die russische Idee nun immer mehr religiös gedeutet wird:

„Der ganzen Welt wird eine Erneuerung bereitet werden durch den russischen Gedanken (der fest verbunden ist mit der Orthodoxie, da haben Sie recht), und das wird irgendwann geschehen, das ist mein leidenschaftlicher Glaube. ${ }^{\text {"7 }}$

Und dieser Gedanke der Erneuerung und Erlösung der ganzen Welt durch die russische Orthodoxie ist - soweit ich sehe - im Roman Der Idiot zum ersten Mal ausführlich entfaltet, und zwar in dem großen emotionalen Ausbruch des Fürsten Myschkin im Salon der Jepantschins. ${ }^{8}$

Bei den Jepantschins sind eine ganze Reihe russischer Würdenträger und Menschen der höheren Schichten eingeladen. Anlaß ist die Verkündigung der Verlobung Myschkins mit Aglaja. Als der Fürst hört, daß sein Pflegevater Pawlistschew von Jesuiten zur Konversion zum Katholizismus überredet wurde, hält er eine erregte, leidenschaftliche, begeisterte Rede, die - nach Zerbrechen der kostbaren chinesischen Vase - in einen epileptischen Anfall mündet. Diese Rede stellt in zugespitzter Form das gesamte Programm der religiös überhöhten russischen Idee dar. Deshalb die ausführliche Zitierung, zusammengefaßt in fünf Thesen:

\section{These I: Ein radikaler Antikatholizismus.}

„Der römische Katholizismus ist sogar schlimmer als der Atheismus [...] Der Atheismus verkündet nur die Null, der Katholizismus aber geht weiter: Er verkündet den entstellten Christus, den er selbst verleugnet und geschändet hat, den Gegen-Christus! Er verkündet den Antichrist, ich schwöre es Ihnen“! [...] Der römische Katholizismus glaubt, daß eine Kirche, die nicht ein mächtiger Weltstaat ist, sich auf dieser Erde nicht wird behaupten können [...] Meine Meinung ist, daß der Katholizismus sogar nicht einmal eine Religion, sondern ganz eindeutig die Fortsetzung des Weströmischen Imperiums und daß alles an ihm von dieser Idee beherrscht ist, vom Glauben angefangen. Der Papst hat sich des Erdballs bemächtigt, des irdischen Throns, und das Schwert ergriffen; und seither ist alles so geblieben, nur hat sich zum Schwert die Lüge gesellt, Intrige, Betrug, Fanatismus, Aberglaube, böser Wille, das Spiel mit den heiligsten, echtesten, aufrichtigsten, feurigsten Gefühlen des Volkes und alles, alles wurde gegen Geld, gegen niedrige irdische Macht eingetauscht.“

7 Brief an A. Majkov vom 18. Febr./ 1. März 1868 aus Genf, PSS 28/II, S. 260.

8 Vgl. Fjodor Dostojewskij: Der Idiot. (Neuübersetzung von Swetlana Geier) Frankfurt am Main 2009 (Teil IV. Kapitel VII), S. 785-788. 
These II: Der Atheismus ist eine Folgeerscheinung des Katholizismus.

„Der Atheismus ist aus ihm hervorgegangen, aus dem römischen Katholizismus selbst! [...] Er ist die Ausgeburt ihrer Verlogenheit und geistigen Ohnmacht! Atheismus! Bei uns haben erst die höheren Stände den Glauben verloren [...] die Entwurzelten; aber dort, in Europa, dort beginnen schon gewaltige Massen des Volkes den Glauben zu verlieren - früher aus Unwissenheit und Verlogenheit und jetzt aus Fanatismus, aus Haß gegen die Kirche und das Christentum."

These III: Auch der Sozialismus ist eine „Ausgeburt des Katholizismus“.

„Auch der Sozialismus ist eine Ausgeburt des Katholizismus und des katholischen Wesens! Auch er ist, wie sein Bruder, der Atheismus, der Verzweiflung entsprungen, um als Antithese, im sittlichen Sinne, zum Katholizismus, die verlorene sittliche Macht der Religion zu ersetzen, um den geistigen Durst der darbenden Menschheit zu stillen und sie nicht durch Christus, sondern ebenfalls durch Gewalt zu erlösen! Auch dort ist Freiheit durch Gewalt, Einigung durch Schwert und Blut! „Untersteh dich, an Gott zu glauben! Untersteh dich, Eigentum zu haben! Untersteh dich, eine Persönlichkeit zu sein, Fraternité ou la mort, zwei Millionen Köpfe!“

These IV: Die Russen mit ihrer Leidenschaft und ihrem „geistigen Durst“ sind besonders anfällig für Atheismus und Sozialismus.

„Wenn einer von uns zum katholischen Glauben übertritt, dann muß er gleich Jesuit werden und noch dazu einer von den ganz fanatischen; wird er Atheist, fordert er unbedingt die Ausrottung des Gottesglaubens mit Gewalt, das heißt, mit dem Schwert. Woher das kommt? [...] Weil er ein Vaterland gefunden hat, das er hier übersehen hatte [...] Er ist an ein Ufer gelangt, er hat Boden unter den Füßen, und nun fällt er nieder, um ihn zu küssen. Es ist [...] geistiger Schmerz, geistiger Durst, Sehnsucht nach einer höheren Aufgabe, nach einem festen, sicheren Ufer, nach der Heimat, an die man nicht mehr glaubt, weil man sie niemals gekannt hat! [...] Wir werden nicht einfach Atheisten, sondern wir beginnen, an den Atheismus zu glauben, er wird zu einer neuen Religion, und wir merken nicht, dass wir nun an eine Null glauben. So stark ist unser Durst! „Wer keinen Grund unter den Füßen hat, der hat auch keinen Gott.“

These V: Gegenwehr - der „russische Christus“.

„... Gegenwehr ist vonnöten, und zwar sehr bald, sehr bald! Es ist vonnöten, dass unser Christus, den wir bewahrt haben und den die anderen nie gekannt haben, als Gegenwehr dem Westen entgegenstrahlt. Wir dürfen nicht sklavisch den Jesuiten an die Angel gehen, sondern wir müssen uns ihnen in den Weg stellen und ihnen unsere russische Zivilisation entgegenhalten [...] Weist den dürstenden 
und fiebernden Gefährten des Columbus das Gestade der „Neuen Welt“, weist den russischen Menschen die russische „Welt", laßt ihn dieses Gold heben, diesen Schatz, der verborgen in der Erde ruht! Weist ihm die künftige Erneuerung und Auferstehung der ganzen Menschheit, vielleicht allein dank der russischen Idee, des russischen Gottes und Christus, und Ihr werdet sehen, welcher Riese, kraftvoll und wahrhaftig, weise und sanft, sich vor der staunenden Welt aufrichten wird, einer staunenden und erschrockenen Welt, weil man von uns nur das Schwert erwartete, das Schwert und die Gewalt, weil man sich uns nach dem eigenen Bilde nicht anders vorstellen kann, denn als Barbaren."

Diese emphatische Rede Myschkins enthält auch das geistige Programm des gewaltigen Werks, das Dostoevskij als nächstes vorschwebt, des großen Romanprojekts mit dem Arbeitstitel „Atheismus“. In den umfassenden Briefen aus Italien wird es immer wieder ausgesprochen: dieses Projekt versteht Dostoevskij als seine Lebensaufgabe, in dem er das, was ihn ,erfüllt, noch vor seinem Tode in irgendeinem Werk möglichst restlos aussprechen will.“9 Er nennt es ein Projekt „vor dem meine ganze bisherige literarische Karriere nur Schund (drjan') und eine Einleitung ist und dem ich mein ganzes weiteres Leben widmen werde. ${ }^{\text {"10 }}$ In einem Brief vom Dezember 1868 aus Florenz wird der Plan zum Atheismus-Buch zum ersten Mal umrissen. Die Hauptfigur ist ein russischer Mann aus gebildeten Kreisen, der plötzlich seinen Glauben verliert:

„Er sucht Anschluß an die neuen Generationen, an die Atheisten, die Slawophilen und die Europäer, die russischen Sektierer und Einsiedler, an die Geistlichen: unter anderem gerät er auch einem polnischen Jesuiten und Propagandisten in die Falle; danach fällt er in den Abgrund der Chlysten-Sekte und findet schließlich Christus und die russische Erde, den russischen Christus und den russischen Gott." ${ }^{\text {"1 }}$

Mit diesem Projekt will Dostoevskij offensichtlich den ganzen Raum der geistigen Debatten seiner Zeit durchschreiten. Er berichtet in den Briefen immer wieder von den umfangreichen Vorstudien, die dazu nötig seien, daß er „eine ganze Bibliothek mit Werken atheistischer, katholischer und orthodoxer Autoren durchlesen " müsse. ${ }^{12}$

Schon in der Schweiz und dann vor allem in Florenz im „Kabinet Vieusseux“ las er den ganzen Winter über Voltaire und Diderot. Und er betont in

9 Brief an S. A. Ivanova aus Florenz vom 8./20. März 1869, PSS 29/I, S. 24.

10 Brief an A. Majkov aus Florenz vom 15./27. Mai 1869, PSS 29/I, S. 44.

11 Brief an A. Majkov aus Florenz vom 11./23. Dezember 1868, PSS 28/II, S. 329.

12 Ebd. S. 329. 
jedem Brief, daß er dieses sein Lebenswerk nur in Rußland schreiben könne, daß er dazu unbedingt als "notwendiges Material“ „die russische Wirklichkeit und die Russen“ brauche. ${ }^{13}$ Die so sehnsüchtig angestrebte Rückkehr nach Rußland konnte er - wie wir wissen - erst fast drei Jahre später realisieren.

Aber trotz der aktuellen politischen und ideologischen Thematik, um die es ihm bei dem Projekt geht, betont er immer wieder, daß dieser Roman nicht einfach „eine Anschuldigung gegen die heute um sich greifenden Überzeugungen, sondern etwas anderes; eine echte Dichtung" sein wird, ${ }^{14}$ eine "Synthese seiner künstlerischen und poetischen Ideen ". ${ }^{15}$

Und gerade in diesen Briefen aus Florenz und im Zusammenhang mit dem so bedeutsamen Romanprojekt über das Leben eines großen Sünders legt Dostoevskij auch seine grundlegende Ästhetik und Poetologie dar, seine berühmten, immer wieder zitierten Gedanken über Realismus und Phantastik: Daß er einen anderen Begriff von der Wirklichkeit und vom Realismus habe als alle Realisten und Kritiker. Sein Idealismus sei realistischer als der ihrige.

„Wenn man nur vernünftig erzählen würde, was wir alle, die Russen, in den letzten zehn Jahren in unserer geistigen Entwicklung durchlebt haben, so würden alle Realisten ein Geschrei erheben, daß dies Phantasie sei. Und doch ist es echter, purer Realismus. ${ }^{\text {16 }}$

\title{
Oder:
}

\begin{abstract}
„Das, was die meisten für beinahe phantastisch und ungewöhnlich halten, erscheint mir manchmal als das tiefste Wesen der Wirklichkeit" (...) Ist denn mein phantastischer „Idiot“ nicht die alltäglichste Wirklichkeit? Gerade heutzutage muß es in unseren Gesellschaftsschichten, die von der Scholle losgelöst sind, in den Schichten, die in der Tat phantastisch zu werden anfangen, solche Charaktere geben. ${ }^{\text {"17 }}$
\end{abstract}

Aber natürlich ist mit seinem Atheismus-Projekt eine ideologische Absicht verbunden: es zielt auf die Verbreitung der russischen Idee in ihrer messianischen Form, was er von nun an als seine Lebensaufgabe betrachtet.

Völlig begeistert ist er deshalb von der Nachricht über eine neue Zeitschrift, die in Rußland erscheint, die Zeitschrift „Morgenröte“ (Zarja). Diese hat sich

13 Brief an S. A. Ivanova aus Florenz vom 25. Jan./6. Febr. 1869, PSS 29/I, S. 11.

14 Brief an S. A. Ivanova aus Florenz vom 25. Jan./6. Febr. 1869, PSS 29/I, S. 11.

15 Brief an S. A. Ivanova aus Florenz vom 8./20. März 1869, PSS 29/I, S. 24.

16 Brief an A. Majkov aus Florenz vom 11./23. Dez. 1868, PSS 28/II, S. 329.

17 Brief an N. N. Strachov aus Florenz 26. Febr../10. März 1869, PSS 29/I, S. 19. 
ganz der russischen Idee verschrieben, „für uns die einzige fortschrittliche und liberale Idee ${ }^{\prime 18}$, die ,jetzt unumgänglich, unausbleiblich ist und der es allein vorbestimmt ist zu wachsen, während die anderen schrumpfen müssen “. ${ }^{19} \mathrm{Die}$ Zeitschrift „Morgenröte“ wird nun in fast allen Briefen aus Italien zu einem der wichtigsten Themen. Redakteur der „Morgenröte“ ist Nikolaj Strachov, ein enger Mitarbeiter Dostoevskijs aus der Zeit seiner eigenen journalistischen und Herausgebertätigkeit Anfang der 60er Jahre. In der „Zarja“ sieht er die Weiterführung dessen, was sie damals begonnen hatten:

„Und so sind unsere Richtung und unsere gemeinsame Arbeit nicht untergegangen. Die „Vremja“ und die „Epocha“ haben trotzdem Früchte getragen - und das neue Projekt mußte notwendigerweise da anknüpfen, wo wir stehen geblieben sind. ${ }^{\text {"20 }}$

Strachov ist ihm die Garantie, daß die „Morgenröte“ „von russischem Geist, wie wir ihn verstehen “ erfüllt wird, schreibt er an Majkov, und er erwartet, daß der Redakteur der Zeitschrift „eine bestimmte politische Färbung verleihen wird“. ${ }^{21}$

Und wenn er die angestrebte politische Richtung „nicht rein slavophil“22 nennt, dann heißt das nur, daß sein Verständnis der russischen Idee über das Denken der damaligen Slavophilen, die ihm längst nicht radikal genug sind, weit hinausgeht. Auf dem Slavenkongreß im Mai 1868 in Moskau war deutlich geworden, daß die meisten Süd- und Westslaven die von den Russen beanspruchte Führungsrolle innerhalb der panslawistischen Bewegung durchaus nicht akzeptierten, weshalb Dostoevskij meint, daß man ihnen „mit unseren brüderlichen Gefühlen nicht nachzulaufen" brauche. ${ }^{23}$

Gleich in der ersten Nummer der Zeitschrift "Zarja" begann der Abdruck eines bedeutenden Werkes, das genau dem Denken Dostoevskij entsprach und das er „ein Handbuch für jeden Russen“ nennt. Es handelt sich um die Schrift von Nikolaj Danilevskij Rußland und Europa.

„Der Artikel stimmt so sehr mit meinen eigenen Ansichten und Überzeugungen überein, daß ich stellenweise über die Identität unserer Schlüsse staunen muß." ${ }^{\text {“4 }}$

18 Ebd. S. 15.

19 Ebd.

20 An N. N. Strachov aus Florenz am 12./24. Dez. 1868, PSS 28/II, S. 335.

21 An A. Majkov aus Mailand 26. Okt./ 7. Nov. 1868, PSS 28/II, S. 323.

22 Ebd. S. 322.

23 Ebd. S. 223.

24 Brief an N. N. Strachov aus Florenz vom 18./30. März 1869, PSS 29/I, S. 28. 
Dostoevskij kannte den Autor von Rußland und Europa schon aus den 40er Jahren, wo der junge Danilevskij, wie er selbst, dem revolutionären Kreis der Petraschewzen (petraševcy) angehört hatte und ebenfalls verbannt worden war. Dostoevskij drückt in einem Brief an Majkov seine Bewunderung darüber aus, daß sich dieser „verrückte Fourierist“ wieder in einen Russen verwandelt und dessen Scholle und Wesensart (počva/suščnost') liebgewonnen habe. Daran erkenne man eben den bedeutenden Menschen, wohingegen Turgenev, der sich aus einem russischen Schriftsteller zum Deutschen gewandelt habe, ein Lumpenkerl (drjannyj čelovek) sei. ${ }^{25}$

Dieses Buch Danilevskijs über "Rußland und Europa“ ist in der Tat bis in unsere Zeit hinein zu einem Basistext der kulturtypologischen Entgegenstellung der untergehenden westlichen und der aufsteigenden, ganz eigenständigen und dem Westen überlegenen russischen Zivilisation geworden. Es findet in Spenglers „Untergang des Abendlandes“ sein Echo und ist heute in Rußland wieder sehr aktuell.

Aber nachdem Dostoevskij die ersten Kapitel des Buches in der „Morgenröte" gelesen hatte, war er doch noch nicht ganz zufrieden. Offenbar war ihm die religiöse Dimension der russischen Idee bei Danilevskij noch nicht ausgeprägt genug:

„Ich bin noch nicht ganz davon überzeugt, dass Danilewskij mit genügendem Nachdruck auf das tiefste Wesen und die letzte Bestimmung des russischen Volkes hinweisen wird; nämlich darauf, daß Rußland der Welt seinen eigenen russischen Christus offenbaren muß, den die Völker noch nicht kennen und dessen Grundlage in unserem eigenen orthodoxen Glauben beschlossen ist. Darin liegt, wie ich glaube, das ganze Wesen unserer zukünftigen zivilisatorischen Bestimmung und der Auferweckung ganz Europas, das Wesen unserer zukünftigen und mächtigen Existenz. ${ }^{\text {“26 }}$

Dieser Gedanke wird in einem Brief an seinen Gesinnungsgenossen und Freund Majkov weiter entfaltet. ${ }^{27}$ Dostoevskij entwirft nämlich für Majkov, dessen Balladen im russisch-patriotischen Geist er hoch schätzt, ein gewaltiges literarisches Projekt, das in vielem mit seinem "Atheismus"-Plan korrespondiert: Majkov soll in eingängigen volkstümlichen Versgattungen (Bylinen, Balladen, Poemen, Gedichten) die gesamte russische Geschichte an ihren wesentlichen Konzentrationspunkten und in Konfrontation zur Entwicklung des Westens „von Anfang an mit unserer Idee, mit unserem russischen Blick“ darstellen.

25 Brief an A. Majkov aus Florenz vom 11./23. Dez. 1868, PSS 28/II, S. 328.

26 Brief an N. N. Strachov aus Florenz, vom 18./30. März 1869, PSS 29/I, S. 30.

27 Brief an A. Majkov aus Florenz vom 15./27. Mai, PSS 29/I, S. $38 \mathrm{ff.}$ 
Ziel eines solchen "großen nationalen Buches“ sei die Wiedergeburt des Selbstbewußtseins des russischen Menschen. Und er skizziert die Geschichte Rußlands von den Anfängen an aus dieser Perspektive:

„die große Idee von der allorthodoxen Bedeutung Rußlands, und es wird der Grundstein gelegt für die künftige Vorherrschaft im Osten, es erweitert sich der Kreis der russischen zukünftigen Bedeutung, es entsteht der Gedanke nicht nur eines großen Staates, sondern einer ganzen neuen Welt, der es bestimmt ist, das Christentum durch die allslawische orthodoxe Idee zu erneuern und in die Menschheit einen neuen Gedanken hineinzutragen, wo der Westen anfängt zu faulen, und er beginnt da zu faulen, wo der Papst Christus endgültig entstellt und damit den Atheismus in der besudelten westlichen Menschheit hervorbringt. ${ }^{\text {" } 8}$

Den Abschluß soll ein phantastisches Zukunftsbild bilden:

„Rußland in 200 Jahren und daneben das verblaßte, zerrissene, vertierte Europa mit seiner Zivilisation. ${ }^{22}$

In diesem Brief aus Florenz wird auch der Begriff der „Menschenrechte“ im westlichen und in „unserem“ Sinne zum ersten Mal explizit gegenübergestellt.

Die Idee eines solchen Buches ist von Majkov ebenso wenig verwirklicht worden wie Dostoevskijs eigenes Atheismus-Projekt, wenn auch alle seine folgenden Romane von diesen Vorstellungen durchdrungen sind. In seiner tausende Seiten umfassenden politischen Publizistik des Tagebuchs eines Schriftstellers (Dnevnik pisatel'ja) jedoch ist die russische Idee in ihrer religiös fundierten, messianischen Ausprägung die grundlegende Ausgangsposition seines Denkens. Entwickelt hat er diese Idee in der Schweiz und in Italien. 


\section{Hans Günther}

\section{Der Kristallpalast der modernen Zivilisation - Utopiekritik nach Dostoevskij}

\section{Kristallpalast und Goldenes Zeitalter}

Die von dem Architekten Joseph Paxton für die erste Weltausstellung von 1851 im Londoner Hyde Park aus Glas und Stahl errichtete Ausstellungs- und Gewächshaushalle von gewaltigen Ausmaßen wurde von vielen Zeitgenossen als eine Art Zauberschloß der modernen Zivilisation empfunden. Diese Bewunderung drückt sich auch in der märchenhaften Bezeichnung Crystal Palace, Kristallpalast, aus. Das Gebäude wurde 1854 in den Park von Sydenham versetzt, wo es 1936 abbrannte. Das Glashaus faszinierte als Wunderwerk der Technik, die es ermöglichte, die moderne Warenwelt und eine üppige, exotische Pflanzenwelt in einer Art künstlichem Paradies zu vereinigen.

Kein Wunder, daß dieser durch die moderne Technik geschaffene Garten Eden zum Fluchtpunkt vieler Sozialutopien des 19. Jahrhunderts wurde. Schon lange vor dem Londoner Kristallpalast hatte Charles Fourier begonnen, seine Idee der Phalanstères zu entwerfen, die er im Lauf der Zeit immer weiter perfektionierte. Phalanstères, das waren architektonisch gestaltete, für eine bestimmte Anzahl von Individuen geplante Lebens- und Produktionswelten, die ihren Bewohnern die optimale Entwicklung ihrer Bedürfnisse und Fähigkeiten garantieren sollten. ${ }^{1}$ Nikolaj Černyševskij projiziert Fouriers Ideen auf den Londoner Kristallpalast, den er 1859 besichtigte und als „Wunder der Kunst, der Schönheit und Herrlichkeit“ ${ }^{\text {¿2 }}$ pries. Vera Pavlovna, die Heldin seines Romans Was tun? (Čto delat'?, 1863), läßt er einen Zukunftstraum träumen, der russische Sozialisten und Revolutionäre aller Schattierungen beflügeln sollte:

„Aber dieser riesige Bau - was ist das? Was für eine Architektur? Noch gibt es dergleichen nicht, oder doch, es gibt schon einen Hinweis darauf, den Palast auf

1 Vgl. Charles Fourier: Theorie der vier Bewegungen und der allgemeinen Bestimmungen. Frankfurt/Wien 1966.

2 Nikolaj M. Černyševskij: Polnoe sobranie sočinenij. Moskau 1971, Bd. 16, S. 91. 
dem Hügel von Sydenham: Eisen und Glas - weiter nichts; doch bildet dies gleichsam ein schützendes Gehäuse, darinnen aber ist das richtige Haus, ein riesiges Haus, es wird von diesem Gebäude aus Eisen und Kristall wie von einem Futteral umschlossen. [...] Überall sind grünende exotische Gewächse aufgestellt, das ganze Haus ist ein großer Wintergarten. “3

In diesem Palast, der im Traum nach Rußland, in eine blühende Kulturlandschaft unweit des Flusses Oka versetzt ist, sieht Vera Pavlovna - ganz im Geiste Fouriers - glückliche Menschen in paradiesischer Harmonie leben und arbeiten.

Bei Dostoevskij taucht der Kristallpalast zum ersten Mal in einem ganz anderen Zusammenhang auf, nämlich in einem Reisebericht über seine Eindrücke der Stadt London. Černyševskijs Roman, der eine sarkastische Polemik seitens Dostoevskijs in seinen Aufzeichnungen aus dem Untergrund (Zapiski iz podpol'ja, 1864) hervorrief, war zu diesem Zeitpunkt noch nicht erschienen. Der Kristallpalast wird von beiden Autoren diametral entgegengesetzt bewertet - für Černyševskij ist er ein Sinnbild utopischer Verheißung, während seine Bedeutung für Dostoevskij aus dem abstoßenden und erschreckenden Gesamteindruck herauswächst, den die Stadt London auf den russischen Reisenden macht. In seinen Winteraufzeichnungen über Sommereindrücke (Zimnie zametki o letnich vpečatlenijach, 1863) schreibt er:

„Sollte das schon das erreichte Ideal sein? fragen Sie sich. Ist das nicht das Ende? Ist das nicht in der Tat schon die verwirklichte ,eine Herde'? [...] All das ist so triumphal, so sieghaft und stolz, daß Ihnen der Atem stockt. Sie betrachten diese Hunderttausende, diese Millionen von Menschen, die aus aller Welt gehorsam hier zusammenströmen - Menschen, von einem Gedanken hierhergeführt, sich unentwegt und stumm in diesem kolossalen Palast drängen, und sie spüren, daß sich hier etwas Endgültiges vollzogen, vollzogen und vollendet hat. Es ist wie ein biblisches Bild, etwas Babylonisches, eine Prophezeiung aus der Apokalypse, die vor unseren Augen Wirklichkeit wird. ${ }^{\text { }}$

Dostoevskijs Bild des Kristallpalastes ${ }^{5}$ verfestigt sich in den kurz darauf erschienenen Aufzeichnungen aus dem Untergrund. Der Untergrundmensch lehnt den Kristallpalast wie auch die mit ihm verbundene strikte Reglementierung des Lebens und Idee des verordneten Glücks ab, weil dem Menschen auf diese

3 Nikolaj Tschernyschewski: Was tun? Berlin 1980, S. 450-451.

4 Fjodor M. Dostojewski: Über Literatur. Leipzig 1971, S. 50.

$5 \mathrm{Zu}$ den Metaphern des Kristallplastes und des Goldenen Zeitalters bei Dostoevskij vgl. Gerhard Dudek: Chrustal'nyj dvorec - Podpol'e - Zolotoj vek, in: Zeitschrift für Slawistik 28 (1983), H. 5, S. 667-682. 
Weise der freie Wille, die Möglichkeit des Leidens als Quelle der Erkenntnis genommen werde:

„Sie glauben an einen ewig unzerstörbaren Kristallpalast, also an etwas, dem man heimlich weder die Zunge noch hinterrücks die Faust wird zeigen können. Nun, ich aber fürchte diesen Palast vielleicht gerade deshalb, weil er aus Kristall und ewig unzerstörbar ist, und weil man ihm nicht einmal heimlich wird die Zunge zeigen können. “6

In den Aufzeichnungen aus dem Untergrund wachsen der Metapher des Kristallpalastes zusätzliche Bedeutungen zu. Sie steht jetzt nicht mehr nur für die „Herde“ und den „Ameisenhaufen“ der kapitalistischen Großstadt-Zivilisation, sondern schließt eine Kritik an sozialistischen Zukunftsvisionen à la Fourier oder Černyševskij ein. Bekanntlich hatte Dostoevskij, in den 1840er Jahren selber ein Anhänger sozialistischer Vorstellungen, diesen Ideen abgeschworen und war in der Haft zu einem Befürworter slavophiler „Bodenständigkeit“ (počvenničestvo) geworden, dessen neue Überzeugungen auf dem Glauben an das russische Volk basierten.

In welchem Maß die Bewertung des Kristallpalastes von dem Standpunkt des Betrachters abhängt, wird deutlich, wenn man Dostoevskijs Einschätzung mit den Worten konfrontiert, die der Westler Turgenev einer Gestalt seines Romans Rauch (Dym, 1867) in den Mund legt:

„In diesem Frühjahr hab ich den Kristallpalast bei London besucht. In diesem Gebäude ist, wie Sie wissen, so etwas wie eine Ausstellung all dessen untergebracht, was menschlicher Erfindungsgeist ersonnen hat - eine Enzyklopädie der Menschheit, so muß man sie schon nennen. Nun, während ich also an all diesen Maschinen, Werkzeugen und Standbildern großer Männer vorüberwandelte, kam mir der Gedanke: wenn einmal ein Erlaß herauskäme, daß bei Verschwinden eines Volkes vom Antlitz der Erde gleichzeitig auch all das aus dem Kristallpalast verschwinden müßte, was jenes Volk erdacht und erfunden hat, könnte unser Mütterchen, das rechtgläubige Rußland, in den Tartarus versinken, ohne daß es auch nur ein einziges Nägelchen oder Nädelchen aufstören würde, das teure; alles könnte seelenruhig an seinem Platz bleiben, denn nicht einmal den Samowar, die Bastschuhe, das Krummholz und die Knute, diese unsere berühmtesten Erzeugnisse, haben wir erfunden. ${ }^{\text {"7 }}$

Man kann sich unschwer vorstellen, wie Dostoevskij sich durch diese Worte verletzt fühlen mußte.

6 Fjodor M. Dostojewski: Sämtliche Werke in zehn Bänden. München/Zürich 1977, Bd. 4, S. 468.

7 Iwan Turgenjew: Rauch. Neuland. Berlin/Weimar 1979, S. 117. 
Daß die europäischen Weltausstellungen ein lebhaftes Echo im Rußland der zweiten Hälfte des 19. Jahrhunderts hervorriefen, geht auch aus der Einschätzung der Pariser Weltausstellung von 1889 durch den russischen Denker Nikolaj Fedorov hervor. In seinen Augen dient die Ausstellung der Verherrlichung des industriellen Fortschritts, wobei „progress“ ein negatives Reizwort für Fedorov darstellt, nämlich Fortschritt als Vernichtung des Gedächtnisses und der Vergangenheit. Die Ausstellung propagiert nach Fedorov Reichtum, Verführung durch Weiblichkeit und schädlichen Luxus und ist ein „Hinweis auf die Bedeutung der Stadt (oder der städtischen, europäisch-amerikanischen Zivilisation und Kultur), eine Bedeutung, die in der Negation des Ziels und Sinns des Lebens besteht“". Die Stadt als künstliches Gebilde, als Ensemble „unbrüderlicher Zustände“ und „Quelle des Bösen“" müsse wieder in das Dorf überführt werden, wobei das Dorf aber durch die Wissenschaft transformiert und auf eine höhere Stufe gehoben werden solle.

Fedorovs Position beruht auf seinem utopischen Projekt der Auferweckung der verstorbenen Väter, ${ }^{10}$ sprich Vorfahren, durch die vereinigten Söhne, wobei Auferweckung wörtlich zu verstehen ist, nicht im religiösen Sinn. Fedorov schwebt vor, die Auferweckung der Toten mit den Mitteln der fortgeschrittenen Technik zu bewältigen. Ziel ist eine brüderliche Menschheit, die alle Generationen umfaßt und kosmische Dimensionen aufweist. Auf bizarre Weise verbindet Fedorov archaischen Ahnenkult und fortgeschrittene Technik. Sein Kosmismus hat in den ersten Jahrzehnten des 20. Jahrhunderts viele russische Künstler und Denker beeinflusst, u.a. den Schriftsteller Andrej Platonov, von dem später noch ausführlich die Rede sein wird.

Wie verhalten sich die vier genannten unterschiedlichen Einschätzungen der Weltausstellungen zueinander? Zunächst ist ihr gemeinsamer Ausgangspunkt nicht zu übersehen, die technisch-zivilisatorische Verspätung Rußlands im Vergleich zu Europa und der Blick auf Europa von der Peripherie des industriellen Fortschritts. Černyševskij verklärt im vierten Traum der Vera Pavlovna den Kristallpalast zum Symbol einer utopischen Zukunft Rußlands; der Westler Ivan Turgenev bekennt sich in seinem Roman Rauch ironisch zur ökonomischen Rückständigkeit seines Landes; Nikolaj Fedorov will sein rückwärtsgewandtes Ideal mit Hilfe der - allerdings vom Westen übernommenen Technik und Wissenschaft realisieren und den Westen damit gleichsam in

8 Nikolaj F. Fedorov: Sobranie sočinenij v četyrech tomach. Moskau 1995, Bd.1, S. 453.

9 Ders.: Bd. 2, S. 388.

10 Vgl. Michael Hagemeister: Nikolaj Fedorov. Studien zu Leben, Werk und Wirkung. München 1989. 
einem salto mortale überbieten; für den „bodenständigen“ Fedor Dostoevskij schließlich wird der Kristallpalast zum Ausgangspunkt seiner radikalen Kritik der modernen Zivilisation in ihrer kapitalistischen wie in ihrer sozialistischen Variante. In seiner Beschreibung des Kristallpalastes spürt man ebenso die Faszination durch die „schreckliche Kraft“, die sich in der Londoner Weltausstellung äußert, wie auch sein Erschrecken vor ihr. Es bedürfe einer „in Jahrhunderten gereiften Gegenwehr und Verneinung", ${ }^{11}$ um diesem überwältigenden Eindruck standzuhalten.

Indem Dostoevskij seine europäischen Reiseeindrücke hyperbolisch übersteigert und apokalyptisch zuspitzt, wird er zu einem visionären Begründer der Kritik am industriellen und utopischen Fortschrittsdenken. Apokalyptische Vorstellungen nehmen im russischen Denken seit jeher einen wesentlichen Platz ein. Seit Peter dem Großen wurden historische Umbrüche und Bedrohungen vom Volk, besonders von Altgläubigen und Sektierern, immer wieder unter Berufung auf die Offenbarung des Johannes als endzeitliches Geschehen gedeutet. ${ }^{12}$ In den Winteraufzeichnungen über Sommereindrücke wird London zum Inbegriff apokalyptischen Schreckens. In der Großstadt erblickt Dostoevskij die vom Gott Baal beherrschte Große Hure Babylon und im Kristallpalast das Non plus ultra, das nicht mehr zu überbietende Resultat einer endzeitlichen Entwicklung. In dem einige Jahre darauf veröffentlichten Roman Verbrechen und Strafe (Prestuplenie i nakazanie, 1866) werden bestimmte Merkmale der Großstadt-Apokalypse auf die Stadt Petersburg übertragen, die Dostoevskij als bedrohlichen, dem Untergang geweihten Fremdkörper im russischen Raum empfindet.

Im Werk Dostoevskijs - wie überhaupt in der Tradition utopischen Denkens - lassen sich zwei grundlegende Raumtypen unterscheiden, die Stadt und der Garten. ${ }^{13}$ Dem auf architektonischen Konstrukten beruhenden Modell der Stadtutopie ist etwa Fouriers Phalanstère oder Černyševskijs Kristallpalast zuzuordnen. Für Dostoevskij dagegen - wie auch für Fedorov - gehört die

11 Fjodor M. Dostojewski (1971), S. 50. Dostoevskij bezieht sich hier offensichtlich auf die von ihm stets betonte Eigenständigkeit der russisch-orthodoxen Kultur.

12 Vgl. Hans Günther: Russische Revolution und apokalyptisches Denken. In: Helmut Lethen u. a. (Hg.): Der sich selbst entfremdete und wiedergefundene Marx. München 2010, S. 115-129.

13 Vgl. Ivan Verč: Nekotorye aspekty izobraženija buduščego v tvorčestve F. M. Dostoevskogo v svete literaturnoj tradicii goroda i sada, in: Slavica tergestina 2 (1994), Ed. università degli studi di Trieste, S. 197-214 und Jacques Catteau: De la métaphorique des utopies dans la littérature russe et de son traitement chez Andrei Platonov, in: Revue des Etudes Slaves 56 (1984), H. 1, S. 42. Der Verfasser unterscheidet konstruktiv-zukunftsgerichtete „prometheische“ und regressive „pelagensische“ (von griech. pélagos = Meer) Utopien. 
Stadt nicht in den Bereich der positiven, sondern der negativen Utopie, der Dystopie. Das positive Gegenbild entwickelt Dostoevskij im Tagebuch eines Schriftstellers (Dnevnik pisatelja) für das Jahr 1876 in dem Kapitel „Das Land und die Kinder“. Auf die historische Epoche der Fabriken, der Städte und der Kristallpaläste, so Dostoevskij, werde die Phase des Gartens (im Russischen mit großem Anfangsbuchstaben geschrieben) folgen: „Die Bourgeoisie wird zu Ende gehen, und es wird die Erneuerte Menschheit entstehen. Sie wird das Land nach Landkommunen (obščina) aufteilen und beginnen im Garten zu leben ". ${ }^{14}$ Während die europäischen Proletarierkinder in trostlosen Fabrikstädten aufwachsen müßten, hätten die Kinder in Rußland genug Land zur Verfügung. Im Gegensatz zu Europa habe sich im russischen Volk das Prinzip erhalten, daß das „Land für es alles“ sei: „Im Land, im Boden liegt etwas Geheiligtes" ${ }^{15}$ Dostoevskijs Ansicht, die Erneuerung der Menschheit könne nur vom Land, vom Boden ausgehen, ist natürlich als Hinweis auf die historische Mission Rußlands zu verstehen.

Der Garten ist gleichermaßen Ziel der Menschheitsentwicklung wie ihr Ausgangspunkt. Man denke an den biblischen Garten Eden, an das Paradies, ein Wort, das im Griechischen einen eingezäunten Raum bezeichnet. Dostoevskij fühlte sich unwiderstehlich angezogen von der Vorstellung des Goldenen Zeitalters, das sich als Traum durch die Menschheitsgeschichte von Ovids Metamorphosen und Hesiods Werken und Tagen bis zu Saint-Simon und anderen französischen Sozialisten zieht, die in der Wiederherstellung des Goldenen Zeitalters das Ziel der Geschichte sahen. Dostoevskij, der nicht müde wurde, Claude Lorrains Gemälde „Küstenlandschaft mit Acis und Galatea“ in der Dresdener Gemäldegalerie zu bewundern, gab ihm den Namen „Das Goldene Zeitalter“. In vielen Werken des Schriftstellers wird das Bild beschrieben und interpretiert, am ausführlichsten in der phantastischen Erzählung Der Traum eines lächerlichen Menschen und dem Roman Der Jüngling (in der neuen Übersetzung Swetlana Geiers Ein grüner Junge). Der Romanheld Versilov sieht im Traum einen Winkel des griechischen Archipels:

„Lichtblaue, liebkosende Wellen, Inseln und Klippen, ein blühendes Gestade, ein zauberhaftes Panorama in der Ferne, die dorthin lockende untergehende Sonne mit Worten nicht wiederzugeben. Hier hat, wie die europäische Menschheit sich erinnert, ihre Wiege gestanden, und dieser Gedanke erfüllte auch meine Seele mit inniger Liebe. Hier war das irdische Paradies der Menschheit. [...] Oh, hier lebten

14 Fedor Dostoevskij: Polnoe sobranie sočinenij v tridcati tomach. Bd. 23. Moskau 1981, S. 96, übersetzt vom Verfasser.

15 Ebd., S. 98. 
herrliche Menschen! Glücklich und unschuldig schliefen sie ein und wachten sie auf; Wiesen und Haine hallten wider von ihren Liedern und fröhlichen Rufen. [...] die Sonne übergoß sie mit Wärme und Licht, voll Freude über ihre schönen Kinder. ${ }^{\text {16 }}$

Von der Darstellung unmittelbaren ${ }^{17}$, natürlichen Lebens fasziniert, erliegt Dostoevskij der magischen Verführungskraft, die von diesem Bild ausgeht. Das Goldene Zeitalter ist für ihn aber nicht nur ein „wunderbarer Traum“, sondern zugleich ein „erhabener Irrtum der Menschheit“ und der „unwahrscheinlichste aller Träume, die es je gegeben hat" ${ }^{18}$ Im Traum eines lächerlichen Menschen warnt Dostoevskij davor, das verlorene ursprüngliche Glück mit den Mitteln der Wissenschaft und Theorie wiederherstellen zu wollen, da dies nur zu der Ausrottung der „Unwissenden“ durch die „Allwissenden“ führe ${ }^{19}$. Die Zukunftsperspektive der Menschheit sieht er dagegen in der "bodenständigen“ Variante des Goldenen Zeitalters, in der Vision des mit dem russischen Boden verbundenen Gartens.

\section{Evgenij Zamjatins gläsernes Paradies}

Bei der Betrachtung der Nachwirkung der Utopiekritik Dostoevskijs im 20. Jahrhundert sollen zwei russische Autoren im Vordergrund stehen - Evgenij Zamjatin und Andrej Platonov. Zamjatin war Herausgeber der russischen Ausgabe des Science-Fiction-Autors George Herbert Wells, in dessen Roman The Time Machine (1895) bereits Zweifel am Fortschrittsoptimismus unüberhörbar sind. Zamjatins Roman $M y$ („Wir“) ${ }^{20}$ entstand 1920, wurde zunächst in einigen westlichen Sprachen und 1927 in einer russischen Kurzfassung veröffentlicht. Eine vollständige russische Fassung erschien 1952 in New York, in der Sowjetunion erst am Ende der Perestrojka im Jahr 1988.

$\mathrm{Zu}$ dem Zeitpunkt, als Evgenij Zamjatin an seinem Werk arbeitete, existierte in Rußland noch kein totalitärer Staat. Die vehementen Angriffe auf Zamjatin setzen bezeichnenderweise zu einem Zeitpunkt ein, wo Stalins Herrschaft sich

16 Fjodor Dostojewskij: Ein grüner Junge. Zürich 2006, S. 663-664.

17 Die Epoche der Unmittelbarkeit geht nach Dostoevskij der Übergangsepoche der Zivilisation voraus. Vgl. die Notiz „Socializm i christianstvo“. In: Polnoe sobranie sočinenij v tridcati tomach, Bd. 20. Moskau 1980, S. 191-192.

18 Fjodor Dostojewskij: Ein grüner Junge. Zürich 2006, S.664.

19 Vgl. Fjodor M. Dostojewskij (1977), Bd. 4, S. 742.

20 Eine Interpretation des Romans und weiterführende Literatur findet sich bei Christine Scholle: Jewgenij Samjatin. Wir. In: Bodo Zelinsky (Hg.): Der russische Roman. Düsseldorf 1979, S. 290311. 
zu etablieren beginnt, nämlich Ende der 1920er Jahre. Der Autor wurde wegen Verleumdung des Sozialismus scharf angegriffen und emigrierte 1931 nach Paris, wo er 1937 starb. Der Roman My erschien noch vor Aldous Huxleys Brave New World (1932) und George Orwells Nineteen Eighty-Four (1949) und ist damit der erste wichtige antiutopische und antitotalitäre Roman des 20. Jahrhunderts. Orwell schätzte das Werk wegen seiner intuitiven Vorwegnahme wesentlicher Merkmale totalitärer Macht und stellte ihn über Huxleys Brave New World. Zamjatins Roman ist aber keineswegs ausschließlich auf die russische Revolution bezogen, sondern greift wesentliche Aspekte der gesamten modernen technischen Zivilisation auf.

In $M y$ entfaltet Zamjatin eine Reihe von Gesichtspunkten der Utopiekritik Dostoevskijs, der in Werken wie Aufzeichnungen aus dem Untergrund, den Bösen Geistern (Besy) oder das Poem vom Großinquisitor (Velikij inkvizitor) „nahezu sämtliche Motive und Argumente der späteren russischen Utopiekritik vorweggenommen hat “. ${ }^{21}$ Dieses Grundgerüst ist angereichert mit Elementen der frühsowjetischen proletarischen Kultur, der Kunst und Architektur der Moderne und Science-Fiction-Motiven. Doch zunächst in aller Kürze die Handlung des Romans. Der Raketentechniker D-503 - alle Figuren des Romans haben Nummern und keine Namen - der zunächst, wie aus seinem Tagebuch hervorgeht, ein bedingungsloser Anhänger des Einheitsstaates ist, wird durch die Liebe zu I-330 in einen Aufstand gegen den Staat hineingezogen. Die Revolte schlägt aber fehl und D-503 wird durch eine Operation von seinem „Splitter“ (S. 241)22 Phantasie befreit. Von seiner „Krankheit“ geheilt und nun der Staatsmacht wieder bedingungslos ergeben, verfolgt er gleichgültig die Folterung seiner zum Tod verurteilten Geliebten.

Während Utopien, wie wir sie seit Thomas Morus' Utopia oder Campanellas Sonnenstaat kennen, Beschreibungen von exemplarischen Ritualen eines idealen Lebens darstellen, durchbrechen Antiutopien dieses Schema und zeichnen sich durch das Aufbegehren eines Außenseiter-Individuums ${ }^{23}$ gegen die herrschende Ordnung aus. Die subversive Bewußtwerdung des Helden vollzieht sich bei Zamjatin im Prozeß des Abfassens seines Tagebuchs. ${ }^{24}$ Dieses

21 Hans Günther: Utopie nach der Revolution (Utopie und Utopiekritik in Russland nach 1917). In: Wilhelm Voßkamp (Hg.): Utopieforschung. Stuttgart 1982, Bd. 3, S. 392. Vgl. auch Patricia Warrick: The Sources of Zamyatin's We in Dostoyevsky's Notes from Underground, in: Extrapolation 16 (1974), H. 1, S. 63-77.

22 Die folgenden Seitenangaben im Text beziehen sich auf die Ausgabe Jewgeni Samjatin: Wir. Roman. Leipzig/Weimar 1991.

23 Vgl. Stephan Meyer: Die anti-utopische Tradition. Frankfurt a. Main u. a. 2001, S. 125-131.

24 Vgl. Brett Cooke: Human Nature in Utopia. Zamyatin's We. Evanston, Illinois 2002, S. 164-186. 
Prinzip ist im Ansatz bereits in den Aufzeichnungen von Dostoevskijs krankem und verbittertem Untergrund-Menschen vorgeprägt, ${ }^{25}$ der das dringende Bedürfnis verspürt, dem unzerstörbaren Kristallpalast die Zunge oder hinterrücks sogar die Faust zu zeigen. In den Romanen Zamjatins und Orwells ist es die Liebe, die den Keim individuellen Aufbegehrens in sich trägt. Die Beziehung zwischen D-503 und I-330 wie die körperliche Vereinigung von Winston Smith und Julia in Nineteen Eighty-Four stellen gravierende Verstöße gegen die staatliche Ordnung dar.

Der gläserne Einheitsstaat Zamjatins läßt sich als gigantische Erweiterung des Kristallpalast-Motivs Dostoevskijs verstehen. Alle Bauten sowie die den Staat umschließende Grüne Mauer sind aus "gleichen harten, ewigen Glas“ (S. 7) gegossen. Über Dostoevskijs Kristallpalast hinaus ist Zamjatin zweifellos von den Gedanken zur modernen Glasarchitektur eines Paul Scheerbart oder Bruno Taut inspiriert worden ${ }^{26}$. Die Glasbauweise garantiert die vollkommene Durchsichtigkeit aller Staatsbürger. Allein während der festgelegten Sex-Stunden, der sogenannten Persönlichen Stunden mit abonnierten Partnern, dürfen die Rollos heruntergelassen werden. Der Transparenz der Gedanken kommt in totalitären Ordnungen ein wesentlicher Stellenwert zu. Ich erwähne in diesem Zusammenhang, daß Vladimir Nabokovs Held Cincinnatus aus der Einladung zur Enthauptung des schrecklichen Verbrechens der "Undurchdringlichkeit“ und „Opazität“ angeklagt und zum Tode verurteilt wird. ${ }^{27}$

Betrachtet man Zamjatins Einheitsstaat unter dem Gesichtspunkt der Unterscheidung von Stadt- und Gartenutopie, so ergibt sich hier eine signifikante Verteilung und Bewertung der beiden Modelle. Das mechanisierte, vollkommene "gläserne Paradies" ist durch eine Mauer abgegrenzt von der Gegenwelt, einer chaotischen „vernunftlosen, ungestalten Welt der Bäume, Tiere, Vögel“ (S. 98), in der atavistische, behaarte Lebewesen, Menschen alter Art leben. Das Garten-Modell ist damit scheinbar von der Stadtutopie überholt und obsolet geworden, zugleich aber erscheint die in dieser Welt beheimatete Phantasie als positives Gegenstück zu der kristallinen, sterilen, vernunftgeordneten Welt des Einheitsstaates. Der staatsergebene D-503 preist die „göttlich-eingrenzende

25 Die Bezeichnung „Außenseiter“ scheint mir auf Dostoevskijs Untergrundmenschen eher zuzutreffen als „Dandy“. Vgl. Wolfgang Lange: Kristallpalast oder Kellerloch? Zur Modernität Dostojewskijs, in: Merkur 40 (1986), S. 14-29.

26 Georg Kohlmaier, Barna von Sartory Barna: Das Glashaus. Ein Bautyp des 19. Jahrhunderts. München 1989. Beide Autoren sehen in dem Glashaus des 19. Jahrhunderts eine „utopische Antizipation der Avantgarde-Architektur des 20. Jahrhunderts“ (vgl. S. 13).

27 Vladimir Nabokov: Einladung zur Enthauptung. Reinbek b. Hamburg 1990, S. 25, 79. 
Weisheit der Mauern, der Schranken“, die ihn von dem grünen wilden Ozean, dem "chaotischen Zustand der Freiheit“ (S. 152) trennen. Das sogenannte "Alte Haus“, in dem sich der Ingenieur mit I-330 trifft, liegt eben in dieser Zone. Hier gibt es keine klaren Linien, alles ist in der Wahrnehmung von D503 „epileptisch verkrümmt“, in keine Gleichung sich fügend (S. 32), und an der Wand hängt das asymmetrische Porträt eines stupsnasigen Dichters aus alter Zeit, vermutlich Aleksandr Puškins.

Die mathematisch-mechanische Geordnetheit des Einheitsstaates Zamjatins verweist in vielem auf Dostoevskijs Aufzeichnungen aus dem Untergrund. Sein Held empfindet die unerbittliche Logik des Zweimal-zwei-ist-vier als eine Frechheit, die ihn zum Widerspruch provoziert. Er widerspricht ihr allein schon aus dem Grund, um seinen freien Willen zu beweisen. Zamjatin greift dieses Motiv auf:

„Und es gibt nichts Glücklicheres als die Zahlen, die nach den harmonischen, unabänderlichen Gesetzen des Einmaleins leben. Ohne Schwanken und ohne Verirrung. Die Wahrheit ist einzig und der wahre Weg ist einzig; und diese Wahrheit heißt zweimal-zwei, und dieser wahre Weg heißt vier" (S. 71).

In den Augen Dostoevskijs stellen die Naturgesetze und die Mathematik eine Mauer dar, durch die die Freiheit des Menschen auf unzulässige Weise eingeschränkt wird. Die sogenannte Gesetzestafeln, die den Alltag im Einheitsstaat regeln, finden ihre Vorläufer in den vom Untergrundmenschen verspotteten Tabellen und Kalendern, die die menschlichen Handlungen akribisch genau bis ins letzte Detail festlegen und dabei den Menschen zu „Klaviertasten“ und „Drehorgelstiften“ degradieren. Derartige den Tagesablauf regulierende Stundenpläne hat es tatsächlich gegeben, man denke etwa an die Tabellen Benjamin Franklins, der auf diese Weise eine effektive Zeitökonomie begründen wollte.

In ähnlicher Weise bezieht sich Zamjatin auf das Taylorsche System, das nach der Oktoberrevolution in der Sowjetunion äußerst populär war, da man sich von ihm eine Rationalisierung der Arbeitsabläufe versprach. Einer der bekanntesten Vertreter dieser Richtung war der Proletkult-Dichter Aleksej Gastev, der das sogenannte Zentrale Arbeitsinstituts (Central'nyj institut truda) gründete und als Befürworter eines rigorosen Kollektivismus in Erscheinung trat. Zamjatin parodiert in seinem Roman derartige Vorstellungen:

„Jeden Morgen stehen wir, viele Millionen, mit sechsrädriger Pünktlichkeit in ein und derselben Stunde, in ein und derselben Minute auf wie ein Mann. Zur 
gleichen Stunde nehmen wir einmillionenmütig die Arbeit auf, einmillionenmütig beenden wir sie. Und zu einem einzigen, millionenhändigen Körper verschmolzen, führen wir in ein und derselben, von der Stundentafel gesetzten Sekunde den Löffel zum Mund, brechen auf zum Spaziergang, gehen ins Auditorium, in den Saal der Taylorschen Übungen, ziehen uns zum Nachtschlaf zurück [...]“ (S. 16).

Auch der Titel von Zamjatins Roman verdankt sich der proletarischen Poesie, die sich gern mit einer prometheischen Stahl- und Eisenmetaphorik schmückte. ${ }^{28}$ So heißt es etwa in dem Gedicht mit dem Titel Wir des Arbeiterdichters Vladimir Kirillov:

Unsere Seele verschmolz mit Metall und Maschinen,

Nicht länger seufzen wir zum Himmel hinauf.

Wir wollen, daß niemand auf Erden mehr Hunger leide, daß Stöhnen und Schreien nach Brot endgültig vorbei. ${ }^{29}$

In der Beschreibung des Einheitsstaates kann Zamjatin auf Vorbilder zurückgreifen, die sich in Dostoevskijs Großinquisitor finden. Die Rolle des Inquisitors, der dem wiederkehrenden Christus die Logik seiner Herrschaft darlegt, wird bei Zamjatin von dem „Wohltäter“ eingenommen, ein Terminus, der bereits bei Dostoevskij vorkommt. ${ }^{30}$ In diesem Zusammenhang erscheint eine Anmerkung zur euphemistischen Sprache Zamjatins angebracht, die sich in Ausdrücken wie Wohltäter, Feinde des Glücks, Tag der Einstimmigkeit usw. widerspiegelt. Hier liegen die Anfänge des sog. Newspeak, der dann in den Sprachregelungen in Orwells Roman Nineteen Eighty-Four perfektioniert wird, wo etwa die Leitsätze der herrschenden Partei lauten: „Krieg ist Frieden. Freiheit ist Sklaverei. Unwissenheit ist Stärke“.

Zamjatins Wohltäter steigt am Tag der Einstimmigkeit wie ein Gott vom Himmel herab zu seinen Untertanen, die ihr Haupt vor dem „wohltuenden Joch der Nummer aller Nummern“ (S. 150) beugen. Die feierliche gottesdienstähnliche „Liturgie“ wird von hymnischen Versen eines Staatsdichters begleitet. Zamjatins Wohltäter argumentiert ähnlich wie Dostoevskijs Großinquisitor:

„Wonach haben sich die Menschen - von der Wiege an - mit ihren Gebeten, Träumen und Qualen verzehrt? Danach: Daß ihnen jemand ein für allemal sagt,

28 Kathleen S. Lewis, Harry Weber: Zamyatin's We, the Proletarian Poets, and Bogdanov's Red Star, in: Russian Literature Triquarterly 12 (1975), S. 254-266.

29 Zit. nach: Richard Lorenz (Hg.): Proletarische Kulturrevolution in Sowjetrußland (1917-1921). München 1969, S. 78.

30 Fjodor M. Dostojewski (1977), Bd. 10, S. 422. 
worin das Glück besteht - und sie mit einer Kette an dieses Glück anschmiedet... Tun wir jetzt etwas anderes? Der alte Traum vom Paradies [...]“ (S. 223).

Auch der Staatsdichter R-13 sieht im Einheitsstaat das Glücks-Problem gelöst:

„Das Paradies ist zurückgewonnen. Und wir sind wieder unschuldig und treuherzig wie Adam und Eva. Nicht die Spur von einer Konfusion der Begriffe Gut und Böse: Alles ist überaus simpel, kindlich, paradiesisch einfach“ (S. 66).

Dostoevskijs Großinquisitor hat eine Ordnung errichtet, die die Menschen von den unerträglichen Qualen der Freiheit erlöst. Er verleiht ihnen den Status von unschuldigen Kindern, nimmt ihnen die freie Gewissensentscheidung ab, gibt ihnen ihr täglich Brot und vereinigt sie zu einer Herde, zu einem „einstimmigen Ameisenhaufen“. Die Menschen in den Stand der paradiesischen Unschuld zurückzuversetzen ist übrigens auch der Plan des Utopisten Šigalev aus den Bösen Geistern, der in seinem Denken ausgehend von der unbeschränkten Freiheit zum unbeschränkten Despotismus gelangt.

Zamjatin gründet seinen Protest gegen die totalitäre Ordnung auf dem Gegensatz zweier Kräfte in der Welt, der Entropie und der Energie, von Begriffen, die der Thermodynamik entlehnt sind. ${ }^{31}$ Während die Entropie dazu tendiert, einen Gleichgewichtszustand herzustellen, zielt die Energie auf die Zerstörung dieses Zustands ab (vgl. S. 172). Zamjatin ist von der Notwendigkeit der häretischen Rolle des Schriftstellers überzeugt:

„Die Ketzer sind die einzige (bittere) Medizin gegen die Entropie des menschlichen Geistes. Wenn (in der Wissenschaft, in der Religion, im sozialen Leben, in der Kunst) die feurig-siedende Sphäre erkaltet, überzieht das Dogma mit einer festen, verknöcherten, unbeweglichen Kruste das glühende Magma. In der Wissenschaft, in der Religion, im sozialen Leben, in der Kunst kommt die Dogmatisierung der Entropie des Geistes gleich. ${ }^{\text {“32 }}$

Schon kurz nach 1917 spürte Zamjatin das Bedürfnis, der der Revolution innewohnenden Tendenz zur Erstarrung entgegenzuwirken.

Es mag verwundern, wenn der Autor seinen Roman konsequent mit Requisiten der modernen Architektur und Kunst ausstattet, die er auf diese Weise in die Nähe totalitärer Tendenzen rückt. Das von den Werkzeugmaschinen inszenierte „mechanische Ballett“ erinnert an Oskar Schlemmers gleichnamiges Werk. Die Schönheit dieses Tanzes liegt, so der Tagebuchschreiber D-513, in

31 Vgl. dazu Rainer Goldt: Thermodynamik als Textem. Der Entropiesatz als poetologische Chiffre bei E. I. Zamjatin. Mainz 1995.

32 Jewgeni Samjatin: Aufsätze, Autobiographie, Brief an Stalin. Leipzig/Weimar 1991, S. 25. 
seiner idealen Unfreiheit. Die Ästhetik des Einheitsstaates beruht ausschließlich auf geometrischen Formen, vor allem dem Quadrat, das ja schon immer als Ausdruck vollkommener Harmonie empfunden wurde. Zamjatins Wohltäter zeigt sich seinen Untertanen auf einem Kubus. Unschwer erkennt man hierin eine Polemik Zamjatins gegen die Kunst der Avantgarde. Im Kubismus, Futurismus und Suprematismus sieht er eine Fehlentwicklung der Kunst, eine reductio ad absurdum. Diese Richtungen seien jedoch nötig gewesen, „um zu erkennen, wohin man nicht zu gehen brauchte". ${ }^{33}$

Die moderne Glasarchitektur hat, das kann hier nur angedeutet werden, auch noch einen anderen russischen Künstler des 20. Jahrhunderts inspiriert, nämlich Sergej Ejzenštejn, der in den Jahren 1927/28 das - nie realisierte Projekt eines antiutopischen Films Das Glashaus entwickelte. ${ }^{34}$ Den Regisseur fasziniert aber im Unterschied zu Zamjatin eine andere Idee, nämlich das Leben im Glashaus unter den Bedingungen der modernen individualistischen Zivilisation. In dem Maße, in dem die Bewohner des durchsichtigen Hauses sich gegenseitig wahrnehmen und beobachten, entstehen Haß, Chaos und Gesetzlosigkeit. Am Ende sollte die apokalyptische Zerstörung des Gebäudes stehen.

\section{Andrej Platonovs scheiternde Stadtutopien}

Während Zamjatins Roman eine negative Welt aus satirisch-parodistischer Sicht imaginiert, sind die Werke Andrej Platonovs komplizierter angelegt - als Grenzgänge auf dem Grat zwischen Utopie und Antiutopie. Malt Zamjatin das Schreckensbild einer nahezu vollendeten Utopie aus, so verfolgt Platonov den widersprüchlichen Prozeß des Scheiterns ihrer Realisierung, der von naiver Hoffnung und gleichzeitig einem tiefen Gefühl der Vergeblichkeit begleitet ist. Zum Problem der Verwirklichbarkeit von Utopien im 20. Jahrhundert hat sich der russische Philosoph Nikolaj Berdjaev geäußert, der an Dostoevskijs Utopiekritik anknüpft, wenn er im Bolschewismus das System des Großinquisitors und Šigalevs wiedererkennt. Angesichts dieser Tatsache schreibt er: „Aber es hat sich als viel leichter erwiesen, Utopien zu verwirklichen, als es früher den Anschein hatte. Und nun sieht man sich vor die andere quälende Frage gestellt: wie man um ihre restlose Verwirklichung herumkommen könne“. ${ }^{35}$ Diese Worte sind bezeichnenderweise von Aldous Huxley als Motto seinem Roman Brave New World vorangestellt worden.

33 Ebd. S. 13.

34 „Stekljannyj dom“ S. M. Ėjzenštejna, in: Iskusstvo kino (1979), H. 3, S. 94-113.

35 Nikolaj Berdjajew: Das neue Mittelalter. Tübingen 1950, S. 122. 
Der proletarische Autor und Anhänger der Oktoberrevolution Andrej Platonov (1899-1951) verdankte der eingangs erwähnten Philosophie der gemeinsamen Sache (Filosofija obščego dela) Nikolaj Fedorovs wesentliche Denkimpulse. Er ist einerseits erfüllt vom Pathos des sozialistischen Aufbaus, verteidigt aber zugleich mit Fedorov die Bewahrung des Gedächtnisses der Väter. In Voronež aufgewachsen, wurde Platonov früh mit der Gedankenwelt des einfachen Volkes und der Sektierer bekannt. Ist für Dostoevskij das utopische Denken, vor allem in seiner sozialistischen Form, eine theoretische „Kopfgeburt“ und zudem ein unerwünschter Import aus Europa, so beschreibt Platonov in seinen Werken das "aus dem Bauch“ kommende Verlangen des notleidenden Volkes nach einer gerechten Welt. ${ }^{36}$ Bei ihm dominiert die auf das Tausendjährige Reich gerichtete chiliastische Variante utopischen Denkens, wie sie etwa auch für die häretischen Bewegungen des europäischen Mittelalters charakteristisch war. Platonovs Romanfiguren sind keine Theoretiker, sondern einfache, kauzige, ja teils leicht verrückte "Philosophen“ aus dem Volk, die auf der Suche nach einer besseren Welt sind. Während Dostoevskij den rationalistischen $\mathrm{Zu}$ kunftsglauben als Betrug entlarvt, zeigt sich Platonov solidarisch mit seinen suchenden Helden und begleitet auch ihre Irrtümer mit Verständnis.

Im Mittelpunkt des Romans Tschewengur (Čevengur, entstanden 1927-29) stehen zwei umherstreifende Helden - Saša Dvanov, der die Suche seines verstorbenen Vaters nach der Wahrheit fortsetzt, und der sozialistische Don Quijote Kopenkin, der auf seinem Roß Proletmacht durch das Land zieht, um Taten $\mathrm{zu}$ Ehren seiner angebeteten Rosa Luxemburg zu vollbringen. Beide gelangen in die Stadt Čevengur, wo angeblich der Kommunismus verwirklicht ist. Nach der Liquidierung und Vertreibung der Bourgeoisie und der Einladung herumziehender „Vaterloser“ in die Stadt bricht ein Kommunismus der Brüderlichkeit und Armut an, ein Zustand, in dem niemand in der Stadt arbeitet außer der Sonne. In Čevengur wird weder das utopische Stadt- noch das Gartenmodell realisiert, so daß die Stadt sich in einem chaotischen Zustand befindet: „Durch das Verrücken der Häuser waren die Straßen in Tschewengur verschwunden - die Gebäude standen nicht mehr ab ihrem Platz, sondern mitten im Weg “. ${ }^{37}$ Nachdem man vergeblich einen ewigen Sommer und eine Existenz ohne Krankheit und Tod erwartet hat, markiert das Sterben eines Kindes für alle Beteiligten das Scheitern des Čevengurer Kommunismus. Schließlich er-

36 Vgl. Hans Günther: Das Goldene Zeitalter aus dem Kopf und aus dem Bauch. Zur Utopieproblematik bei Dostoevskij und Platonov, in: Zeitschrift für slavische Philologie 53 (1993), H. 1, S. 157-168.

37 Andrej Platonow: Tschewengur. Die Wanderung mit offenem Herzen. Berlin 1990, S. 257. 
liegt die Stadt einem Angriff fremder Truppen. In dem Schicksal von Čevengur hat man Parallelen zu den Ereignissen im Münster der Wiedertäufer der Jahre 1534/35 gesehen, ${ }^{38}$ von denen Platonov aus Karl Kautskys ins Russische übersetzte Buch über die Vorläufer des neueren Sozialismus erfahren haben mag. Platonovs halb poetischer, halb komisch-absurder Roman konnte in der Sowjetunion erst 1988 erscheinen.

In dem Roman findet sich eine signifikante Episode, die sich auf Dostoevskij bezieht. Der Bevollmächtigte des Kreisrevolutionskomitees Ignatij Mošonkov benennt sich im Zuge einer von ihm ersonnenen Kampagne zur Selbstvervollkommung der Bürger in Fedor Dostoevskij um. Er quält sich mit Gedanken über das Wesen der Seele und stellt sich den Sozialismus als eine Gesellschaft guter Menschen vor, ohne, wie es heißt, „von Dingen und Bauwerken“ eine Ahnung zu haben. Als ihm aufgetragen wird, den sowjetischen Sinn des Lebens zu bestimmen, ist er so in seine Aufgabe vertieft, daß er nicht wahrnimmt, daß schöne Mädchen ihm Borschtsch mit Schweinefleisch bringen, und das Essen unberührt zurückgehen läßt. In der Begebenheit könnte man eine ironische Auseinandersetzung Platonovs mit dem „Idealisten“ Dostoevskij vermuten, der sich den „Sozialismus als eine Gesellschaft guter Menschen ${ }^{\text {"39 }}$ vorstellt, sich um materielle Gesichtspunkte jedoch nicht schert.

Die Enttäuschung des proletarischen Autors Platonov über die Entwicklung des Sozialismus in der Sowjetunion schlägt sich kurz darauf in einem anderen Roman nieder, der das Scheitern eines utopischen Projekts behandelt und damit Dostoevskij letztlich doch noch Recht zu geben scheint. Es handelt sich um Die Baugrube (Kotlovan, 1929-30), die wegen ihrer kritischen Behandlung des Aufbau-Themas und der Kollektivierung der Landwirtschaft ebenfalls erst 1988 in der Sowjetunion erscheinen konnte. In der Baugrube wird von dem Vorhaben eines Ingenieurs berichtet, der einen Turm für das Proletariat der ganzen Welt bauen will. Während der Arbeiten wird beschlossen, die Baugrube immer mehr zu vertiefen und zu erweitern. Auf diese Weise entsteht kein Turm, dafür wird die Grube zum Grab für viele Arbeiter, u. a. auch für das Mädchen Nastja, das die Zukunftshoffnung aller Beteiligten verkörpert. Der Name Nastja, abgeleitet von Anastasija = Auferstehung, läßt jedoch die Möglichkeit einer späteren Auferstehung - ein deutlicher Anklang an die Philosophie Nikolaj Fedorovs - offen. Verknüpft mit dem Geschehen der Baugrube

38 Vgl. Vladimir Varšavskij: „Čevengur” i „Novyj Grad”, in: Novyj žurnal 1976, H. 122, S. 193-213; Hans Günther: Čevengur i „Opon'skoe carstvo”. K voprosu narodnogo chiliazma v romane A. Platonova, in: Russian Literature 32 (1992), S. 211-225.

39 Ebd., S. 142. 
ist die Darstellung der Katastrophe der bäuerlichen Welt, der Entkulakisierung und Zerstörung des Dorfes. Entgegen allen Regeln der ritualisierten sowjetischen Aufbauliteratur, die stets in ein positives Resultat zu münden hatte, beschreibt der Roman einen Vorgang der Konstruktion, der sich im Lauf seiner Realisierung in Destruktion verkehrt. Die paradoxe Absurdität dieses Geschehens findet ihren Ausdruck in einer Sprache, die sich der Klischees der offiziellen Ideologie bedient und diese ad absurdum führt.

In Platonovs Baugrube kann man durchaus eine Variante des biblischen Mythos des Turmbaus zu Babel sehen. Dieses Bild läßt sich über verschiedene Zwischenstationen bis zu Dostoevskij zurückverfolgen. Eine wichtige Station bildet dabei ein in rhythmischer Prosa gehaltener Text des bereits erwähnten proletarischen Dichters Aleksej Gastev mit dem Titel Der Turm (Bašnja, 1917), zu dem der Verfasser durch den Anblick des Pariser Eiffelturms angeregt wurde. Der Text, der die unzähligen namenlosen Erbauer erwähnt, dessen Gräber sich unter dem Turm befinden, endet mit den pathetischen Worten:

„Mögen noch Katastrophen kommen...

Vor uns liegen noch viele Gräber, noch viele Stürze...

Mögen sie kommen!

Alle Gräber unter den Türmen werden noch einmal mit schwerem Beton zugegossen, die unterirdischen Grabgewölbe mit Eisen umflochten, auf der unterirdischen Stadt des Todes stürme furchtlos voran

O gehe,

O brenne,

Durchbohre mit deiner Spitze die Höhen

Du unsere kühne Welt der Türme!"40

Trotz des katastrophischen Opfer-Motivs strahlt Gastevs Text einen Optimismus aus, der dem Geist der aufstrebenden proletarischen Kultur entspringt.

Geht man noch einen Schritt weiter zurück in der russischen proletarischen Tradition, dann stößt man auf das Babel-Motiv in der einflußreichen Schrift Anatolij Lunačarskijs, des späteren ersten sowjetischen Kommissars für Volksbildung, Religion und Sozialismus (Religija i socializm). ${ }^{41}$ Hier wird, ebenso wie bei Karl Kautsky, der prometheische Aufstand der Menschheit gegen die Götter verherrlicht, der unter gewaltigen Opfern und Rückschlägen die Errichtung des ewigen Turms der Kultur in Babylon zum Ziel hat. Lunačarskijs Ausführungen

40 Zit. nach: Hans Günther: Das Opfer bei Andrej Platonov. In: Rainer Grübel, Gun-Britt Kohler (Hg.): Gabe und Opfer in der russischen Literatur und Kultur der Moderne. Oldenburg 2006, S. 325.

41 Anatolij Lunačarskij: Religija i socializm. Bd. 1. Sankt Petersburg 1908, S. 189-190. 
können als polemische Auseinandersetzung mit der Deutung des Babel-Motivs vom Großinquisitor verstanden werden. Sein sogenanntes "Gotterbauertum“ (bogostroitel'stvo), demzufolge die in der Arbeit an der Zukunft vereinigte Menschheit der werdende Gott ist, stellt eine Replik auf den von Dostoevskij abgelehnten „Gottmenschen“ dar. Der Großinquisitor der Legende spricht zu Christus:

„An der Stelle Deines Tempels wird sich ein neues Bauwerk erheben, wird wieder der schreckliche babylonische Turm gebaut werden, und wenn er auch wie der erste nicht vollendet werden wird, so hättest du doch diesen neuen Turmbau ersparen und die Leiden der Menschen um tausend Jahre abkürzen können, denn zu wem sonst, wenn nicht zu uns, sollen sie kommen, nachdem sie sich tausend Jahre lang mit ihrem Turmbau gequält haben. “ 42

Der Turmbau bestätigt auch die These des Großinquisitors von der schwächlichen Rebellion des Menschengeschlechts:

„Sie [...] werden uns finden und anflehen: ,Sättigt uns, denn die, so uns das Feuer vom Himmel versprachen, haben es uns nicht gegeben.' Und dann werden schon wir ihren Turm vollenden, denn vollenden wird derjenige, der den Hunger stillt $[\ldots] .{ }^{443}$

Der Turmbau, Symbol des prometheischen Aufruhrs gegen Gott, ist, so der Großinquisitor, aufgrund der Schwäche der Menschen zum Scheitern verurteilt und läßt sich nur mit seiner, des Großinquisitors Hilfe zu Ende führen. Lunačarskij setzt demgegenüber auf die Stärke und den unaufhaltsamen Fortschritt der Menschheit, die allen Niederlagen und Opfern zum Trotz den Turmbau der Kultur vollenden werde. Was in Dostoevskijs Großinquisitor negativ gesehen wird, erscheint dem "Gotterbauer" im Licht einer strahlenden Zukunft der Menschheit.

Bei dem Turmbau-Motiv läßt sich also eine Linie von Platonov zu Dostoevskij ziehen, für den der Turm zu Babel neben dem Kristallpalast eine Variante des utopischen Stadtmodells darstellt. Platonovs Stadtutopien sind zum Scheitern verurteilt, sowohl in Čevengur als auch in der Baugrube. In der Baugrube als einer Art Nekropolis haben wir es mit einer Umkehrung der Stadt-Utopie zu tun, bei der anstelle des nach oben, zum Himmel strebenden Bauwerks sein Gegenteil, ein in die unheilvolle Tiefe der Erde reichendes Loch entsteht. Es

42 Fjodor M. Dostojewski (1977), Bd. 10, S. 411-412.

43 Ebd., S. 412. 
scheint, als seien die düstersten Prophezeiungen Dostoevskijs in dem Werk eines Autors in Erfüllung gegangen, der sich stets gegen eine derartige apokalyptische Sicht der Dinge gewährt hatte.

\section{Babylonische Türme}

In der europäischen Kultur nimmt das Motiv des Turmbaus zu Babel einen prominenten Platz ein. Ein Überblick über die verbreiteten bildlichen Darstellungen des Babel-Sujets zeigt, daß sich das Motiv durch eine tiefgehende Ambivalenz auszeichnet. ${ }^{44}$ Der Turm wurde als Inbegriff menschlicher Anmaßung und apokalyptisches Symbol des selbstverschuldeten Weltuntergangs gedeutet, aber auch als Zeichen der technischen Leistungsfähigkeit und der Hoffnung auf ein geeintes Zusammenleben der Menschheit. Galt bis zum Ende des Mittelalters der Turm als Symbol menschlicher Hybris, so treten seit dem 16. und 17. Jahrhundert im Zuge der zunehmenden Faszination durch die Technik auch positive Aspekte in den Vordergrund. Seit Pieter Breughels monumentalen Babel-Gemälden (das sogenannte Wiener Bild von 1563 und das um 1568 gemalte Rotterdamer Bild) hält die Diskussion darüber an, ob es sich um unfertige oder zerstörte, um verherrlichende oder um warnende Darstellungen des Turms handelt. In den Bildern des 16. und 17. Jahrhunderts scheint das Streben nach dem Ausloten gesetzter Grenzen und das Motiv des ruhmvollen Scheiterns eine wichtige Rolle zu spielen. ${ }^{45}$

Im 20. Jahrhundert gewinnt das Turmbau-Motiv im Zusammenhang mit den Möglichkeiten der modernen Wolkenkratzer-Architektur eine neue Aktualität. Der babylonische Turm wird zum Symbol einer weltumfassenden Moderne. Die 1925 in Paris erscheinende Zeitschrift La Tour de Babel versteht sich als Vorreiter einer neuen spirituellen Einheit der Menschheit. Zugleich aber wird im Film Metropolis von Fritz Lang (1925-26) auch der bedrohliche Aspekt der modernen Großstadt gestaltet. Aus der russischen Kultur des 20. Jahrhunderts ${ }^{46}$ lassen sich zwei gegensätzliche Beispiele nennen, das berühmte und in Modellen oft gezeigte Denkmal der III. Internationale des russischen

44 Vgl. Antje Senarclens de Grancy: Der Turm von Babel. Ambivalenz eines Symbols in der Kunst der Neuzeit. In: Götz Pochat, Ulrike Wagner (Hg.): Utopie. Gesellschaftsformen. Künstlerträume. Graz 1996, S. 186-203. Reiches Bildmaterial bietet Helmut Minkowski: Vermutungen über den Turm zu Babel. Freren 1991.

45 Vgl. Ulrike B. Wegener: Faszination des Maßlosen. Hildesheim 1995, S. 178.

46 Vgl. den Überblick bei Andreas Guski: Babylonische Türme. $\mathrm{Zu}$ einem Motiv der neueren russischen Kulturgeschichte. In: Helmut Girke u.a. (Hg.): Vertograd mnogocvetnyj. Festschrift für Helmut Jachnow. München 1999, S. 59-70. 
Konstruktivisten Vladimir Tatlin von 1919/20 und der seit 1931 über mehrere Jahre hinweg geplante Palast der Sowjets. Beide Entwürfe wurden nie realisiert.

Tatlins Turm aus Glas und Stahl mit seinen beweglichen Elementen, der eine Höhe von über 400 Metern haben sollte, kann als Ausdruck der befreiten technischen Phantasie der Moderne gelten. Die für ihn charakteristische Spiralform wurde von jeher als Ausdruck der nach oben gerichteten Dynamik gesehen. Der Sowjetpalast mit seiner geplanten Höhe von 415 Metern und einer gewaltigen Leninstatue an seiner Spitze stellt demgegenüber das Symbol eines totalitären Monumentalismus dar. In der Legende von dem tyrannischen Riesen Nimrod als Erbauer des Turms zu Babel war die Vorstellung von dem Bauwerk als Symbol der Staatsmacht ohnehin von Anfang an präsent.

Dostoevskij griff in seiner Deutung auf die bis ins späte Mittelalter vorherrschende biblische Interpretation des babylonischen Turms zurück und integrierte diese in seine visionäre Utopiekritik. Mag die Polemik Dostoevskijs gegen alle möglichen Formen des Fortschrittsdenkens seiner Zeit auch extrem ungerecht und maßlos übertrieben erscheinen, so ist ihnen jedoch nachträglich eine prophetische Bedeutung zugewachsen. Die Konkurrenz zwischen Dostoevskij und den prometheischen Babel-Deutungen aber dauert bis ins 20. Jahrhundert an. Ich zitiere die optimistische Einschätzung der Entwicklung der Sowjetunion, die Lion Feuchtwanger in seinem Buch Moskau 1937 gab:

Noch ist überall Schutt und schmutziges Gerüst, aber schon hebt sich rein und deutlich der Umriß des gewaltigen Baus ab. Es ist ein wahrer Turm von Babel, doch ein solcher, der nicht die Menschen dem Himmel, sondern den Himmel den Menschen näher bringen will. Und das Werk ist geglückt, sie haben ihre Sprache nicht verwirren lassen, sie verstehen sich untereinander. ${ }^{47}$

Zum Abschluss ein symbolisches Faktum, das noch einmal zu Platonovs Baugrube zurückführt. Im Großinquisitor ist die Rede davon, daß an der Stelle des gestürzten Tempels Christi das neue Bauwerk des schrecklichen babylonischen Turms entstehen werde. 1931 wurde in Moskau die Erlöserkathedrale gesprengt, um Platz für den geplanten gigantischen Sowjetpalast zu schaffen, der jedoch nie gebaut wurde. Möglicherweise hat Platonov von diesen Plänen gewusst. Die ausgehobene Baugrube von gewaltigen Ausmaßen blieb Jahrzehnte lang ungenutzt, bis man schließlich dort in den 1960er Jahren ein Schwimmbecken anlegte. Inzwischen ist aber auch dieses durch den Neubau der zerstörten Erlöserkirche ersetzt...

47 Lion Feuchtwanger: Moskau 1937. Ein Reisebericht für meine Freunde. Amsterdam 1937, S. 153. 


\section{Clemens Heithus}

\section{Deutsche Dostojewskij-Bibliographie 2009}

(mit Nachträgen aus den Jahren 2003 - 2008)

\section{WERKE IN DEUTSCHEN ÜBERSETZUNGEN}

a) Einzelne Romane und Erzählungen

\section{DVOJNIK [DER DOPPELGÄNGER]. 1846}

1 Der Doppelgänger. Übersetzt von Arthur Luther. Nachwort von Angela Martini-Wonde. [Nachdruck]. Stuttgart: Reclam, 2009. 214 S. (Reclams Universal-Bibliothek, 8423). ISBN 978-3-15-008423-6

\section{PRESTUPLENIE I NAKAZANIE [SCHULD UND SÜHNE]. 1866}

2 Schuld und Sühne. Roman. Aus dem Russischen übertragen von Richard Hoffmann. Mit Zeittafel, Nachwort, Anmerkungen und Literaturhinweisen von Barbara Conrad. Vollständige Ausgabe, 25. Auflage. München: Deutscher Taschenbuch Verlag, 2009. 747 S. (dtv, 12405). ISBN 978-3423-12405-8.

3 Schuld und Sühne. Roman. Übersetzt von Hermann Röhl. Nachwort von Birgit Harreß. [Nachdruck]. Stuttgart: Reclam, 2009. 890 S. (Reclams Universal-Bibliothek, 2481). ISBN 978-3-15-002481-2

4 Verbrechen und Strafe. Roman. Aus dem Russischen neu übersetzt von Swetlana Geier. 2. Auflage. Frankfurt, M. : Fischer Taschenbuch Verlag, 2009. 746 S. (Fischer, 90010. Fischer Klassik). ISBN 978-3-596-90010-7

5 Verbrechen und Strafe. Fassung von Andrea Breth nach der Übersetzung von Swetlana Geier. 1. Auflage. Zürich: Ammann, 2009. 172 S. ISBN 978-3-250-10901-3 
IGROK [DER SPIELER]. 1867

6 Der Spieler. Roman. (Aus den Aufzeichnungen eines jungen Mannes). Aus dem Russischen von Swetlana Geier. 1. Auflage. Zürich: Ammann, 2009. 228 S. ISBN 978-3-250-10521-3

\section{IDIOT [DER IDIOT]. 1868}

7 Der Idiot. Roman. Aus dem Russischen neu übersetzt von Swetlana Geier. Ungekürzte Ausgabe. Frankfurt am Main: Fischer Taschenbuch Verlag, 2008. 878 S. (Fischer Taschenbuch, 90186. Fischer Klassik). ISBN 978-3-596-90186-9

8 Der Idiot. Roman. Aus dem Russischen neu übersetzt von Swetlana Geier. Frankfurt am Main: Fischer Taschenbuch Verlag, 2009. 878 S. (Fischer Taschenbuch, 90186 : Fischer Klassik). ISBN 978-3-596-90186-9 Mit dem Werkbeitrag aus dem neuen „Kindlers Literatur Lexikon“.

9 Der Idiot. Roman. Aus dem Russischen von E. K. Rahsin. Nachwort von Ilma Rakusa. Ungekürzte Taschenbuchausgabe, 2. Auflage. München; Zürich: Piper, 2008. 981 S. (Serie Piper, 5265) (Sämtliche Werke). ISBN 978-3-492-24265-3

10 Der Idiot. Roman. Aus dem Russischen von Hermann Röhl. Köln : Anaconda, 2009. 943 S. (Russische Weltliteratur). ISBN 978-3-86647-104-7

\section{BESY [DIE DÄMONEN]. 1872}

11 Die Dämonen. Roman. Aus dem Russischen von E. K. Rahsin. Nachwort von Aleksandar Flaker. Ungekürzte Taschenbuchausgabe, 2. Auflage. München; Zürich : Piper, 2008. 1033 S. (Serie Piper, 5265) (Sämtliche Werke). ISBN 978-3-492-24263-9

12 Die Dämonen. Ein Film von Andrzej Wajda. Omar Sharif, Isabelle Huppert, Lambert Wilson ... Buch \& Dialoge: Jean-Claude Carrière. München: Concorde Home Entertainment, 2009. 1 DVD-Video. (Classic selection)

Sprachen: dt., franz. - Untertitel: dt. 


\section{PODROSTOK [DER JÜNGLING].1875}

13 Ein grüner Junge. Roman. Aus dem Russischen von Swetlana Geier. Frankfurt am Main: Fischer Taschenbuch Verlag, 2009. 829 S. (Fischer Taschenbuch 17692). ISBN 978-3-596-17692-2

\section{KROTKAJA [DIE SANFTE]. 1876}

14 Die Sanfte. Gelesen von Klaus-Dieter König. Schwäbisch Hall: Steinbach, 2009. (Klassiker Hörbuch, Gold-Edition). ISBN 978-3-88698-334-6

15 Die Sanfte. Eine phantastische Erzählung. Aus dem Russischen übertragen von Johannes von Guenther. Nachwort von Birgit Harreß. Um ein Nachwort ergänzte Ausgabe, 1999. [Nachdruck]. Stuttgart: Reclam, 2009. 83 S. (Reclams Universal-Bibliothek, 6570). ISBN 978-3-15-006570-9

b) Sammlungen und Auszüge

16 Der Bauer Marej. Aus dem Russischen von Swetlana Geier. Zürich: Ammann, 2008. 14 S. ISBN 978-3-250-20007-9 Sonderdruck anlässlich des 85. Geburtstags von Swetlana Geier.

17 Polsunkow \& ein Roman in neun Briefen. Ungekürzte Lesung. Gelesen von Julian Mehne. Ein Roman in neun Briefen. Aus dem Russischen von Wilhelm Plackmeyer. Polsunkow. Aus dem Russischen von Georg Schwarz. Daun/Vulkaneifel: TechniSat Digital, Radioropa Hörbuch, 2009. 1 CD. (Radioropa-Hörbuch-Klassik-Edition). ISBN 978-3-8368-0417-2

\section{DOSTOJEWSKIJ IN WERKEN DER SCHÖNEN LITERATUR. VARIA}

18 AUER, OSWALD: Dostojewskis Räume. Erstausgabe. Wien: PassagenVerlag, 2009. 61 S. : zahlr. Ill. ISBN 978-3-85165-876-7 Bleistiftzeichnungen.

19 BERŽAJTE, D.: O literature i ljubvi (D. Cypkin: „Leto v Badene“). In: Literatūra = Literatura 50 (2008), 2, S. 53-63

20 CYPKIN, LEONID [Leonod Zypkin]: Ein Sommer in Baden-Baden. Aus dem Russischen übersetzt von Alfred Frank. Sprecher: Sylvester Groth. 
Regie von Walther Adler. 1. Auflage. Dänikon: Hörkultur Medien, 2008. ISBN 978-3-905808-18-6

Online-Audio-Datei (Download).

21 ZWEIG, STEFAN: Jürgen Hentsch liest Stefan Zweig, Sternstunden der Menschheit. Vierzehn historische Miniaturen. MDR 1. Regie: Petra Meyenburg. Ungekürzte Lesung. Berlin: Argon-Verlag, 2008. 1 CD + Booklet (4 Bl.) (Argon-Klassiker)

Darin: „Heroischer Augenblick“ (Schilderung der Scheinhinrichtung Dostojewskijs in Gedichtform).

22 ZWEIG, STEFAN [Stephan Tsbaïch]: Hoi megales stigmes tēs anthrōpotēstas. Metaphrasē: Maria Angelidu. 4. Ekd. Athēna: Ekd. Patakē, 2008. 249 S. (Klasika keimena, 11). ISBN 978-960-600-029-4

23 ZWEIG, STEFAN: Momenti fatali. Quattordici miniature storiche. Trad. di Donata Berra. 4. ed. Milano: Adelphi Ed., 2009. 306 S. (Biblioteca Adelphi, 479). ISBN 978-88-459-1998-5

24 ZWEIG, STEFAN: Zvězdné hodiny lidstva. Transl. V. Bláha ... Zvole u Prahy: Štástný, 2007. 302 S. : Ill. ISBN 978-80-8673931-1

25 ZWEIG, STEFAN: Sternstunden der Menschheit. Vierzehn historische Miniaturen. Frankfurt, M.: Fischer-Taschenbuch-Verlag, 2009. 286 S. (Fischer, 90196. Fischer Klassik). ISBN 978-3-596-90196-8

\section{SEKUNDÄRLITERATUR}

26 AZADOVSKIJ, KONSTANTIN MARKOVIČ: „Nadejus’, moja kniga Vas zainteresuet“. Rajner Marija Ril'ke i L. F. Dostoevskaja. In: Dostoevskij i mirovaja kul'tura 24 (2008), S. 188-199

27 BAUER, CHRISTIANE: Der Blitz aus heiterem Himmel. Darstellung und Bewertung von Epilepsie in autobiografischen Schriften und ausgewählten Romanen Dostoevskijs. Salzburg, 2009. 90 Bl.

Salzburg, Univ., Diplomarb.

28 BAUMBACH, OLGA: Rezeption Dostojewskis in Italien. Dostojewski in der Perspektive der italienischen Literaturkritik. Sein Einfluss auf die italienische Literatur (Ende des 19. und Anfang des 20. Jahrhunderts: 1869 - 1936). Stuttgart, 2009. $81 \mathrm{~S}$.

Stuttgart, Univ., Magisterarb., 2008. 
29 BIRKAN, RAFAIL IOSIFOVIČ: Preodolenie nigilizma (Chajdegger i Dostoevskij). Sankt-Peterburg: Sankt-Peterburgskij Gosudarstvennyj Universitet Kul'tury i Iskusstv, 2007. 454 S. ISBN 978-5-947080-64-3

30 BORISOVA, I. V.; DMITRIJ N. ŽATKIN: Nemeckaja muzykal'naja klassika v tvorčeskom osmyslenii F. M. Dostoevskogo. In: Vestnik Rossijskogo Universiteta Družby Narodov. Serija: literaturovedenie, žurnalistika 2008, 2, S. 5-10

31 CASPERS, OLGA: Dostoevskijs „Besy“: Zur Geschichte der sowjetischen Einzelausgabe von 1935. In: Dostoevsky studies. The journal of the International Dostoevsky Society 12 (2008), S. 23-35

32 CASPERS, OLGA: Dostoevskijs Musen: die "Sanfte“ und die „Femme fatale“. M. Isaeva und A. Suslova. In: Deutsche Dostojewskij-Gesellschaft. Jahrbuch 15 (2008) [vgl. Nr. 35], S. 47-62 : Ill.

33 CAVAGNARO, GABRIELLE: Leonid Tsypkin's „Leto v Badene“ and the art of reproduction. In: Poetics. Self. Place. Essays in honor of Anna Lisa Crone. Ed. by Catherine O'Neil, Nicole Boudreau, Sarah Krive. Bloomington, Ind.: Slavica, 2007. ISBN 0-89357-341-8=978-0-89357341-6, S. 494-507

34 CHERKASOVA, EVGENIA: Dostoevsky and Kant. Dialogues on ethics. Amsterdam u.a.: Rodopi, 2009. XIV, 128 S. (Value inquiry book series, 206. Social philosophy). ISBN 90-420-2610-3=978-90-420-2610-0

35 Deutsche Dostojewskij-Gesellschaft. Jahrbuch. Herausgegeben von Maike Schult. Flensburg: Clasen-Druck. Bd. 15 (2008). 160 S. : Ill. ISBN 978-39809877-4-5.

Erschienen im April 2009. Die F. M. Dostojewskij betreffenden Beiträge des Jahrbuchs sind in der vorliegenden Bibliographie einzeln verzeichnet. Außerdem enthalten: „Vorwort“ von Maike Schult, S. 7-8; „Wladimir Solowjow: Kurze Erzählung vom Antichrist“ von Rainer Goldt, S. 157-158; „Autorenverzeichnis“, S. 159.

36 DOKUTOVIČ, Ė. Š.: „Igrok“ F. M. Dostoevskogo. Problema peredači rečevych charakteristik personažej pri perevode. In: Kul'tura kak tekst 8 (2008), S. 245-256

Betr. Übersetzungen ins Deutsche.

37 DUKKON, AGNES: [Rezension von] Horst-Jürgen Gerigk, Rudolf Neuhäuser: Dostojewskij im Kreuzverhör. Ein Klassiker der Weltliteratur oder Ideologe des neuen Rußland? Zwei Abhandlungen. Heidelberg: Mattes Verlag, 2008. In: Dostoevsky studies. The journal of the International Dostoevsky Society 13 (2009), S. 227-231 
38 GAREEVA, Ė. A.: Božestvennaja radost' kak simvol ljubvi u Fichte, Novalisa i Dostoevskogo. In: Jazyk, literatura i kul'tura na rubeže XX XXI vekov. Ufa, 2008, S. 154-161

39 GERIGK, HORST-JÜRGEN: Dostojewskij und Deutschland. Swetlana Geier zu Ehren. In: Deutsche Dostojewskij-Gesellschaft. Jahrbuch 15 (2008) [vgl. Nr. 35], S. 9-19

Festvortrag anläßlich der Verleihung der Ehrendoktorwürde der Philosophischen Fakultät der Albert-Ludwigs-Universität Freiburg an Swetlana Geier am Dienstag, den 10. Juli 2007, im Großen Saal des Hauses „Zur Lieben Hand“.

40 GERIGK, HORST-JÜRGEN: [Rezension von] Dunja Brötz: Dostojewskis „Der Idiot“ im Spielfilm. Analogien bei Akira Kurosawa, Saša Gedeon und Wim Wenders. Bielefeld: transcript Verlag, 2008. In: Dostoevsky studies. The journal of the International Dostoevsky Society 13 (2009), S. 231-232

41 GERIGK, HORST-JÜRGEN: [Rezension von] Katalin Kroó: „Tvorčeskoe slovo" F. M. Dostoevskogo - geroj, tekst, intertekst. Sankt-Peterburg: Akademičeskij Proekt, 2005 (Sovremennaja zapadnaja russistika ; 54). In: Dostoevsky studies. The journal of the International Dostoevsky Society 12 (2008), S. 223-225

42 GERIGK, HORST-JÜRGEN: [Rezension von] Robert Louis Jackson: Vision in darkness. Introduction to Fyodor Dostoevsky: „Notes from underground“ and „The double“. London; New York: Penguin classics, 2009. In: Dostoevsky studies. The journal of the International Dostoevsky Society 13 (2009), S. 226-227

43 GERIGK, HORST-JÜRGEN: [Rezension von] William Mills Todd III: The rise of the Russian novel, in: The novel, 2 vols., ed. Franco Moretti. Princeton; Oxford: Princeton University Press, 2006. Vol. 1: History, geography, and culture. In: Dostoevsky studies. The journal of the International Dostoevsky Society 12 (2008), S. 227-232

44 GERISCH, BENIGNA: „Sie war der einzige Mensch, den ich für mich vorbereitete:" Psychoanalytische Überlegungen zum Suizid in Dostojewskijs Erzählung „Die Sanfte“. In: Deutsche Dostojewskij-Gesellschaft. Jahrbuch 15 (2008) [vgl. Nr. 35], S. 97-112

45 GOES, GUDRUN: Anna Dostoevskajas Tagebücher, Briefe und Erinnerungen: Selbstdarstellung oder Verweigerung? In: Deutsche DostojewskijGesellschaft. Jahrbuch 15 (2008) [vgl. Nr. 35], S. 31-46

46 GRILLAERT, NEL: What the god-seekers found in Nietzsche. The reception of Nietzsche's Übermensch by the philosophers of the Russian 
religious renaissance. Amsterdam u.a.: Rodopi, 2008. 282 S. (Studies in Slavic literature and poetics, 50). ISBN 978-90-420-2480-9

Behandelt u.a. Dostojewskij.

47 HARRESS, BIRGIT : „Besy“ als Sendschreiben Dostoevskijs an Russland. In: Dostoevsky studies. The journal of the International Dostoevsky Society 12 (2008), S. 37-50

48 HASSINE, JULIETTE; MARGARET TOPPING: [Rezension von] Proust à la recherche de Dostoïevski. In: Romanische Forschungen 116 (2004), 1, S. $117-118$

49 HAWKES, DAVID: The Faust myth. Religion and the rise of representation. 1. ed. New York, NY u.a.: Palgrave Macmillan, 2007. 247 S. ISBN 1-403-97559-0=978-1-403-97559-1

Behandelt u.a. Dostojewskij.

50 HEITHUS, CLEMENS: Deutsche Dostojewskij-Bibliographie 2007 (mit Nachträgen 2002 - 2006). In: Deutsche Dostojewskij-Gesellschaft. Jahrbuch 15 (2008) [vgl. Nr. 35], S. 145-153

51 HERLTH, JENS: Nichts dahinter? Zur Logik des Terrors in Fëdor Dostoevskijs „Dämonen“. In: Deutsche Dostojewskij-Gesellschaft. Jahrbuch 15 (2008) [vgl. Nr. 35], S. 129-144

52 HERZFELD, CLAUDE: Charles-Louis Philippe. Entre Nietzsche et Dostoievski. Paris: L’Harmattan, 2009. 110 S. (Espaces littéraires). ISBN 978-2296-09085-9

53 HIELSCHER, KARLA: „Du bist meine ganze Zukunft“. Anna Grigorjewna Dostojewskaja. In: Deutsche Dostojewskij-Gesellschaft. Jahrbuch 15 (2008) [vgl. Nr. 35], S. 21-29

54 IVANTSOV, DMITRI: Russland - eine Weltmacht auf der Suche nach der verlorenen Identität. Praktikabilität eines Transfers der Russischen Idee Dostojewskis in das Zeitalter der Globalisierung. 1. Auflage. Leipzig: Meine, 2008. V, 195 S. , graph. Darst. + 1 CD

Vechta, Hochschule, Diss., 2007.

55 JANTSCH, FRANZ: Die römische Kirche im Urteil Dostojewskis. Inauguraldissertation aus dem Gebiete der Kirchengeschichte, Wien 1936. Mit einem Anhang von Wolfgang Punz. Mödling: Verlag AltMödling, 2009. 159 S. (Kultur Niederösterreich). ISBN 3-902405-066=978-3-902405-06-7

56 KAIBACH, BETTINA: Hostovský und Dostoevskij: der Untergrundmensch auf Tschechisch. In: Dostoevsky studies. The journal of the International Dostoevsky Society 12 (2008), S. 105-122 
57 KANTOR, VLADIMIR: „Besy“ versus Madonna. In: Oktjabr'. Literaturno-chudožestvennyj i obščestvenno-političeskij žurnal 2007, 9, S. 138145

58 KOGUT, MARINA: Dostoevskij auf Deutsch. Vergleichende Analysen fünf deutscher Übersetzungen des Romans „Besy“. Im Anhang Interviews der Autorin mit Swetlana Geier und Egon Ammann. Frankfurt am Main u.a.: Peter Lang, 2009. 300 S. : Ill. (Heidelberger Publikationen zur Slavistik. B: Literaturwissenschaftliche Reihe, 35). ISBN 978-3-63156660-2

59 KORENEVSKAJA, O. V.: Svoeobrazie perevoda romana F. M. Dostoevskogo „Brat’ja Karamazovy“ na nemeckij jazyk v kontekste dialoga kul'tur. Na materiale analiza neopredelennosti. In : Russkojazyčnyj bi(poli)lingvizm v mežkul'turnoj kommunikacii XXI veka. Pjatigorsk: 2008, S. 90-94

60 LACHAPELLE, LOUISE: L'interieur est l'asile ou se refugie. In: Voix plurielles 2008 may, 5(1), S. 1-16

Elektronische Publikation. - Über Dostojewskij und Walter Benjamin.

61 LACHMANN, RENATE : Die Lehre der Affekte und ihre Rolle im Werk Dostoevskijs. In: Arcadia 44 (2009), 1, S. 121-136

62 LOZOWY, ERIC: La maison des morts: notre monde, notre modernité? Reflexions sur Dostoïevski et Herling. In: Zagadnienia rodzajów literackich 46 (2003), 1/2, S. 221-235

63 MICHALEVA, A. A.: „Prestuplenie i nakazanie“ i „Ėliksiry satany“ Ė. T. A. Gofmana. In: Gotičeskaja tradicija v russkoj literature. N. D. Tamarčenko (otv. red.). Moskva: Rossijskij Gosudarstvennyj Gumanitarnyj Universitet, 2008. ISBN 978-5-7281-0967-9, S. 164-199

64 MORILLAS, JORDI: „Über das Verbrechen.“ Raskolnikows philosophische Lehre. In: Dostoevsky studies. The journal of the International Dostoevsky Society 12 (2008), S. 123-137

65 NEUHÄUSER, RUDOLF [R. Nojchojzer]: Dostoevskij. In: Sub specie tolerantiae. Pamjati V. A. Tunimanova. Otv. red. A. G. Grodeckaja. SanktPeterburg: Nauka, 2008. ISBN 978-5-02-025212-7

Mit einem Beitrag Neuhäusers.

66 NEUHÄUSER, RUDOLF: [Rezension von] Susan McReynolds: Redemption and the merchant god. Dostoevsky's economy of salvation and antisemitism. Evanston, Ill.: Northwestern University Press, 2008. In: Dostoevsky studies. The journal of the International Dostoevsky Society 13 (2009), S. 217-220 
67 NOVIKOVA, E. G.: „Na kartine ètoj izobražen Christos, tol'ko čto snjatyj so kresta“. F. M. Dostoevskij, S. N. Bulgakov o kartine Gansa Gol'bejna ml. „Christos vo grobe“. In: Evangel'skij tekst v russkoj literature XVIII - XX vekov. Citata, reminiscencija, motiv, sjužet, žanr. Vyp. 5. Petrozavodsk, 2008, S. 414-428

68 PAVLENKO, O. V.: Obrazy „nemeckogo mira“ v tvorčestve F. M. Dostoevskogo. Na primere čudakovatych doktorov-nemcev. In: Aktual'nye problemy naučnogo znanija v XXI veke. Č. 1. Barnaul; Rubcovsk, 2008, S. 146-151

69 PYŠNOVSKAJA, ZINAIDA SERGEEVNA: Russkaja literatura i nemeckie chudožniki-èkspressionisty. In: Germanija. XX vek. Modernizm, avangard, postmodernizm. Germanija, XX vek. Literatura, živopis', architektura, muzyka, kino, teatr. Red.-sost. V. F. Koljazin. Moskva: Rosspèn, 2008. (Humanitas). ISBN 978-5-8243-1026-9, S. 161-181

Zur Rezeption russischer Schriftsteller des 19. Jahrhunderts - darunter Dostojewskij - durch deutsche expressionistische Maler.

70 REEMTSMA, JAN PHILIPP: „Dämonen“? Dostojewski als Theoretiker des modernen Terrorismus. In: Geisteswissenschaften in der Offensive. Hamburger Standortbestimmungen. Hrsg. von Jörg Dierken ... Hamburg: Europäische Verlags-Anstalt, 2009. ISBN 978-3-434-50621-8, S. $117-128$

71 ROSANOW, WASSILI: Dostojewskis Legende vom Großinquisitor. Versuch eines kritischen Kommentars. (Mit zwei Vorwörtern, einem Nachwort, fünf Beilagen und zwei Etüden über Gogol). Hrsg. und mit einer Vorbemerkung sowie einem Nachwort versehen von Rainer Grübel. Aus dem Russischen von Rainer Grübel ... Oldenburg: BIS-Verlag der Carlvon-Ossietzky-Universität, 2009. 446 S. (Studia slavica Oldenburgensia, 18). ISBN 978-3-8142-2143-4

72 RÜEGG, BETTINA: Die Degenerationsproblematik in Dostoevskijs „Die Brüder Karamazov" und Zolas „La bête humaine“. Smerdjakov - ein determinierter Verbrecher? Konstanz, 2008. $38 \mathrm{Bl}$.

Konstanz, Univ., Bachelorarb.

73 SAVINA, T. A.: Dva psichoanalitičeskich portreta. Leonardo da Vinči i F. M. Dostoevskij. In: Avstrija kak kul'turnyj centr Evropy. Tezisy dokladov Meždunarodnogo Naučnogo Simpoziuma, Ekaterinburg, 13-17 maja 2008. M. B. Tjupaev (otv. red.). Ekaterinburg: Izdatel'stvo Ural'skogo Universiteta, 2008. ISBN 978-5-7996-0294-9, S. 101-106 Über zwei Arbeiten von Sigmund Freud. 
74 ŠČENNIKOV, GURIJ KONSTANTINOVIČ: „Dvojnik“ Dostoevskogo kak tvorčeskij dialog s Ė. T. A. Gofmanom. In: Dostoevskij i mirovaja kul'tura 24 (2008), S. 58-65

75 SCHADE, ROBERT: Zur Rede- und Schweigeproblematik in Dostojewskijs „Schuld und Sühne“. In: Deutsche Dostojewskij-Gesellschaft. Jahrbuch 15 (2008) [vgl. Nr. 35], S. 113-128

76 SCHMID, ULRICH: [Rezension von] Swetlana Geier: Ein Leben zwischen den Sprachen. Russisch-deutsche Erinnerungsbilder. Aufgezeichnet von Taja Gut. Dornach: Pforte Verlag, 2008. - Swetlana Geier: Leben ist Übersetzen. Gespräche mit Lerke von Saalfeld. Zürich: Ammann Verlag, 2008. In: Dostoevsky studies. The journal of the International Dostoevsky Society 12 (2008), S. 225-227

78 SCHMID, ULRICH: $\mathrm{Zu}$ russisch oder zu ritterlich? Konzeptionen der Beichte bei Joseph Conrad und Fedor Dostoevskij. In: Dostoevsky studies. The journal of the International Dostoevsky Society 11 (2007), S. 7-24

79 SCHMID, WOLF: Apogej sobytijnosti v „Brat'jach Karamazovych“. In: Archiv und Anfang. Festschrift für Igor' Pavlovič Smirnov zum 65. Geburtstag. Hrsg. von Susi K. Frank und Schamma Schahadat. München: Kubon \& Sagner u.a., 2007. (Wiener slawistischer Almanach, 59). ISBN 978-3-86688-020-7, S. 477-486

80 SCHMID, WOLF: Zum „Autor im Text“. Eine Replik auf Willem Weststeijn am Beispiel Dostoevskijs. In: Literature and beyond. Festschrift for Willem $G$. Weststeijn on the occasion of his $65^{\text {th }}$ birthday. Ed. by Eric de Haard ... Bd. 2. Amsterdam: Uitg. Pegasus, 2008. (Pegasus oosteuropese studies, 11,2). ISBN 978-90-6143-326-2, S. 701-712

81 SCHULT, MAIKE: „Alles ist Täuschung.“ Nabokovs Roman „Verzweiflung" als Kunstkrimi. In: Dostoevsky studies. The journal of the International Dostoevsky Society 11 (2007), S. 130-145

82 SCHULT, MAIKE: Ein Klassiker im Kreuzverhör: Drei neue Arbeiten zu Dostojewskij. In: Deutsche Dostojewskij-Gesellschaft. Jahrbuch 15 (2008) [vgl. Nr. 35], S. 154-156

Besprochen werden folgende Werke: Horst-Jürgen Gerigk, Rudolf Neuhäuser: Dostojewskij im Kreuzverhör. Ein Klassiker der Weltliteratur oder Ideologe des neuen Rußland? Zwei Abhandlungen. Heidelberg 2008 (Mattes Verlag), XII, 119 S., $16 €$. ISBN 978-3-86809-003-1. - Raffaela Vassena: Reawakening national identity. Dostoevskii's „Diary of a writer“ and its impact on Russian society. Bern u.a. 2007 (Peter Lang), 229 S., 43,90 €. ISBN 978-3-03911-206-7. - Susan McReynolds: Redemption and the merchant god. Dostoevsky's economy of salvation 
and antisemitism. Evanston, Illinois 2008 (Northwestern University Press: Studies in Russian literature and theory), XIII, 241 S., 69,95 \$. ISBN 978-0-8101-2439-4.

83 SCHULZ, CHRISTIANE: Psychologie der Nachtseite. Dostoevskij und der Dresdener Arzt Carl Gustav Carus. In: Deutsche Dostojewskij-Gesellschaft. Jahrbuch 15 (2008) [vgl. Nr. 35], S. 63-82

84 ŠEŠNEV, S. Ė.: O nekotorych osobennostjach recepcii F. M. Dostoevskogo nemeckoj filosofii. In: Russkaja literature $v$ mirovom kul'turnom $i$ obrazovatel'nom prostranstve. T. 1, č. 1. Sankt-Peterburg, 2008, S. 414422

85 SOLOVIEVA, OLGA VIKTOROVNA: A discourse apart. The body of Christ and the practice of cultural subversion. In: Dissertation abstracts international. Section A. The humanities and social sciences 2007, june, 67 (12), S. 4535

Yale, Univ., Diss., 2006. Betr. u.a. Dostojewskij.

86 VAGANOVA, N. A.: Teodiceja Lejbnica i roman F. M. Dostoevskogo „Brat’ja Karamazovy“. In: XVIII Ežegodnaja Bogoslovskaja Konferencija Pravoslavnogo Svjato-Tichonovskogo Gumanitarnogo Universiteta, T. 1. Moskva, 2008, S. 193-200

87 VASIL'EVA, TAT'JANA V.: Nemeckij kontekst perevodov romana F. M. Dostoevskogo „Prestuplenie i nakazanie“. In: Vestnik Novgorodskogo Gosudarstvennogo Universiteta Imeni Jaroslava Mudrogo 47 (2008), S. 44-46

88 VITIELLO, VINCENZO: Christianity and nihilism. In: Contemporary Italian philosophy. Crossing the borders of ethics, politics and religion. Ed. by Silvia Benso and Brian Schroeder. Albany, NY: State University of New York Press, 2007. (SUNY series in contemporary Italian philosophy). ISBN 0-7914-7135-7. - 0-7914-7136-5

Betr. u.a. Dostojewskij, Thomas Mann, Immanuel Kant, Georg Wilhelm Friedrich Hegel und Martin Heidegger.

89 VLADIV-GLOVER, SLOBODANKA: [Rezension von] In praise of hermeneutics and against messianism: Horst-Jürgen Gerigk and Rudolf Neuhäuser on how to read Dostoevsky. In: The Dostoevsky journal. An independent review 8/9. 2007/08 (2010), S. 89-97

90 WYMAN, ALINA: The task of active empathy. Scheler, Bakhtin and Dostoevsky. In: Dissertation abstracts international. Section A, The humanities and social sciences, 2008, oct; 69 (4), S. 1388

Chicago, Univ., Diss., 2008. 
91 ZHU, JIANGANG: Cong „Di xia shi ren“ dao „Qun mo“-Tuositooyefusiji yu Eguo xu wu zhu yi. In: Foreign language studies = Wai Guo Wen Xue Yan Jiu 2008, oct. 30 (5 [133]), S. 50-57

Betr. Dostojewskij und Friedrich Nietzsche. 


\section{Rezension}

Raimund Johann Weinczyk: Myškin und Christus. Ein fiktives Gespräch mit J. Ratzinger auf der Basis von F.M. Dostoevskijs Roman Idiot. Heidelberg: Winter 2006 (Beiträge zur slavistischen Philologie 13). 870 S. 88,-€

Selten dürfte ein Slavist gejubelt haben, als der Name eines neu gewählten Papstes bekannt gegeben wurde. Raimund Weinczyk aber muss gejubelt haben, als Kardinalprotodiakon Medina Estévez am 19. April 2005 verkündete: „[... [ Habemus Papam: Eminentissimum ac Reverendissimum Dominum Josephum, Sanctae Romanae Ecclesiae Cardinalem Ratzinger qui sibi nomen imposuit Benedicti XVI." Mit diesen Worten beginnt Weinczyk dann auch seine 2006 erschienene, von Wilfried Potthoff betreute Dissertation, die Benedikt XVI. in einen Dialog mit Dostoevskij bzw. mit dem Helden von dessen Roman Idiot (1867/69) bringt. Den methodischen Anstoß dazu gab Ratzingers Dialog mit Habermas' Dialektik der Säkularisierung (2005).

Das Gespräch mit Dostoevskij wird ohne Bachtins Konzept der Dialogizität entwickelt, was insofern konsequent ist, als Fürst Myškin für Weinczyk ,aphoristische Axiome" (S. 30) äußert. Den Äußerungen des fiktionalen Helden wird also Geltungsanspruch unterlegt. Damit fällt der Verfasser zurück in die alte russische Routine eines philosophischen Streitens mit vermeintlichen Geltungsaussagen der fiktionalen Texte Dostoevskijs (Merežkovskij u.a.). Da müssen Bachtin und die Bachtinologen, die in seiner Folge gezeigt haben, dass Geltungsaussagen im Romantext durch ihren Kontext konterkariert werden (wie die slavophil-christologische Wutrede Myškins durch sein ungeschicktes Umstoßen einer kostbaren Vase), natürlich außen vor bleiben. Weinczyk bestreitet sogar explizit, dass es, wie Bachtin erklärt hat, keinerlei Axiomatik bei Myškin gebe („Ein festes und ganzheitliches monologisches Wort kennt auch er [Myškin] nicht.“) (S. 477). Nun ist Bachtins Dialogtheorie alles andere als jenes Allheilmittel, für das sie die postsowjetische Bachtinologie nimmt; doch wäre, um der Literarizität von Dostojevskijs Roman gerecht zu werden, anstelle von Ratzingers persuasiv-agonalem Dialogbegriff (S. 20) Bachtins konterkarikierendes Dialogverständnis heilsam gewesen.

Weinczyks Buch zerfällt in drei Hauptteile, die Einleitung, den Myškin- und 
den Ratzinger-Teil, der zweite wiederum in 53 Teilkapitel, die nach einem seriellen Prinzip aneinandergereiht sind; in jedem Kapitel würden „jeweils Aussagen Myškins zur Diskussionsgrundlage“ (S. 66) genommen.

De facto liefert der umfangreichste zweite Teil (S. 68-597) ein close reading des Romans entlang der Ereignisfolge, das an vielen Stellen gar nicht so axiomzentriert ausfällt wie angedroht. So filtert Weinczyk feinsinnig Details heraus wie Myškins „Bündelchen“ (S. 68-74), das 20-Kopeken-Kreuz (S.266-268) oder Myškins "groteskes Axiom“ vom „Esel als gutem und nützlichem Menschen“ (S. 159-167). In dieser Detaillektüre kommt leider das oben angesprochene, Myškins „russische Christologie“ konterkarierende Umstoßen der Vase zu kurz.

Der dritte Teil der Arbeit gehört einem anderen Genre an, argumentiert nicht mehr philologisch, sondern entfaltet Ratzingers katholische Glaubenslehre. Diesen Teil für sich genommen zu kommentieren fühlt sich der Rezensent nicht berufen.

Wie aber hält es Weinczyk mit der Titelfrage nach Myškin und Christus, diesem Dauerthema der Slavistik? Der Autor hat die vielsprachige Idiot-Forschung profund eingearbeitet und eigenes Plädoyer für "Internationalisierung“ der Forschung (S. 66) vorbildlich eingelöst (bedauerlich nur, dass Altgriechisch ohne Akzente und Spiritus zitiert wird). Er votiert gegen die Annahme einer Christushaftigkeit von Myškin selbst; ihm zufolge "präsentiert der Schriftsteller einen Menschen, der Christus interpretiert“ (S. 598).

Dennoch spielt Weinczyk in seiner Metasprache stellenweise mit Christusmetaphern, etwa bei „Myškins irdische[r] Auferstehung“ (S. 480). Er verwahrt sich gegen die vorschnelle Identifikation der „Welt-rettenden Schönheit“ als "Schönheit Christi“ (S. 486-496), wie es Ratzinger kursorisch vertreten hatte (S. 24). Wenig überraschend zeichnet Weinczyk auf Grundlage von Myškins „Axiomatik“ das Bild eines kenotischen Christus: Für ihn glaubt Myškin an den "leidensbewussten, mit-leidenden, unbehausten und nachdenklichen Christus“ (S. 121). Von diesem Vorbild leite sich das Mitleiden als Christusnachfolge her (S. 292); mithin verfechte Myškin ein „Axiom von der Demut“ (S. 499).

Der Ertrag von Weinczyks Arbeit, dass sich bei Dostoevskij ein kenotisches Christusverständnis findet, - im Gegensatz zu Ratzinger, der auf die Auferstehung (S. 607) abstellt - also Erhöhung und, wie Weinczyk immer wieder hervorhebt (S. 629, 658 und öfters), „Fülle Christi“ statt seiner Erniedrigung, ist für die Slavistik nicht neu, darauf haben bereits Fedotov, Gorodetzky u.a. hingewiesen. Im Kontrast zur vermeintlichen „Fülle“ des katholischen ChristusBildes erscheint der tote Christi von Holbeins Bild, über den Myškin und Rogožin diskutieren, als „Ausschnitt einer Fülle und ,Teil der Bewegung ““ (S. 746). 
Welches ist der Ertrag der Arbeit jenseits der Dostoevskij-Forschung? Weinczyk inszeniert einen ungleichen Dialog zwischen einem kanonischen Romancier und einem noch lebenden Kleriker, der auch weiterhin schriftstellerisch aktiv ist. So erschien der erste Teil von Ratzingers christologischem Hauptwerk "Jesus von Nazareth“ erst 2007, nach Drucklegung von Weinczyks Arbeit.

Rezensiert von Dirk Uffelmann

Zuerst erschienen in: Osteuropa 3/2008, S. 171-173. 


\section{Nachruf auf Swetlana Geier}

Sie kannte die praktischen Regeln des Übersetzens, und sie beherrschte sie meisterhaft. Doch was ihr selbst beim Übersetzen gelang, war mehr als das. Swetlana Geier machte aus einem unsichtbaren Handwerk eine Kunst im Schatten der Kunst. Viele Bilder hat sie für die professionellen Grenzgänger gefunden: Puschkins Postpferde etwa oder das Gehäuse des Kirchenvaters Hieronymus als Wohnort derer, die ihr Leben lang unterwegs sind von einer Sprachwelt in die andere, ohne ihre Fracht verlustfrei von A nach B transportieren zu können. Übersetzen ist Annäherung, bleibende Sehnsucht nach dem Original. Doch was das Original auf der einen Seite durch die Übertragung verliert, gewinnt es auf der anderen hinzu durch die interpretierende Handschrift des Übersetzers. Swetlana Geiers Dostojewskij-Interpretationen sind das beste Beispiel hierfür. Seit den 1990er Jahren hat sie fast ausschließlich Dostojewskij übersetzt und dabei, inspiriert durch Michail Bachtin, der lang verkannten Poetik des Schriftstellers zur Würdigung verholfen. Sie hat Romantitel neu gesetzt, der Figurensprache individuellen Klang verliehen, sie hat Wortwiederholungen gelten lassen und den deutschen Lesern einen Neologismus wie nadryw zugemutet. So hat sie Dostojewskij der Öffentlichkeit sichtbar gemacht als das, was er für die Slavistik längst ist: ein großer Provokateur und Sprachkünstler mit sorgfältig konstruierten Werken, deren Anspielungsreichtum nun auch nachvollziehen kann, wer nicht des Russischen mächtig ist.

Für ihre Übersetzungen hat sich Frau Geier viel Zeit gelassen. Werktreue war ihr oberstes Gebot, und dafür suchte sie den Text so zu verinnerlichen, dass sie „hinter jeden Buchstaben gucken“ konnte. Zugleich wusste sie, dass eine Übertragung nicht am einzelnen Wort hängen darf, sondern das Ganze im Blick haben muss, um zeitgemäß zu sein: „Nase hoch beim Übersetzen!“ Für dieses doppelte Ziel - Detailtreue einerseits, Zeitgemäßheit andererseits hatte sie sich eine Arbeitsmethode erdacht, die den Prozess zerdehnte und das Ergebnis bewusst verzögerte: Zunächst lernte sie den russischen Text auswendig, diktierte dann, was sie im Kopf hatte, ihrer Mitarbeiterin auf Deutsch in die Schreibmaschine, das Original auf ihrem Schoß. Dann ließ sie sich den Text von ihrem Musikerfreund noch einmal vorlesen, ließ sich gelegentlich von ihm auch etwas sagen und korrigierte mit schwarzem, rotem und grünem 
Buntstift im Durchschlag herum. Im Zweifelsfall entschied der Klang. So übersetzte sie kontinuierlich, konzentriert und beharrlich und schaffte doch nur wenige Seiten pro Tag. Leben kann man von so etwas nicht, aber das musste sie auch nicht. Für sie waren die Wörter belebt, und sie belebte die Wörter. Ihr Geld verdiente sie anderswo.

Gerade dies anachronistische Verständnis von Geld, Zeit und Effizienz brachte ihr paradoxerweise den späten Erfolg. Swetlana Geier, am 26. April 1923 als Kind russischer Eltern in Kiew geboren und 1943 nach Deutschland gekommen, arbeitete nach dem Krieg an verschiedenen Hochschulen als Russischlektorin. Nebenbei begann sie mit ihrer Übersetzertätigkeit und übertrug neben Dostojewskij auch Puschkin, Tolstoj, Bunin, Belyj, Bulgakow und Platonow, Solschenizyn und Sinjawskij. Erst nach ihrer Pensionierung, mit 65 Jahren, startete sie die Dostojewskij-Übersetzungen für den Ammann-Verlag, die den längst Bekannten auf die Bestsellerlisten katapultierten und seine Übersetzerin in die Öffentlichkeit. Zahlreiche Preise, Ehrungen und zwei Ehrendoktorate haben seither den hohen Wert ihrer Arbeit belegt, und nicht zuletzt die Deutsche Dostojewskij-Gesellschaft, die Swetlana Geier $2001 \mathrm{zu}$ ihrem Ehrenmitglied ernannt hat, hat dieser Arbeit so viel zu verdanken.

In ihren Augen aber waren die höchsten Prädikate des Übersetzers: Unauffälligkeit und Transparenz. Seine Person sollte das Original in eine andere Sprache vermitteln, aber nicht selbst sichtbar werden. Das ist ihr - zum Glück - nur bedingt gelungen. Anders als die andere große Dostojewskij-Übersetzerin, Less Kaerrick, die Dostojewskij zu Beginn des 20. Jahrhunderts für den Piper-Verlag übertragen und sich dabei so geschickt hinter dem Pseudonym E. K. R. (E. K. Rahsin) verborgen hat, dass ihre Identität tatsächlich lange unklar geblieben ist, hatte Frau Geier in ihrer ganzen Bescheidenheit doch eine auffallende Art, sich im Hintergrund zu halten. Und wo Less Kaerrick ihr eigenes Leben ganz verschlungen sah vom „Walfisch“ Dostojewskij, da wurde Swetlana Geier zu einer Dompteurin, die sich nicht nur in Dostojewskijs „fünf Elefanten“, sondern auch in der Öffentlichkeit zu behaupten wusste. Leise, bestimmt, auch streitbar wand sie sich aus dem Schatten des Schriftstellers und wurde selbst „abendfüllend“: Wer von Dostojewskij sprach, der sprach von ihr und mit ihr und musste sich mitunter auch Unbequemes anhören wie ihre Schelte auf das liebgewordene Klischee von der russischen Seele.

Zahllose Zeitungsartikel, Interviews und zwei Bücher über ihr Leben (von Lerke von Saalfeld und Taja Gut) sind seither erschienen. Doch die schönste Würdigung war ihr zum Schluss vergönnt: Vadim Jendreyko hat der Übersetzerin mit seinem Dokumentarfilm „Die Frau mit den fünf Elefanten“ ein 
bleibendes Denkmal geschaffen und sie dafür noch einmal selbst hinübergesetzt ans andere Ufer: Er ist mit ihr in die Vergangenheit zurückgefahren, nach Kiew, zu ihrem Elternhaus und an das Grab ihres Vaters. Auf eine ungewöhnlich feinfühlige, poetische Weise erzählt der Film dieses schwere, verlustreiche Leben, das trotz allem durchsichtig geblieben ist für die andere Seite der Dinge: für die Schönheit, die Güte und die fein gewobenen Texturen der Literatur. Im November 2009 kam der Film in die Kinos. Er wurde ein unglaublicher, vielfach ausgezeichneter Erfolg. Swetlana Geier hat all dies noch mit wachen Sinnen miterleben und genießen dürfen. Ein Jahr später nun, am 7. November 2010, ist sie in ihrem Haus in Günterstal bei Freiburg gestorben.

Maike Schult 


\section{Autorenverzeichnis}

Prof. Dr. Gudrun Goes

Erlenweg 6

39291 Hohenwarthe

Prof. Dr. Hans Günther

Tiefentalweg 6

82402 Seeshaupt

Prof. Dr. Guski

Ehrenbergerstraße 27

14195 Berlin

Dipl.-Bibl.Clemens Heithus

Flerrenwiete 81

22559 Hamburg

Dr. Dagmar Herrmann

Verlag Wilhelm Fink GmbH \& Co.

Verlags-KG

Postfach 2540

33055 Paderborn
Dr. Karla Hielscher

Tiefentalweg 6

82402 Seeshaupt

Prof. Dr. Hans Rothe

Giersbergstraße 29

53229 Bonn

Dr. Maike Schult

Adalbertstr. 3

24106 Kiel

Prof. Dr. Christiane Schulz

Leunaweg 16

06132 Halle

Prof. Dr. Dirk Uffelmann

Universität Passau, Phil. Fak.

Ost-Mitteleuropa-Studien

Innstraße 25

94030 Passau 


\section{Das Jahrbuch der Deutschen Dostojewskij-Gesellschaft}

Die Deutsche Dostojewskij-Gesellschaft e. V. (DDG), am 13. Mai 1990 gegründet und Mitglied der Arbeitsgemeinschaft Literarischer Gesellschaften und Gedenkstätten e. V. (ALG), ist einem russischen Schriftsteller gewidmet, der durch sein Werk und seine Person das deutsche Kultur- und Geistesleben in besonderer Weise geprägt hat. Ihr Ziel ist es, die Kenntnis Dostojewskijs zu verbreiten, das Studium seiner Werke zu vertiefen und zur eigenständigen Auseinandersetzung mit seiner Roman- und Ideenwelt anzuregen. Die Gesellschaft vermittelt Ergebnisse gegenwärtiger Dostojewskij-Forschung und steht allen offen, die sich für Autor und Werk interessieren.

Ihr Jahrbuch dokumentiert Vorträge, die über das Jahr auf Fachtagungen gehalten wurden, und damit einen grundlegenden Aspekt der Bildungsarbeit der Gesellschaft. Der erste Band erschien 1992. Das Jahrbuch wird von der Vorsitzenden der Gesellschaft herausgegeben, die sich dabei mit den Mitgliedern des Wissenschaftlichen Beirats berät, und bietet auch angehenden Dostojewskij-Forschern die Möglichkeit, ihre Arbeitsergebnisse einer breiteren Öffentlichkeit vorzustellen. Vortragsmanuskripte, Aufsätze und Rezensionen können der Vorsitzenden oder den Mitgliedern des Wissenschaftlichen Beirats zugesandt werden. Über die Veröffentlichung entscheidet die Herausgeberin. Den Inhalt der Beiträge verantworten die Autoren.

Deutsche Dostojewskij-Gesellschaft e.V. (DDG) www.dostojewskij-gesellschaft.de

Vorsitzende: Prof. Dr. Gudrun Goes

IFPH Otto-von-Guericke Universität

Zschokkestraße 32

39104 Magdeburg

Volksbank Lüneburger Heide eG

BLZ: 25891636 · Konto-Nr.: 522049100

Amtsgericht Flensburg VR 1325 
Worldwide Distributor:

\section{Kubon \& Sagner}

Servicing libraries since 1947

ISBN: 978-3-86688-128-0

ISSN $1437-5265$

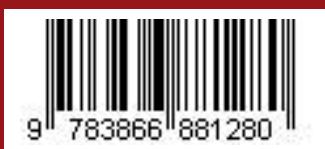

